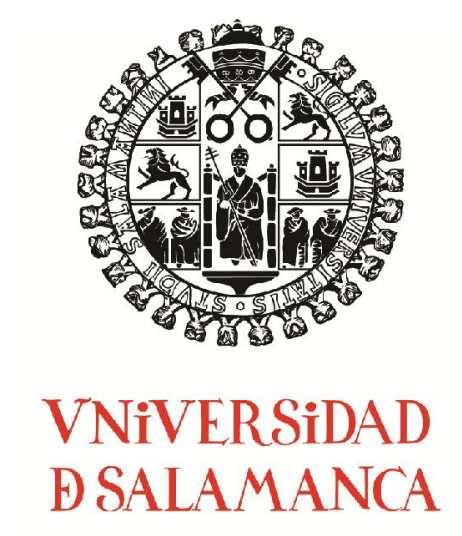

Departamento de Geología

Reconstrucción paleoceanográfica de los últimos 32 ka en el Atlántico Nororiental y Mediterráneo Occidental a partir del desarrollo de técnicas geoquímicas en asociaciones de cocolitofóros

Débora Simón Baile

Tesis Doctoral

Salamanca, 2011
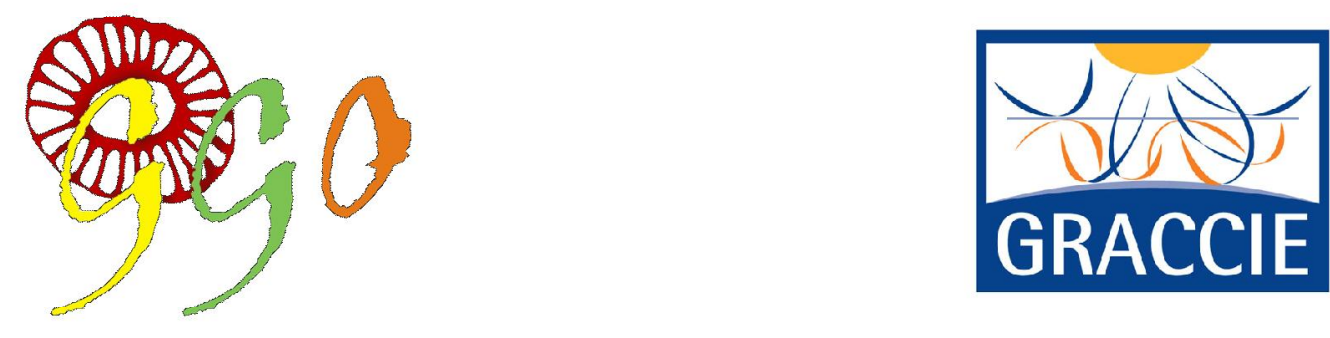



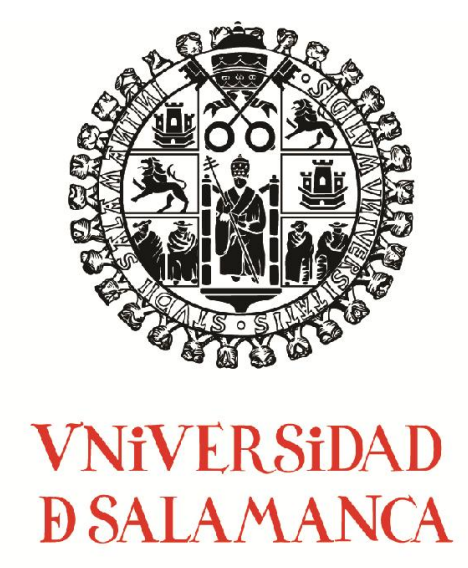

Departamento de Geología

\title{
Reconstrucción paleoceanográfica de los últimos 32 ka en el Atlántico Nororiental y Mediterráneo Occidental a partir del desarrollo de técnicas geoquímicas en asociaciones de cocolitofóros
}

Memoria presentada por Débora Simón Baile para optar al Grado de Doctor en Geología por la Universidad de Salamanca con Mención "Doctor Europaeus"

Esta Tesis Doctoral se ha realizado bajo la dirección de los profesores

\author{
Dr. D. José Abel Flores Villarejo \\ Dr. D. Francisco Javier Sierro Sánchez \\ Catedráticos del Departamento de Geología (Paleontología) \\ Universidad de Salamanca
}



Dr. D. José Abel Flores Villarejo y Dr. D. Francisco Javier Sierro Sánchez, catedráticos del Área de Paleontología del Departamento de Geología de la Universidad de Salamanca.

CERTIFICAN que,

Débora Simón Baile ha realizado bajo nuestra dirección, en el Departamento de Geología de la Universidad de Salamanca, el trabajo:

"Reconstrucción paleoceanográfica de los últimos 32 ka en el Atlántico Nororiental y Mediterráneo Occidental a partir del desarrollo de técnicas geoquímicas en asociaciones de cocolitóforos"

Y para que conste, firmamos el presente certificado en Salamanca, en Agosto de 2011.

Los directores:

J. Abel Flores Villarejo $\quad$ Francisco J. Sierro Sánchez

La doctoranda

Débora Simón Baile 
La realización de esta tesis doctoral ha sido posible gracias a la concesión de la beca predoctoral AP2005-5003 del programa Nacional de Formación de Profesorado Universitario (FPU) del Ministerio de Educación y Ciencia, y a la financiación de los proyectos GRACCIE (CONSOLIDER-INGENIO CSD 2007-00067), CGL 2006-10593, CGL 2008-05560 y CGL 2009-08651 del Ministerio de Ciencia y Tecnología y GR34 (Grupo de excelencia) de la Junta de Castilla y León. Adicionalmente, se ha obtenido financiación de la Universidad de Salamanca a través del Programa de Difusión de Resultados de la Agencia de Investigación. 


\section{Gracias...}

Y por fin llegaron los agradecimientos, el final del camino hacia la tesis y el momento de una mirada atrás para agradecer sinceramente a las muchas y maravillosas personas que han pasado por mi vida estos años y que han hecho posible todo esto.

Quisiera empezar agradeciendo a mis directores de tesis José Abel Flores Villarejo y Francisco Javier Sierro Sánchez, Abel y Paco, por brindarme la oportunidad de formar parte de su grupo de investigación, por la confianza mostrada en todo momento, por motivarnos y facilitarnos participar en congresos y estancias y por estar siempre disponibles para solucionar todo tipo de dudas y problemas. A Paco, por todo el tiempo dedicado a discutir los resultados de isótopos, por lo mucho que se aprende de él, y por hacernos reir con sus ocurrencias. A Abel, porque siempre nos facilita la vida y busca lo mejor para nosotros, porque nos contagia su optimismo científico y por haber afrontado con el mejor humor todas mis idas y venidas y apoyado mis decisiones aunque no fueran del todo científicas.

Al Grupo de Geociencias Oceánicas al completo, por que es un auténtico lujazo tener estos jefes y estos compañeros, siempre dispuestos para lo técnico y lo extraacadémico. Empezando por Lines y Elena, piedras angulares del grupo y un gran apoyo en todo momento y continuando con todos mis compañeros del "depar", Andrés, Mieke, Mariem, Iván, Eloy, Montse, Margarita, Alejandra, Aleix, Carmen, Diego Corrochano (un infiltrado muy bienvenido), Bea, Gatsby, Miguel Angel, José Ignacio, los que me recibieron, los nuevos fichajes y los que pronto vendrán sólo de visita. A Andrés y Mieke, por su buen rollito, por la enorme ayuda y los ánimos en el sprint final, por las charlas cómplices y hasta por la Covatilla. Espero que os vaya genial en vuestras nuevas aventuras. A Mariem, nuestra "principita", por alegrar el despacho y responder todas las dudas con su mejor sonrisa. A Iván y Eloy, por su buen humor y por ser los mejores chicos para todo. Y a todos los demás, por el buen ambiente de trabajo y por contribuir a que los días fueran más llevaderos y amenos, os echaré mucho de menos, chic@s, no es fácil encontrar compañeros como vosotros.

Durante las estancias he tenido la suerte de conocer a mucha y muy buena gente!

Grazie mille to Patrizia Ziveri for receiving me in the Autónoma of Barcelona. I am really grateful for the laboratory borrowed, her helpful suggestions and her availability to help me with the daily questions and in the distance. Thanks to Kathë Stolz for teaching me the tricks for the coccolith separation and the good company in the lab.

Many thanks also to Heather Stoll, for kindly hosting me in Oviedo and USA, her full availability while I was in USA, for offering me the opportunity to learn from her scientific enthusiasm and of course, for her kind and good advices everytime I needed them.

Muito obrigada a Mário Cachão pelo apoio em Lisboa, pela orientação cientifica e os esclarecimento de dúvidas sempre que estas iam surgindo e pela constante disponibilidade, o bom humor e os ânimos. Muito obrigada também a Aurea pelo enorme apoio em Lisboa, a amizade e os divertidos momentos de descontracçao e festa em Lisboa. E aos companheiros do Nanolab por o agradável convívio.

En la ciudad condal, pude reencontrarme con muchos buenos amigos, un lujo tener a MariMery, al trío Olzinelles y a los titos Arex para compartir la mejor Barcelona, y hacer muchos otros nuevos, Ely (Verdeny) mi compi en aguas del Pacífico, Alba (Tello) y los outsiders de sus amigos. 
Como no, recordar a mi clan de ambientólogos y nuestro pensar en verde, esas magníficas, Anita, Are y Colino y nuestra sincronía de doctorandos, a mis chicas de italiano, mis cooperantes, y a mis buenos amigos, la super inspectora "cacahué", miEli, mi Paco-Fullbright y mi primísimaloquísima Ne. Todos cómplices de tantas charlas y momentazos, y los que faltan...por que sabéis sacar lo mejor de mí.

Por último, inmensas gracias a toda mi familia, que esperemos siga creciendo! y sobre todo, a mis papitos, por estar siempre ahí, para lo urgente y lo importante, "por habermi insinhau a valorar y esforzarmi, por aguantar us kilómetrus y devaneus y recibirmi sempris con unha boa dosis de mimus, sois us milloris du mundu mundial"

Gracias a todos y cada uno... por que lo valéis, vaya si lo valéis....y ay! la falta que me hacéis.... 


\section{Índice}

I. Presentación y justificación de la tesis vii

II. Objetivos $\quad$ ix

III. Estructura de la tesis $\quad x$

CAPÍTULO 1: CIRCULACIÓN OCEÁNICA Y ATMOSFÉRICA

1.1. Circulación general de la atmósfera 3

1.2. Circulación oceánica global 4

1.3. El Mar Mediterráneo 4

1.3.1. Marco fisiográfico 4

1.3.2. Circulación atmosférica 5

$\begin{array}{ll}\text { 1.3.3. Circulación oceánica y masas de agua } & 6\end{array}$

1.3.4. Productividad 8

1.4. El Mar de Alborán 9

1.4.1. Marco fisiográfico 9

1.4.2. Circulación atmosférica 9

1.4.3. Circulación oceánica y masas de agua 9

1.4.4. Productividad 11

1.5. Margen Noroccidental Africano 12

1.5.1. Circulación atmosférica 12

1.5.2. Circulación oceánica y masas de agua 16

$\begin{array}{ll}\text { 1.5.3. Productividad } & 18\end{array}$

\section{CAPÍTULO 2: MATERIALES DE ESTUDIO}

2.1. El testigo MD95-2043 23

2.1.1. Localización y descripción lito-estratigráfica 23

$\begin{array}{ll}\text { 2.1.2. Modelo de edad } & 24\end{array}$

2.2. El testigo MD03-2705-DUST 25

2.2.1. Localización y descripción lito-estratigráfica 25

$\begin{array}{ll}\text { 2.2.2. Modelo de edad } & 27\end{array}$

\section{CAPÍTULO 3: BIOLOGÍA Y ECOLOGÍA DE LOS COCOLITÓFOROS}

3.1. Generalidades e importancia de los cocolitóforos 31

3.2. Estructuras biológicas 33

3.3. Cocosfera y grupos de cocolitóforos 34

3.4. Ciclo de vida $\quad 36$

3.5. Funciones de las cubiertas calcáreas $\quad 37$

3.6. Transporte y sedimentación 38

3.7. Distribución biogeográfica

3.7.1. Distribución vertical 39

3.7.2. Distribución horizontal 41 


\section{CAPÍTULO 4: INDICADORES GEOQUÍMICOS EN COCOLITÓFOROS}

$\begin{array}{ll}\text { 4.1. Isótopos estables } & 46\end{array}$

4.1.1. Isótopos de oxígeno $\quad 47$

4.1.1.1. Composición isotópica del agua. Factor hielo y salinidad 47

4.1.1.2. Temperatura del agua $\quad 49$

4.1.1.3. Herramientas para la interpretación de isótopos de oxígeno 50

$\begin{array}{ll}\text { 4.1.2. Isótopos de carbono } & 51\end{array}$

4.1.2.1. Cambios isotópicos globales en el ciclo del carbono 52

4.1.2.2. Cambios isotópicos regionales. Subreservorios del océano 53

4.1.3. Equilibrio isotópico versus efectos vitales $\quad 54$

4.1.3.1. Efectos vitales en cocolitóforos $\quad 55$

$\begin{array}{ll}\text { 4.1.3.2. Causas de los efectos vitales en cocolitóforos } & 57\end{array}$

4.1.4. Aplicación paleoceanográfica de los isótopos estables de cocolitos $\quad 59$

4.2. Sr/Ca de los cocolitos como indicador de productividad 60

4.2.1. Influencias secundarias en el $\mathrm{Sr} / \mathrm{Ca}$ de cocolitos $\quad 62$

4.2.2. Aplicación paleoceanográfica del $\mathrm{Sr} / \mathrm{Ca}$ de cocolitos 63

\section{CAPÍTULO 5: METODOLOGÍA}

5.1. Separación de fracciones de cocolitos $\quad 67$

$\begin{array}{ll}\text { 5.1.1. Reactivos } & 67\end{array}$

5.1.2. Preparación y limpieza de muestras $\quad 69$

5.1.3. Antecedentes y mejoras en los métodos de separación $\quad 73$

5.1.4. Cálculo teórico del tiempo de decantación $\quad 74$

$\begin{array}{ll}\text { 5.1.5. Decantaciones sucesivas } & 76\end{array}$

$\begin{array}{ll}\text { 5.1.6. Microfiltración con membrana de policarbonato } & 78\end{array}$

$\begin{array}{ll}\text { 5.1.7. Consideraciones } & 78\end{array}$

5.2. Análisis geoquímicos de isótopos estables y $\mathrm{Sr} / \mathrm{Ca} \quad 79$

5.3. Recuentos y estimación del carbonato de cocolitos 79

5.4. Estudios morfométricos de $\boldsymbol{C}$. pelagicus y análisis factorial 80

CAPÍTULO 6: PICKING DE COCOLITOS Y ANÁLISIS DE Sr/Ca EN SONDA IÓNICA

6.1. Picking de cocolitos $\quad 83$

6.2. Análisis de $\mathrm{Sr} / \mathrm{Ca}$ en sonda iónica $\quad 85$

6.3. Potencial y limitaciones del método $\quad 85$

6.4. Aplicación del picking de cocolitos en sedimentos de California 86 


\section{CAPÍTULO 7: THE LAST 20 ka PALEOCEANOGRAPHIC RECONSTRUCTION OF ALBORAN SEA (WESTERN MEDITERRANEAN) FROM COCCOLITH CHEMISTRY}

$\begin{array}{ll}\text { Abstract } & 91\end{array}$

7.1. Introduction $\quad 92$

7.2. Climatic and oceanographic setting 93

7.3. Material \& Methods $\quad 95$

7.3.1. Separation of coccoliths size fractions for geochemical analysis 95

7.3.2. Quantification of coccoliths and coccolith carbonate contribution 96

$\begin{array}{ll}\text { 7.4. Results } & 97\end{array}$

7.4.1. Coccolith composition of size fractions and efficiency of separations 97

7.4.2. Coccolith stable isotopes and comparison with planktonic foraminifer 101

$\begin{array}{ll}\text { 7.4.3. } \mathrm{Sr} / \mathrm{Ca} \text { ratios and constraint of the temperature effect } & 104\end{array}$

7.5. Discussion 106

7.5.1. Sea surface conditions: temperature and meltwater influences 106

$\begin{array}{ll}\text { 7.5.2. Paleoproductiviy variations during the last } 20 \mathrm{ka} & 107\end{array}$

$\begin{array}{ll}\text { 7.6. Conclusions } & 112\end{array}$

CAPÍTULO 8: VARIABILITY IN THE COCCOLITHOPHORE GEOCHEMICAL IMPRINT OFF NW AFRICA DURING THE LAST $32 \mathrm{ka}$ : THE ROLE OF THE INTERTROPICAL CONVERGENCE ZONE

$\begin{array}{ll}\text { Abstract } & 117\end{array}$

$\begin{array}{ll}\text { 8.1. Introduction } & 118\end{array}$

8.2. Climatic and oceanographic setting 119

8.3. Material \& Methods 121

8.3.1. Separation of coccolith size fractions for inorganic chemistry analysis 122

$\begin{array}{ll}\text { 8.3.2. Coccolith assemblages and carbonate contribution } & 122\end{array}$

$\begin{array}{lr}\text { 8.4. Results } & 123\end{array}$

$\begin{array}{ll}\text { 8.4.1. Efficiency of separations } & 123\end{array}$

8.4.2. Isolating productivity variations in coccolith $\mathrm{Sr} / \mathrm{Ca}$ ratios $\quad 126$

8.4.2.1. Correction for temperature effect in $\mathrm{Sr} / \mathrm{Ca}$ ratios $\quad 126$

$\begin{array}{ll}\text { 8.4.2.2. } \mathrm{Sr} / \mathrm{Ca} \text { ratios of different coccolith size fractions } & 128\end{array}$

$\begin{array}{ll}\text { 8.4.3. Coccoliths isotopic signal } & 129\end{array}$

8.5. Discussion: Paleoceanography off NW Africa 131

$\begin{array}{ll}\text { 8.5.1. Latitudinal migrations of the upwelling center during the LGM } & 131\end{array}$

8.5.2. Upwelling intensification and offshore extension during early deglaciation $\quad 133$

$\begin{array}{ll}\text { 8.5.3. Enhanced productivity despite reduced upwelling } & 134\end{array}$

$\begin{array}{ll}\text { 8.5.4. Influence of the continent: Saharan dust episodes } & 134\end{array}$

$\begin{array}{ll}\text { 8.5.5. Stratification of surface waters and seasonality changes } & 135\end{array}$

$\begin{array}{ll}\text { 8.5.6. Regional upwelling gradients } & 136\end{array}$

$\begin{array}{ll}\text { 8.6. Conclusions } & 136\end{array}$ 
CAPÍTULO 9: MORPHOMETRIC VARIABILITY OF C. PELAGICUS AND

ITS PALEOCEANOGRAPHIC SIGNIFICANCE IN THE NORTHEAST

ATLANTIC AND WESTERN MEDITERRANEAN DURING THE LAST DEGLACIATION

$\begin{array}{ll}\text { Abstract } & 141\end{array}$

9.1. Introduction and objectives 142

9.2. Cores location and oceanographic setting 143

9.3. Chronology \& Methods $\quad 145$

$\begin{array}{ll}\text { 9.4. Results } & 146\end{array}$

9.4.1. Multivariate Morphon Analysis on core MD95-2043 (Alboran Sea) 146

9.4.1.1. Identification of C. pelagicus morphotypes and its boundaries from factor loadings

9.4.1.2. C. pelagicus behaviour on MD95-2043 from factor scores $\begin{array}{ll}\text { and comparison with other proxies } & 147\end{array}$

9.4.2. Multivariate Morphon Analysis on core MD03-2705 (off Mauritania) 150

9.4.2.1. Identification of $C$. pelagicus morphotypes and its boundaries from factor loadings

9.4.2.2. C. pelagicus behaviour on MD03-2705 from factor scores and comparison with other proxies 151

9.5. Discussion

9.5.1. Paleoecological and paleoceanographic reconstruction from

$\begin{array}{ll}\text { C. pelagicus morphotypes during the last deglaciation } & 153\end{array}$

9.5.1.1. Alboran Sea 153

9.5.1.2. Off Mauritania 155

9.5.2. Latitudinal variations of the C. pelagicus morphotypes 156

$\begin{array}{ll}\text { 9.6. Conclusions } & 159\end{array}$

CAPÍTULO 10: CONCLUSIONES/ CONCLUSIONS 163

$\begin{array}{ll}\text { BIBLIOGRAFÍA } & 171\end{array}$

ANEXOS

$\begin{array}{ll}\text { A I. Sistemática de cocolitóforos y consideraciones ecológicas } & 195\end{array}$

A II. Fotografías de microscopio electrónico y óptico 205 


\section{Resumen}

Los cocolitóforos son algas calcáreas unicelulares que juegan un importante papel en el ciclo del carbono ya que toman carbono de las aguas superficiales durante la fotosíntesis y la calcificación y lo transfieren al océano profundo. Por ello, los cocolitóforos son actores clave en la regulación de la tasa de intercambio de $\mathrm{CO}_{2}$ entre la atmósfera y el océano, y por tanto, en el cambio climático global.

Esta tesis presenta estudios sobre geoquímica y morfometría en cocolitos de los testigos MD95-2043 y MD03-2705, recuperados del mar de Alborán y la costa de Mauritania, respectivamente. El mar de Alborán es la cuenca más occidental del mar Mediterráneo, y por ello, la conexión directa con el Atlántico. La interacción con aguas atlánticas hace que este mar sea una de las áreas más productivas del Mediterráneo, además, al ser una cuenca semicerrada, presenta una sensibilidad particular a los cambios climáticos que ocurren en regiones de latitudes medias. Por otra parte, la costa noroccidental africana es una región altamente productiva donde los vientos alisios del noreste inducen la aparición de una surgencia costera mientras que los aportes eólicos desde el cercano Sáhara fertilizan las aguas superficiales. En ambas regiones, las condiciones climáticas y paleoceanográficas están controladas por el ciclo estacional de migraciones latitudinales de la Zona de Convergencia Intertropical (ZCIT).

La química de la calcita de los cocolitos puede proporcionar información valiosa e innovadora, porque, a diferencia de los foraminíferos, los cocolitóforos son productores primarios calcáreos de amplia distribución geográfica con un vínculo directo con las dinámicas de surgencia oceánica y porque, producen calcita intracelularmente y su registro sedimentario marino, tanto inorgánico como orgánico, presenta buenas condiciones para la preservación temporal.

Aunque los cocolitos sean un componente mayoritario, y con frecuencia dominante en los sedimentos marinos carbonatados, su reducido tamaño y por tanto, la dificultad para tomar muestras monoespecíficas han supuesto una limitación básica para la aplicación de la química de la calcita de los cocolitos en reconstrucciones paleoceanográficas y paleoclimáticas. Sin embargo, recientemente, se han desarrollo ciertas técnicas que, aunque requieren mucho tiempo, permiten la separación y concentración de fracciones restringidas de cocolitos a través de decantaciones sucesivas y microfiltración, o incluso, el picking de un único espécimen.

Un primer estudio se dedicó al picking de cocolitos individuales para el análisis de ratios $\mathrm{Sr} / \mathrm{Ca}$ en sonda iónica SIMS. Se estudiaron cuatro especies distintas de cocolitóforos, G. oceanica, H. carteri, C. leptoporus y C. pelagicus con el fin de analizar las diferencias interespecíficas y se investigó la relación de sus ratios $\mathrm{Sr} / \mathrm{Ca}$ con variaciones en la productividad asociadas a oscilaciones interanuales en los eventos ENSO (El Niño-La Niña) durante la última mitad del siglo pasado. 
En el segundo y tercer trabajos de la tesis, se aplicaron las técnicas de separación de cocolitos, consiguiendo fracciones con una alta concentración de carbonato de una única especie. La eficiencia de las separaciones fue mejor para las fracciones de cocolitos grandes en el testigo de Mauritania, mientras que, en el testigo de Alborán, las fracciones de cocolitos pequeños fueron más fiables. Los isótopos de oxígeno $\left(\delta^{18} \mathrm{O}\right.$ y $\left.\delta^{13} \mathrm{C}\right)$ y los ratios de $\mathrm{Sr} / \mathrm{Ca}$ se utilizaron para: (1) reconstruir la paleotemperatura del agua marina y la paleoproductividad en el Mediterráneo occidental y el margen nororiental africano, (2) evaluar los procesos oceánicos y atmosféricos responsables de las variaciones en las condiciones ambientales, (3) identificar las conexiones climáticas entre altas y bajas latitudes.

En el mar de Alborán, la gran variabilidad en las condiciones de las aguas superficiales y la productividad desde el último máximo glacial se ha asociado con cambios en las condiciones atmosféricas, en la tasa de intercambio de agua con el Atlántico y en la mezcla vertical de la columna de agua. Estas variaciones sugieren una fuerte conexión del clima del mar de Alborán no sólo con las perturbaciones del Atlántico Norte, sino también con las dinámicas tropicales.

Los cambios en los registros $\delta^{18} \mathrm{O}$ de los cocolitos del mar de Alborán durante los últimos $20 \mathrm{ka}$ se relacionaron con cambios en las temperaturas superficiales del mar y con la entrada desde el Atlántico de agua de deshielo procedente de icebergs durante el evento Heinrich 1 (H1). Esto último pudo producir una fuerte estratificación y dificultar la surgencia de nutrientes a la zona fótica superior, reduciendo, en última instancia, la productividad primaria en la superficie. Durante el Younger Dryas (YD), el desplazamiento hacia el sur de la ZCIT favoreció la prevalencia de bajas presiones atmosféricas sobre el Mediterráneo Occidental y la intensificación de los vientos del oeste. Estas condiciones atmosféricas contribuyeron a un incremento del flujo de entrada de aguas ricas en nutrientes desde el Atlántico, la reactivación de la mezcla de aguas y el desarrollo de células de surgencia. Todo ello fue responsable de una elevada productividad marina. Por el contrario, la productividad primaria durante el periodo Bolling-Allerod (B/A) y el inicio del Holoceno pudo haber sido baja en el mar de Alborán debido a un debilitamiento de los vientos del oeste y una reducción de la surgencia y del flujo de entrada de agua desde el Atlántico. Tales cambios se relacionan con un desplazamiento hacia el norte de la ZCIT y el establecimiento de un sistema de altas presiones sobre la región.

En el área del testigo MD03-2705, las fluctuaciones en las condiciones de las aguas superficiales están determinadas por la interconexión de varios procesos atmosféricos y oceanográficos. Las oscilaciones en la posición y en la intensidad de las células de surgencia junto a su extensión hacia el océano abierto y el contenido variable de nutrientes en las aguas de afloramiento fueron probablemente la causa de los pronunciados cambios en la productividad a lo largo de la deglaciación. Tales variaciones pudieron haber estado conectadas con cambios en la dirección y fuerza de los vientos y, en última instancia, con desplazamientos latitudinales de la ZCIT. Además, ocasionales aportes masivos de 
terrígenos desde el cercano desierto del Sahara pudieron afectar enormemente tanto a los patrones isotópicos como a los de productividad. En las costas de Mauritania, los valores de productividad derivados del ratio $\mathrm{Sr} / \mathrm{Ca}$ fueron generalmente bajos entre 32 y $20 \mathrm{ka}$, pero mostraron marcadas oscilaciones y una larga inestabilidad durante la deglaciación. La migración de la ZCIT hacia una posición más meridional parece ser un factor clave en la intensificación de la surgencia oceánica y de la productividad registrada durante el H1 mientras que el desplazamiento de la ZCIT hacia el norte durante el Holoceno temprano pudo reducir la influencia de la surgencia y por tanto, la productividad primaria. La reconstrucción paleoceoanográfica para los eventos B/A y el YD resulta más compleja e implica otros procesos además de la ZCIT. La señal geoquímica de los cocolitos durante el evento B/A pudiera ser la consecuencia de las diferentes preferencias ecológicas del grupo de especies de mayor tamaño de cocolitóforos, principalmente de C. leptoporus y H. carteri, las cuales presentan mayor afinidad por condiciones mesotróficas. Durante el YD, un aporte masivo de polvo (80 \%) pudo limitar la disponibilidad de luz en la zona fótica superior y por tanto, reducir el crecimiento de los cocolitóforos.

La última sección de esta tesis es un estudio morfométrico que complementa los trabajos geoquímicos previos y que comprende análisis estadísticos realizados sobre los datos morfométricos de $C$. pelagicus obtenidos a partir de 64 muestras de los testigos MD95-2043 y MD03-2705. El análisis permitió la identificación de los tres morfotipos descritos previamente en Parente et al. (2004), mientras que la comparación con otros indicadores hizo posible relacionar su ocurrencia con las variaciones climáticas durante la última deglaciación. En el mar de Alborán, el incremento significativo en la importancia del morfotipo más pequeño, C. pelagicus subsp. pelagicus, durante el evento H1, indica la llegada de aguas subárticas hasta el Mediterráneo, mientras que la dominancia relativa del morfotipo intermedio, C. pelagicus subsp. braarudii durante el YD se asocia a un aumento de la surgencia oceánica. En la zona del testigo MD03-2705, la predominancia del morfotipo de mayor tamaño, C. pelagicus subsp. azorinus, tanto en el $\mathrm{H} 1$ como en el $\mathrm{YD}$, se relaciona con la intensificación de la corriente de las Azores debido al efecto combinado del desplazamiento del frente polar y el incremento del flujo de salida del Mediterráneo. En conjunto, podría decirse que el mar de Alborán es más sensible a las oscilaciones climáticas que la costa norafricana. La comparación de los resultados morfométricos con los de dos testigos adicionales reveló que la presencia de un morfotipo concreto así como su intervalo y sus límites morfométricos, varían latitudinalmente, lo cual indicaría una adaptación a las condiciones ambientales de cada localización, evolución, o lo más probable, una combinación de ambas.

Palabras clave: Cocolitóforos, geoquímica de cocolitos, morfometría, mar de Alborán, costa de Mauritania, ZCIT, deglaciación, paleoceanografía. 


\begin{abstract}
Coccolithophores are calcareous unicellular algae that play an important role in the carbon cycle because they take carbon from the surface waters during the photosynthesis and the calcification and transfer it to the deep ocean. Hence, they are key actors in the regulation of the rate of $\mathrm{CO}_{2}$ exchange between the atmosphere and the ocean, and therefore, in the global climate change.
\end{abstract}

This thesis presents studies on coccolith geochemistry and morphometry from cores MD95-2043 and MD03-2705 retrieved from the Alboran Sea and off Mauritania respectively. The Alboran Sea is the westernmost basin of the Mediterranean Sea, and therefore, the direct link with the Atlantic. The interaction with the Atlantic waters makes it one of the most productive areas within the Mediterranean, moreover, as a semienclosed basin, is particularly sensitive to the climatic changes occurring at the mid-latitude regions. Alternatively, the northwest African coast is a highly productive region where NE trade winds induce a coastal upwelling whereas eolian supplies from the nearby Sahara fertilize the surface waters. In both sites, the climatic and paleoceanographic conditions are controlled by the seasonal latitudinal migrations of the Intertropical Convergence Zone (ITCZ).

Coccolith calcite chemistry can provide valuable and innovative information, because, unlike foraminifera, coccolithophores are calcareous primary producers geographically widespread that have a direct link to the upwelling dynamics and because they produce calcite intracellularly and both its organic and inorganic remains enjoy long term preservation in marine sediments. Although coccoliths are a major and often dominant component of marine carbonate sediments their small size and so, the difficulty to pick monospecific samples, has been a basic limitation for the application of the coccolith calcite chemistry in paleoceanographic and paleoclimatic reconstructions. However, recent techniques, although time consuming, allow the separation and concentration of restricted coccoliths fractions through repeated decanting and microfiltration or even the picking of single specimens.

A first study was dedicated to the picking of individual coccoliths to be analized for $\mathrm{Sr} / \mathrm{ca}$ ratios in a SIMS ion probe. We studied four different coccolith species, G. oceanica, H. carteri, C. leptoporus and $C$. pelagicus in order to identify interspecific differences, and investigated the relationship between their $\mathrm{Sr} / \mathrm{Ca}$ ratios and the productivity variations associated to interannual oscillations of $\mathrm{El}$ Niño-Southern Oscillation events during the last half century.

In the second and third works of the thesis, we applied the coccolith separation techniques achieving fractions with high carbonate concentration of single species. The efficiency of the separations was better for the coarse coccolith fractions in the Mauritanian core whereas, in the Alboran core, the small coccolith fractions were more reliable. The stable isotopes $\left(\delta^{18} \mathrm{O}\right.$ and $\left.\delta^{13} \mathrm{C}\right)$ and $\mathrm{Sr} / \mathrm{Ca}$ ratios from restricted coccolith fractions were used to: (1) reconstruct seawater paleotemperatures and 
paleoproductivity in the Western Mediterranean and off NW Africa, (2) assess the marine and atmospheric processes that might drive variations in the environmental conditions, (3) identify the climatic connection between high and low latitudes.

In the Alboran Sea, the large varibility in the sea surface conditions and the productivity since last glacial maximum has been associated to changes in the atmospheric conditions, the rate of water exchange with the Atlantic and the vertical mixing within the water column. These variations suggest a strong connection of the Alboran Sea climate not only with North Atlantic perturbations but also with tropical dynamics.

Changes in the Alboran coccolith $\delta^{18} \mathrm{O}$ record during the last $20 \mathrm{ka}$ were related to changes in the sea surface temperatures and to the entrance of iceberg meltwaters from the Atlantic at Heinrich 1 times. The latter may have produced strong stratification and hampered the upwelling of nutrients to the upper photic zone, ultimately, reducing the surface primary productivity. During Younger Dryas, the southward displacement of the ITCZ favoured the prevalence of low atmospheric pressure over the Western Mediterranean and the intensification of the westerlies. These atmospheric conditions contributed to the increase in the nutrient-richer Atlantic inflow, the reactivation of water mixing and the development of upwelling cells that altogether, were responsible for the high marine productivity. On the contrary, primary productivity during Bolling Allerod and early Holocene might have been low in the Alboran Sea due to the weakening of the westerlies and reduced upwelling and Atlantic inflow. Such changes are related to a northward migration of the ITCZ and the establishment of a high pressure system over the region.

At site MD03-2705, fluctuations in the conditions of surface waters are determined by the interconnection of several atmospheric and oceanographic processes. Oscillations in the position and intensity of the upwelling cell together with its offshore extension and variable nutrient content of the upwelled waters were likely behind the pronounced changes in productivity throughout the deglaciation. Such variations might have been connected to changes in wind stress and direction and ultimately, to latitudinal shifts of the ITCZ. Moreover, occasional massive terrigenous supplies from the nearby Sahara may have strongly affected both the isotopic and productivity patterns.

Off Mauritania, the $\mathrm{Sr} / \mathrm{Ca}$-derived productivity values were generally low between 32 and $20 \mathrm{ka}$, but they showed marked oscillations and a large instability during the deglaciation. A southward migration of the ITCZ seems to be a major controlling factor that account for the enhanced upwelling and productivity recorded during $\mathrm{H} 1$ while a northward shift during the early Holocene may have reduced the upwelling influence and so, the primary productivity. The paleoceanographic reconstruction for the $\mathrm{B} / \mathrm{A}$ and the YD events is more complex, and involves other processes besides ITCZ. The coccolith geochemical signal during the B/A may be the consequence of the distinct ecological preferences of 
the group of coarse coccolithophore species, mainly of $C$. leptoporus and H. carteri, which have higher affinity for mesotrophic conditions. At YD times, in turn, a massive dust input (80\%) may have caused a limited availability of light in the upper photic zone and hence, reduced the coccolithophores growth.

The last section of this thesis is a morphometry study that complements the previous geochemical works. It comprises statistical morphometric analysis performed on the C. pelagicus dataset of 64 samples from cores MD95-2043 and MD03-2705. The analysis allowed to identify the three morphothypes previously described in Parente et al. (2004) while the comparison with other proxies helped relating its ocurrence to climatic variations during last deglaciation.

In the Alboran Sea, the significant increase in the importance of the smaller morphotype, C. pelagicus subsp. pelagicus during H1 indicates the arrival of subarctic waters as far as the Mediterranean, whereas the relative dominance of the intermediate morphotype, $C$. pelagicus subsp. braarudii during YD is associated to enhanced upwelling. At site MD03-2705, the dominance of the large morphotype, C. pelagicus subsp. azorinus, during both $\mathrm{H} 1$ and $\mathrm{YD}$, is related to the intensification of the Azores Current due to a combined effect of the polar front shift and to an increase of Mediterranean outflow waters. Overall, it seems that the Alboran Sea is more sensitive to climatic oscillations than the NW African margin. Comparison of the morphometric results with those of two additional cores revealed that the presence of a specific morphotype as well as its morphometric boundaries and interval, vary latitudinally and would indicate either adaptations to the environmental conditions of each location, evolution or, most likely, a combination of both.

Keywords: Coccolithophores, cocccolith geochemistry, morphometry, Alboran Sea, off Mauritania, ITCZ, deglaciation, paleoceanography. 


\section{Presentación y justificación de la tesis}

En la actualidad, los cambios climáticos predichos en el cuarto informe del Panel Internacional sobre el Cambio Climático (IPCC, 2007) son objeto de intensa discusión entre los especialistas. El debate se centra en los posibles efectos del aumento de los gases de efecto invernadero. En el caso del $\mathrm{CO}_{2}$, responsable en un $55 \%$ del efecto invernadero total, se ha constatado que el paso de épocas glaciales a interglaciales supuso incrementos equivalentes a los actuales. Con especial interés nos referimos a la productividad marina como factor clave en la regulación del intercambio de $\mathrm{CO}_{2}$ entre océano y atmósfera y por tanto del contenido atmosférico de $\mathrm{CO}_{2}$. La productividad marina determina la cantidad de $\mathrm{CO}_{2}$ almacenado en el océano y la velocidad a la que éste pasa a formar parte de los sedimentos marinos. Variaciones en la productividad regulan el $\mathrm{CO}_{2}$ atmosférico pudiendo provocar un efecto en el sistema climático global.

El objetivo final de esta investigación es la reconstrucción paleoceanográfica y paleoclimática de secuencias marinas en el entorno Mediterráneo y Atlántico, en particular, la identificación, datación y caracterización de cambios abruptos acontecidos durante la última transición glacial-interglacial. Para comprender en profundidad el carácter y la magnitud de la variabilidad climática durante el último ciclo estadial/interestadial, debemos identificar los diferentes procesos oceanográficos y atmosféricos implicados, la conexión entre ellos y su potencial para propagar su influencia desde una escala regional a una global.

Las técnicas de estudio habitualmente empleadas para esta reconstrucción climática son micropaleontológicas, sedimentológicas y geoquímicas, aplicadas a material recuperado de testigos oceánicos. Con dichas técnicas se evalúan las características y dinámica de las masas de agua superficiales y profundas, los procesos de formación de las mismas, los regímenes de productividad oceánica, así como su correlación con eventos detectados en el continente. El objetivo último es la identificación de escenarios que permitan posteriormente la predicción de dichos cambios en el futuro.

En la presente propuesta, se plantea el estudio de material biogénico, concretamente cocolitóforos. Aunque los cocolitóforos sean un componente mayoritario en los sedimentos marinos carbonatados (en general $>60 \%$ del total) (Baumann et al., 2004), la mayor parte de los estudios sobre este tipo de sedimentos se han realizado a partir de foraminíferos, debido a la facilidad para tomar muestras monoespecíficas. Así es que, el reducido tamaño de los cocolitos $(\leq 20 \mu \mathrm{m})$ ha supuesto una limitación básica para la aplicación de los cocolitóforos en estudios geoquímicos (Stoll y Ziveri, 2004). Sin embargo, recientemente, se han desarrollo técnicas que han permitido la separación de fracciones de cocolitos dominadas en un alto grado por el carbonato de una única especie (Minoletti et al., 2001; Stoll y Ziveri, 2002) e incluso, el picking o selección de cocolitos individuales (Stoll et al., 2007b; 
Stoll y Shimizu, 2009). Una vez constatada la fiabilidad de los análisis biogeoquímicos en cocolitos (Stoll y Ziveri, 2002; Stoll et al., 2007a; c), la aplicación de éstos permitirá obtener información paleoclimática novedosa, ya que, a diferencia de los foraminíferos, los cocolitóforos son productores primarios cuyo registro sedimentario presenta condiciones más favorables de preservación y resistencia a la disolución. Por tanto, la presente propuesta supone un reto metodológico que además, aporta información geoquímica innovadora con respecto a los clásicos estudios sobre foraminíferos.

La reconstrucción climática de las masas de aguas oceánicas se sirve de datos de temperatura, salinidad y contenido en nutrientes y productividad entre otros. Para la obtención de este tipo de datos y su aplicación a series temporales se han desarrollado diferentes técnicas de naturaleza biogeoquímica (índice Uk'37-alquenonas-, relación $\mathrm{Mg} / \mathrm{Ca}$, o estudio de isótopos estables en foraminíferos) o micropaleontológica (funciones de transferencia, análogos modernos, etc). Sin embargo, el trabajo que presentamos propone el empleo de isótopos estables $\left(\delta^{18} \mathrm{O}\right.$ y $\left.\delta^{13} \mathrm{C}\right)$ en cocolitos y de un nuevo indicador de productividad, el ratio $\mathrm{Sr} / \mathrm{Ca}$ de los cocolitos (Stoll et al., 2002a; b). La utilización de estos indicadores, supone la introducción de varias singularidades, por una parte, el hecho de que los estudios geoquímicos se basan en agrupaciones de cocolitóforos en lugar de en foraminíferos y en segundo lugar, la elección de elementos minoritarios, como el estroncio, para dichos análisis.

Previamente a la aplicación de dicha técnica, es precisa una revisión exhaustiva de las asociaciones de cocolitóforos en las áreas de estudio a partir de muestras de sedimentos, así como la definición sistemática de los taxones a emplear. Para el presente proyecto, se pretende obtener la señal isotópica y de química elemental de cocolitóforos de dos testigos oceánicos, del Atlántico tropical (sector de Mauritania) y el Mediterráneo (mar de Alborán), para posteriormente abordar la ulterior reconstrucción climática de estas regiones, con características y asociaciones diferentes. A saber, mar de Alborán, un ambiente semi-eutrófico que se engloba dentro de la oligotrofía generalizada del Mediterráneo y, margen noroccidental africano, un medio relacionado con el upwelling oriental atlántico, aunque no directamente bajo los efectos de la surgencia perenne frente a Cabo Blanco.

MD95 2043 (36 8’ N, 2 37’ W; 1.841 m). Mar de Alborán. Mediterráneo occidental MD03-2705 DUST (18 $\left.10^{\circ} \mathrm{N}, 21^{\circ} \mathrm{W} ; 3.100 \mathrm{~m}\right)$. Margen noroccidental africano

Se pretende así establecer un gradiente temporal y espacial de las variaciones de productividad, temperatura y balance hídrico que presentan estas dos regiones durante los últimos 32 ka. 


\section{Objetivos}

El objetivo principal de esta tesis es la reconstrucción de la paleoceanografía y más en concreto, la paleotemperatura y la paleoproductividad en el Mediterráneo occidental y el margen oriental Atlántico durante los últimos $32 \mathrm{ka}$, y el estudio de su relación con variaciones climáticas y oceanográficas. Para la consecución de este objetivo central, se plantearon una serie de objetivos específicos que se desglosan a continuación:

- Aplicación de una técnica de separación de cocolitos a partir de la depuración y adaptación de la técnica propuesta por Stoll y Ziveri (2002) y de la técnica auxiliar de microfiltración (Minoletti et al., 2001).

- Verificación de la eficiencia de la separación a partir de la cuantificación de los cocolitos y la estimación de la masa de carbonato relativa aportada por cada una de las especies presentes en las fracciones a analizar (Young y Ziveri, 2000).

- Aplicación de la técnica de picking de cocolitos y análisis de $\mathrm{Sr} / \mathrm{Ca}$ en sonda iónica (Stoll et al., 2007b) y, evaluación de sus potencialidades y limitaciones con respecto a otras técnicas.

- Calibración de la señal isotópica de oxígeno y carbono y de la relación $\mathrm{Sr} / \mathrm{Ca}$ en las diferentes fracciones de cocolitóforos. Comparación con la señal obtenida mediante otras técnicas de naturaleza biogeoquímica, micropaleontológica y sedimentológica.

- Correlación de las asociaciones de cocolitóforos, la señal isotópica y el ratio $\mathrm{Sr} / \mathrm{Ca}$ de cocolitos con estimaciones actuales de temperatura y productividad primaria derivadas de datos obtenidos por satélites (Sea-WIFS) y, datos acerca del flujo de productividad en trampas de sedimento.

- Realización de un estudio morfométrico sobre la especie Coccolitus pelagicus y tratamiento estadístico de los datos obtenidos según el método de Análisis Multivariada de Morphons (Parente et al., 2004) para su aplicación en la reconstrucción paleoceanográfica. 


\section{Estructura de la tesis}

El presente trabajo de tesis doctoral opta al grado de "Doctor Europaeus" y además, se presenta por artículos, por ello, contiene algunos capítulos escritos en castellano y otros en inglés, que se corresponden con los artículos científicos derivados de la investigación. La tesis comprende tres secciones:

- Primera sección, de los capítulos 1 al 5, en la que se describen la circulación oceánica y atmosférica de las áreas de estudio (capítulo 1), los materiales empleados (capítulo 2), la biología y ecología de los cocolitóforos (capítulo 3), los indicadores geoquímicos de cocolitóforos empleados en la tesis (capítulo 4) y la metodología (capítulo 5). De esta sección, cabría destacar la técnica de separación y concentración de cocolitos que se explica en detalle en el capítulo 5.

- $\quad$ Segunda sección, entre los capítulos 6 al 9, contiene los principales resultados de la tesis y su discusión. El capítulo 6, en castellano, es esencialmente metodológico y explica detalladamente la técnica del picking de cocolitos y el análisis de $\mathrm{Sr} / \mathrm{Ca}$ mediante sonda iónica exponiendo un ejemplo de su aplicación en la reconstrucción de la productividad en sedimentos laminados de la costa de California. Los capítulos 7 al 9 son los manuscritos que serán enviados a revistas científicas internacionales:

-Capítulo 7: D. Simón-Baile, P. Ziveri, H. Stoll, J.A. Flores, F.J. Sierro. "The last $20 \mathrm{ka}$ paleoceanographic reconstruction of Alboran Sea (Western Mediterranean) from coccolith chemistry". Para ser enviado a Palaeogeography, Palaeoclimatology, Palaeoecology.

-Capítulo 8: D. Simón-Baile, H. Stoll, P. Ziveri, J.A. Flores, F.J. Sierro, M.A. Bárcena, A. MejíaMolina. "Variability in the coccolithophore geochemical imprint off $N W$ Africa during the last 32 ka: the role of the Intertropical Convergence Zone". Para ser enviado a Paleoceanography.

-Capítulo 9: D. Simón-Baile, M. Cachão, J.A. Flores, A. Narciso, F.J. Sierro. "Morphometric variability of $C$. pelagicus and its paleoceanographic significance in the Northeast Atlantic and Western Mediterranean during the last deglaciation". Para ser enviado a Marine Micropaleontology.

- Tercera sección, capítulo 10, en el que se recogen las principales conclusiones de esta tesis doctoral tanto en castellano como en inglés.

Al final de la tesis, se incluyen dos anexos que resumen la sistemática y la ecología de los principales taxones de cocolitóforos empleados en este estudio y que se complementan con una serie de fotografías de microscopio electrónico y óptico. 




\subsection{Circulación general de la atmósfera}

Las diferencias latitudinales en la insolación solar y la rotación terrestre condicionan la circulación general de la atmósfera que está compuesta por seis células convectivas, tres en cada uno de los Hemisferios. Las dos células de Hadley, sobre los trópicos, una a cada lado del Ecuador, las dos células de Ferrel, situadas en latitudes medias-templadas, y las dos células polares, en las zonas polares (Fig.1.1). Estas células convectivas son las responsables de redistribuir el exceso de calor acumulado en los trópicos hacia las altas latitudes, y su dinámica da lugar al desarrollo de cinturones de bajas y altas presiones.

Las altas presiones se sitúan en ambos hemisferios, en torno a los $30^{\circ}$, mientras que las bajas presiones están sobre el ecuador y sobre los $60^{\circ} \mathrm{N}$ y S. La baja ecuatorial corresponde con la Zona de Convergencia Intertropical (ITCZ, InterTropical Convergence Zone) mientras que la bajas entorno a $\operatorname{los} 60^{\circ}$ definen las posiciones de los Frentes Polares.

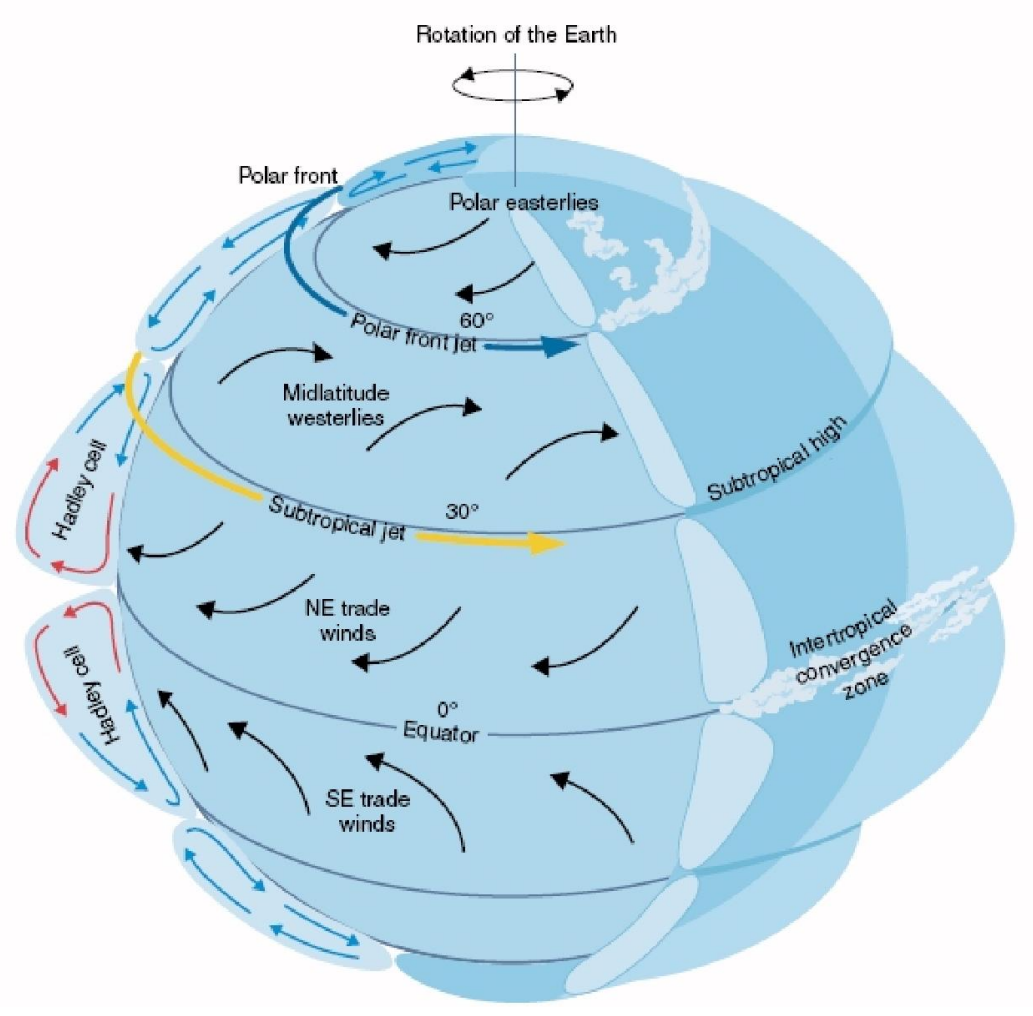

Figura 1.1. Circulación atmosférica general. Imagen tomada del Space Science and Engineering Center. University of Wisconsin-Madison. http://cimss.ssec.wisc.edu/sage/meteorology/lesson2/concepts.html. 
Esta dinámica atmosférica lleva asociado un sistema de vientos de superficie, que se dirigen desde los centros de altas presiones a los de bajas presiones, y que son desviados por la rotación terrestre, según el efecto Coriolis, de modo que:

-Los alisios o trade winds, son los vientos asociados a las células de Hadley que circulan entre los trópicos, desde los $30-35^{\circ}$ de latitud hacia el ecuador y soplan del noreste en el hemisferio Norte y del sureste en el Sur.

-Los contraalisios o westerlies, son los vientos de las células de Ferrel, centrados a $45^{\circ} \mathrm{N}$ y a $45^{\circ} \mathrm{S}$ que se dirigen desde las altas presiones subtropicales, hacia las bajas presiones polares en dirección suroeste en el hemisferio Norte y noroeste en el Sur.

-Los vientos polares del este o polar easterlies, son los vientos asociados a las células polares.

\subsection{Circulación oceánica global}

El sistema de circulación oceánica global, también conocido como circulación oceánica termohalina o cinta transportadora oceánica es el encargado, junto con la circulación atmosférica general, de redistribuir el calor desde las regiones tropicales hacia los polos, siendo decisivo en la configuración climática terrestre.

En esta circulación intervienen el conjunto de las masas de agua oceánicas, tanto superficiales, como intermedias y profundas. Las aguas superficiales comienzan a calentarse en regiones tropicales del Pacífico y el Índico y llegan al Atlántico tropical donde alcanzan la mayor concentración de calor y salinidad. Del atlántico tropical parte la Corriente del Golfo, que se dirige hacia el Atlántico norte aportando la sal necesaria para que las aguas superficiales, enfriadas por los vientos polares, aumenten su densidad y se hundan en profundidad formando el Agua Profunda del Atlántico Norte (NADW). La NADW es una masa de agua fría y densa que circula en profundidad a lo largo del Atlántico hasta volver a aflorar en el Pacífico y el Índico.

\subsection{El Mar Mediterráneo}

\subsubsection{Marco fisiográfico}

El Mediterráneo es una cuenca marina semicerrada, situada entre $\operatorname{los} 30^{\circ}-45^{\circ} \mathrm{N}$ y $\operatorname{los} 5^{\circ}-35^{\circ} \mathrm{O}$ y rodeada por completo por las grandes masas continentales de Europa, África y Asia. Su posición marginal y de aislamiento geográfico se debe a la ausencia de conexiones con otros océanos, de hecho el único intercambio de aguas con el océano abierto se materializa a través del estrecho de Gibraltar, esta franja de $15 \mathrm{~km}$ de longitud y $284 \mathrm{~m}$ de profundidad que conecta el Mediterráneo con el océano Atlántico. 


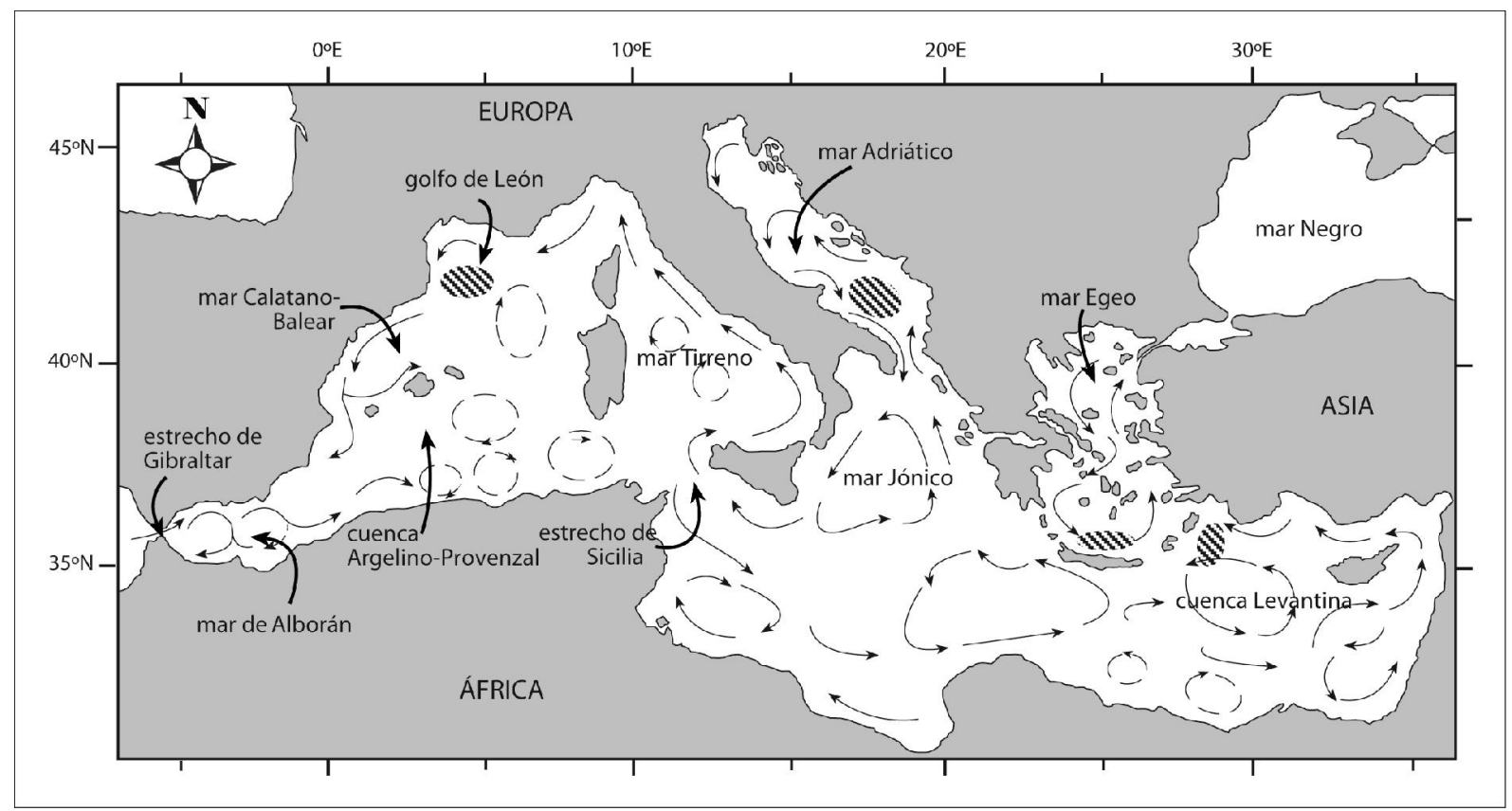

Figura 1.2. Mapa del mar Mediterráneo. Detalle de las subcuencas principales, la circulación superficial y las zonas de hundimiento de aguas profundas (áreas rayadas). Tomada de Colmenero-Hidalgo (2004). Modificada a partir de Bethoux (1980) y Lascaratos et al. (1999).

La peculiaridad del Mediterráneo deriva de su estratégica posición geográfica, situada entre la franja subtropical y semidesértica del norte de África y la región templada del sur de Europa, y dentro de los límites de la Zona de Convergencia Intertropical (ZCIT).

Esta múltiple influencia ambiental dota al Mediterráneo de una especial sensibilidad para reaccionar ante las variaciones climáticas, por lo que el estudio de su registro fósil se revela una tarea tan interesante como compleja.

\subsubsection{Circulación atmosférica}

Las condiciones meteorológicas imperantes en el área mediterránea dependen en gran medida de la situación del anticiclón de las Azores y de su situación intermedia entre un ambiente semidesértico al sur y este y templado al norte, ambos con una pluviosidad de moderada a escasa. La posición de la zona de convergencia intertropical y sus migraciones latitudinales también ejercen una importante influencia sobre el Mediterráneo.

El anticiclón de las Azores presenta una situación de altas presiones en verano que deriva en condiciones cálidas y secas, mientras que en invierno, las bajas presiones y la entrada de frentes húmedos desde el Atlántico, dan lugar a condiciones frías y húmedas. 


\subsubsection{Circulación oceánica y masas de agua}

E1 Mediterráneo es un claro ejemplo de cuenca de concentración, consecuencia de un balance hídrico anual negativo, es decir, aquel en el que los aportes por precipitación o escorrentía fluvial son menores a las pérdidas totales por evaporación (Béthoux, 1979). Esto da lugar a un régimen de circulación antiestuarino, con entrada de aguas superficiales atlánticas de baja salinidad y contenido en nutrientes pero ricas en oxígeno y salida de aguas mediterráneas profundas con alta salinidad y mayor contenido en nutrientes. Este intercambio de masas de agua confiere al Mediterráneo un marcado carácter oligotrófico (Minas et al., 1984). La circulación general dentro del Mediterráneo está controlada por el gradiente de densidades existente entre las dos cuencas, Oriental y Occidental. La alta tasa de evaporación de la cuenca Oriental provoca el hundimiento de masas de agua y la generación de la masa de agua intermedia levantina (LIW), que discurre por toda la cuenca mediterránea.

Por su parte, la circulación profunda está controlada por el intercambio de aguas entre el Atlántico y el Mediterráneo y por la tasa de formación de agua profunda en áreas del norte como el golfo de León, el mar Egeo, el mar Adriático y el noroeste del Mediterráneo (Pinardi y Masetti, 2000). A su vez, el hundimiento de aguas profundas se debe a los vientos de invierno, fríos y secos, que barren la cuenca con dirección norte y oeste. La diferencia de temperaturas entre el agua y el aire induce una transferencia de calor del océano a la atmósfera y un enfriamiento que incrementa la densidad del agua superficial y hace que ésta se hunda en profundidad (Beckers et al., 1997; Bethoux et al., 2002).

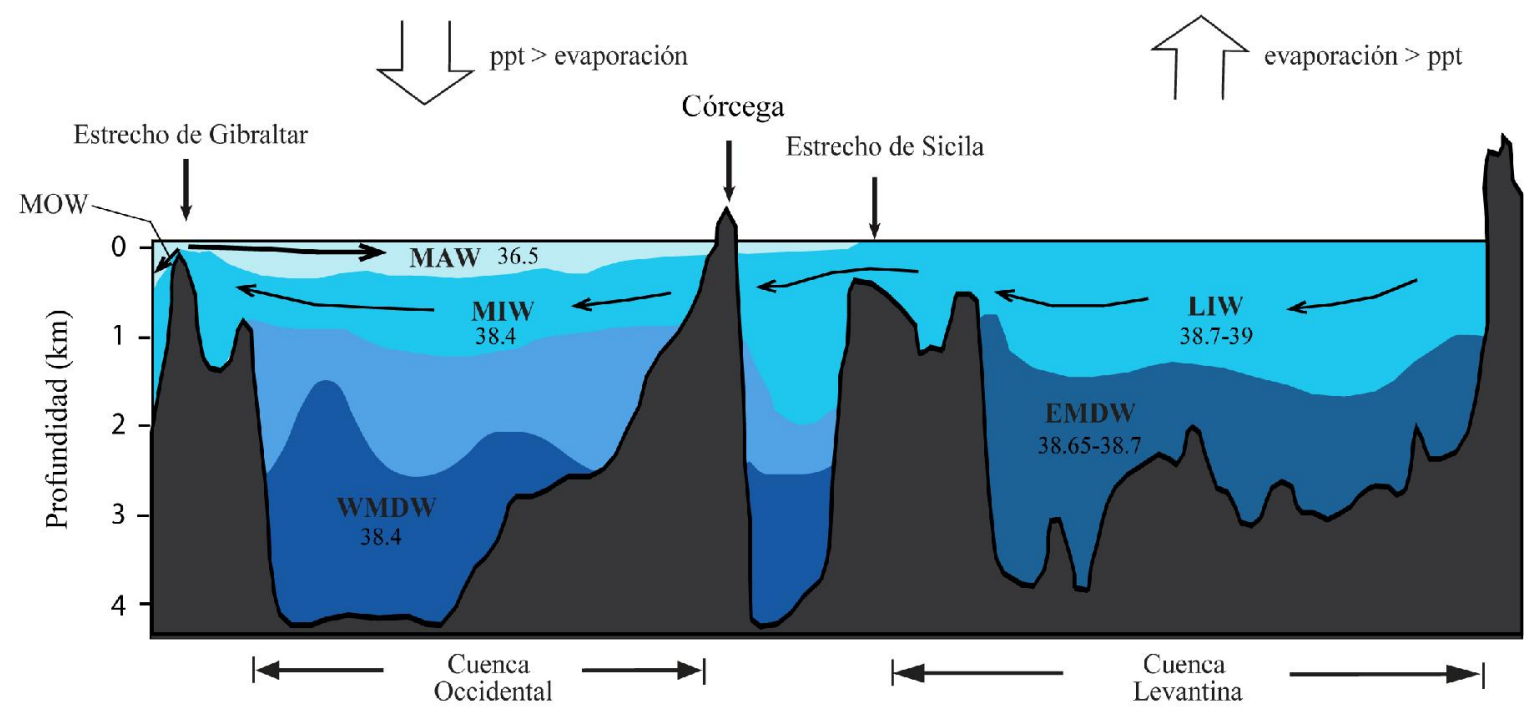

Figura 1.3. Esquema de la circulación de masas de agua en el Mediterráneo. WMDW: aguas profundas del Mediterráneo occidental; EMDW: aguas profundas del Mediterráneo oriental; LIW: aguas intermedias levantinas; MIW: aguas intermedias mediterráneas; MAW: aguas atlánticas modificadas; MOW: aguas de salida del Mediterráneo. La salinidad de cada masa de agua se especifica en psu. Tomada de Rigual-Hernández (2011). Modificada de Cramp y O'Sullivan (1999). 
Las masas de agua definidas para el Mediterráneo son:

- Agua Atlántica modificada o Modified Atlantic Water (MAW), fluye hacia el este desde el estrecho de Gibraltar hasta la cuenca argelina circulando entre los primeros 200-300 metros de la columna de agua (Pujol y Vergnaud-Grazzini, 1995). Procede de la entrada del Agua Noratlántica Superficial (NASW) a través del estrecho de Gibraltar y a medida que penetra en el Mediterráneo, va aumentando su temperatura y salinidad gradualmente como resultado de la evaporación y la mezcla de aguas.

- Agua Levantina Intermedia o Levantine Intermediate Water (LIW) se forma en la cuenca levantina debido a la alta evaporación y circula en dirección oeste a una profundidad de entre 200 y 600 m. (Astraldi et al., 2002; Masqué et al., 2003). Es una corriente de alta salinidad (hasta $39 \mathrm{psu}$ ) (Cramp y O'Sullivan, 1999) con una temperatura media de $14,5{ }^{\circ} \mathrm{C}$ (Millot, 1999).

- Agua Mediterránea Intermedia o Mediterranean Intermediate Water (MIW), discurre también en dirección oeste y se nutre mayoritariamente de la LIW. Su recorrido termina en el estrecho de Gibraltar donde se une parcialmente con la WMDW para formar el flujo de salida del Mediterráneo (MOW). La cantidad de WMDW está sujeta a una gran variabilidad anual.

- Flujo de salida del Mediterráneo o Modified Outflow Water (MOW) caracterizado por una temperatura de $13{ }^{\circ} \mathrm{C}$ y una salinidad de 38,4 psu (Zahn et al., 1997) cuyos valores descienden al mezclarse con la aguas atlánticas del golfo de Cádiz (O'Neil-Baringer y Price, 1999). La MOW se extiende por el Atlántico entre los 600 y $2500 \mathrm{~m}$ de profundidad y puede ser detectada incluso en las costas de Noruega o Canadá (Vergnaud-Grazzini et al., 1989). Sus especiales valores de salinidad y temperatura ejercen una clara influencia sobre la dinámica termohalina del Atlántico y global.

- Agua Mediterránea Occidental Profunda o Western Mediterranean Deep Water (WMDW), se forma en el golfo de León y se caracteriza por una alta densidad y por temperaturas y salinidades de $12,7^{\circ} \mathrm{C}$ y 38,4 psu respectivamente (Drakopoulos y Lascaratos, 1999). Su formación es estacional, en invierno, y su volumen varía anualmente según la intensidad de los vientos (Pinardi y Masetti, 2000) y la temperatura, de modo que en inviernos suaves no se hunde del todo y discurre a profundidades de 1500 m (Millot, 1999).

- Agua Mediterránea Oriental Profunda o Eastern Mediterranean Deep Water (EMDW), se forma a partir del hundimiento de aguas en el mar Egeo, el mar Adriático y el noroeste del Mediterráneo, y se caracteriza por altas salinidades. El estrecho de Sicilia separa las dos masas de aguas profundas del Mediterráneo (WMDW y EMDW) e impide cualquier intercambio entre ellas. 
Las aguas superficiales atlánticas, más dulces y ligeras, entran en el Mediterráneo rebasando el estrecho de Gibraltar y circulan superficialmente en sentido contrario a las aguas del Mediterráneo, salinas y densas, que salen en forma de chorro (MOW).

Las aguas atlánticas modifican sus características a medida que se desplazan hacia el este y se van mezclando con las aguas intermedias del Mediterráneo (LIW). Este desplazamiento superficial es muy complejo y se compone de varios ciclos ciclónicos (sur) y anticiclónicos (mar de Alborán).

Las condiciones hidrodinámicas del Mediterráneo están ulteriormente condicionadas por variaciones estacionales en la evaporación y el régimen de vientos, y por el volumen de intercambio de aguas que derivan de estos cambios.

\subsubsection{Productividad}

A nivel global, el Mediterráneo se caracteriza por su oligotrofía (Estrada, 1996), ya que la concentración de nutrientes en superficie es en general pobre y la fuerte haloclina impide la mezcla de aguas (Pujol y Vergnaud-Grazzini, 1995). Tanto el fósforo como el nitrógeno son nutrientes limitantes, aunque el fósforo suele serlo más a menudo (Margalef, 1963). Si a esto añadimos las pérdidas por salida de aguas de fondo ricas en nutrientes y por entrada de aguas atlánticas relativamente pobres en nutrientes, el resultado es un escenario oligotrófico con valores de clorofila a relativamente bajos (<0,2 $\left.\mu \mathrm{g} \operatorname{chl} a 1^{-1}\right)$ (Siokou-Frangou et al., 2010).

En el Mediterráneo, la estratificación de las masas de agua es alta y la coincidencia de los factores de producción (luz, nutrientes y $\mathrm{O}_{2}$ ) complicada (Pinardi et al., 2002). Sin embargo, la intensificación invernal de los vientos favorece la mezcla vertical de masas de agua y la fertilización de la base de la zona fótica, provocando la formación de pequeños upwellings o surgencias temporales, como el conocido frente de Alborán (Bárcena y Abrantes, 1998).

Existe un gradiente decreciente de productividad desde el oeste hasta el este (D'Ortenzio y Ribera d'Alcala, 2009), de modo que la cuenca occidental es más productiva que la oriental, ya que en ésta se registran mayores aportes superficiales y una mejor conexión estacional entre las capas de la columna de agua, y entre éstas y la atmósfera. En concreto, el Mediterráneo Noroccidental presenta los valores más altos de productividad primaria con concentraciones de clorofila de hasta $3 \mu \mathrm{g} \operatorname{chl} a \mathrm{l}^{-1}$ durante la transición invierno-primavera (Siokou-Frangou et al., 2010). 


\subsection{El Mar de Alborán}

\subsubsection{Marco fisiográfico}

EL mar de Alborán es la cuenca más occidental del mar Mediterráneo y la que recibe las aguas atlánticas a través del somero estrecho de Gibraltar.

La cuenca forma un arco de $54.000 \mathrm{~km}^{2}$ de extensión y presenta una topografía de fondo muy irregular caracterizada por diversas mesetas y bancos. El centro de este arco está surcado por una alineación volcánica que divide al mar de Alborán en dos subcuencas: oriental y occidental. Presenta una batimetría creciente hacia el este, donde la profundidad máxima es de 1500 metros en la subcuenca occidental y de 2000 metros en la oriental.

\subsubsection{Circulación atmosférica}

La estructura de la columna de agua en el mar de Alborán depende en gran medida de los cambios estacionales en la circulación atmosférica.

En verano, la migración del anticiclón de las Azores sobre la península Ibérica, establece un sistema de altas presiones que resulta en un tiempo cálido y seco con predominio de vientos de levante, ligeros. A nivel oceanográfico, esto se traduce en un calentamiento de las aguas superficiales y la formación de una termoclina estacional en la columna de agua.

En invierno, el anticiclón remite y deja paso al predominio de vientos fríos y secos provenientes del continente, vientos de poniente. Esto provoca un aumento en la evaporación del océano y un aumento de la densidad de las aguas superficiales, escenario ideal para la aparición de surgencias (Cano y García, 1991).

La dinámica atmosférica también controla el efecto del influjo atlántico o el papel de los vientos del sur y suroeste en el transporte de polvo rojizo en suspensión procedente de las áreas desérticas que circundan la cuenca de Alborán (Parrilla y Kinder, 1987).

\subsubsection{Circulación oceánica y masas de agua}

La circulación general del mar de Alborán es de origen termohalino y está controlada por los valores del balance hídrico y por la relación entre el influjo atlántico y el reflujo mediterráneo a través del estrecho de Gibraltar (Cacho et al., 2000; Pierre, 1999).

El agua superficial atlántica entra en el Mediterráneo y forma una corriente superficial de baja salinidad. La mezcla vertical con las aguas mediterráneas superficiales e intermedias (LIW) va 
modificando sus características al avanzar hacia el este y da lugar al agua atlántica modificada (MAW) (Bormans et al., 1986). Las aguas intermedias y profundas (LIW y WMDW) avanzan en sentido contrario a las superficiales, y dan origen al flujo de salida del Mediterráneo (MOW) que discurre hacia el Atlántico modificando progresivamente sus altas salinidades y temperaturas.

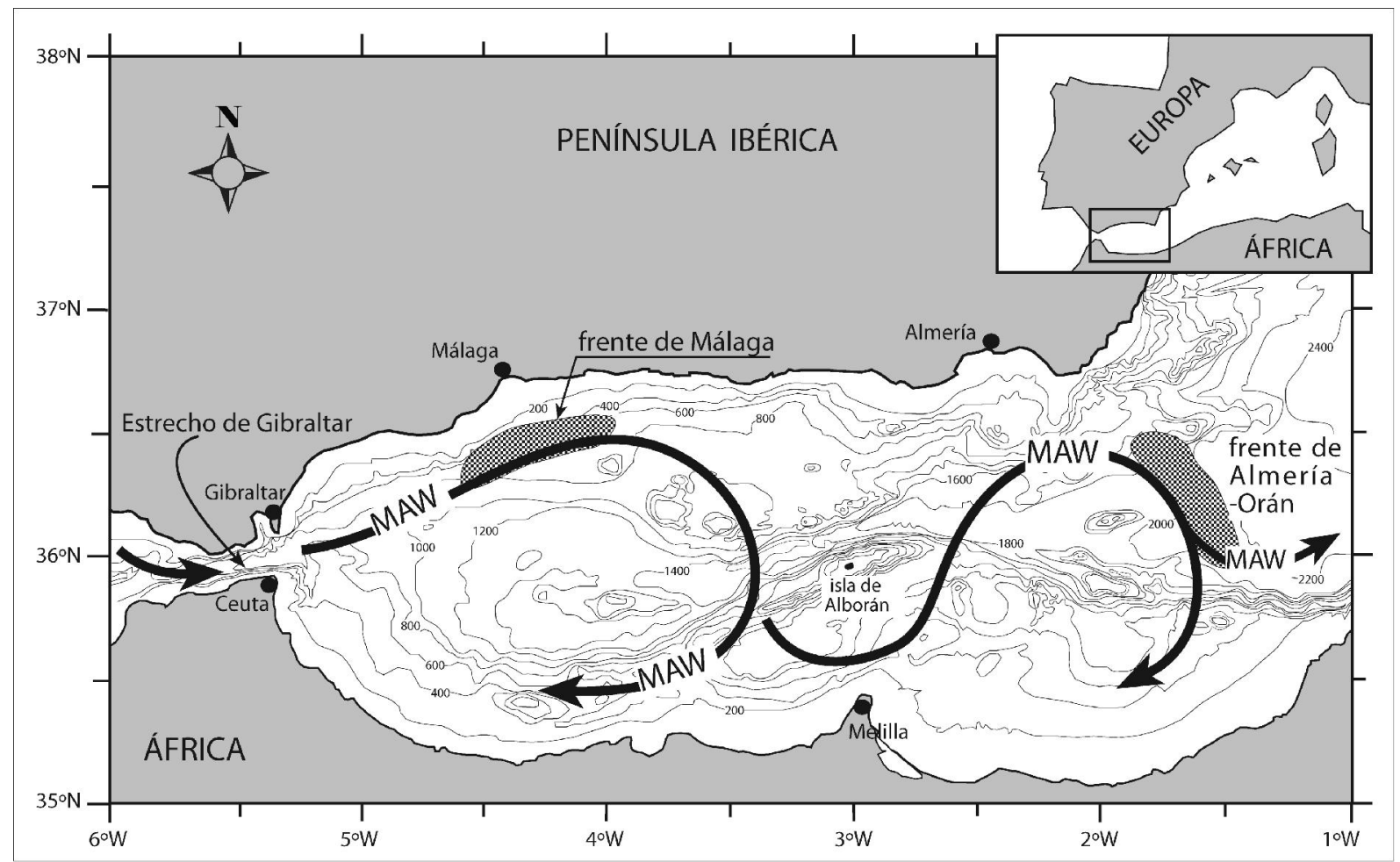

Figura 1.4. Mapa batimétrico del mar de Alborán y circulación oceánica superficial (MAW). Las dos áreas punteadas representan las zonas de surgencia (frentes de Málaga y de Almería-Orán). Tomada de ColmeneroHidalgo (2004).

La compleja hidrografía de la cuenca se debe en parte a la existencia de dos giros anticiclónicos que describe la MAW en su avance hacia el este, que coinciden aproximadamente con las dos subcuencas definidas y que son los rasgos oceanográficos más significativos del mar de Alborán.

Los dos giros anticiclónicos, denominados Giro de Alborán Occidental (Western Alboran Gyre, WAG) y Giro de Alborán Oriental (Eastern Alboran Gyre, EAW), tienen dimensiones similares y presentan una amplia variabilidad estacional controlada por los valores de salinidad y temperatura de las aguas superficiales (Vargas-Yáñez et al., 2002) aunque, el giro occidental presenta más estabilidad que el oriental (Heburn y La Violette, 1990; Perkins et al., 1990). Durante los meses de verano, la circulación en el mar de Alborán presenta una mayor estabilidad y el desarrollo de ambos giros. En invierno, existe un predominio de la circulación costera de la corriente atlántica que presenta menor ángulo y dificulta el desarrollo de los giros. Primavera y otoño, son periodos transicionales (VélezBelchí et al., 2005) con frecuentes episodios en los que se desarrollan tres giros (Vargas-Yáñez et al., 2002). Esta variabilidad puede modificar la posición de los giros hasta $50 \mathrm{~km}$. 


\subsubsection{Productividad}

En contraste con las condiciones oligotróficas del resto del Mediterráneo, el mar de Alborán presenta dos áreas de alta productividad relacionadas con la desarrollo de surgencias (Sarhan et al., 2000). Estas áreas están asociadas a la circulación anticiclónica y derivan del encuentro de dos masas de agua con características muy dispares, las atlánticas y las mediterráneas.

El área más occidental aparece en el flanco norte del giro occidental (WAG), en las proximidades de la costa andaluza, y se conoce como frente de Málaga (Parrilla y Kinder, 1987). Este frente se desarrolla por la inestabilidad creada por el contacto de la AW, la LIW y la topografía del fondo (Perkins et al., 1990) y presenta alta productividad primaria como resultado de la mezcla de aguas y el aporte de nutrientes de aguas atlánticas (Bárcena y Abrantes, 1998).

El otro área de alta productividad se sitúa cerca del cabo de Gata, se conoce como frente de AlmeríaOrán (Minas et al., 1991; Viudez et al., 1998) y se forma al noreste del giro anticiclónico oriental, controlado por su tamaño y posición.

Los mecanismos que controlan la dinámica de upwelling en el mar de Alborán son principalmente la acción del viento y el flujo hacia el sur de la corriente de aguas atlánticas que vienen bordeando la península Ibérica y que hacen aflorar aguas sub-superficiales más ricas en nutrientes produciendo una fertilización de la zona fótica.

Además, el paso de las aguas atlánticas por el estrecho de Gibraltar supone una contribución adicional de nutrientes. La mayor disponibilidad de nutrientes permite una intensa actividad biológica que da origen a una zona de oxígeno mínimo en el centro del giro.

La evolución estacional de la productividad superficial muestra unos regímenes bien diferenciados para cada estación: el régimen de eclosión de invierno (noviembre a marzo) con temperaturas superficiales (SST) $\leq 17^{\circ} \mathrm{C}$, el régimen de no eclosión de verano (mayo a septiembre) que presenta $\mathrm{SST} \geq 19,5^{\circ} \mathrm{C}$ y las dos fases de transición de abril-mayo y octubre-noviembre, cuando comienza a estratificarse y desestratificarse la columna de agua en respuesta a la acción de los vientos (GarciaGorriz y Carr, 2001). 


\subsection{Margen Noroccidental Africano}

\subsubsection{Circulación atmosférica}

El actual escenario climático en el margen noroccidental africano está gobernado por la variación estacional en la posición de la Zona de Convergencia Intertropical (ZCIT) (Nicholson, 2000), cuyo desplazamiento latitudinal viene asociado a cambios en la insolación terrestre.

En tiempo geológico, las variaciones en los máximos de insolación han provocado cambios en los gradientes térmicos interhemisféricos, que a su vez, se han asociado con desplazamientos meridionales de la ZCIT durante periodos más fríos (Broccoli et al., 2006; Tisserand et al., 2009), de ahí, la importancia de entender sus causas y efectos para interpretar su rol en paleoclimatología. La ZCIT es un rasgo atmosférico de mesoscala que delinea la rama ascendente de la célula de Hadley y la confluencia de los alisios del norte y del sur (Koutavas y Lynch-Stieglitz, 2005) y cuya migración estacional, condiciona la distribución de las precipitaciones y el régimen de vientos.

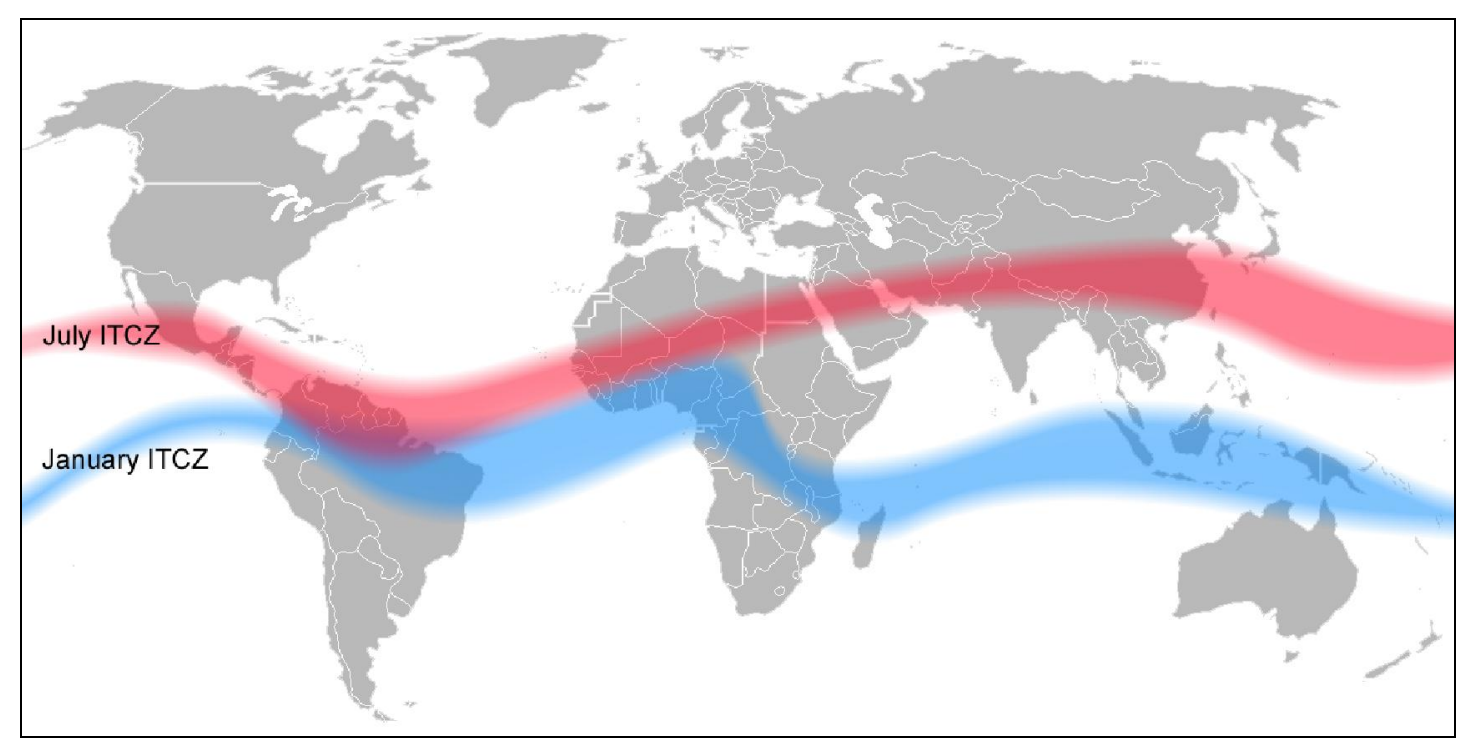

Figura 1.5. Desplazamiento estacional de la Zona de Convergencia Intertropical (ZCIT). Posiciones de julio y enero. Tomada de http://es. wikipedia.org/wiki/Zona de convergencia intertropical.

La ZCIT es un cinturón de bajas presiones que ciñe el globo terrestre en la región ecuatorial, y que, como su nombre indica, se forma por la convergencia de aire cálido y húmedo de latitudes por encima y por debajo del ecuador. Las masas de aire cálido son forzadas a ascender a la ZCIT por la acción de la célula de Hadley y la actividad convectiva de las tormentas. Esto origina abundante nubosidad y fuertes precipitaciones, acompañadas ocasionalmente de descargas eléctricas, de modo que las regiones situadas en la ZCIT reciben precipitación más de 200 días al año. Los desplazamientos de la 
ZCIT afectan a las precipitaciones en los países tropicales produciendo estaciones secas y húmedas en lugar de frías y cálidas como en las latitudes superiores.

A pesar de experimentar desplazamientos estacionales regulares, la ZCIT mantiene actualmente una posición cuasi-permanente desviada hacia el hemisferio Norte (Koutavas y Lynch-Stieglitz, 2005) que, aún no coincidiendo con el ecuador, si lo hace con un ecuador "térmico" o "meteorológico", situado aproximadamente $5^{\circ}$ al norte del ecuador geográfico. Esta ligera desviación de la ZCIT hacia al norte es una característica peculiar de la circulación atmosférica tropical, cuyo origen, aún por determinar, puede deberse a diversas causas, desde la distribución asimétrica de las masas continentales o la geometría de las líneas de costa, hasta la cobertura de nubes estratiformes o procesos relacionados con la surgencia de aguas frías en superficie (Philander et al., 1996; Xie y Saito, 2001).

La localización de la ZCIT varía con el ciclo estacional siguiendo la posición del sol en el cenit, de modo que alcanza su posición más al norte durante el verano del hemisferio Norte, y su posición más al sur durante el invierno boreal, en el Atlántico oriental, fluctúa entre los 5 y $15^{\circ} \mathrm{N}$ (Höflich, 1984).

Sin embargo, la ZCIT no es uniforme y puede variar de unas longitudes a otras, siendo menos móvil en las longitudes oceánicas donde el gradiente térmico estacional es menor que en los continentes. Sobre los océanos, la ZCIT mantiene una posición más estable al norte del Ecuador, por tanto, las variaciones estacionales afectan a un área más restringida, aunque los efectos climáticos se mantienen. Existe también un ciclo diurno en el que se desarrollan cúmulos convectivos a mediodía que forman tormentas por la tarde.

Durante el verano boreal, la ZCIT alcanza su posición más septentrional alrededor de 15 o $20^{\circ} \mathrm{N}$ permitiendo que las condiciones húmedas del monzón se extiendan al norte hasta áreas subtropicales de África. Esto restringe la influencia de los cálidos y secos vientos alisios y el aporte de polvo a latitudes más septentrionales correspondientes con el norte del Sahara. La pluma de polvo africano en verano se extiende entre los 15 y $25^{\circ} \mathrm{N}$ siguiendo la dirección este marcada por los alisios y bloqueada al sur por la posición de la ZCIT. Mientras tanto, durante el invierno del hemisferio Norte, la migración de la ZCIT hasta los $5^{\circ} \mathrm{N}$ permite la llegada de los alisios más al sur, estos presentan ahora sus mayores intensidades y dan lugar a un régimen más seco. En invierno es cuando el Harmattan, un alisio de origen continental, sopla en dirección sudoeste a bajas altitudes y favorece un mayor aporte de polvo al océano (Chiapello et al., 1995).

La oscilación de la ZCIT da origen a la formación de un frente de monzones al norte y al sur, que generan veranos lluviosos e inviernos secos enmarcando una zona ecuatorial húmeda con dos máximos de precipitaciones (Gasse, 2000). 
La circulación zonal a lo largo del Ecuador está condicionada por las diferencias topográficas esteoeste y las temperaturas de la troposfera, que en conjunto ejercen un efecto importante sobre la regulación de los climas tropicales. Fluctuaciones en las precipitaciones registradas en diversas áreas del continente se han podido relacionar estadísticamente con el ENSO (El Niño Southern Oscillation), aunque bien pueden ser una respuesta directa a la variación de la temperatura marina superficial en la India y el océano Atlántico (Nicholson, 1996).
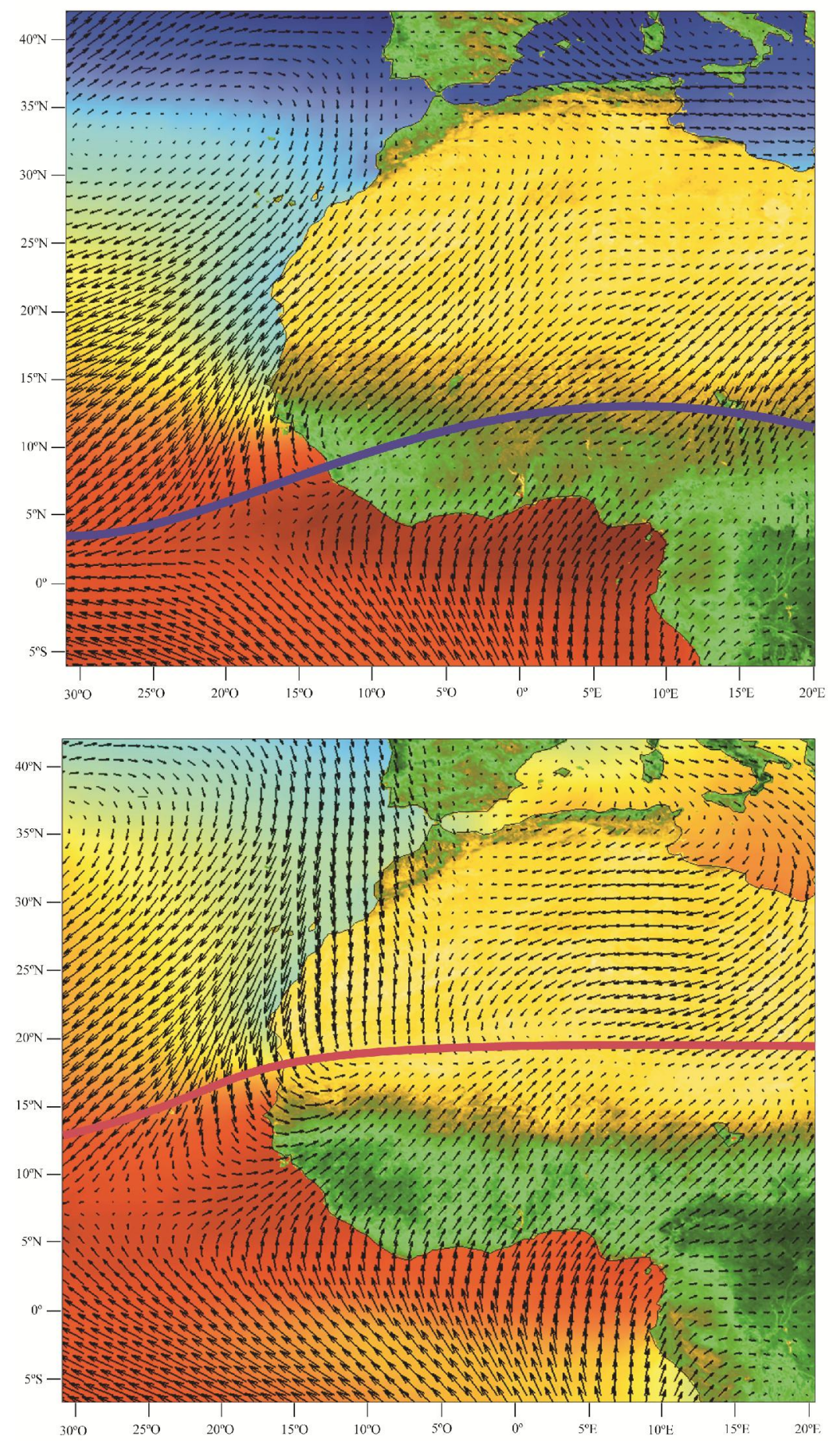

Figura 1.6. Mapa del sistema de vientos superficiales (flechas negras) del margen noroccidental africano, cobertura vegetal en el continente (verde), y temperaturas superficiales del océano. Izquierda: Condiciones de invierno (diciembre, enero $\mathrm{y}$ febrero) cuando la ZCIT alcanza su posición más al sur (línea azul). Derecha: Condiciones de verano (junio, julio y agosto) y posición más septentrional de la ZCIT (línea roja). Modificada de (Adkins et al., 2006). 
Según Gasse (2000) la asimetría en el patrón climático este-oeste se relaciona tanto con características topográficas, como el escarpe del sur de África, como con el efecto de las corrientes marinas superficiales, entre ellas, la corriente fría de Benguela y la corriente cálida de Agulhas.

Esta circulación atmosférica superficial controla en gran parte, tanto el aporte de polvo africano al margen noroccidental atlántico como la formación e intensidad de la surgencia costera. Sin embargo, la circulación atmosférica en capas más altas de la atmósfera, como agente transportador de la Capa de Aire del Sahara (SAL, Saharan Air Layer), también juega un papel decisivo en el clima de África.

La SAL se forma cuando el aire del Sahara más cálido se sitúa por encima de la capa de aire monzónico más fría. Se localiza entre los 1,5 y 5-7 km sobre el nivel del mar, hacia el nivel medio de la troposfera (Prospero y Lamb, 2003) y actúa como reservorio de partículas de polvo que han sido movilizadas previamente (Buckle, 1996) facilitando el transporte de polvo desde el margen africano hasta el Atlántico. Este fenómeno atmosférico es el responsable del transporte de polvo hacia el Atlántico y Europa (Gasse, 2000; Stuut et al., 2005) y una fuerte influencia en la dinámica general como indican estudios anteriores que registran que los aportes eólicos han llegado a alcanzar incluso el Caribe o Escandinavia (Dunion y Velden, 2004; Prospero y Lamb, 2003).

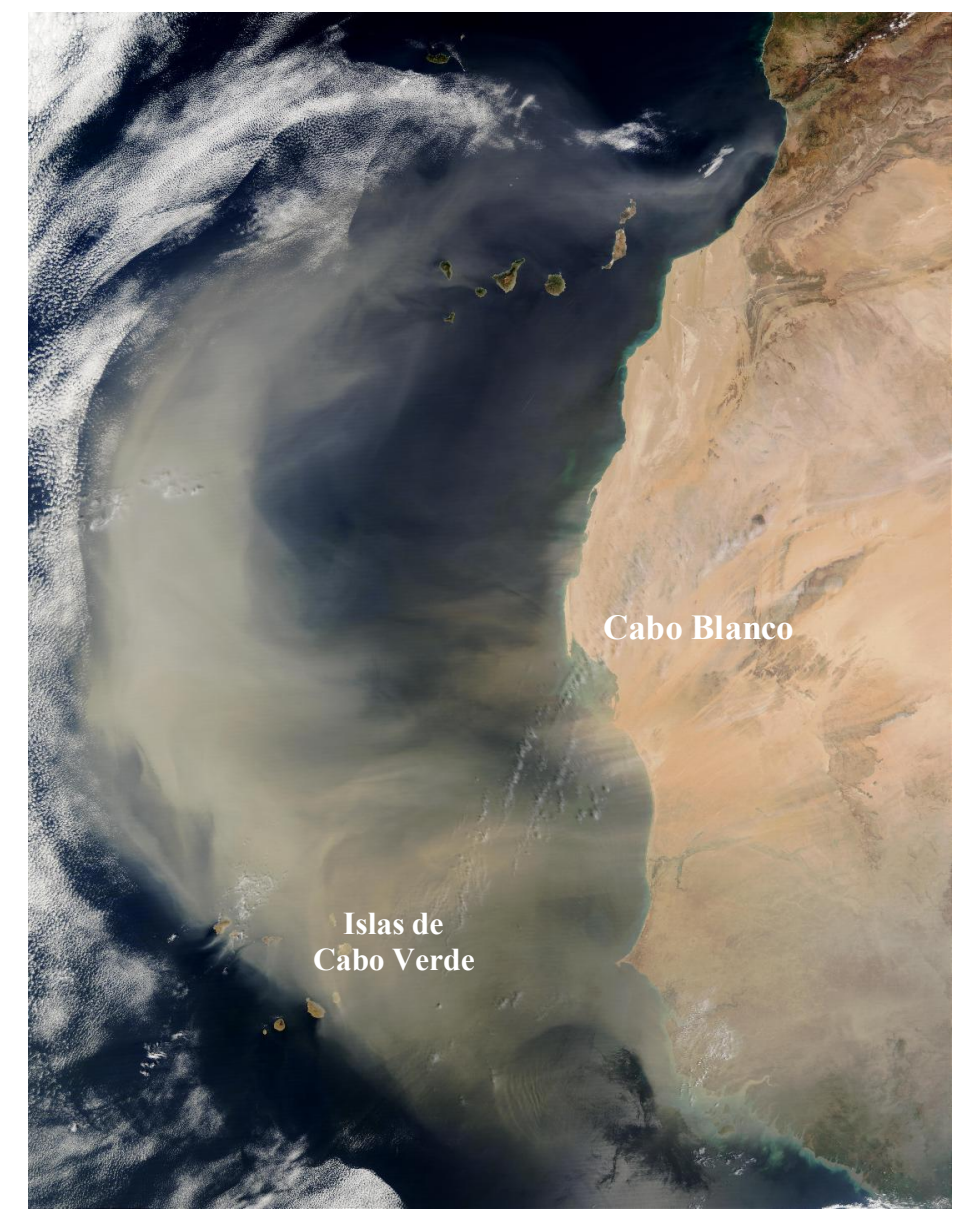

Figura 1.7. Imagen satelital que muestra una nube de polvo sahariano sobre el Atlántico oriental. Tomada de http://earthobservatory.nasa.gov. 
La distribución global de polvo africano ocurre predominantemente durante el verano boreal debido a la formación y desarrollo de la SAL en la troposfera media, sin embargo, el mayor transporte de polvo de tamaño limoso hacia el Atlántico oriental se produce a bajas altitudes y tiene lugar durante el invierno cuando los alisios son más intensos debido a la migración al sur de la ZCIT (Swap et al., 1996). En concreto, el Harmattan, un alisio de origen continental, se intensifica en invierno y transporta grandes cantidades de polvo desde el Sahara hasta el Atlántico oriental (Stuut et al., 2005).

El volumen de polvo procedente del norte de África se relaciona con periodos de aridez de las zonas fuente y una intensificación de los procesos de erosión eólica, sin embargo, el proceso global de formación y transporte de polvo hacia la atmósfera no depende sólo de la aridez sino también de la combinación de una serie de condiciones meteorológicas asociados con la ZCIT (Jullien et al., 2007; Mulitza et al., 2008). A escala geológica, las variaciones en el balance hidrológico del África subtropical se han registrado a partir de variaciones en el aporte de polvo en los sedimentos marinos (deMenocal, 1995; Rea, 1994; Tiedemann et al., 1994; Tiedemann et al., 1989), ya que el aporte de polvo aumenta cuando las condiciones de aridez reducen la cobertura vegetal y los suelos áridos son entonces más propensos a sufrir erosión eólica.

El testigo MD03 2705 DUST se sitúa en el límite norte de la actual pluma de invierno de polvo del Sahara, y directamente bajo el eje de la pluma de polvo de verano, la cual, con valores de casi medio billón de toneladas al año, es la mayor fuente de aporte de polvo a la atmósfera a nivel global (Mulitza et al., 2010; Prospero et al., 2002). Por tanto, su ubicación es ideal para monitorizar el aporte de polvo, su relación con la dinámica eólica y la productividad primaria del nanoplancton dentro de los estadios glaciales e interglaciales en el noroeste africano.

\subsubsection{Circulación oceánica y masas de agua}

En un marco global, nuestro testigo se sitúa en el flanco oriental del giro subtropical del Atlántico norte (Eastern Boundary Current System). La circulación oceánica superficial en las latitudes altas y subtropicales del Atlántico oriental está asociada a dos corrientes principales (Flores et al., 2000): la Corriente Ecuatorial del Norte, NEC (North Equatorial Current) y la Corriente Ecuatorial del Sur , SEC (South Ecuatorial Current) separadas por la Contracorriente Norecuatorial, NECC (North Equatorial Counter Current), una corriente más somera que fluye hacia el noreste. Las aguas de la NEC y la SEC se generan como respuesta a los alisos del noreste y el sureste. El límite entre los alisios del noreste y los del sureste marca la zona de convergencia intertropical.

El flanco oriental del giro subtropical está enmarcado por la corriente de Azores que fluye hacia el sur, y alimenta la corriente de Canarias (CC), una masa de agua superficial, que transporta las aguas frías del Atlántico norte a lo largo del margen noroccidental africano. Bajo la CC se encuentra el Agua 
Central del Atlántico Norte (NACW) (Hagen, 2001) que discurre en dirección sur y presenta mayor salinidad y contenido en oxígeno y menor concentración de nutrientes. Al sur de cabo Blanco, el Agua Central del Atlántico Sur (SACW), una masa de agua con mayor contenido en nutrientes y menor oxígeno y salinidad, fluye hacia el norte entre los 200 y $600 \mathrm{~m}$ de profundidad.

Alrededor de los $22^{\circ} \mathrm{N}$, la corriente de Canarias se separa de la costa para continuar en dirección oeste como Corriente Ecuatorial del Norte y forma un frente que separa la surgencia costera de la productividad en el océano abierto y que además favorece la mezcla entre aguas de la NACW y la SAC a través de eddies (Barton, 1998; Hagen, 2001). El desplazamiento de la NACW es compensado por el Agua Intermedia Antártica (AIW) procedente del sur. A estas latitudes, el Agua Profunda del Atlántico Norte (NADW) ocupa profundidades entre 1500 y 4000 m, mientras que el Agua Profunda Antártica (AABW), es la masa de agua más profunda, situada por debajo de los $4000 \mathrm{~m}$.
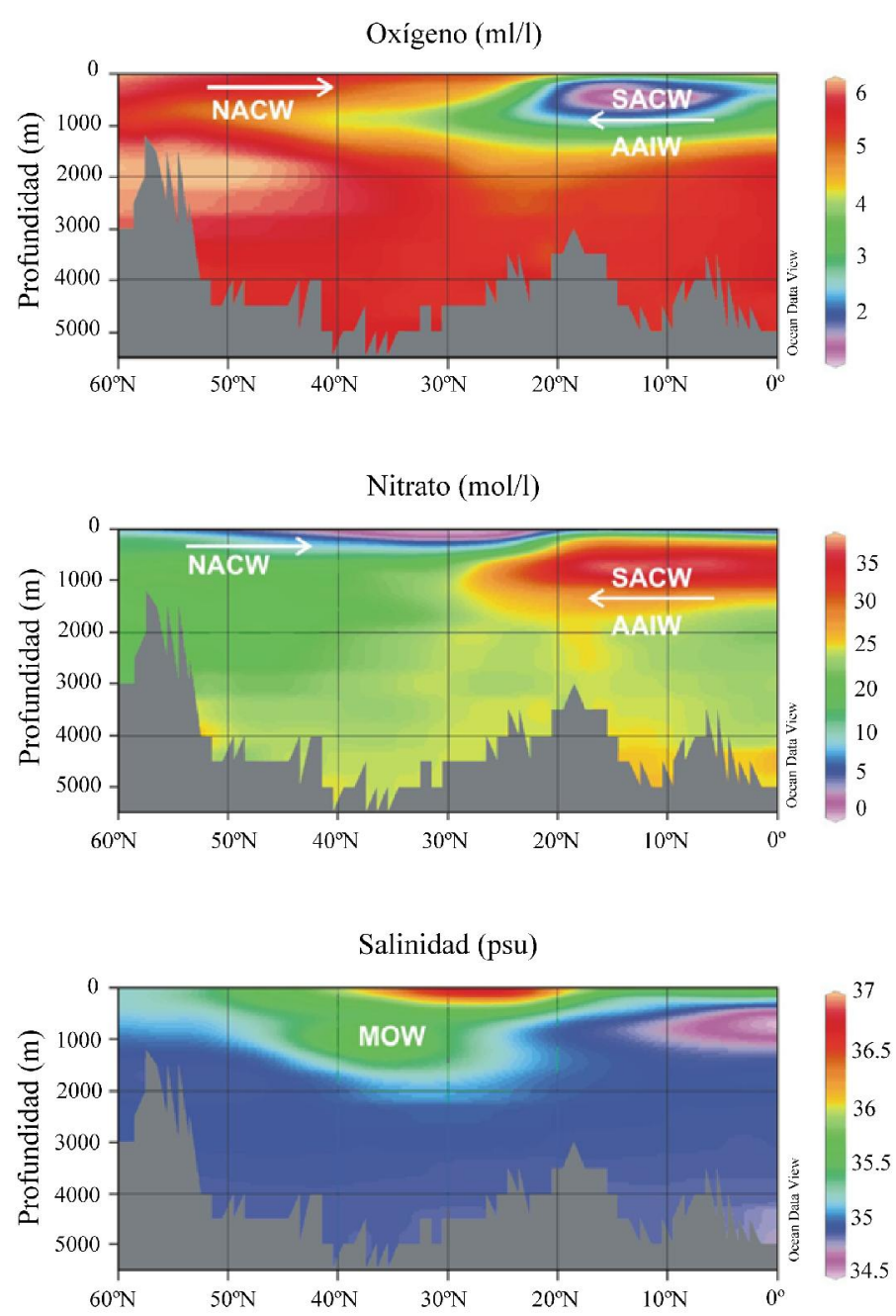

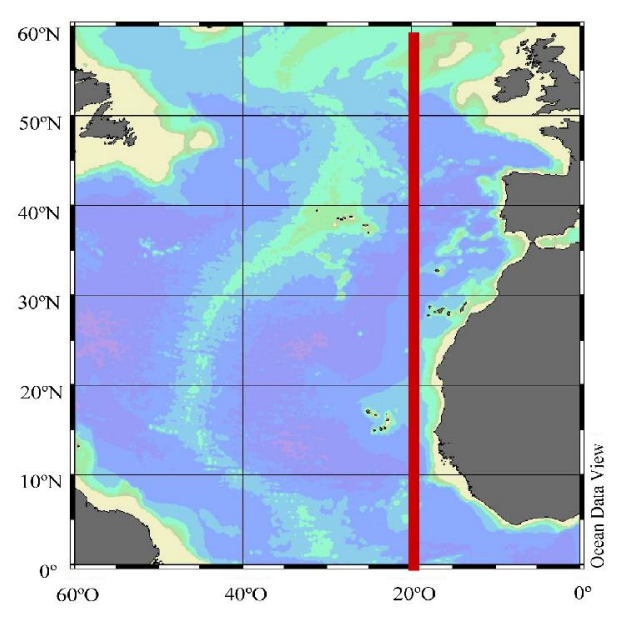

Figura 1.8. Perfil en profundidad a $20^{\circ} \mathrm{O}$ mostrando la media anual de la concentración de oxígeno y nitrato y la salinidad de las masas de agua entre $60^{\circ} \mathrm{N}$ y el Ecuador. NACW: Agua Central del Atlántico Norte; SACW: Agua Central del Atlántico Sur; AAIW: Agua Intermedia Antártica; MOW: Flujo de Salida del Mediterráneo. A partir del Ocean Data View, y la base de datos del World Ocean Atlas (Conkright et al., 2002). 


\subsubsection{Productividad}

Las regiones asociadas al flanco oriental del giro subtropical del Atlántico norte (Eastern Boundary Current System, EBCs), entre ellas, el margen noroccidental africano donde fluye la corriente de Canarias, han sido ampliamente descritas como áreas de alta productividad primaria (Barber y Smith, 1981). Aunque estás zonas de alta productividad ocupan sólo un $0,3 \%$ de los océanos del mundo, su productividad supone más de un $2 \%$ de la productividad marina a nivel global (Carr y Kearns, 2003) y un $17 \%$ de las capturas pesqueras mundiales (Pauly y Christensen, 1995). Las concentraciones de clorofila en estas regiones son superiores a $2 \mathrm{mg} \mathrm{Chl} a \mathrm{~m}^{-3}$ mientras que la productividad potencial supera $\operatorname{los} 3 \mathrm{~g} \mathrm{C} \mathrm{m}^{-2}$ day $^{-1}$ (Carr y Kearns, 2003).

La elevada productividad primaria del margen noroccidental africano resulta del efecto combinado de la surgencia de aguas ricas en nutrientes a la superficie y de la fertilización con nutrientes minerales derivada del aporte de polvo del Sahara por los alisios (Moore y Braucher, 2007). En concreto, la biomasa desarrollada a partir de una determinada concentración de nutrientes, es dos veces superior en el Atlántico EBCs que en el Pacífico EBCs. Esta mayor eficiencia podría deberse a una mayor disponibilidad de hierro por aportes eólicos y a diferencias en la estructura de la comunidad planctónica (Carr y Kearns, 2003).

Las migraciones latitudinales de la ZCIT ejercen una enorme influencia sobre los sistemas atmosférico y oceánico, controlando la fuerza y la posición de los vientos alisios que a su vez, condicionan la intensidad y persistencia de la surgencia en el Atlántico nororiental y el aporte de terrígenos provenientes del Sahara y el Sahel. Los alisios del noreste, que dominan la circulación atmosférica superficial en el margen noroccidental africano, inducen una zona de divergencia de las masas de agua superficiales que origina una intensa surgencia costera (upwelling). Los cambios estacionales en el sistema de los Alisios dan lugar a una alta variabilidad latitudinal del upwelling. En invierno, los Alisios son más intensos entre los 10 y $25^{\circ} \mathrm{N}$, mientras que en verano y otoño se desplazan hacia latitudes más altas (Eriksen y Katz, 1987). Además, el upwelling costero norafricano presenta un marcado ciclo estacional con altas concentraciones de clorofila a $\left(>1 \mathrm{mg} \mathrm{m}^{-3}\right)$ entre enero y junio, y un máximo alrededor de febrero y marzo (Pradhan et al., 2006).

Los $\mathrm{EBC}_{\mathrm{S}}$ se caracterizan por una alta variabilidad tanto estacional como latitudinal, de entre ellos, el upwelling costero norafricano presenta la mayor variabiliad (Carr, 2001). Sin embargo, el EBCs norafricano es perenne y más intenso alrededor de $20^{\circ} \mathrm{N}$, a la altura de Cabo Blanco, donde la corriente de Canarias desemboca en la contracorriente Norecuatorial desviando su dirección hacia el océano abierto. A estas latitudes se produce el encuentro entre masas de agua intermedias provenientes tanto del Atlántico Norte como del Sur (NACW y SACW) (Martinez et al., 1999), por tanto, las aguas que afloran, bien pueden provenir de una u otra masa de agua. Sin embargo, la NACW y la SACW son 
masas de agua con diferentes características, de las que la SACW presenta mayor concentración de nutrientes. Por ello, algunos estudios sugieren que aumentos de la productividad estarían relacionados con la surgencia de aguas de la SACW (Romero et al., 2008), lo cual podría depender de variaciones en la Oscilación del Atlántico Norte (NAO) o en el fenómeno de El Niño (ENSO) (Hagen, 2001).

Aunque la surgencia se concentra en las aguas más próximas a la costa, su alcance puede extenderse mar adentro entre 300 y 600 km gracias a eddies y filamentos (Hill et al., 1998; Pradhan et al., 2006).

Diferentes estudios mantienen que la surgencia del margen noroccidental africano no es uniforme, si no que existen varios filamentos de diferente intensidad y extensión, cuyo desarrollo viene determinado por la topografía y la dirección e intensidad de los vientos (Nykjær y van Camp, 1994). Estos filamentos constituyen una zona de transición entre las aguas costeras eutróficas y las aguas oligotróficas del giro subtropical (Barton, 1998).

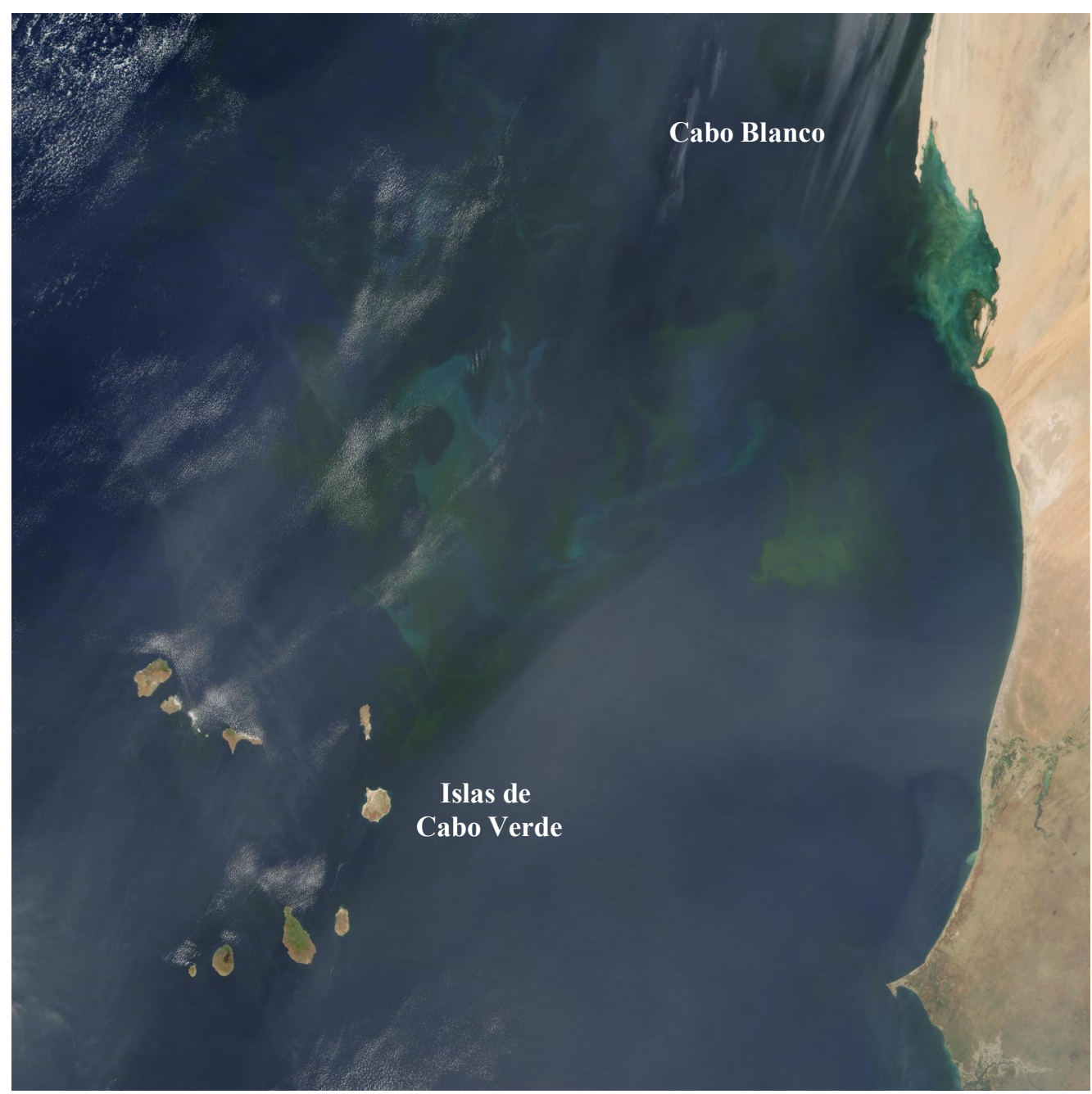

Figura 1.9. Imagen satelital que muestra la concentración de clorofila por el upwelling frente a Cabo Blanco y los filamentos que se extienden mar adentro hacia Cabo Verde. Tomada de http://earthobservatory.nasa.gov. 
En general, las aguas que afloran en la costa de Mauritania provienen de profundidades entre los 50 y 200 metros, y por tanto, son más frías que las aguas circundantes de áreas del océano abierto situadas a la misma latitud.

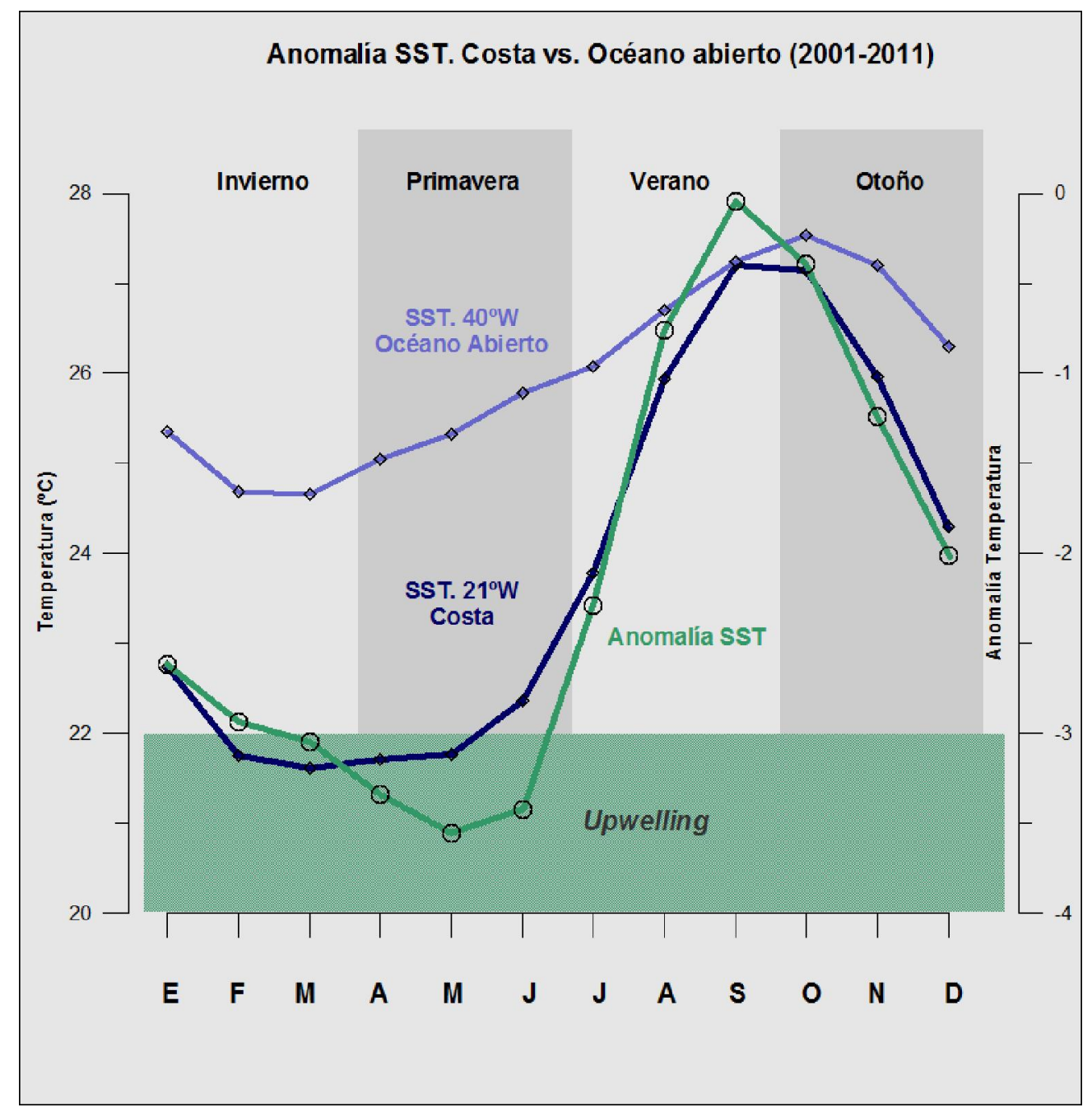

Figura 1.10. La diferencia entre la temperatura de las aguas superficiales de la zona de surgencia (costa, $21^{\circ} \mathrm{W}$ ) y la de las aguas de un área del océano abierto $\left(40^{\circ} \mathrm{W}\right)$ a una misma latitud $\left(18^{\circ} \mathrm{N}\right)$, puede servir para determinar la influencia de la surgencia (Colling, 2001). Esta diferencia o anomalía de temperatura superficial (Anomalía SST), define un índice, según el cual, valores inferiores a -3 estarían relacionados con eventos de upwelling (Speth y Köhne, 1983). Los datos de temperaturas para un periodo de diez años (2001-2010) se obtuvieron de http://iridl.ldeo.columbia.edu/SOURCES/.IGOSS/.nmc/.Reyn_SmithOIv2/ (Reynolds et al., 2002). 


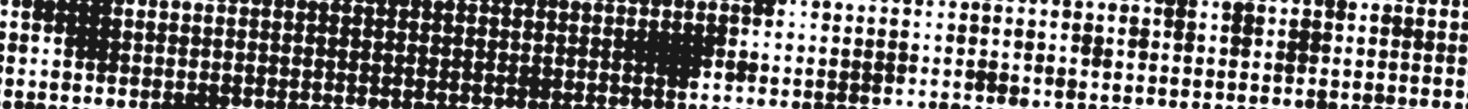
I:

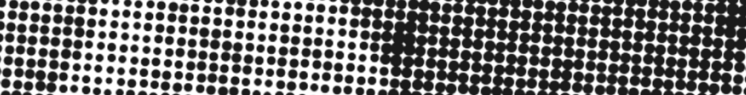

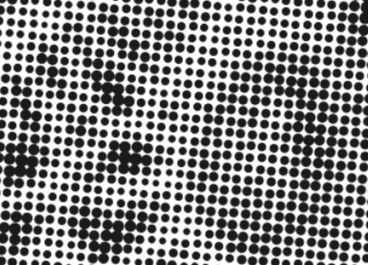
:

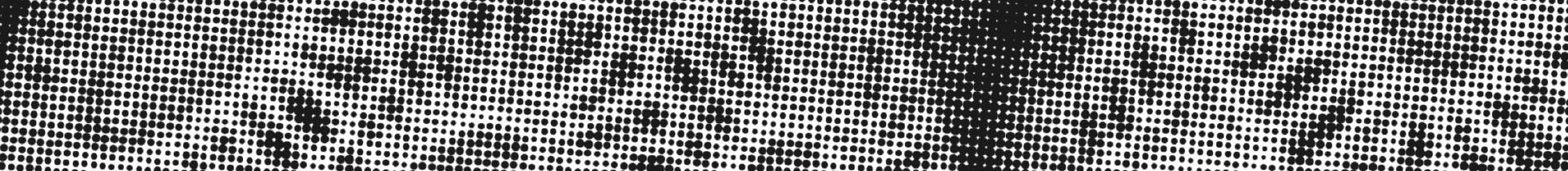

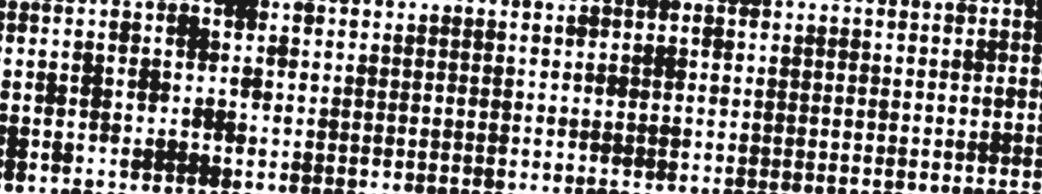
:

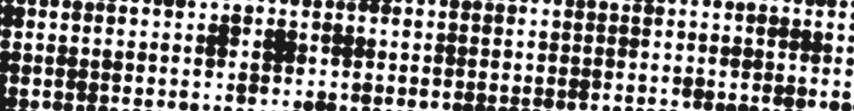
น

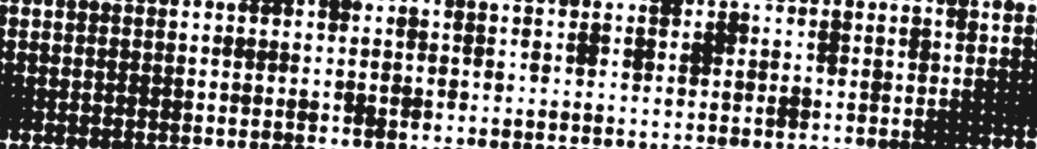



Este trabajo aborda el estudio de dos testigos sedimentarios situados en el margen oriental atlántico y el Mediterráneo occidental respectivamente:

1. El testigo MD95 2043 (36 8’ N, 2 37’ W; 1.841 m). Mar de Alborán. Mediterráneo occidental

2. El testigo MD03-2705- DUST $\left(18^{\circ} 10^{\prime} \mathrm{N}, 1^{\circ} \mathrm{W} ; 3.085 \mathrm{~m}\right)$. Margen noroccidental africano

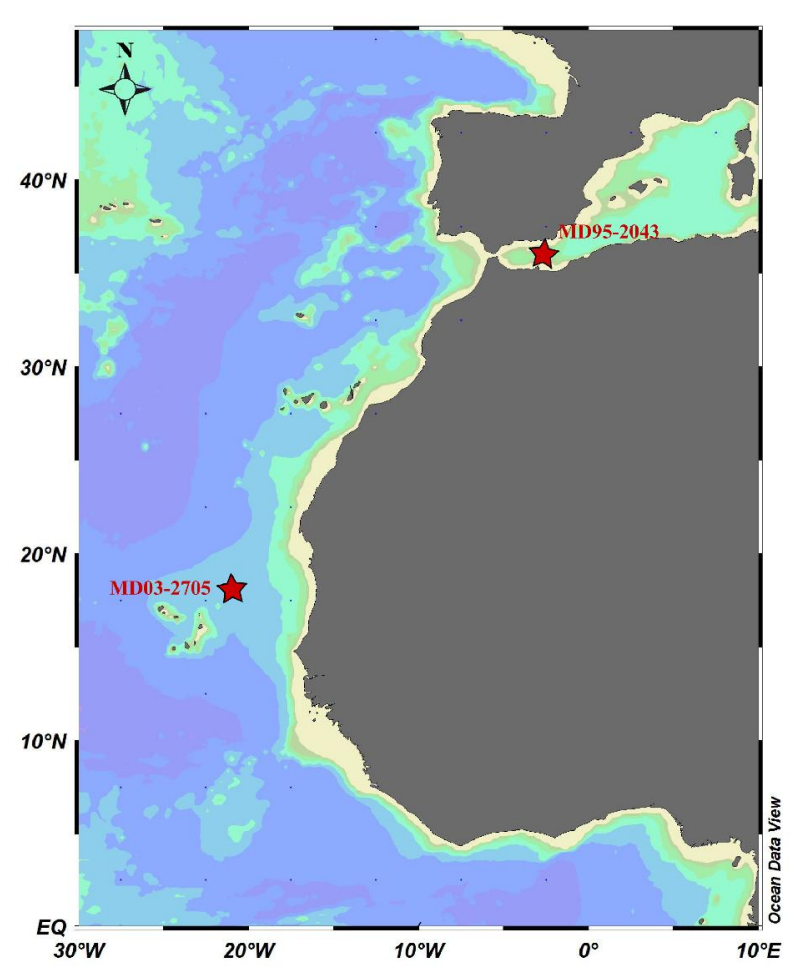

Figura 2.1. Localización de los testigos estudiados en la tesis

\subsection{El testigo MD95-2043}

\subsubsection{Localización y descripción lito-estratigráfica}

El testigo de pistón MD95-2043 fue recuperado en 1995 durante el transcurso de la campaña IMAGES-I a bordo del buque oceanográfico francés Marion Dufresne, con una longitud total de de 37,6 m. Su situación a $1.841 \mathrm{~m}$ de profundidad en el mar de Alborán (36 8' 598' ' N, 2 37’ 269'” W) es ideal para registrar la influencia de aguas procedentes del Atlántico.

El testigo ha sido ampliamente estudiado mediante análisis de biomarcadores (Cacho et al., 1999; 2000; 2002; 2006; Moreno et al., 2004; 2005), palinológicos (Sánchez Goñi et al., 2002), sedimentológicos (Plaza, 2001; Moreno et al., 2002) y micropaleontológicos (Sierro et al., 1998; 
Bárcena et al., 2001; Pérez Folgado et al., 2003; Colmenero-Hidalgo et al., 2002; Colmenero-Hidalgo et al., 2004; Sierro et al., 2005).

La descripción estratigráfica de Plaza (2001) diferencia los siguientes intervalos:

- 0-460 cm: fangos hemipelágicos compuestos por arcilla limosa con una fracción arenosa escasa y una composición biogénica del $75 \%$ aproximadamente. Porosidad del 63,45 \% y susceptibilidad magnética media de 29,02 SI.

- 461-999 cm: fangos mixtos con una fracción superior a 50 micras de composición terrígena y biogénica de un $50 \%$. Es un tramo de transición entre los fangos hemipelágicos y los depósitos de gravedad con una porosidad y susceptibilidad magnética medias de 63,96 \% y 13,18 SI respectivamente.

- 1.000-1.650 cm: Fangos gravitativos formados por una fracción arcillo-limosa con una composición mixta en terrígenos y biogénicos en la fracción superior a 50 micras. La porosidad y susceptibilidad magnética medias son de 63,31 \% y 11,82 SI. Se distinguen además ciertos niveles de turbiditas en las profundidades entre (1000-1011), (1273-1283) y (1600-1605) con una porosidad del 51,91 \% y susceptibilidad magnética de 14,74 SI.

\subsubsection{Modelo de edad}

Para el testigo MD95-2043 se han publicado dos modelos de edad (Cacho et al., 1999). El primer modelo de edad (Modelo 1) se basó en la datación con AMS-carbono 14 de 21 puntos y su posterior calibración a edades de calendario mediante el programa Calib 4.1 (Stuiver y Reimer, 1993; Stuiver et al., 1998). Adicionalmente, se realizó la identificación de tres eventos isotópicos (3.1, 3.13 y 3.3) (Martinson et al., 1987) en la curva de isótopos de oxígeno del foraminífero planctónico G. bulloides.

El segundo modelo (Modelo 2) se obtuvo mediante la correlación punto por punto del registro de temperaturas superficiales marinas (TSM) de alquenonas del testigo con la curva de isótopos de oxígeno del testigo de hielo GISP2 (Dansgaard et al., 1993). Ambos modelos de edad indican que en los materiales que componen este testigo han quedado representados sin lagunas ni hiatos los últimos $52 \mathrm{ka}$, con una tasa de sedimentación media de $30 \mathrm{~cm} / \mathrm{ka}$.

En el presente estudio, se ha decidido emplear el primero de los dos modelos de edad por considerar que la datación con edades de radiocarbono y la identificación de eventos isotópicos aporta una cronoestratigrafía más independiente que la basada en la correlación entre la señal de TSM-alquenonas del propio testigo y la señal de $\delta^{18} \mathrm{O}$ del testigo de hielo GISP2 de Groenlandia. 


\subsection{EI testigo MD03 2705 DUST}

\subsubsection{Localización y descripción lito-estratigráfica}

La extracción del testigo oceánico MD03 2705 DUST se realizó mediante el sacatestigos CALYPSO del buque francés Marion Dufresne utilizado en la campaña MD134/PICABIA (Paleoclimatologie Images Calypso Sur La Bordure Iberique Et Africaine) durante el verano de 2003.

El lugar del sondeo donde fue recuperado el testigo se sitúa a $480 \mathrm{~km}$ al Noroeste de Dakar, entre $18^{\circ}$ $\mathrm{N}$ y $21^{\circ} \mathrm{W}$ aproximadamente, sobre el istmo submarino que comunica África con las islas de Cabo Verde, a una profundidad de $3.085 \mathrm{~m}$ (Fig. 2.1). Esta montaña submarina culmina a $300 \mathrm{~m}$ sobre el fondo que la rodea (aproximadamente $3.300 \mathrm{~m}$ ) lo que permite que no esté influenciada por aportes de corrientes de advección desde el fondo (Moyes et al., 1976) o fenómenos de gravedad, situación que parece favorable al registro de las contribuciones de aerosoles desde la superficie. Estudios previos mostraron la ausencia de hiatos lo que hace del sitio hidrodinámicamente tranquilo y propicio a un registro de calidad. Aún más, se sitúa en un área casi libre de contribuciones fluviales (Kolla et al., 1979).

Para los últimos $32 \mathrm{ka}$, la tasa de sedimentación promedio del testigo alcanza el valor de 11,4 cm/ka, con un máximo de $20,6 \mathrm{~cm} / \mathrm{ka}$ durante la deglaciación.

Los primeros $750 \mathrm{~cm}$ del testigo, representan una serie casi continua, salvo el intervalo correspondiente a los centímetros 439 a 448 donde no hay registro, así mismo no se destaca la presencia de ningún horizonte especial (Grousset com. pers., 2005). La presencia de materiales finos (fangos pelágicos y arcillas) domina el registro indicando un medio marino profundo de baja energía alejado del área fuente donde los procesos de bioturbación se presentan como uno de los bioeventos destacables.

La descripción estratigráfica de Grousset, com.pers., (2005) (Fig. 2.2) diferencia los siguientes intervalos:

- 0-46 cm: Fangos pelágicos arenosos, muy gruesos en la parte superior, con presencia de bioclastos (fragmentos de moluscos) y carbonatos visibles, y más finos y bioturbados en la parte inferior.

- 46-56 cm: Fangos arcillosos laminados

- 143-150 cm: Fangos con sets de laminación y niveles con abundantes foraminíferos planctónicos, líticos y bioclastos de carbonato.

- 150-300 cm: Fangos pelágicos arenosos con niveles con abundantes manchas de sulfuros de hierro. Fangos arcillosos de forma lenticular hacia el final del tramo. 
- 300-450 cm: Fangos pelágicos arenosos, más gruesos y bioturbados al inicio del tramo, que dan paso a bandas de material más fino entre los 343 y $358 \mathrm{~cm}$. Manchas de sulfuros de hierro entre los 373 y $438 \mathrm{~cm}$ y perturbaciones en la extracción al final del tramo.

- 450-600 cm: Fangos pelágicos arenosos con niveles bioturbados y manchas de sulfuros de hierro $(450-492 \mathrm{~cm} ; 543-545 \mathrm{~cm})$ y otros niveles de fangos arcillosos muy finos $(560-600 \mathrm{~cm})$. Abundantes foraminíferos planctónicos, líticos de arena de tamaño mayor, muchas manchas de color rosa de algunos bioclastos de carbonato y abundante arcilla a $\operatorname{los} 460 \mathrm{~cm}$.

- 600-750 cm: Fangos pelágicos arenosos con un estrato verdoso hacia los $638 \mathrm{~cm}$. Manchas de sulfuros de hierro y bioturbaciones ocasionales. Fango arenoso más fino entre 718 y $727 \mathrm{~cm}$.

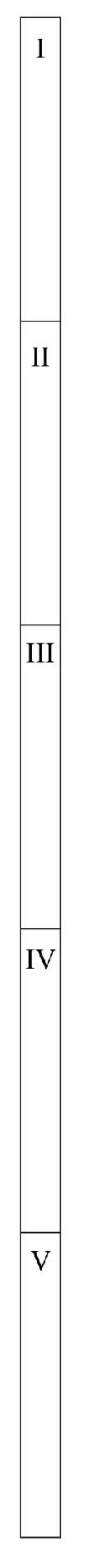

(a)

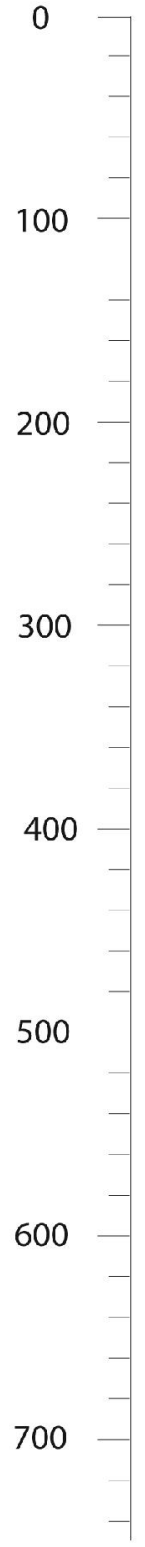

(b)

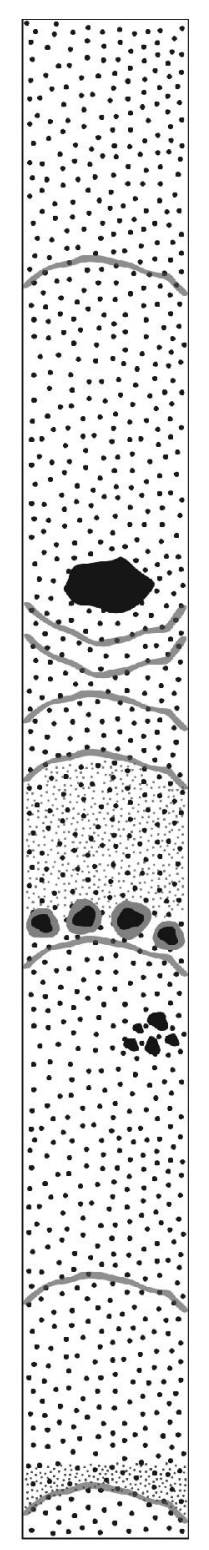

(c)

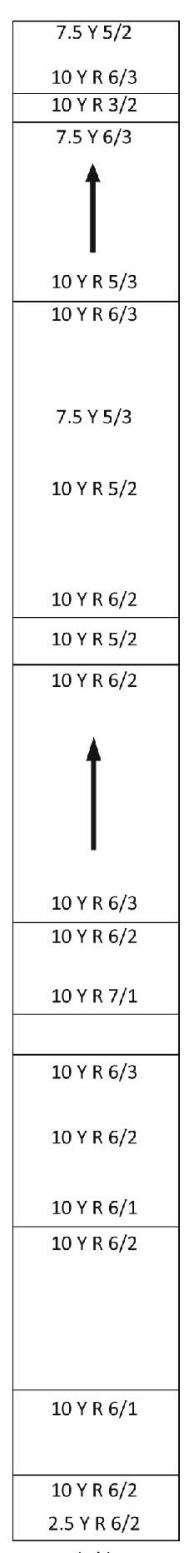

(d)

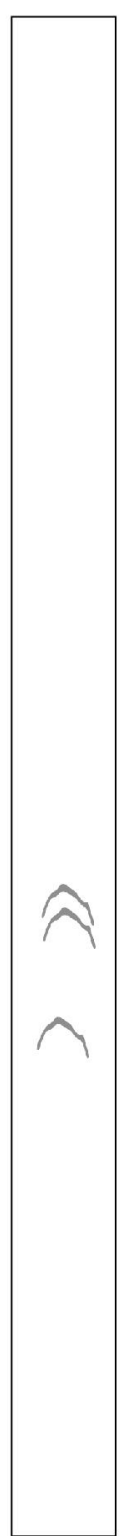

Figura 2.2. Columna estratigráfica del testigo MD03 2705 DUST.
(a) Secciones del testigo.
(b) Profundidad de la sección.
(c) Litología y estructuras sedimentarias.

(d) Escala Munsell de color.

(e) Perturbaciones en la extracción. La descripción litológica se realizó a bordo del barco oceanográfico Marion Dufrene II. Modificada de Grousset, com. pers., (2005).

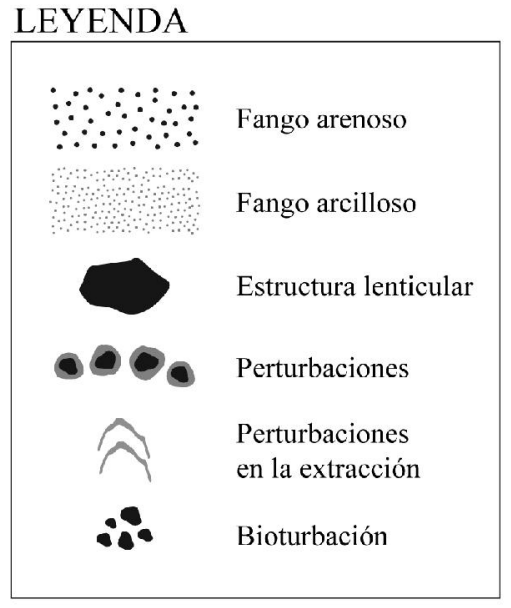

(e) 
El testigo MD03-2705 se encuentra situado en el límite septentrional del área de alcance de la pluma de invierno de polvo del Sahara, pero directamente dentro del área correspondiente a la pluma de verano del polvo procedente del Sahara (Husar et al., 1997). Teniendo en cuenta dicha localización, se puede considerar que el testigo está formado por dos componentes principales:

- una fracción biogénica calcárea resultante de la sedimentación de foraminíferos y cocolitóforos desde las aguas superficiales. El porcentaje de ópalo biogénico resultante de las diatomeas, se considera despreciable al ser inferior al $5 \%$ (deMenocal et al., 2000).

-una fracción detrítica terrígena de origen eólico. Estos aerosoles procedente del Sahara y el Sahel constituyen una mezcla de minerales de arcilla y cuarzo de tamaño fino-limoso junto con diatomeas de agua dulce y fitolitos (Jullien et al., 2007).

\subsubsection{Modelo de edad}

El modelo de edad del testigo MD03-2705 (Jullien et al., 2007) se construyó a partir de la comparación de la curva de isótopos $\left(\delta^{18} \mathrm{O} / \delta^{13} \mathrm{C}\right)$ del foraminífero bentónico Planulina wuellerstorfi con la curva LR04 Stack propuesta por Lisiecki y Raymo et al. (2005) y con la señal de $\delta^{18} \mathrm{O}$ del testigo vecino ODP-658C obtenida por deMenocal et al. (2000) (Tabla 2.1).

Además, para los primeros $400 \mathrm{~cm}$ se realizó la datación de 8 puntos con edades radiaocarbono obtenidas del foraminífero planctónico G. bullloides $(>150 \mu \mathrm{m})$. Dada la posible influencia de agua procedente de los filamentos del upwelling, las edades radiocarbono fueron corregidas considerando un efecto reservorio de 500 años (deMenocal et al., 2000). Posteriormente, se realizó la calibración a edades calendario (Stuiver y Reimer, 1993; Stuiver et al., 1998). Adicionalmente, se utilizaron tres bioeventos relacionados con cambios significativos en la asociación de foraminíferos: un abrupto incremento de Globorotalia menardii entre los centímetros 0 y $34 \mathrm{~cm}$ que define el Holoceno, y las variaciones en la abundancia del foraminífero Globorotalia inflata, con un pronunciado descenso en el inicio del Último Máximo Glacial y un marcado incremento en la base del Bolling-Allerod.

A partir de lo anterior, las edades correspondientes a los eventos identificados para el testigo fueron utilizadas como puntos de control e introducidas en el programa Analyseries 1.1 (Paillard et al., 1996) para obtener la datación de la serie de muestras estudiada.

La edad del sedimento superficial coincide aproximadamente con los 5,1 ka, ya que los sedimentos correspondientes al Holoceno tardío no pudieron ser recuperados durante la extracción del testigo. 


\begin{tabular}{|c|c|c|c|c|c|c|c|c|c|c|c|c|c|c|}
\hline 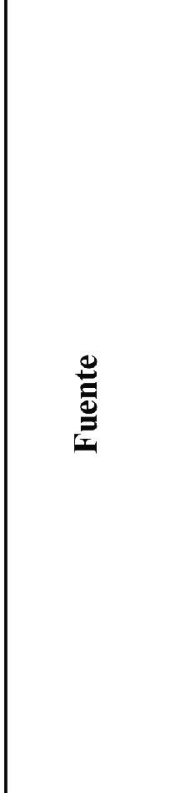 & 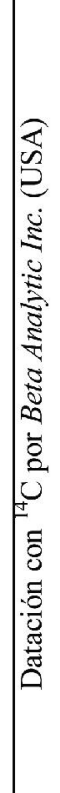 & 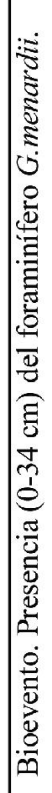 & 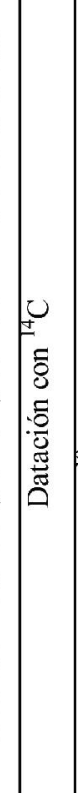 & 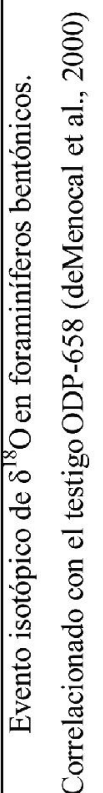 & 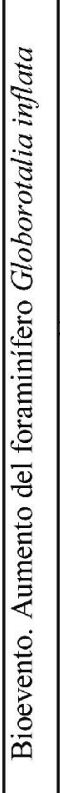 & 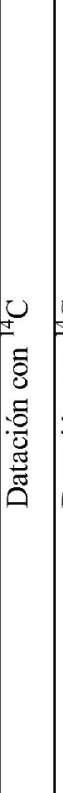 & 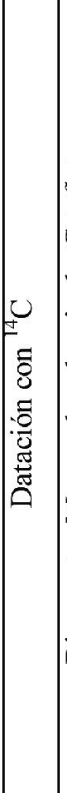 & 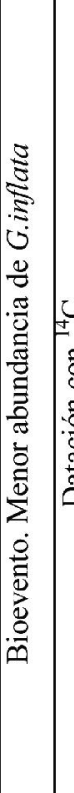 & 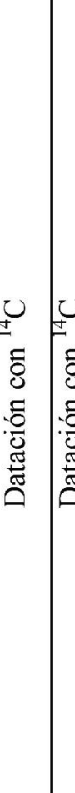 & 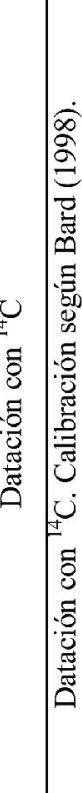 & 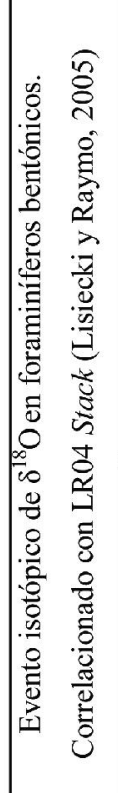 & 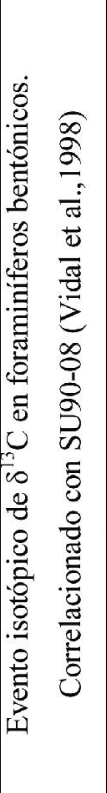 & 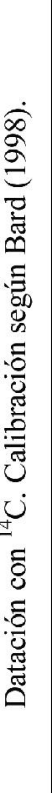 & 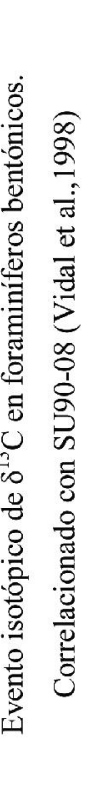 \\
\hline 苞 & $\frac{8}{n}$ & $\begin{array}{l}8 \\
: \\
=\end{array}$ & 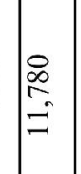 & $\begin{array}{l}\frac{9}{1} \\
\text { తi }\end{array}$ & 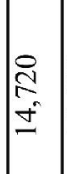 & 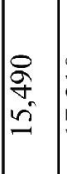 & $\begin{array}{l}0 \\
\stackrel{0}{m} \\
\underline{=}\end{array}$ & 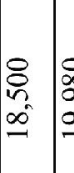 & 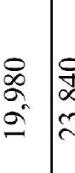 & 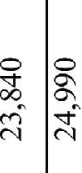 & $\hat{\imath}$ & $m$ & $\left|\begin{array}{c}\overrightarrow{\tilde{N}} \\
\infty \\
\infty \\
m \\
m \\
m\end{array}\right|$ & "q \\
\hline 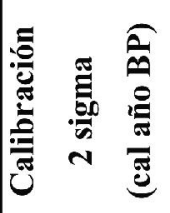 & $\begin{array}{l}8 \\
8 \\
0 \\
0 \\
0 \\
0 \\
0 \\
0 \\
n \\
n\end{array}$ & 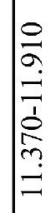 & 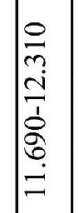 & 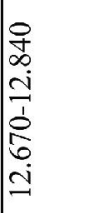 & 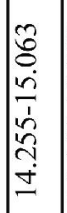 & 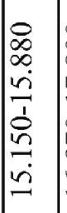 & 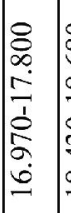 & 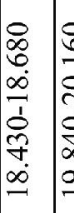 & 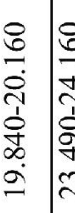 & 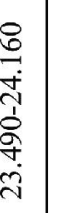 & & & & \\
\hline 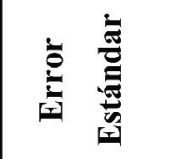 & f & & $?$ & & & $\infty$ & 우 & & 8 & 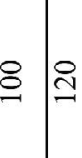 & & & & \\
\hline 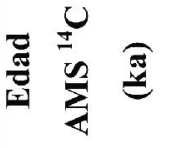 & \begin{tabular}{l}
$\infty$ \\
$\stackrel{\infty}{m}$ \\
\multirow{f}{*}{}
\end{tabular} & $\varrho$ & $\stackrel{n}{n}$ & $\stackrel{0}{\circ}$ & I & $\begin{array}{l}\overrightarrow{0} \\
- \\
-\end{array}$ & 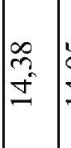 & $\mid \begin{array}{l}\varkappa \\
\hat{\Xi} \\
\dot{\Xi}\end{array}$ & \begin{tabular}{l|l}
$\underbrace{\prime}$ & $\infty$ \\
$\underbrace{0}_{0}$ & 0
\end{tabular} & 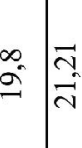 & & & & \\
\hline 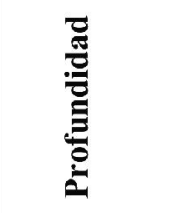 & $m$ & 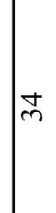 & $\prod_{m}^{\infty}$ & 寻 & $\infty$ & I & $\Xi$ & I & I & $\stackrel{0}{8}$ & $\stackrel{\infty}{\varrho}$ & ते & 命 & § \\
\hline
\end{tabular}

Tabla 2.1. Puntos de control utilizados para la construcción del modelo de edad de los primeros $400 \mathrm{~cm}$ del testigo MD03 2705-DUST. Adaptada de Jullien et al. (2007). 


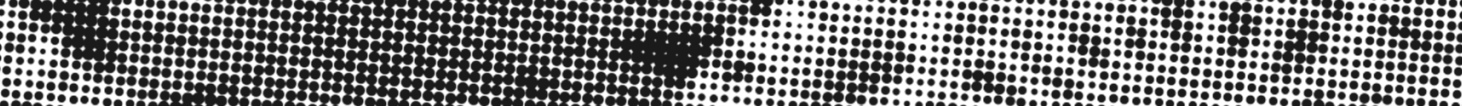

:

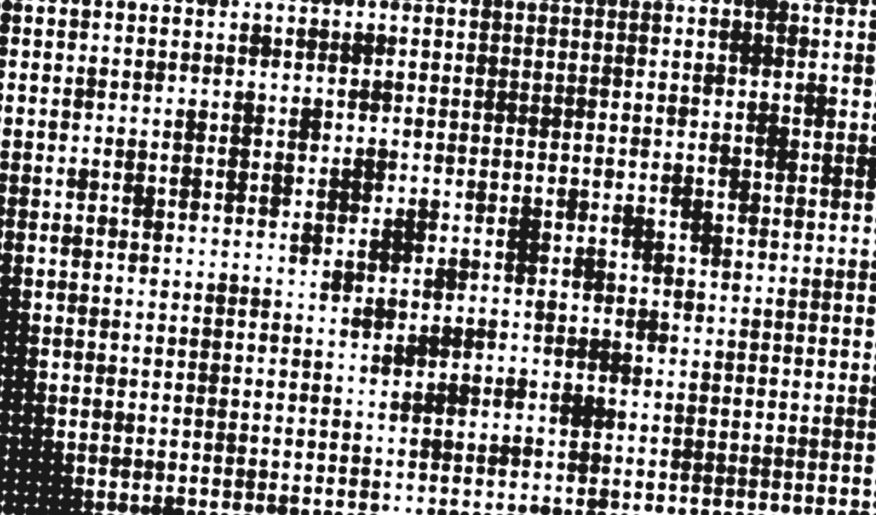

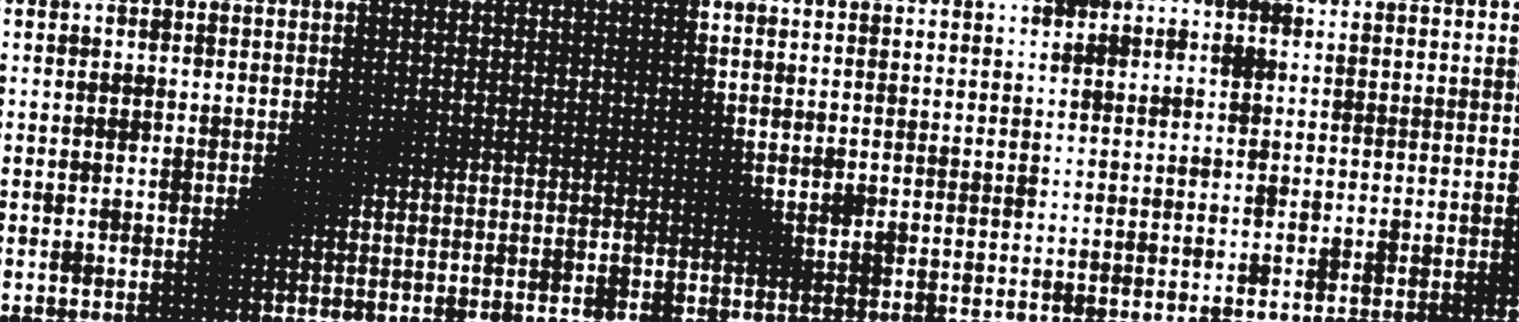

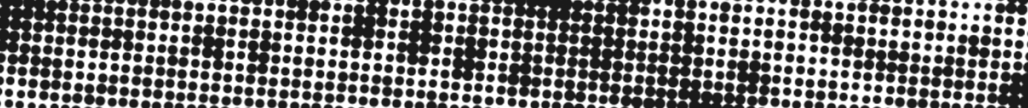

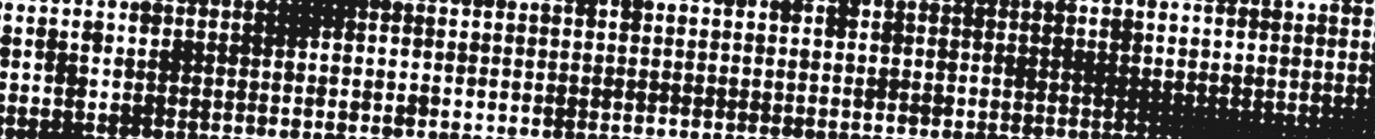

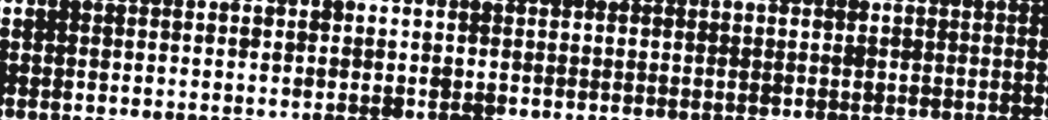

1

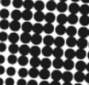

It:

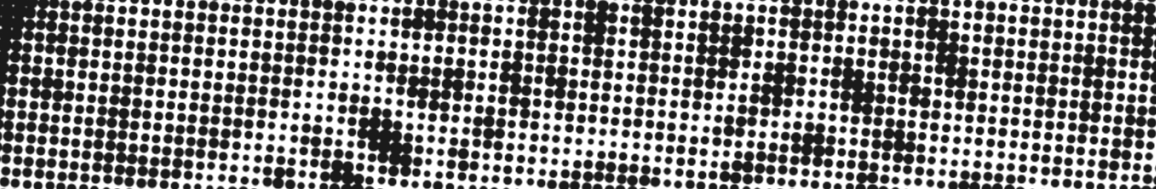

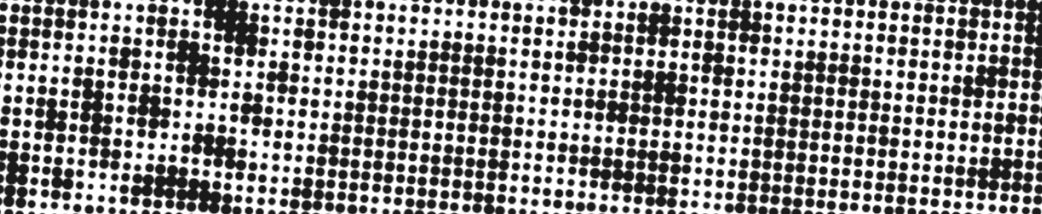

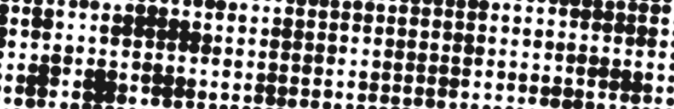

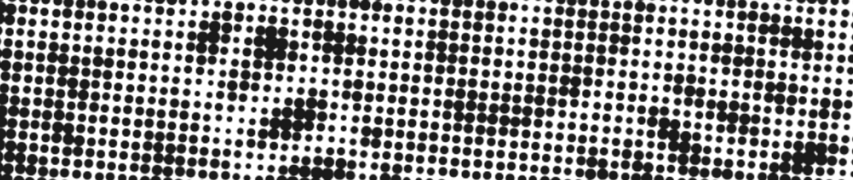

HัM

H.

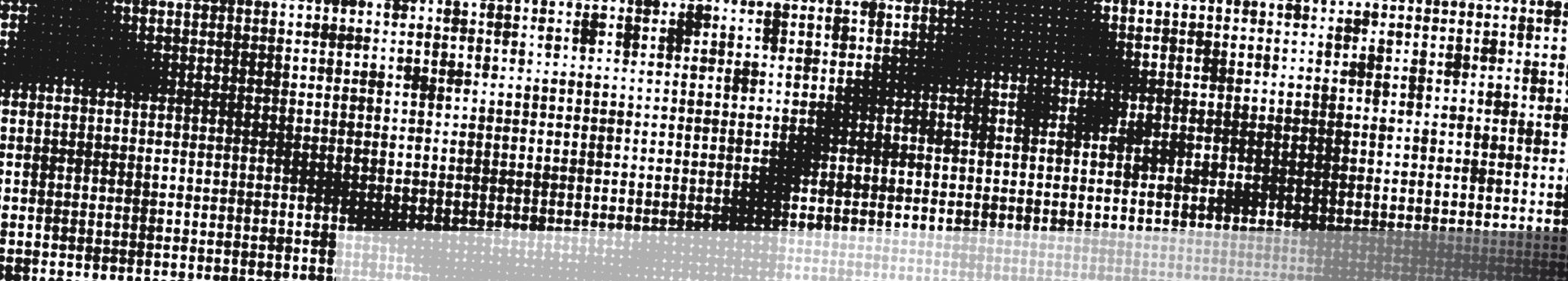

:

H.:

Capítulo 3:

It:

HัM

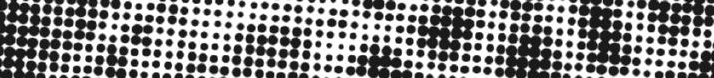

1

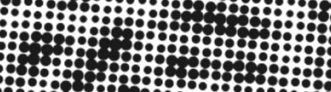

17m?
Biología y ecología de 1os cocolitóforos 



\subsection{Generalidades e importancia de los cocolitóforos}

Los cocolitóforos son un grupo de organismos unicelulares y autótrofos que pertenece a la división o phylum de algas pardas o Haptophyta, a la clase Prymnesiophyceae (Jordan y Chamberlain, 1997) y a su vez, al Reino Cromista (Cavalier-Smith, 1998).

Estos organismos de tamaño generalmente inferior a $30 \mu \mathrm{m}$, son un grupo mayoritario en el fitoplancton marino, encontrándose entre uno de los principales productores primarios del océano. Aunque tradicionalmente se hayan descrito como organismos autótrofos, estudios recientes indican que la mixotrofía es relativamente común entre los cocolitóforos (Aubry, 2009; Liu et al., 2009).

Su distribución es prácticamente global, desde las zonas ecuatoriales a las subpolares (McIntyre y Bé 1967), y su diversidad variable, mayor en las zonas tropicales y subtropicales donde encuentran aguas cálidas y oligotróficas, y decreciente hacia aguas más frías. Aunque la mayoría de las especies viven en las aguas estratificadas de las regiones tropicales y templadas, se han llegado a registrar eclosiones o blooms en zonas más eutróficas, donde estacionalmente se alteran las condiciones de estratificación de las aguas o se producen surgencias de aguas frías y ricas en nutrientes. Estas eclosiones pueden llegan a concentrar $1-2 \cdot 10^{6}$ células/litro cuya clorofila sobre la superficie del océano hace que éste presente un color azul-verdoso perfectamente detectable por satélites y aviones (Marchant y Thomsen, 1994).

La importancia de los cocolitóforos en el ciclo del carbono y por ende, en el sistema climático global se debe a su participación en los siguientes procesos:

-Bomba biológica o de carbono orgánico. Consiste en la retirada del $\mathrm{CO}_{2}$ disuelto en las aguas más superficiales del océano y su conversión en materia orgánica a través de la fotosíntesis. Cuando los cocolitóforos mueren, se produce el hundimiento de la materia orgánica hacia el fondo oceánico donde se oxida y remineraliza. Este carbono puede volver a la superficie a través de la surgencia de aguas profundas.

-Bomba física o del carbonato, es decir, la retirada del carbonato disuelto en las aguas superficiales para la formación de cocolitos o placas de carbonato cálcico, que más tarde se disolverán o preservarán en los sedimentos marinos profundos, representando la mayor parte del carbonato acumulado por encima del nivel de compensación de la calcita.

-Emisión a la atmósfera de sulfuro de dimetilo (DMS), gas crucial en los procesos de formación de las nubes (Bornemann et al., 2003) cuya abundancia condiciona el albedo terrestre. 


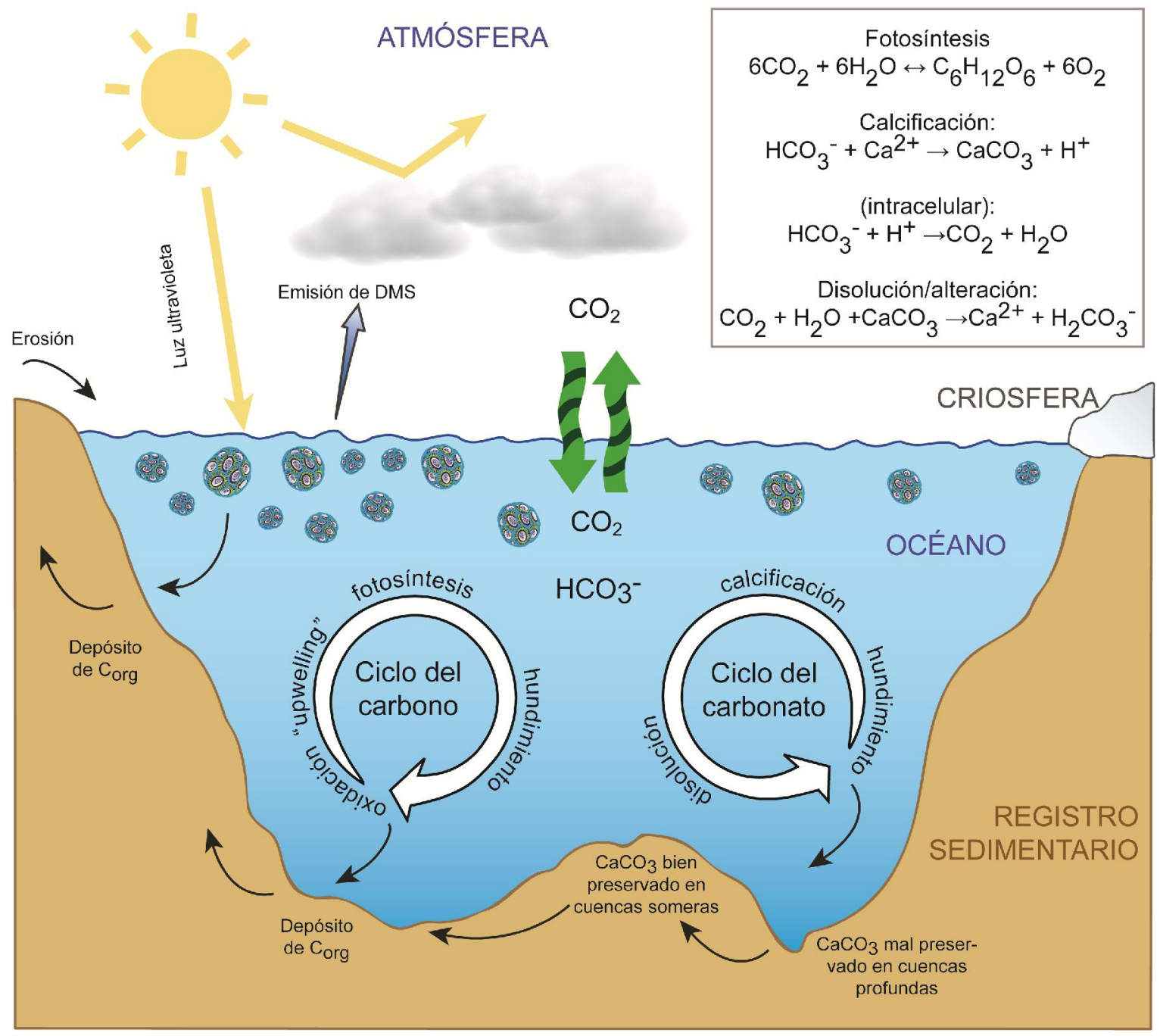

Figura 3.1. Importancia de los cocolitóforos en el ciclo del carbono. Participación en la bomba biológica y la bomba física del $\mathrm{CO}_{2}$.Tomada de Saavedra-Pellitero (2009). Modificada de Boeckel (2003).

Desde la aparición del grupo de los cocolitóforos en el Triásico Superior, hace 225 millones de años (Di Nocera y Scandone, 1977; Bralower et al., 1991; Bown et al., 2004), su registro sedimentario ha sido especialmente continuo y abundante convirtiéndose en uno de los componentes principales de los sedimentos marinos, y por ello, en precisos marcadores en bioestratigrafía.

Por otra parte, la distribución y abundancia de los diferentes taxones dependen de factores como la luz, la disponibilidad de nutrientes, la temperatura superficial marina (TSM) o la salinidad, por lo que, cambios en las características de las masas de agua alteran la composición de las asociaciones de cocolitóforos y a su vez, quedarán reflejados en las asociaciones preservadas en los sedimentos oceánicos, haciendo de este grupo, un valioso indicador en reconstrucciones paleoceanográficas y paleoclimáticas. 


\subsection{Estructuras biológicas}

La organización celular de los cocolitóforos consta de dos partes, el protoplasma y la cubierta celular. El protoplasma incluye el núcleo, el aparato de Golgi, las mitocondrias, los cloroplastos y algunas otras vesículas. Mientras que la cubierta celular suele estar formada por dos componentes: placas orgánicas resistentes, inmediatamente alrededor del protoplasma, y placas inorgánicas calcáreas que se corresponden con los cocolitos (Young, 1994). Los cloroplastos de las haptofitas, como organismos fotosintetizadotes, poseen clorofilas del tipo a, c1 y c2 además de otros pigmentos carotenoides como la didadinoxantina y la fucoxantina, los cuales confieren su característico color amarillo-parduzco a los cocolitóforos. El aparato de Golgi se sitúa bajo la región basal flagelar y es el responsable de la síntesis de las placas orgánicas y de la cocolitogénesis (Billard e Inouye, 2004).

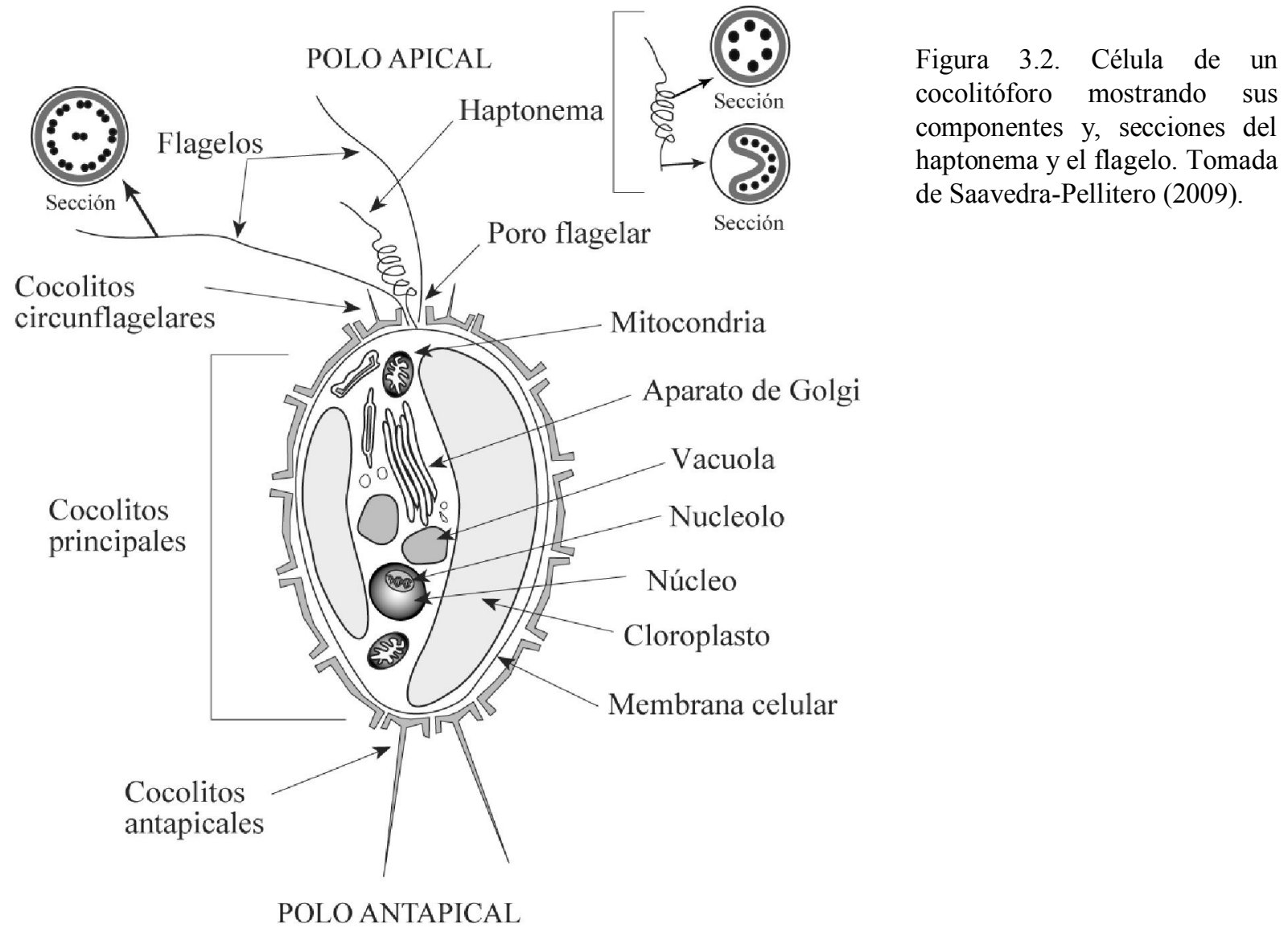

Entre las estructuras características de las algas cocolitoforales aparecen los flagelos y el haptonema. Los dos flagelos desiguales se sitúan en posición polar, presentan la típica estructura biológica $(9+2)$ y ayudan a la célula a cambiar su posición dentro de la zona fótica. La posesión de un haptonema confiere a los cocolitóforos una particularidad diferenciadora con respecto a otros grupos de fitoplancton también flagelados (Piennar, 1994; Brand, 1994). Este órgano multifuncional y de tamaño variable, está compuesto por 6 ó 7 microtúbulos, rodeados de retículo endoplasmático, que hacia la base aumentan hasta 8 ó 9 y cambian su disposición de anillo a arco (Billard e Inouye, 2004). Parece 
que a algunas especies les permite adherirse a superficies (Hibberd, 1976) mientras que otras lo utilizan para capturar partículas. En varios grupos de cocolitóforos, aparece reducido o incluso llega a desaparecer, denominándose haptonema vestigial.

\subsection{Cocosfera y grupos de cocolitóforos}

Los cocolitóforos presentan la peculiaridad de desarrollar una cubierta rígida calcárea o cocosfera en un determinado periodo de su ciclo de vida. Esta envoltura, generalmente esférica, la componen un número variable de placas de calcita o cocolitos que oscilan entre los 3 y $15 \mu \mathrm{m}$ en función de la especie (Armstrong y Brasier, 2005).

En función de como precipiten y ordenen los cristales de calcita que los componen, los cocolitos pueden subdividirse en dos grupos: los heterococolitos y los holococolitos.

Sin embargo, algunas haptofitas actuales producen estructuras que no pueden equipararse a ninguno de los dos grupos anteriores, y a los que por exclusión, se ha definido como nanolitos (Young y Bown, 1997). Los nanolitos son nanofósiles calcáreos que se han formado por procesos de biomineralización distintos y que son de afinidad incierta ya que carecen de las estructuras características de los heterococolitos o los holococolitos (Cros y Fortuño, 2002; Flores y Sierro, 2007). Sus representantes más comunes, Florisphaera profunda y Braarudosphaera bigelowii, presentan ambos una cocosfera formada por placas de calcita unicristalinas.

Los heterococolitos se ordenan radial y verticalmente a partir de complejas unidades cristalinas de tamaño y forma variable. Su formación y crecimiento se produce durante la fase diploide (Westbroek et al., 1989; Pienaar, 1994), en vesículas intracelulares asociadas al aparato de Golgi que serán expulsadas al exterior una vez finalizado el proceso de biomineralización. Con una estructura más resistente, aumentan sus posibilidades de preservación en el registro fósil y la posterior caracterización de individuos a partir de las diferencias a nivel de familia, género y especie.

Los heterococolitos son el grupo más numeroso y variable morfológicamente. Según su morfología se pueden diferenciar tres subgrupos (Young et al., 2003):

-Placolitos, de forma elíptica o circular, pueden tener el área central abierta o seccionada por un puente o barra central. Presentan dos escudos, el proximal y el distal y se disponen de forma imbricada entre sí para configurar la cocosfera. Con un $90 \%$ de las formas, es el grupo más abundante del nannoplancton actual de los océanos. Algunos ejemplos son, Emiliana huxleyi, Gephyrocapsa sp. o Calcidiscus leptoporus. 
-Murolitos, presentan un área central amplia que está delimitada por un borde perpendicular de altura variable, cuya forma da nombre al grupo. Los cocolitos se entrelazan entre sí para formar la cocosfera, como es el caso de Syracosphaera sp.

-Planolitos, también se caracterizan por un área central dilatada, pero en este caso, el borde se encuentra en el mismo plano dando lugar a un único escudo. La organización de la cocosfera se basa en la superposición de los diferentes cocolitos. Acanthoica sp. es un ejemplo de este subgrupo.

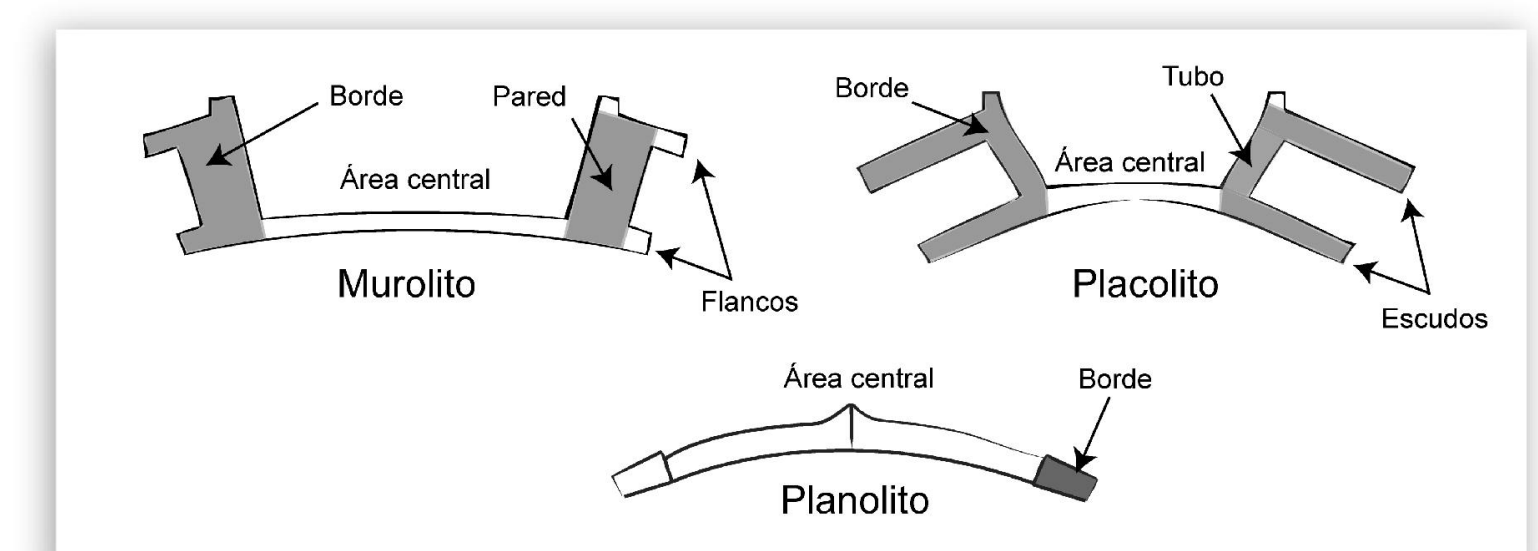

Figura 3.3. Tipos de heterococolitos según su morfología: murolito, placolito y planolito. Modificada de Saavedra-Pellitero (2009).

Por su parte, los holococolitos están formados por un elevado número de pequeños (aprox. $0,1 \mu \mathrm{m}$ ) cristales euhedrales, idénticos entre sí (Billard e Inouye, 2004). La calcificación de los holococolitos aparentemente ocurre fuera de la membrana celular, en el interior de una cubierta orgánica que rodea a la célula (Rowson et al., 1986). La estructura de los holococolitos es menos resistente y se desintegra fácilmente, con lo que su preservación en el registro fósil es deficiente y su diferenciación a nivel de especie más complicado (Cros y Fortuño, 2002). Por ello, en comparación con los robustos heterococolitos, su abundancia en el registro sedimentario es más limitada (Siesser y Winter, 1994).

A pesar de las variaciones morfológicas de los cocolitos, parece que tanto los representantes actuales como los extintos presentan un mismo mecanismo de cristalización, por lo que es posible hablar de un origen común desde el que evolucionaron los distintos grupos. 


\subsection{Ciclo de vida}

Gracias a los estudios de especimenes vivos a través de trampas de sedimento y de cultivos se han podido observar células de cocolitóforos que presentan en su cubierta dos tipos distintos de cocolitos, que en estudios anteriores del registro fósil, se habían clasificado como especies diferentes (Cros et al., 2000). La localización de cocosferas formadas simultáneamente por heterococolito/holococolito, holococolito/holococolito y heterococolito/nanolito revela el desarrollo de diversas fases dentro del ciclo de vida de estos organismos y la existencia de una transición entre unas y otras fases.

El ciclo de vida de las algas cocolitoforales suele presentar dos fases bien marcadas, la haploide (n) y la diploide (2n) (Young et al., 2005), si bien, aún se desconocen los mecanismos que desencadenan la transición entre una y otra fase. La transición entre la fase diploide y la haploide se realiza a través de la meiosis, mientras que la transición inversa, de haploide a diploide, implica la fusión de dos células mediante la singamia (Young y Henriksen, 2003). La diploide puede ser móvil o no móvil y se caracteriza generalmente por el desarrollo de heterococolitos, mientras que la haploide es principalmente móvil y puede manifestarse en forma de holococolitos (Crystallolithus rigidusCalcidiscus leptoporus), nanolitos (Ceratholithus) o escamas orgánicas (Emiliania spp., Gephyrocapsa spp.) (Cros y Fortuño, 2002; Young et al., 2005).
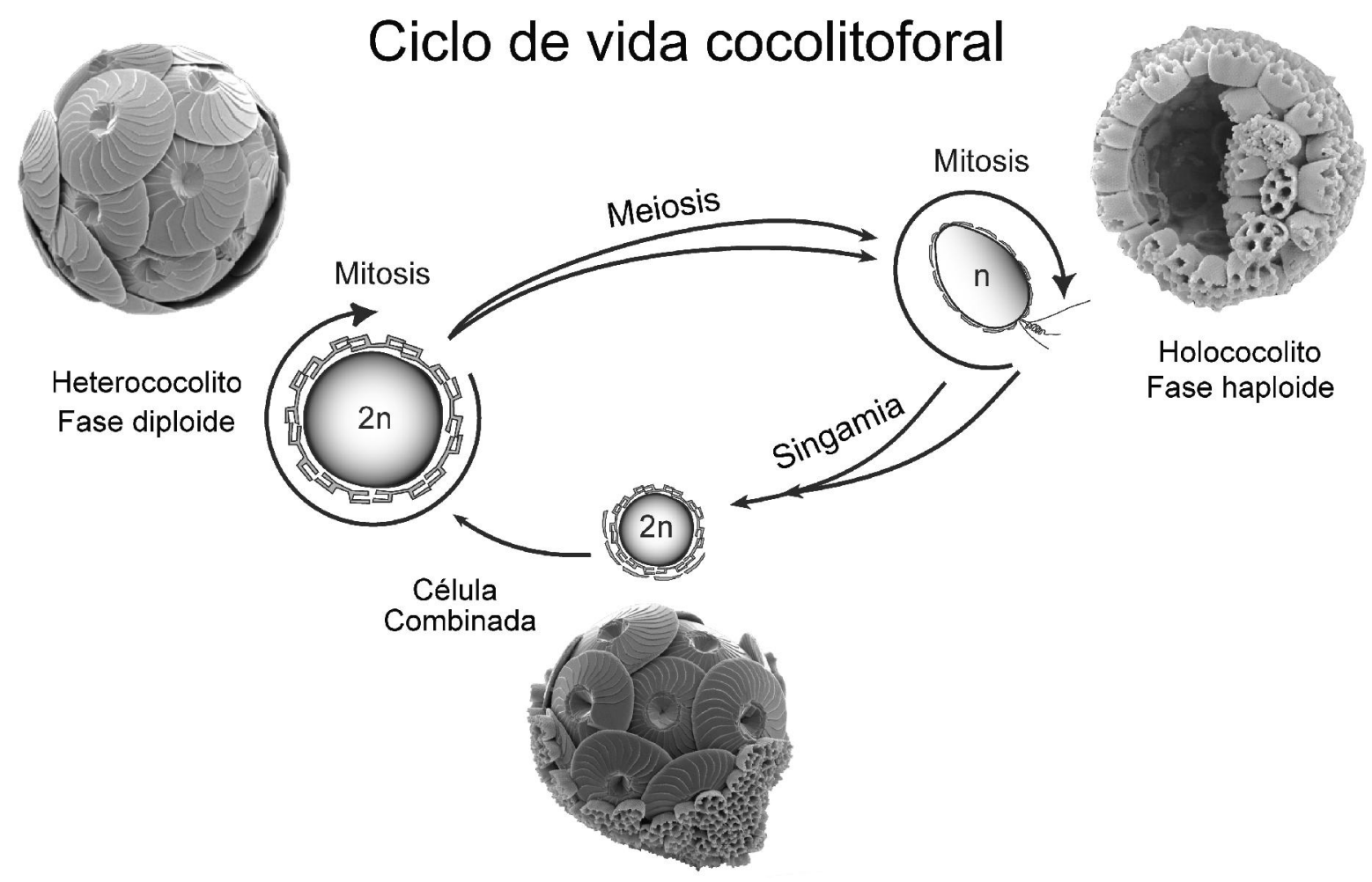

Figura 3.4. Ciclo de vida cocolitoforal. Modificada de Geisen et al. (2002) y Saavedra-Pellitero (2009). 
En muestras actuales se han encontrado cocosferas formadas por heterococolitos y holococolitos de manera combinada (Geisen et al., 2002; Cortés, 2000; Cortés y Bollmann, 2002; Cros et al., 2000; Renaud y Klaas, 2001; Crudeli et al., 2006; Frada et al., 2009). Geisen et al. (2002) interpretan la presencia de estas células combinadas como la manifestación morfológica de la transición entre fases. Ambas fases del organismo pueden reproducirse por mitosis (asexual) de manera ilimitada, de modo que los cocolitos son redistribuidos entre las dos células hijas (Billard e Inouye, 2004). Estudios realizados bajo condiciones óptimas de luz y nutrientes desvelan que E. huxleyi puede dividirse dos veces y media al día, $G$. oceanica dos veces al día y C. leptoporus una sóla vez al día.

\subsection{Funciones de las cubiertas calcáreas}

Se han propuesto varias posibilidades acerca de la función de las cocosferas, y aunque el debate aún sigue abierto, la mayoría de los científicos sugieren que no se trata de una única función si no más bien de la combinación de varias. A continuación se explican algunas de las planteadas por Young en 1994:

-Barrera protectora que proporciona cohesión y protección física a la vez que regula el intercambio de material entre célula y entorno.

-Cubierta robusta y continua que protege frente a la predación del zooplancton, o al ataque de virus, bacterias o protozoos. Sin embargo, estudios de depredación de zooplancton muestran similares tasas de éxito tanto para células calcificadas como para no calcificadas (Harris, 1994). De igual modo, la opción de la protección frente a virus fue doblemente descartada por Bratbak et al. (1996) y Wilson et al. (2002). La posible protección de la cocosfera frente a infecciones bacterianas no ha sido suficientemente investigada (Billard e Inouye, 2004).

-Economizador de energía. La precipitación de $\mathrm{CaCO}_{3}$ para formar una cubierta calcítica, además de aportar rigidez, es más rentable energéticamente que otras estructuras de moléculas orgánicas. Además, el $\mathrm{CO}_{2}$ liberado durante la calcificación es utilizado en la fotosíntesis, por lo que la producción de cocolitos podría estar aumentando la eficiencia de estos procesos biogeoquímicos y suponer un vínculo entre ellos (Paasche, 1962).

-Regulador de la tasa de hundimiento y la flotación. El número de cocolitos y la orientación de las cocosferas no esféricas determinan la aceleración o frenado en la velocidad de hundimiento, condicionando así una mayor o menor absorción de los nutrientes del agua e incluso el transporte a aguas más profundas y con mayor contenido en nutrientes.

-Regulador de la luz. Se barajan aquí dos versiones, una basada en la capacidad de los cocolitos para reflejar la luz ultravioleta y permitir así la vida en la parte superior de la zona fótica y una segunda hipótesis sobre el menor índice de refracción de la calcita frente al agua, que permitiría a los cocolitóforos desarrollarse a mayor profundidad en la columna de agua. 


\subsection{Transporte y sedimentación}

Al morir la célula del cocolitoforal, las membranas orgánicas que unen los cocolitos entre sí se desintegran y la cocosfera se disgrega en su trayecto hasta el fondo marino. Sólo las cocosferas formadas por cocolitos fuertemente entrelazados podrían preservarse completas en los sedimentos, pero la mayor parte de los sedimentos contienen únicamente los cocolitos de forma individual (Roth, 1994). La escasa masa del cocolito junto a su elevada área superficial dan lugar a una velocidad de hundimiento de aproximadamente 13,8 cm/día (Steinmetz, 1994). Con esta velocidad tan lenta, es muy posible que en su transporte hasta el fondo, los cocolitos sean disueltos por las aguas subsaturadas en carbonato o que las corrientes oceánicas los arrastren lejos de su área de origen.

Una interpretación adecuada del registro sedimentario debe considerar que el transporte y sedimentación de los cocolitos hacia el fondo oceánico está sometido a diferentes procesos que hacen variar la composición original de la asociación viva de cocolitóforos. Además de la amenaza de organismos heterótrofos, los cocolitos pueden verse afectados por efectos diagenéticos (Berger y Roth, 1975; Steinmetz, 1994) y por disolución química o preservación selectiva.

La disolución selectiva afecta a los cocolitos más delicados, de modo que, en ocasiones, muchos de los holococolitos y varios heterococolitos acaban por disolverse, preservándose sólo los cocolitos más robustos como Calcidiscus spp., Reticulofenestra spp., Gephyrocapsa spp., Coccolithus spp. o Helicosphaera spp. (Berger y Roth, 1975). Por ello, únicamente una parte de las especies de cocolitóforos existentes poseen un registro sedimentario representativo.

Sin embargo, los estudios de sedimentos oceánicos consideran que existe alta correlación con la asociación de cocolitóforos correspondiente a la zona fótica inmediatamente superior, con lo que se concluye que los cocolitos alcanzan el fondo marino mediante otros mecanismos de transporte. Estos mecanismos consisten en el hundimiento a través de macroagregados en forma de pellets fecales o de nieve oceánica (Kinkel et al., 2000; McIntyre y Bé, 1967; Okada y Honjo, 1973; Baumann et al., 2000). Los pellets fecales son generados por el zooplancton que ocupa la zona eufótica, ingiriendo enormes cantidades de cocolitóforos y produciendo agregados no orgánicos de hasta 100.000 cocosferas.

Se llama nieve oceánica todo agregado, aglomerado o partícula de material orgánico o inorgánico que se mantiene unida por fuerzas intra o intermoleculares, tensión superficial, cohesión orgánica o fuerzas electrostáticas y que puede medir desde $0,5 \mathrm{~mm}$ hasta centímetros o incluso metros de longitud (Steinmetz, 1994). Estos mecanismos, que pueden alcanzar tasas de hasta $160 \mathrm{~m} /$ día (Honjo, 1976), aceleran el hundimiento de los restos inorgánicos de los cocolitos protegiéndolos frente a la disolución y al arrastre por corrientes. 


\subsection{Distribución biogeográfica}

La distribución biogeográfica de los cocolitóforos depende de un amplio rango de factores ambientales como la disponibilidad de nutrientes, la luz, la salinidad o la temperatura superficial marina (Winter et al., 1994). La variabilidad de estos factores presenta complejas interdependencias e incluso, procesos de retroalimentación y además, está condicionada por otras características de los océanos como la turbidez, la estratificación, la surgencia de aguas o las corrientes oceánicas. Por tanto, considerar cada factor de manera independiente resulta complicado y supondría simplificar sus complejas interacciones (Flores y Sierro, 2007). Los requerimientos ecológicos difieren de unas especies a otras, de modo que cada una alcanzará su óptimo desarrollo en una masa de agua determinada.

\subsubsection{Distribución vertical}

Los cocolitóforos viven en la zona fótica (ZF) de la columna de agua ya que necesitan la luz para realizar la fotosíntesis. Los niveles de luz que requieren los cocolitóforos para su correcto desarrollo son similares a los de otras grupos de células eucariotas que también conforman el fitoplancton (Brand, 1994).

La extensión vertical de la zona fótica oscila en función de la latitud y de la turbidez de la columna de agua. En las aguas estratificadas de las zonas subtropicales se alcanzan las mayores profundidades de la ZF, pudiendo alcanzar hasta los $220 \mathrm{~m}$ (Winter et al., 1994). La mayoría de las especies ocupan los primeros metros de la columna de agua (entre 50 y $80 \mathrm{~m}$ ), la denominada zona eufótica, mientras que otras especies encuentran su nicho a mayores profundidades, como es el caso de, Oolithothus spp., que ocupa la zona fótica media, o de Florisphaera profunda, habitante de la zona fótica inferior (ZFI).

La ZFI no sólo presenta bajos niveles de intensidad lumínica (menores a $4 \%$ ) sino también temperaturas más bajas, por lo que, para una misma latitud, las especies que se desarrollan a estas profundidades lo harán en condiciones más frías y de menor luminosidad.

La termoclina es una capa en la vertical del cuerpo de agua que marca un cambio brusco de temperatura en profundidad y separa, las aguas profundas y frías, de las superficiales, sometidas al calentamiento solar y al efecto del viento que distribuye ese calor en los primeros metros de la columna de agua estableciendo la capa de mezcla.

La termoclina varía con la latitud y la estación: es estable en los trópicos, variable en regiones templadas, más marcada en verano, y casi inexistente en altas latitudes, donde la columna de agua está tan fría en superficie como en el fondo. 
Otro factor que varía en profundidad, es la disponibilidad de nutrientes, en concreto, los nutrientes biolimitantes para el desarrollo de los cocolitóforos son el nitrato y el fosfato, cuya concentración aumenta en profundidad. Este gradiente vertical de concentración de nutrientes determina la profundidad de la nutriclina, que a su vez, está ligada a la termoclina.

Variaciones en la posición relativa de la nutriclina y la termoclina controlan la composición de la asociación de cocolitóforos, de modo que:

-Si la nutriclina y la termoclina ocupan posiciones más someras, esto supone una mayor disponibilidad de nutrientes en superficie junto con temperaturas más bajas, favoreciendo el desarrollo de especies de cocolitóforos eutróficas como Emiliania huxleyi u otros pequeños placolitos del género Gephyrocapsa spp. Estas especies son oportunistas, con una alta tasa de reproducción, y siguen una estrategia ecológica de la $\mathrm{R}$ pudiendo eclosionar en gran número bajo condiciones estacionales de surgencia de aguas profundas, frías y ricas en nutrientes (Westbroek et al., 1993; Winter et al., 1994). Por el contrario, el ascenso de la nutriclina, conlleva el descenso de la abundancia relativa de los habitantes de la ZFI como F.profunda (Molfino y McIntyre, 1990).

-Si la nutriclina y la termoclina descienden en profundidad, las aguas superficiales tendrán menor concentración de nutrientes y temperaturas más elevadas. Esto favorecerá el desarrollo en superficie de especies mesotróficas u oligotróficas, normalmente de la asociación cálida, que se ajustan a una estrategia ecológica de la K por ser especies especialistas y de baja tasa de crecimiento. Paralelamente, las especies características de la ZFI aumentan su abundancia respecto a las de la ZFS.

Por tanto, el estudio de la composición de la asociación y la comparación de las abundancias de especies características de la ZFS y la ZFI aporta información sobre las variaciones en la posición de la nutriclina y la termoclina y pueden aplicarse en la reconstrucción de las condiciones paleoceanográficas (McIntyre y Molfino, 1996; Ahagon et al., 1993; Castradori, 1993; Baumann et al., 1999; Flores et al., 1999; Kinkel et al., 2000; Liu et al., 2008).

\subsubsection{Distribución horizontal}

El estudio de distribución de los diferentes taxones ha permitido definir diferentes zonas biogeográficas en los principales océanos. Aunque su distribución responda a un criterio latitudinal, al establecerse sobre masas de agua en continuo movimiento, los limites de dichas zonas biogeográficas no son rectilíneos, si no que se adaptan a las peculiaridades latitudinales de los cuerpos de agua (Ziveri et al., 2004). 
McIntyre y Bé establecieron en 1967 cinco zonas biogeográficas en el Atlántico, mientras que Okada y Honjo (1973) identificaron cuatro provincias biogeográficas para el Pacífico norte y tropical. Con posterioridad, Winter et al. (1994) llevaron a cabo una revisión y una descripción sintética que integraba las provincias biogeográficas propuestas anteriormente para el Atlántico y el Pacífico, mientras que Ziveri et al. (2004) realizaron una revisión de la distribución en el oceáno Atlántico de cinco especies representativas de cocolitóforos. Más recientemente, Saavedra-Pellitero et al. (2007) establecieron cinco zonas biogeográficas de cocolitóforos en el Pacífico suroriental y tropical.

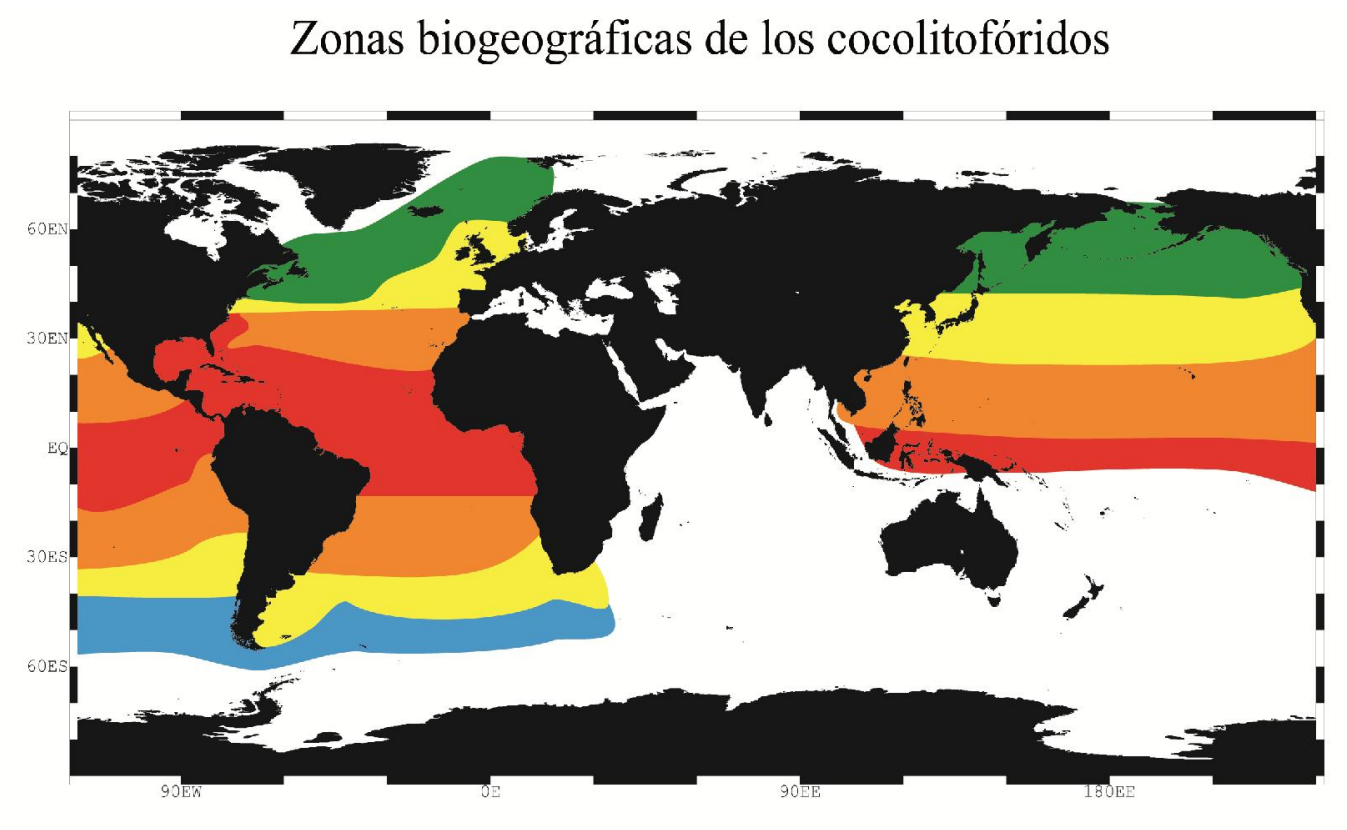

\section{Subártica Templada $\square$ Subtropical $\square$ Tropical $\square$ Subantártica}

Figura 3.5. Mapa con las zonas biogeográficas de los cocolitóforos actuales (McIntyre y Bé, 1967; Okada y Honjo, 1973; Winter et al., 1994, Saavedra-Pellitero et al., 2007). Modificada de Flores y Sierro (2007).

Winter et al., 1994 establecen las zonas biogeográficas obviando rasgos característicos como serían las regiones de surgencia, las cuencas cerradas o los eddies. Asumiendo esto, cada zona viene definida por un rango de valores de los diferentes parámetros ambientales y por tanto, por un hábitat óptimo para una asociación concreta de cocolitóforos según la siguiente clasificación:

-Zona Subártica: Definida por la Familia Papposphaeraceae en regiones costeras, máximas abundancias de Coccolithus pelagicus y la presencia de Calciopapus caudatus en océano abierto.

-Zona Templada: Dominada por placolitos, principalmente Emiliania huxley, Gephyrocapsa oceanica y Gephyrocapsa muellerae.

-Zona Subtropical: Caracterizada por holococolitóforos, y especies como, Rhabdosphera clavigera, Umbellosphaera spp., Umbilicosphaera sibogae, Syracosphaera spp. y F. profunda en la ZFI. 
-Zona tropical: Dominada por placolitos, especialmente, Emiliania huxleyi, Gephyrocapsa oceanica y Calcidiscus leptotporus. Otras especies también características serían Florisphaera profunda, Umbellosphaera spp. y Helicosphaera carteri, que presenta su máxima abundancia en esta zona.

- Zona Subantártica: Con escasa diversidad de especies, todas ellas pertenecientes a la Familia Papposphaeraceae. 


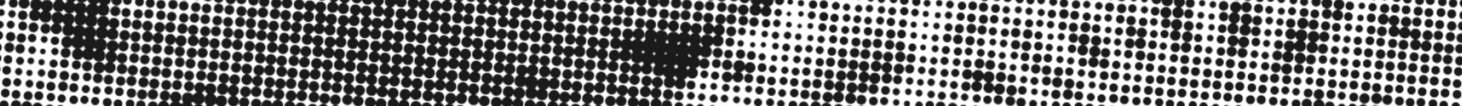

:

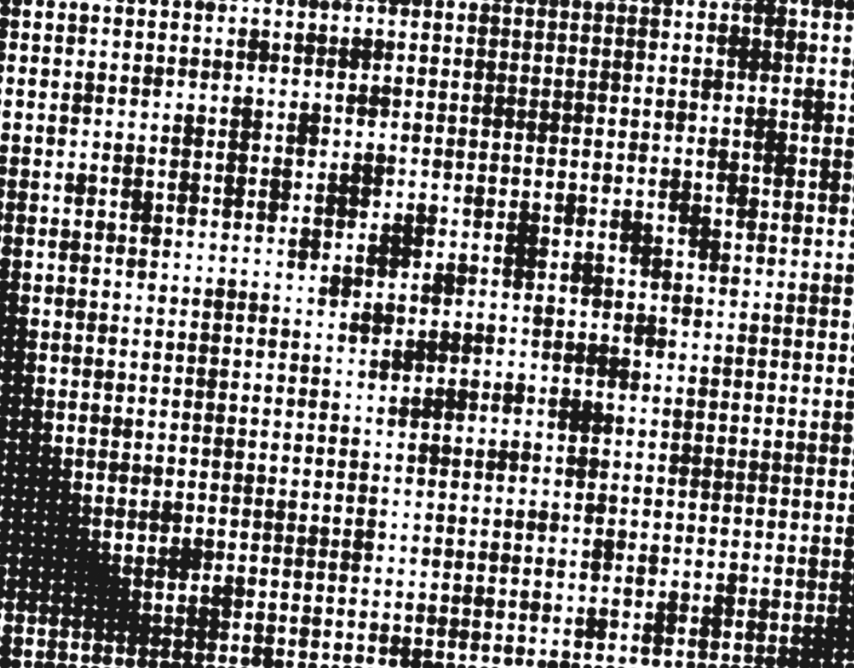

:

H.

ᄂ

H?tht?

I H.

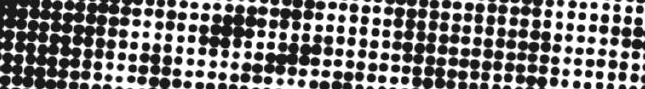

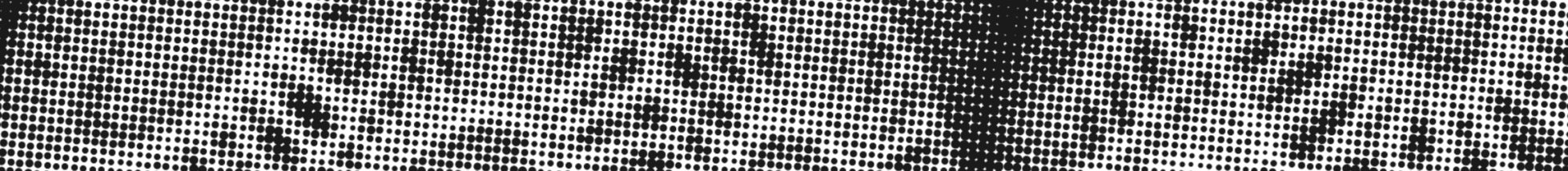

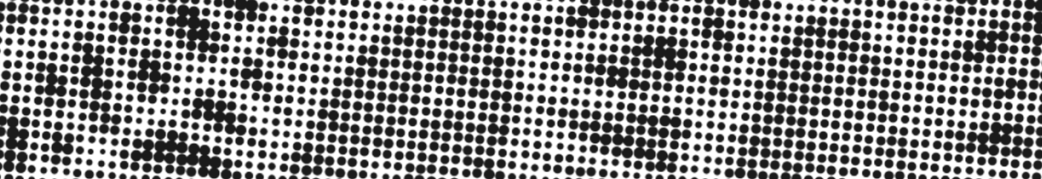
H

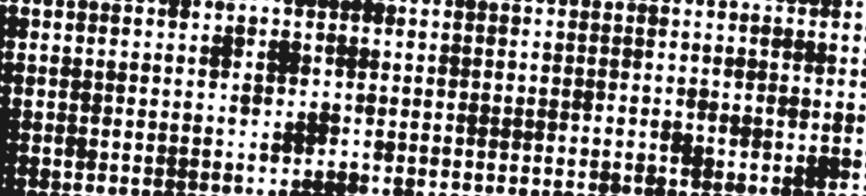

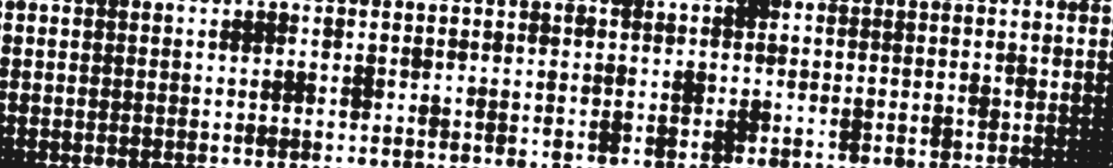

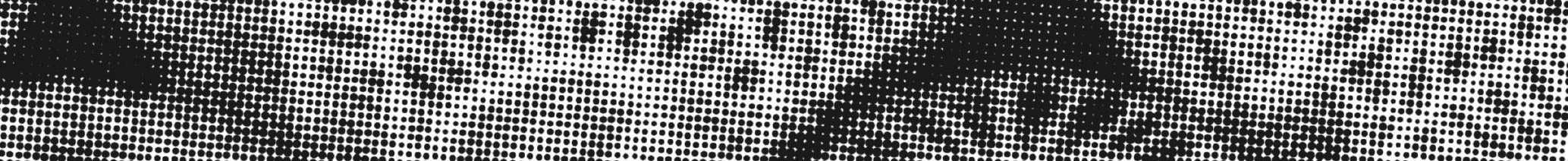

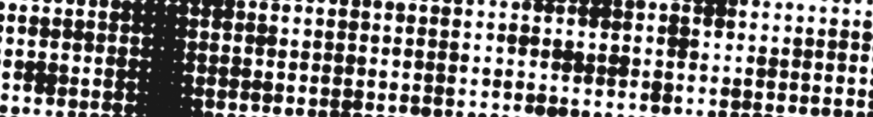

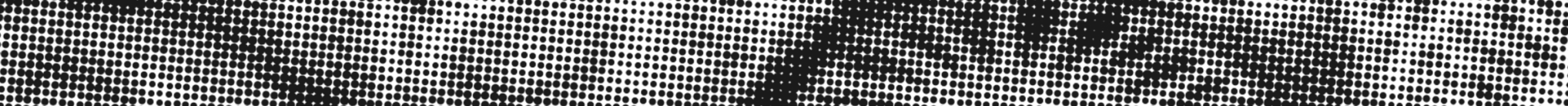
I: i: :mamm:mam

Capítulo 4:

Indicadores geoquímicos in cocolitóforos 



\section{Indicadores geoquímicos en cocolitóforos}

El presente trabajo se centra en el estudio de indicadores biogeoquímicos de los cocolitóforos, presentando las posibilidades y limitaciones de su uso en paleoceanografía y comparando su potencialidad con la clásica aplicación de foraminíferos en la geoquímica del carbonato marino.

Los cocolitóforos son los únicos organismos marinos que pueden proporcionar indicadores paleoceanográficos y paleoclimáticos a partir de sus restos tanto orgánicos como inorgánicos presentes en los sedimentos (Stoll y Ziveri, 2004). Ciertas especies de cocolitóforos sintetizan moléculas orgánicas denominadas alquenonas que presentan gran resistencia a la degradación y sirven así como fiables biomarcadores (Brassell et al., 1986; Prahl et al., 1988; Prahl y Wakeham, 1987; Schneider et al., 1995). Por su parte, el estudio de la química de las cubiertas calcáreas que recubren la célula cocolitoforal, desprende varios parámetros, tanto de la química elemental como de la composición isotópica (Tabla 4.1).

\begin{tabular}{|c|c|c|c|c|}
\hline & Indicador & Variable inferida & $\begin{array}{l}\text { Influencias } \\
\text { secundarias }\end{array}$ & Limitaciones \\
\hline \multirow{2}{*}{ Orgánico } & $\begin{array}{c}\mathrm{U}_{37}^{\mathrm{K}} \\
\text { (subsaturación de } \\
\text { alquenonas) }\end{array}$ & Temperatura & $\begin{array}{l}\text { Fisiología o tasa de } \\
\text { crecimiento }\end{array}$ & --- \\
\hline & $\varepsilon^{13} \mathrm{C}$ alquenonas & $\mathrm{pCO}_{2}$ & $\begin{array}{c}\text { Tasa de crecimiento } \\
\text { de la célula y tamaño } \\
\text { de la célula }\end{array}$ & $\begin{array}{l}\text { Precisa una estimación de } \\
\delta^{13} \mathrm{C} \text { del carbono } \\
\text { inorgánico disuelto }\end{array}$ \\
\hline \multirow{4}{*}{$\begin{array}{l}\text { Inorgánico } \\
\text { (cocolitos) }\end{array}$} & $\mathrm{Sr} / \mathrm{Ca}$ & $\begin{array}{l}\text { Productividad/ tasa } \\
\text { crecimiento }\end{array}$ & $\begin{array}{l}\text { Temperatura y } \mathrm{Sr} / \mathrm{Ca} \\
\text { del agua del mar }\end{array}$ & $\begin{array}{c}\text { Registros superiores a } 10^{6} \\
\text { años requieren una } \\
\text { corrección del } \mathrm{Sr} / \mathrm{Ca} \text { del } \\
\text { agua marina }\end{array}$ \\
\hline & $\mathrm{Mg} / \mathrm{Ca}$ & Temperatura & $\begin{array}{l}\text { Efectos según } \\
\text { especies }\end{array}$ & $\begin{array}{l}\text { Requiere limpieza del } \mathrm{Mg} \\
\text { de las fracciones no } \\
\text { carbonatadas }\end{array}$ \\
\hline & $\delta^{18} \mathrm{O}$ & $\begin{array}{c}\text { Temperatura y } \\
\delta^{18} \mathrm{O} \text { del agua del } \\
\text { mar }\end{array}$ & Efectos vitales & \multirow{2}{*}{$\begin{array}{l}\text { Puede precisar separación } \\
\text { de muestras } \\
\text { monoespecífias, asumir } \\
\text { efectos vitales constantes e } \\
\text { inferir efectos vitales para } \\
\text { especies extintas. }\end{array}$} \\
\hline & $\delta^{13} \mathrm{C}$ & $\begin{array}{l}\delta^{13} \mathrm{C} \text { del carbono } \\
\text { inorgánico disuelto }\end{array}$ & Efectos vitales & \\
\hline
\end{tabular}

Tabla 4.1. Resumen de los indicadores geoquímicos derivados de las fracciones orgánica (alquenonas) e inorgánica (cocolitos) de los cocolitóforos. Basada en Stoll y Ziveri, 2004.

En los estudios paleoceanográficos sobre cocolitóforos, la química de los biomarcadores orgánicos se ha utilizado más común y ampliamente que la química de los componentes inorgánicos debido a su mayor facilidad analítica. Aunque los cocolitóforos sean un componente dominante de los sedimentos marinos carbonatados, la mayor parte de los estudios geoquímicos sobre este tipo de sedimentos se han realizado a partir de foraminíferos, debido a la facilidad para tomar muestras monoespecíficas por 
su mayor tamaño. Sin embargo, en los últimos años, técnicas para la separación de fracciones de cocolitos "casi” monoespecíficas (Minoletti et al., 2001; Stoll y Ziveri, 2002) o monoespecíficas (Stoll et al., 2007a; Stoll y Shimizu, 2009), han permitido un enorme desarrollo de la aplicación de los cocolitóforos en estudios geoquímicos.

\subsection{Isótopos estables}

Los isótopos, del griego, mismo lugar, son todos los átomos de un mismo elemento cuyo núcleo contiene el mismo número de protones pero diferente número de neutrones y que por tanto ocupan un mismo lugar en la tabla periódica. En la naturaleza existen isótopos estables (300) y radiactivos (más de 1.200). Sólo 21 elementos poseen un único isótopo natural.

Las mediciones de isótopos estables de oxígeno y carbono en materiales carbonatados han sido una herramienta esencial en los estudios paleoceanográficos desde que en los años cincuenta se publicaran una serie de artículos sobre isótopos de oxígeno en foraminíferos planctónicos del género Globigerina. Sin embargo, el estudio de los isótopos estables en el carbonato de los cocolitos es relativamente reciente comparado con el caso de los foraminíferos.

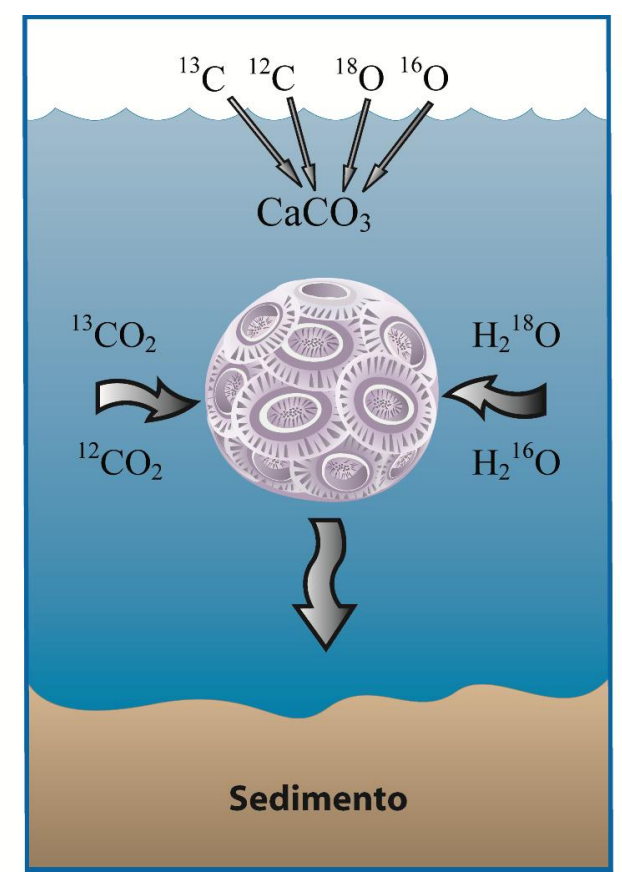

Figura 4.1. Los organismos marinos carbonatados toman el oxígeno y el carbono necesario para sintetizar la calcita de su cubierta, del oxígeno y carbono presente en el agua del mar en la que viven. Por ello, sus valores isotópicos varían en función de la composición isotópica del agua del mar.

La capacidad analítica para medir la abundancia absoluta de un isótopo es mucho menor que la existente para medir el ratio en el contenido isotópico de dos compuestos. Es por ello, que los resultados isotópicos se presentan generalmente como unidades delta $(\delta)$, cuyos valores se expresan en partes por mil (\%o). 


$$
\delta_{\mathrm{PDB}}{ }^{18} \mathrm{O} \text { ó }{ }^{13} \mathrm{C}=(\mathrm{Re} / \mathrm{Rr}-1) \cdot 1000
$$

donde :

-Re es la relación ${ }^{18} \mathrm{O} /{ }^{16} \mathrm{O}$ ó ${ }^{13} \mathrm{C} /{ }^{12} \mathrm{C}$ en la sustancia a analizar.

-Rr es la relación ${ }^{18} \mathrm{O} /{ }^{16} \mathrm{O}$ ó ${ }^{13} \mathrm{C} /{ }^{12} \mathrm{C}$ en una sustancia referencia o estándar.

El estándar empleado son unos belemnites de la formación Pee Dee en USA (Pee Dee Belemnite, PDB). Para el agua marina, el estándar es el Vienna Standard Mean Ocean Water (VSMOW) (Gonfiantini, 1978).

\subsubsection{Isótopos de oxígeno}

En la naturaleza existen dos isótopos estables del oxígeno, el isótopo ligero $\left({ }^{16} \mathrm{O}\right)$ y el isótopo pesado $\left({ }^{18} \mathrm{O}\right)$. La proporción presente en la naturaleza es de aproximadamente el 99,762 \% para el isótopo ligero y tan sólo el 0,2 \% para el isótopo pesado. Pero esta relación (500/1) puede variar ligeramente de unas sustancias a otras y servir así de indicador.

El $\delta^{18} \mathrm{O}$ de una organismo carbonatado depende de la composición isotópica del agua del mar y de la temperatura existente en esa agua durante la etapa de segregación de su cubierta (Epstein y Mayeda, 1953; McCrea, 1950a). A su vez, la composición isotópica del agua del mar varia en función del volumen de hielo y de la relación entre precipitaciones y evaporación, o balance hídrico, parámetro correlacionado positivamente con la salinidad (Craig y Gordon, 1965; Ostund et al., 1987).

\subsubsection{Composición isotópica del agua. Factores hielo y salinidad}

La composición isotópica del hielo almacenado en los casquetes polares oscila entre -30 y $-55 \%$, valores muy negativos si se comparan con la composición isotópica media del agua del océano (0 (Fig. 4.2). Aunque actualmente, el reservorio de hielo en los polos solo constituya el 1,64\% del agua terrestre, el volumen de hielo terrestre llegó a alcanzar el 4 \% en el último periodo glaciar.

Durante los periodos glaciales, el volumen de hielo aumenta, y el agua del océano se enriquece en el isótopo pesado $\left({ }^{18} \mathrm{O}\right)$ ya que el hielo extrae preferente el isótopo ligero $\left({ }^{16} \mathrm{O}\right)$ del océano, mientras que durante un deshielo, sucede lo contrario. En ambos casos la composición isotópica del agua del mar varía a nivel global. 


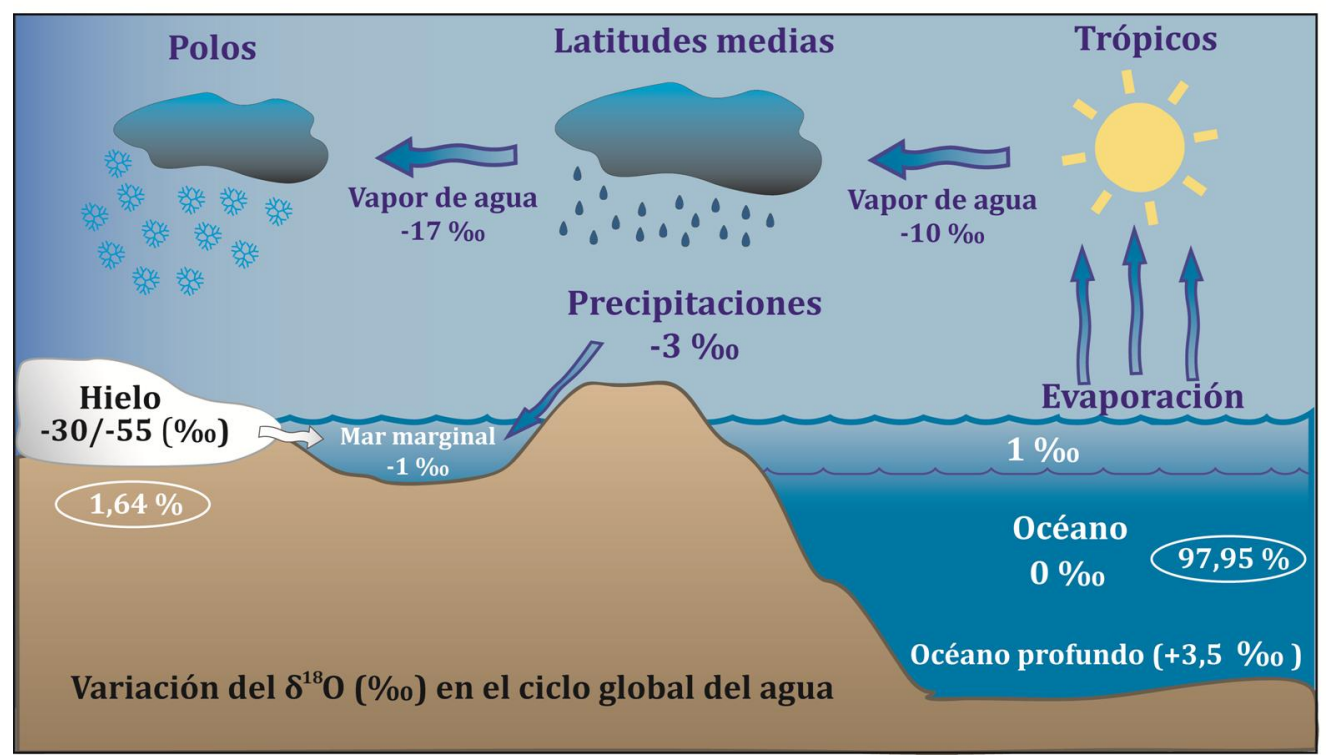

Figura 4.2. Variación del $\delta^{18} \mathrm{O}$ en el ciclo global del agua y en los diferentes reservorios debido al fraccionamiento isotópico durante la evaporación y condensación del vapor de agua. Basada en Ruddiman, 2001

La circulación atmosférica es responsable del trasvase de vapor de agua desde zonas ecuatoriales a zonas polares. Durante la evaporación, se produce un enriquecimiento del vapor de agua con el isótopo ligero. Una masa de vapor de agua que parta del ecuador hacia los polos se verá sometida a sucesivas condensaciones a medida que se enfríe, así, las primeras precipitaciones eliminarán preferentemente el isótopo pesado y aumentarán la concentración del isótopo ligero en el vapor de agua restante. Este proceso de fraccionamiento continúa durante el avance de esa masa de vapor de agua hasta las altas latitudes, de forma que los valores isotópicos de las precipitaciones son más bajos cuanto mayor sea la latitud (Fig. 4.2).

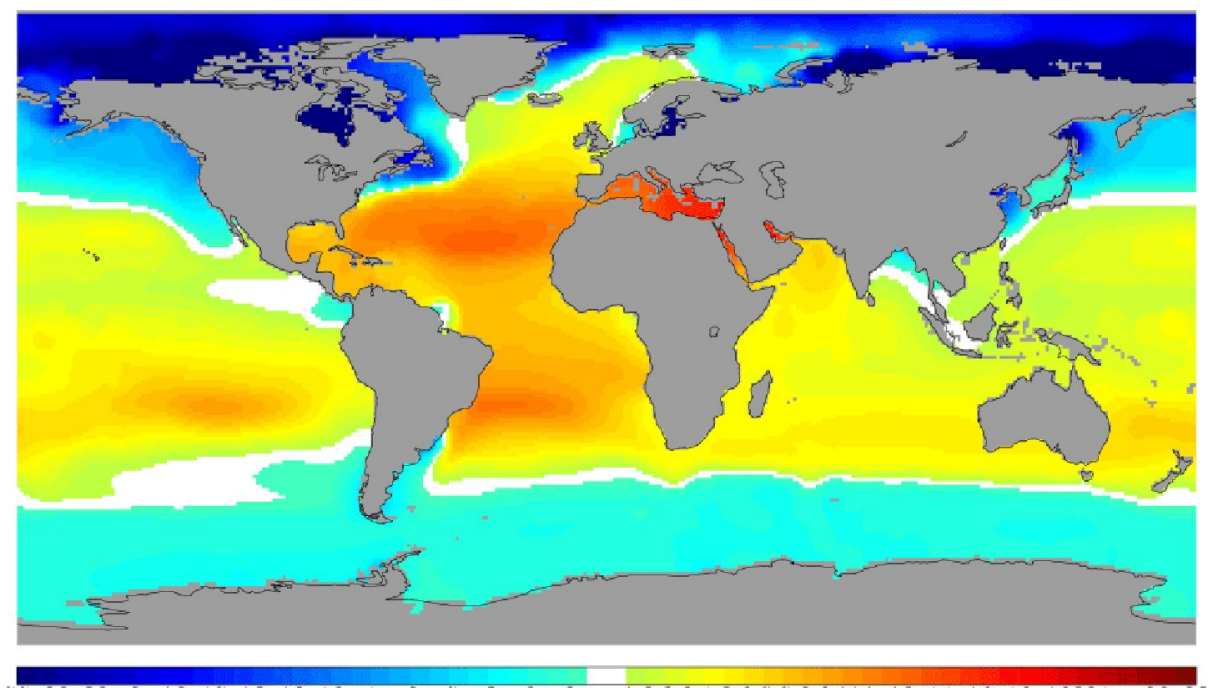

Figura 4.3. Mapa global del $\delta^{18} \mathrm{O}$ del agua superficial del océano expresado en relación al estándar V-SMOW. Tomada de http://data.giss.nasa.gov/o18data/. 
A su vez, la relación entre evaporación y precipitaciones $(\mathrm{E} / \mathrm{P})$, el balance hídrico, da lugar a gradientes regionales en el $\delta^{18} \mathrm{O}$ del océano de hasta $2 \%$ (Ostund et al., 1987) y controla tanto el $\delta^{18} \mathrm{O}$ del agua del mar como la salinidad. Por ello, su distribución global (Fig. 4.3) es muy similar y ambas alcanzan sus máximos valores en las zonas tropicales donde se dan escasas precipitaciones y fuerte evaporación.

\subsubsection{Temperatura del agua}

La temperatura no condiciona el $\delta^{18} \mathrm{O}$ del océano sino que determina directamente la composición isotópica del carbonato que se forma en equilibrio con el agua que le rodea. Al igual que la salinidad, también es un factor que varía a nivel regional.

Por cada grado centígrado que desciende la temperatura, la concentración del isótopo pesado $\left({ }^{18} \mathrm{O}\right)$ en el carbonato aumenta en un 0,23 \% (Bemis et al., 1998). De modo que, a temperaturas altas la composición isotópica del carbonato será inferior a la del agua, mientras que a temperaturas muy bajas la calcita del organismo será isotópicamente más pesada que el agua.

En 1947, Urey realizó un estudio pionero que establecía de manera teórica las propiedades termodinámicas de los compuestos isotópicos. Posteriormente, McCrea (1950b) y O'Neil et al. (1969) con carbonatos inorgánicos y (Epstein et al., 1953) y (Emiliani, 1954), con moluscos y foraminíferos, confirmaron de manera experimental los resultados teóricos predichos por Urey y demostraron que el contenido en ${ }^{18} \mathrm{O}$ de los organismos calcificadores marinos depende no sólo de la composición isotópica del agua del mar en que precipitan sino también de la temperatura.

A raíz de estos trabajos, se realizaron diversos experimentos de precipitación de carbonatos para la definición de una ecuación de paleotemperaturas, que ha sido sucesivamente modificada y calibrada para diferentes organismos calcificadores (Bouvier-Soumagnac y Duplessy, 1985; Erez y Luz, 1983; Kim y O'Neil, 1997; Shackleton, 1974). Posteriormente se ha realizado una revisión exhaustiva de ecuaciones de paleotemperatura (Bemis et al., 1998). Las diversas ecuaciones siguen un formato similar, que se ajustaría al ejemplo de la propuesta por (Kim y O'Neil, 1997):

$\mathrm{T}\left({ }^{\circ} \mathrm{C}\right)=16,1-4,64\left(\delta_{\mathrm{C}}-\delta_{\mathrm{W}}\right)+0,09\left(\delta_{\mathrm{C}}-\delta_{\mathrm{W}}\right)^{2}$

Donde $\mathrm{T}$ es la temperatura del agua del mar, $\delta_{\mathrm{C}}$ es el $\delta^{18} \mathrm{O}$ del carbonato, $\delta_{\mathrm{W}}$ es el $\delta^{18} \mathrm{O}$ del agua en la que precipita el carbonato y $\delta^{18} \mathrm{O}_{\mathrm{w} \text { (VPDB) }}=\delta^{18} \mathrm{O}_{\mathrm{w} \text { (VSMOW) }}-0,27 \%$. 


\subsubsection{Herramientas para la interpretación de isótopos de oxígeno}

Por tanto, a la hora de interpretar los isótopos de oxígeno de la asociación de microfósiles de un testigo oceánico, debemos considerar estos tres factores ya que una variación en el $\delta^{18} \mathrm{O}$ puede deberse a cualquiera de ellos o a la combinación de varios. En principio, resulta difícil discriminar entre cada uno de los tres factores, por ello es necesario la utilización de otras métodos.

Dado que el factor hielo es el único de los tres que presenta un carácter global, se propuso la obtención de una curva isotópica de referencia global que indicara las variaciones en el volumen de hielo a lo largo del tiempo. Con el fin de minimizar la influencia de la variabilidad regional, se decidió estudiar los foraminíferos del Pacífico profundo al ser ésta una zona alejada de las áreas de formación de aguas profundas donde la temperatura y la salinidad pueden asumirse constantes ya que no variaron significativamente durante el Cuaternario.

El alcance global del factor hielo hace que los diferentes registros marinos de $\delta^{18} \mathrm{O}$ presenten similitudes que permiten correlacionarlos y situarlos en una escala de tiempo común para desarrollar series temporales compuestas de $\delta^{18} \mathrm{O}$ (stack) que incorporan varios registros de $\delta^{18} \mathrm{O}$ de diferentes testigos.

Edad (ka) BP

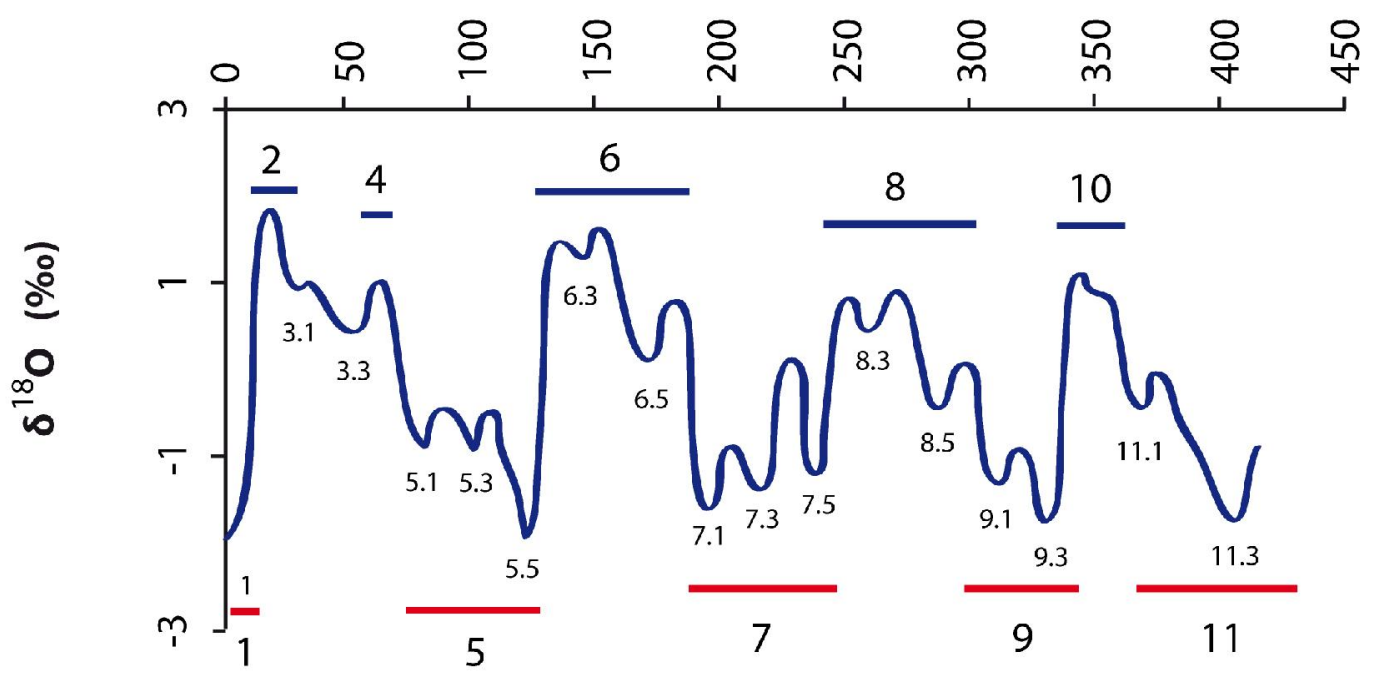

Figura 4.4. El primero de los registros compuestos de $\delta^{18} \mathrm{O}$ fue elaborado por SPECMAP (Mapping Spectral Variability in Global Climate Project) (Imbrie et al., 1984; Martinson et al., 1987) a partir de 5 registros de foraminíferos planctónicos que abarcaban los últimos $750 \mathrm{ka}$. 
La estructura básica de la curva SPECMAP (Martinson et al., 1987) ha sido confirmada por muchos estudios posteriores que apoyan su uso como una herramienta imprescindible para la correlación precisa de curvas isotópicas. Sin embargo, posteriormente, se han desarrollado otras series compuestas de $\delta^{18} \mathrm{O}$ de mayor resolución y alcance temporal, basadas generalmente en foraminíferos bentónicos (Huybers y Wunsch, 2004; Karner et al., 2002; Lisiecki y Raymo, 2005; Shackleton et al., 1995).

La serie LR04 de Lisiecki y Raymo (2005) se construyó a partir de la correlación gráfica de 57 registros de $\delta^{18} \mathrm{O}$ bentónico a muy alta resolución. El LR04, se extiende sobre los últimos 5,3 Ma constituyendo el mejor indicador global de volumen de hielo en el pasado.

La observación de los registros compuestos de $\delta^{18} \mathrm{O}$ revela una variación de forma cíclica que sirve para su subdivisión en diferentes intervalos denominados estadios isotópicos marinos del oxígeno (Marine oxygen Isotope Stages, MIS), que a nivel práctico corresponden con unidades cronoestratigráficas. El grupo de estadios isotópicos que presenta valores isotópicos bajos se corresponde con periodos interglaciales y se denota mediante números impares mientras que los periodos glaciales que presentan valores isotópicos altos coinciden con números pares. El actual periodo cálido (Holoceno) se corresponde con el estadio isotópico 1 y el estadio inmediatamente anterior, que coincide con el último máximo glacial, se denomina estadio isotópico 2 .

Los estadios se definen siempre que se produce un cambio relativo de volumen de hielo, aunque éste sea pequeño. Por ejemplo, el estadio 2 viene definido por un cambio contundente que ocurre después de la ligera variación que marca el estadio 3. Este descenso no es comparable al registrado en los estadios 1 ó 5 , ya que hay estadios mucho más pronunciados que otros.

\subsubsection{Isótopos de carbono}

En la naturaleza existen dos isótopos estables del carbono, el isótopo ligero $\left({ }^{12} \mathrm{C}\right)$, con una abundancia del 98,9\% y el isótopo pesado $\left({ }^{13} \mathrm{C}\right)$, alrededor del $1,1 \%$.

La relación isotópica del carbono en los organismos carbonatados refleja con bastante precisión la composición isotópica del agua circundante (Goodney et al., 1980; Winter y Siesser, 1994; Zeebe y Wolf-Gladrow, 2001), ya que la influencia de otros factores como la temperatura, no es suficientemente relevante $\left(0,03 \% / 1{ }^{\circ} \mathrm{C}\right)$.

El $\delta^{13} \mathrm{C}$ de los carbonatos marinos puede servir para inferir modificaciones del ciclo del carbono (Dickens, 2001) a nivel global, o bien para identificar cambios en la paleoproductividad y en la circulación oceánica (Broecker, 1971) a escala regional . 


\subsubsection{Cambios isotópicos globales en el ciclo del carbono}

La composición isotópica del carbono en el agua del mar varía de unas masas de agua a otras y depende de la tasa de intercambio de carbono entre las masas de agua y los cuatro reservorios de carbono en la tierra: hidrosfera, atmósfera, biosfera y litosfera (Kroopnick, 1985). Cada uno de estos reservorios contiene una cantidad de carbono determinada con una composición isotópica media muy diferente. La biosfera presenta una composición isotópica media de $-20 \%$, el agua del océano de +2 \% y la atmósfera de -7 \%. La litosfera es el mayor reservorio de carbono, sin embargo, intercambia carbono con los otros reservorios a menor velocidad. Su composición isotópica media resulta más difícil de calcular, si bien las rocas y sedimentos carbonatados, presentan un $\delta^{13} \mathrm{C}$ medio parecido al del océano mientras que las rocas ricas en materia orgánica, como los petróleos o carbones, presentan valores semejantes a los de la biosfera.

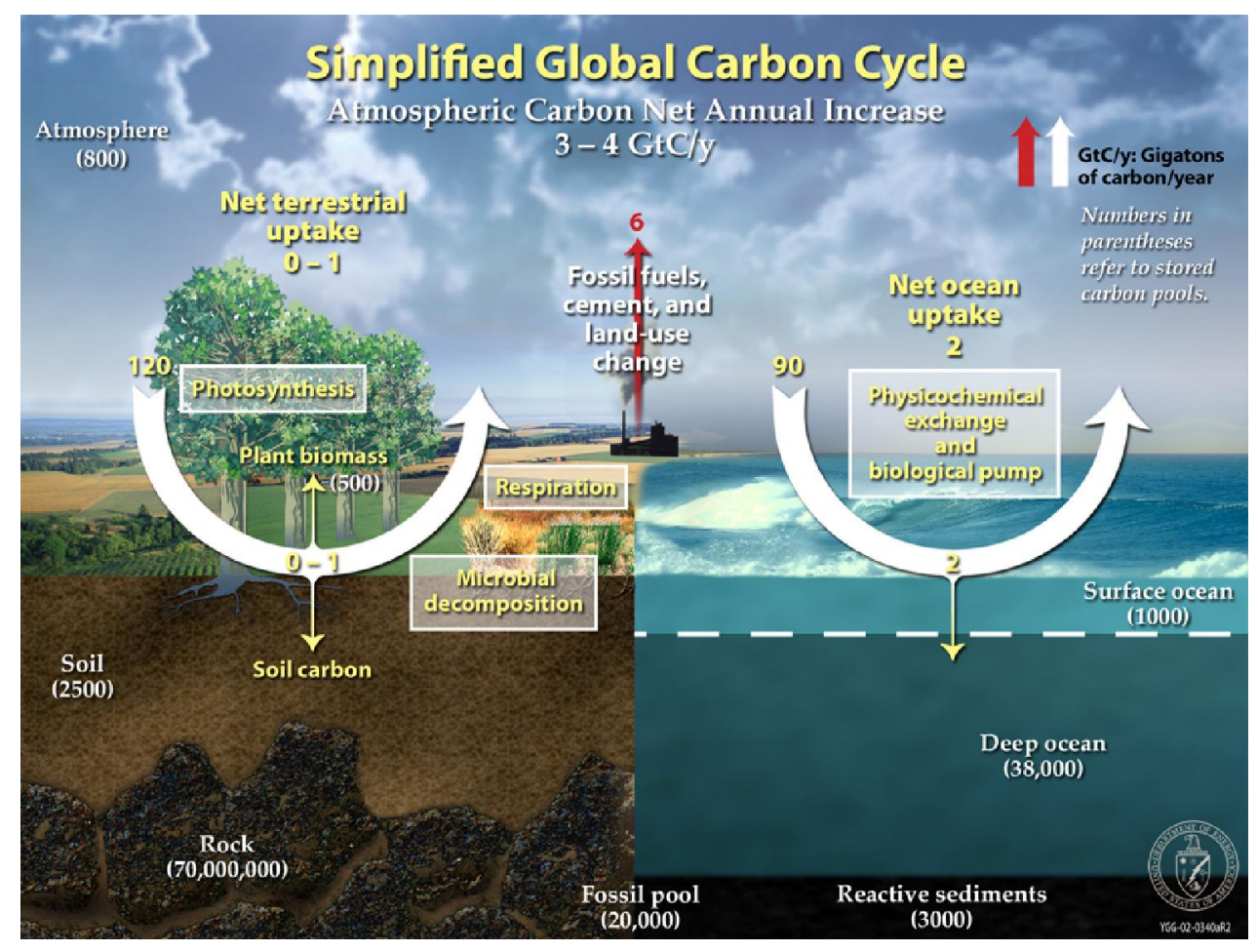

Figura 4.5. Ciclo del carbono y contenido e intercambio entre los diferentes reservorios. Tomada de United States Department of Energy. http://genomics.energy.gov.

Los cambios a nivel global en la composición isotópica del carbono inorgánico disuelto en el océano pueden deberse a múltiples causas, entre ellas:

- Liberación repentina de metano al océano a partir de los hidratos de gas del fondo oceánico por un cambio brusco de temperatura o presión. O liberación de $\mathrm{CO}_{2}$ por erupciones volcánicas.

- Cambios del nivel del mar. Cuando se produce una trasgresión, parte de la plataforma se inunda y aparecen ambientes de estuario o marismas, con alta productividad y condiciones de anoxia que 
favorecen la preservación de la materia orgánica. Este escenario determina un trasvase de ${ }^{12} \mathrm{C}$ océanobiosfera-litosfera, y un aumento del $\delta^{13} \mathrm{C}$ del océano. Por el contrario cuando el nivel del mar baja, los sedimentos ricos en materia orgánica de la plataforma, son erosionados y el ${ }^{12} \mathrm{C}$ vuelve al océano.

- Oscilaciones en la extensión de la biosfera continental debido a cambios climáticos de carácter glaciar-interglaciar. Durante el periodo glacial máximo, el bosque boreal desaparece por la expansión del casquete de hielo, mientras que el bosque tropical reduce sus dimensiones a expensas del desierto. Los bosques constituyen uno de los principales sumideros de $\mathrm{CO}_{2}$, por lo que su reducción conllevaría un descenso del $\delta^{13} \mathrm{C}$ de la atmósfera y el océano.

- Quema intensiva de hidrocarburos fósiles de origen biológico que produce un trasvase acelerado de

${ }^{12} \mathrm{C}$ desde la litosfera a la atmósfera y al océano.

\subsubsection{Cambios isotópicos regionales. Subreservorios de carbono del océano}

-Por utilización de nutrientes y productividad oceánica. $\mathrm{El} \delta^{13} \mathrm{C}$ del agua superficial depende del aporte de nutrientes a la superficie y del consumo de nutrientes por el fitoplancton. Durante la fotosíntesis, el fitoplancton extrae preferentemente el carbono ligero $\left({ }^{12} \mathrm{C}\right)$ y el $\delta^{13} \mathrm{C}$ del agua superficial aumenta. Por el contrario, si aunque la disponibilidad de nutrientes sea alta, la productividad oceánica no aumenta, entonces, el $\delta^{13} \mathrm{C}$ del agua superficial se mantendrá bajo. Esto ocurre en el océano del sur, donde hay escaso desarrollo del fitoplancton a pesar de la alta concentración de nutrientes.

-Por gradiente vertical y eficacia del bombeo biológico. El perfil batimétrico del $\delta^{13} \mathrm{C}$ presenta valores diferentes para el agua superficial y el agua profunda, las primeras contienen una menor cantidad de carbono, pero su $\delta^{13} \mathrm{C}$ es mayor (James, 2005). En la masa de agua superficial, el fitoplancton realiza la fotosíntesis e incorpora el ${ }^{12} \mathrm{C}$ del agua. $\mathrm{Al}$ morir el plancton, cae al fondo donde sus restos orgánicos se oxidan liberando de nuevo el ${ }^{12} \mathrm{C}$ a las aguas profundas (Rohling and Cooke, 2003). Este mecanismo conocido como bombeo biológico, trasvasa $\mathrm{CO}_{2}$ desde la superficie al fondo oceánico, regulando el $\mathrm{CO}_{2}$ atmosférico.

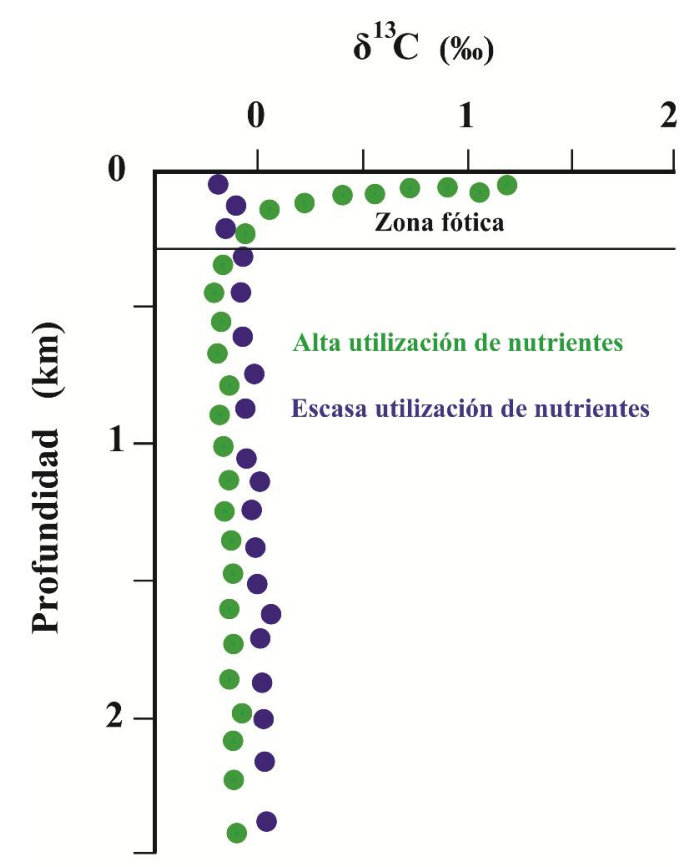

Figura 4.6. Gradiente vertical del $\delta^{13} \mathrm{C}$ y variabilidad según la utilización de nutrientes. Basada en James, 2005. 
-Por circulación oceánica y capacidad de renovación del agua. El $\delta^{13} \mathrm{C}$ de las aguas oceánicas también varía en función de los intercambios entre masas de agua y del tiempo de residencia del agua en una cuenca, de modo que si la comunicación es restringida y el agua se renueva lentamente, el $\delta^{13} \mathrm{C}$ presentará valores más bajos.

\subsubsection{Equilibrio isotópico versus efectos vitales}

El uso de ecuaciones determinadas empíricamente puede servirnos en el cálculo de la composición del equilibrio isotópico de un carbonato formado a partir de un agua con valores isotópicos conocidos para el oxígeno y el carbono y a una temperatura dada.

Sin embargo, muchos organismos carbonatados no presentan el esperado equilibrio isotópico que se deduce de la composición isotópica de las aguas en que se desarrollan, sino que muestran ciertos desfases respecto al equilibrio. La suma de factores que regulan estos desfases se denomina "efectos vitales" (vital effects) y supone una limitación en el estudio paleoceanográfico de isótopos estables, especialmente en el caso de los cocolitóforos.

Los foraminíferos planctónicos también parecen mostrar efectos vitales, aunque sus magnitudes exactas son más difíciles de calcular ya que éstos ocupan hábitats con diferentes profundidades que pueden contribuir a un aparente desequilibrio isotópico (Bijma et al., 1991).

Investigaciones al respecto han sorteado el problema de los efectos vitales aislando el carbonato de una sola especie y asumiendo que la aportación de sus "efectos vitales" es constante y no varía con el tiempo. De modo que las variaciones isotópicas pudieran ser interpretadas como resultado de cambios en la composición isotópica del agua o en la temperatura de la misma.

Esta medida ha sido ampliamente utilizada con foraminíferos del Cuaternario, sin embargo, la menor abundancia y mayor disolución de los foraminíferos durante el Cenozoico Inferior y el Mesozoico, han generalizado el uso de la fracción total de carbonato, dominada por los cocolitos, en los análisis isotópicos de estos periodos (Bains et al., 1999).

Aunque las señales isotópicas de la fracción de foraminíferos y la poliespecífica dominada por los cocolitos puedan ser comparables (Tabla 4.2), el uso de la fracción de nanoplancton estaría restringido a los casos en que la asociación no presente grandes cambios temporales. 


\begin{tabular}{|c|c|c|c|c|}
\hline Estudio & $\begin{array}{c}\text { Tamaño de la } \\
\text { fracción }\end{array}$ & Edad & Localización & Resultado \\
\hline $\begin{array}{c}\text { Anderson y Cole, } \\
1975\end{array}$ & $<44 \mu \mathrm{m}$ & Pleistoceno & Caribe & $\begin{array}{l}\delta^{18} \mathrm{O} \text { y } \delta^{13} \mathrm{C} \text { de la fracción de } \\
\text { cocolitos covarían con los de la } \\
\text { fracción de foraminíferos } \\
\text { planctónicos aunque con un } \\
\text { desfase. }\end{array}$ \\
\hline $\begin{array}{c}\text { Margolis et al., } \\
1975\end{array}$ & $<44 \mu \mathrm{m}$ & Cenozoico & $\begin{array}{l}\text { Océano del } \\
\text { Sur }\end{array}$ & $\begin{array}{l}\delta^{18} \mathrm{O} \text { y } \delta^{13} \mathrm{C} \text { de la fracción de } \\
\text { cocolitos covarían con los de la } \\
\text { fracción de foraminíferos } \\
\text { planctónicos }\end{array}$ \\
\hline $\begin{array}{c}\text { Goodney et al., } \\
1980\end{array}$ & $<44 \mu \mathrm{m}$ & $\begin{array}{l}\text { Reciente } \\
\text { (core-top) }\end{array}$ & Global & $\begin{array}{l}\delta^{18} \mathrm{O} \text { de la fracción de cocolitos no } \\
\text { está en equilibrio con } \delta^{18} \mathrm{O} \text { del } \\
\text { agua superficial, y depende de la } \\
\text { temperatura. }\end{array}$ \\
\hline $\begin{array}{l}\text { Anderson y } \\
\text { Steinmetz, } \\
1981,1983\end{array}$ & $3-25 \mu \mathrm{m}$ & Cuaternario & Caribe & $\begin{array}{l}\delta^{18} \mathrm{O} \text { de la fracción de cocolitos } \\
\text { covaría con la fracción de } \\
\text { foraminíferos planctónicos pero } \\
\text { con mayores desfases }\end{array}$ \\
\hline $\begin{array}{l}\text { Paull y } \\
\text { Thierstein, } \\
1987\end{array}$ & $\begin{array}{c}<38 \mu \mathrm{m} \text {, en } \\
\text { subfracciones }\end{array}$ & $\begin{array}{l}\text { Reciente y } \\
\text { último } \\
\text { máximo } \\
\text { glacial }\end{array}$ & Global & $\begin{array}{l}\text { Las diferentes subfracciones de } \\
\text { cocolitos muestran un amplio } \\
\text { rango de desequilibrio tanto para } \\
\delta^{18} \mathrm{O} \text { como para } \delta^{13} \mathrm{C} \text {. }\end{array}$ \\
\hline $\begin{array}{c}\text { Dudley y Nelson, } \\
1989\end{array}$ & $<38 \mu \mathrm{m}$ & Cuaternario & $\begin{array}{l}\text { Mar de } \\
\text { Tasmania }\end{array}$ & $\begin{array}{l}\text { Los efectos vitales calculados } \\
\text { mediante cultivo de cada especie } \\
\text { puede servir para corregir los } \\
\text { cambios en las asociaciones } \\
\text { aunque la corrección se limite a un } \\
\text { desfase constante }\end{array}$ \\
\hline $\begin{array}{l}\text { Stoll y Ziveri, } \\
2002\end{array}$ & $\begin{array}{c}<12 \mu \mathrm{m} \text {, en } \\
\text { subfracciones }\end{array}$ & $\begin{array}{l}\text { Reciente } \\
\text { (core-top) }\end{array}$ & $\begin{array}{l}\text { Atlántico, } \\
\text { Índico } \\
\text { y Pacífico }\end{array}$ & $\begin{array}{l}\text { Los desfases de } \delta^{18} \mathrm{O} \text { y } \delta^{13} \mathrm{C} \text { entre } \\
\text { las diferentes especies son } \\
\text { relativamente constantes para } \\
\text { diferentes localizaciones y } \\
\text { concuerdan con los resultados de } \\
\text { los cultivos }\end{array}$ \\
\hline
\end{tabular}

Tabla 4.2. Resumen de estudios previos sobre isótopos estables en cocolitos presentes en sedimentos marinos. Basada en Stoll y Ziveri, 2004.

\subsubsection{Efectos vitales en cocolitóforos}

Los estudios pioneros desarrollados por Dudley y Goodney (1979) y posteriormente Dudley et al. (1980, 1986) sobre los efectos vitales en isótopos estables de cocolitóforos actuales a través de cultivos de laboratorio, mostraron por primera vez un amplio rango de efectos vitales en los isótopos de oxígeno de las diferentes especies de cocolitos. El cultivo de ocho especies de cocolitóforos a diferentes temperaturas reflejó que, para una temperatura dada, algunas especies presentaban relaciones isotópicas superiores a las del equilibrio, por tanto isotópicamente más pesadas, mientras que otras especies tenían radios isotópicos menores que los del equilibrio. Sucesivos cultivos de las mismas especies en diferentes laboratorios mostraron resultados comparables confirmando así que los efectos vitales se deben a factores intrínsecos a cada especie. 
Experimentos más recientes sobre cultivos de ocho especies de cocolitóforos bajo condiciones de nutrientes, temperatura y luz idénticas confirmaron el amplio rango interespecífico de efectos vitales para los isótopos de oxígeno y abordaron además el estudio de los isótopos de carbono, revelando unos resultados similares (Ziveri et al., 2003).

\begin{tabular}{|l|c|c|l|}
\hline Especies & $\begin{array}{l}\text { Desfase } \\
\text { del isótopo } \\
\text { de oxígeno }\end{array}$ & $\begin{array}{l}\text { Desfase } \\
\text { del isótopo } \\
\text { de carbono }\end{array}$ & Estudio \\
\hline Calcidiscus leptoporus & $-2,4$ & & Dudley et al., 1986 \\
\hline Calcidiscus leptoporus & $-0,2$ & $-1,6$ & Ziveri et al., 2003 \\
\hline Coccolithus pelagicus pel. (Het) & 1,7 & $-2,1$ & Ziveri et al., 2003 \\
\hline Emilania huxleyi & 2,8 & & Dudley et al., 1986 \\
\hline Emilania huxleyi & 3,1 & 3,2 & Ziveri et al., 2003 \\
\hline Gephyrocapsa oceanica & 2,0 & & Dudley et al., 1986 \\
\hline Gephyrocapsa oceanica & 2,5 & & Ziveri et al., 2003 \\
\hline Helicosphaera carteri & $-0,1$ & & Ziveri et al., 2003 \\
\hline Oolithotus fragilis & $-0,9$ & & Ziveri et al., 2003 \\
\hline Reticulofenestra sessilis & 2,0 & & Dudley et al., 1986 \\
\hline Syracosphaera pulcra & $-2,2$ & & Dudley et al., 1986 \\
\hline Umbilicosphaera hulburtiana & $-1,9$ & & Dudley et al., 1986 \\
\hline Umbilicosphaera sibogae & $-1,5$ & & Dudley et al., 1986 \\
\hline Umbilicosphaera sibogae foliosa & $-0,5$ & $-1,7$ & Ziveri et al., 2003 \\
\hline Umbilicosphaera sibogae sibogae & $-0,3$ & $-1,9$ & Ziveri et al., 2003 \\
\hline
\end{tabular}

Tabla 4.3. Desfases de diferentes especies de cocolitóforos respecto al equilibrio isotópico "efectos vitales" a $17^{\circ} \mathrm{C}$ (expresados en \%o). La composición isotópica del oxígeno en equilibrio se calculó a partir de la ecuación de paleotemperatura de O’neil et al. (1969). Para los isótopos de carbono, la diferencia se expresa con respecto al equilibrio calculado entre la calcita y el bicarbonato, que es $0,23 \%$ para $17{ }^{\circ} \mathrm{C}$. Basada en Stoll y Ziveri, 2004.

Tanto los isótopos de oxígeno como los de carbono presentan un rango de $5 \%$ en epsilon $\varepsilon^{18} \mathrm{O}(\sim$ $\left.\delta^{18} \mathrm{O}_{\text {calcita }}-\delta^{18} \mathrm{O}_{\text {media }}\right)$ y $\varepsilon^{13} \mathrm{C}\left(\sim \delta^{13} \mathrm{C}_{\text {calcita }}-\delta^{13} \mathrm{C}_{\text {media DIC }}\right)$ con valores tanto superiores como inferiores respecto al equilibrio esperado para la precipitación del oxígeno y el carbono desde el agua marina a una temperatura de $17^{\circ} \mathrm{C}$ (Ziveri et al., 2003) (Tabla 4.3).

Estas diferencias interespecíficas en el fraccionamiento isotópico no parecen correlacionarse con parámetros filogenéticos de los cocolitóforos ni con la biogeografía, pero si que presentan una clara correlación con varias variables fisiológicas del experimento del cultivo. Las diferencias interespecíficas tanto del carbono como del oxígeno no estaban correlacionadas con diferentes tasas de precipitación de la calcita en las diferentes especies ni tampoco con diferentes tasas de fijación de carbono orgánico. Sin embargo, ambos elementos presentan una fuerte correlación con las tasas máximas de crecimiento de las diferentes especies bajo condiciones de saturación luminosa y de nutrientes, aunque, para tasas de crecimiento inferiores a 1 por día, no se producía ningún descenso en el valor de $\varepsilon^{13} \mathrm{C}$. En cuanto al tamaño de célula y a la relación área superficial/volumen de la célula, el carbono presenta una alta correlación mientras que el oxígeno muestra una correlación moderada. (Stoll y Ziveri, 2004; Ziveri et al., 2003). 


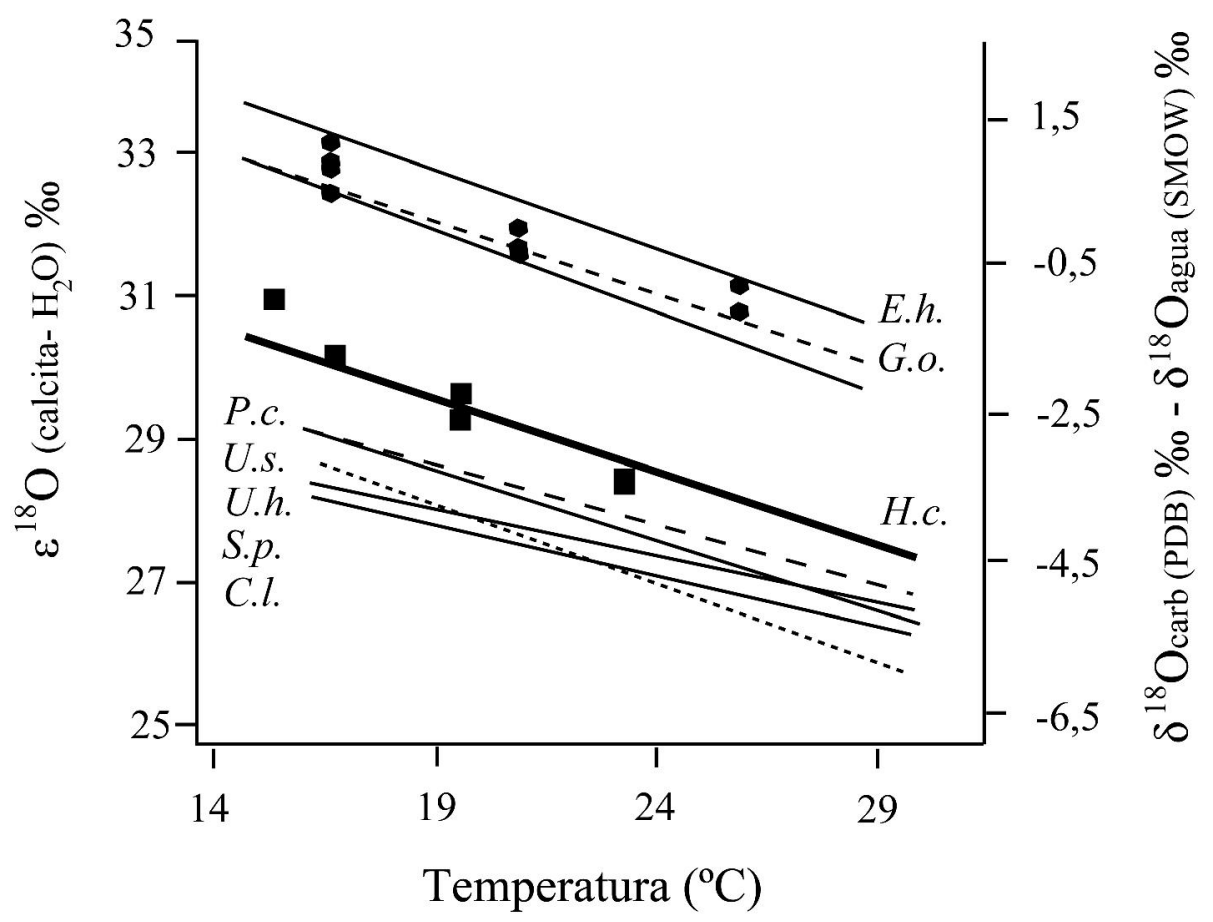

Figura 4.7. Factor de desequilibrio $\varepsilon^{18} \mathrm{O}$ versus temperatura para cocolitos en cultivo. (E.h.= Emiliania huxleyi; G.o. $=$ Gephyrocapsa oceanica; P.c. $=$ Pleurochrysis carterae; U.s. $=$ Umbilicosphaera sibogae; U.h. $=$ Umbilicosphaera hulburtiana; S.p.= Syracosphaera pulcra; C.1.= Calcidiscus leptoporus). Todos los resultados de Dudley et al. (1986) excepto G. oceanica (diamantes) y H. carteri (cuadrados) de Ziveri et al. (2003). La línea negra marca el equilibrio según la ecuación de paleotemperatura de O'neil et al. (1969): $1000 \cdot \ln \varepsilon=\left(2,78 \cdot 10^{6}\right.$. $\left.\mathrm{T}^{-1}\right)-2,89$, donde la temperatura está en grados Kelvin. Basada en Stoll y Ziveri, 2004.

Para comprobar si los efectos vitales de una especie son constantes, se realizaron experimentos adicionales sobre las especies Calcidiscus leptoporus y Gephyrocapsa oceanica induciendo variaciones en sus tasas de crecimiento a partir de cambios en la intensidad de luz .Los resultados de estos experimentos mostraban que para una misma especie la variación de efectos vitales no es significativa ya que un aumento de la tasa de crecimiento de $G$. oceanica desde 0,5 a 1,9 por día, modificaba el valor de $\varepsilon^{18} \mathrm{O}$ en menos del $1 \%$, mientras que el $\varepsilon^{18} \mathrm{O}$ de $C$. leptoporus sólo oscilaba un $1,5 \%$ para cambios de tasa de crecimiento entre 0,7 y 0,2 por día (Ziveri et al., 2003).

\subsubsection{Causas de los efectos vitales en cocolitóforos}

Aunque las variaciones interespecíficas de $\varepsilon^{18} \mathrm{O}$ se correlacionen claramente con las tasas de crecimiento, el hecho de que los valores isotópicos de una misma especie no varíen al inducir cambios en su tasa de crecimiento debidos a la temperatura o la luminosidad, sugieren que la tasa de crecimiento en sí misma no sea el factor que controle ulteriormente los efectos vitales en los cocolitos.

Por otra parte, el tamaño de célula y la relación área superficial/volumen son otros factores fisiológicos correlacionados con las variaciones isotópicas, los cuales varían considerablemente de 
unas especies a otras, pero no presentan cambios significativos (menos del $20 \%$ ) en individuos de la misma especie.

La correlación entre el tamaño de la célula y la tasa de crecimiento puede reflejar un crecimiento de la célula limitado por la tasa de adquisición de nutrientes a través de las membranas celulares (Popp et al., 1998; Rost et al., 2002) por lo que las células más grandes con menor relación área superficie/volumen crecen más lentamente. Dichas correlaciones demuestran que los efectos vitales de las diferentes especies se deben a un mecanismo común a todas ellas.

El hecho de que, a diferencia de los foraminíferos, los cocolitóforos calcifiquen en vesículas especializadas situadas intracelularmente (Billard e Inouye, 2004) plantea nuevos retos en la comprensión de las relaciones entre los procesos termodinámicos y cinéticos del fraccionamiento isotópico y la precipitación y adquisición celular del carbonato y del carbono respectivamente. Mientras los estudios no hayan discriminado aún si el carbono es tomado sólo por difusión pasiva en forma de $\mathrm{CO}_{2} \mathrm{o}$ también por transporte activo de $\mathrm{CO}_{2} \mathrm{o}_{\mathrm{HCO}_{3}}{ }^{-}$, éste continuará siendo un gran reto en la biogeoquímica de los cocolitóforos (Brownlee y Taylor, 2004; Keller y Morel 1999; McConnaughey et al., 1997; Rost y Riebesell, 2004).

En síntesis, según Ziveri et al. (2003), las variaciones isotópicas observadas en los cocolitos pueden deberse a tres factores:

1. Los efectos cinéticos en el fraccionamiento isotópico durante la precipitación de carbonato son el mecanismo al que se apela más comúnmente (McConnaughey, 1989a; McConnaughey, 1989b). Si la precipitación del carbonato es más rápida que la hidroxilación del $\mathrm{CO}_{2}\left(\mathrm{CO}_{2}+\right.$ $\mathrm{OH}^{-} \rightarrow \mathrm{HCO}_{3}{ }^{-}$), entonces el carbonato será isotópicamente más ligero tanto para el oxígeno como para el carbono. Aún así, los efectos cinéticos no pueden explicar la presencia de carbonatos enriquecidos con los isótopos pesados respecto al equilibrio, como ocurre con algunas especies de cocolitóforos.

2. Si se diera un intercambio entre los reservorios de carbono utilizados para la fotosíntesis y la calcificación, la composición isotópica del carbono de los cocolitos se vería influenciada por el fuerte fraccionamiento isotópico que se produce durante la fotosíntesis (McConnaughey et al., 1997). Ya que el carbono ligero es extraído preferentemente por el carbón orgánico, el carbono residual que no se fija mediante la fotosíntesis, es isotópicamente más pesado y su incorporación al carbonato de los cocolitos podría explicar la existencia de valores de $\delta^{13} \mathrm{C}$ superiores al equilibrio, aunque no podría justificar los valores superiores de $\delta^{18} \mathrm{O}$. 
3. La influencia del pH en el fraccionamiento isotópico está condicionada a su vez por la composición isotópica del carbonato, ya que la composición isotópica del oxígeno de $\mathrm{HCO}_{3}{ }^{-}$ es más pesada que la del $\mathrm{CO}_{3}^{-}$, y la abundancia relativa de estas dos moléculas depende del $\mathrm{pH}$. Si el carbonato precipitado toma $\mathrm{HCO}_{3}{ }^{-} \mathrm{y} \mathrm{CO}_{3}{ }^{-}$según su abundancia relativa en el fluido de calcificación y todo el carbono inorgánico disuelto es precipitado, entonces el valor de $\delta^{18} \mathrm{O}$ depende del $\mathrm{pH}$ y esto podría explicar los valores de $\delta^{18} \mathrm{O}$ superiores al equilibrio en las especies más pequeñas. Sin embargo, para explicar un rango interespecífico de valores isotópicos del $5 \%$, deberían darse variaciones de $\mathrm{pH}$ de casi 4 unidades, por lo que, es más lógico considerar que el efecto del $\mathrm{pH}$ sea mínimo y siempre superpuesto a otros efectos.

Una mejor comprensión de la influencia de cada uno de estas variables en las variaciones isotópicas interespecíficas pasaría por la integración de los tres factores potenciales en modelos numéricos que consideraran el fraccionamiento de isótopos estables y el crecimiento celular (Ziveri et al., 2003) como en los modelos ya desarrollados para el caso de la materia orgánica de las algas (Keller y Morel, 1999)

\subsubsection{Aplicación paleoceanográfica de los isótopos estables de cocolitos}

La confirmación de un amplio rango de efectos vitales interespecíficos tanto para los isótopos de oxígeno como para los de carbono (Dudley et al., 1986; Ziveri et al.,2003) implica que cualquier cambio en la composición de la asociación de cocolitóforos supondría una variación de los valores isotópicos de la fracción poliespecífica de cocolitos que podría enmascarar la señal debida a los cambios en la temperatura y la composición isotópica del agua marina y dificultaría discriminar el efecto de la variabilidad oceánica.

Pero si la magnitud de los efectos vitales de las diferentes especies es calculada mediante cultivos de laboratorio, entonces, se pueden determinar factores de corrección para los registros isotópicos obtenidos a partir de muestras poliespecíficas dominadas por cocolitos, siempre que la contribución al carbonato de otros organismos sea restringida, y que la asociación sea previamente cuantificada (Dudley y Goodney, 1979). Dudley et al. (1989) calcularon ecuaciones de paleotemperatura y determinaron los primeros factores de corrección para los isótopos de oxígeno de diferentes especies, mientras que Ziveri et al. (2003), confirmaron lo anterior, y aportaron los primeros factores de corrección para el caso del carbono, aunque estas correcciones no pueden ser aplicadas a las especies extintas.

Los estudios de los efectos vitales de las mismas especies aisladas en un amplio rango de localizaciones oceanográficas e incluso con grandes diferencias en la calcificación y la tasa de división celular, muestran una alta constancia en los valores, lo que demuestra que los valores de los efectos vitales de una misma especie varían en mucha menor medida (1\%) (Rosenthal et al., 2000; Ziveri et 
al., 2003) que los interespecíficos (5\%). Sin embargo, cambios en la bioquímica de la célula derivados de cambios en el $\mathrm{pH}$ o los nutrientes del agua, pueden provocar algunas variaciones en los efectos vitales, y deben ser estudiados con mayor detalle.

Lejos de ser una limitación, los efectos vitales sirven en sí mismos como valiosos indicadores paleoceanográficos (Lea et al., 1999; Spero et al., 1997) y pueden proporcionar información sobre la ecología de los cocolitóforos y los procesos biológicos en los que toman parte. Por ello, una vez confirmada la homogeneidad en los efectos vitales de una misma especie, la aplicación fiable del estudio de isótopos estables en cocolitos en la reconstrucción paleoceanográfica pasa por el desarrollo de técnicas de separación de fracciones monoespecíficas de cocolitos o bien de factores de corrección para cada especie a partir de cultivos en laboratorio.

De hecho, nuevas técnicas de decantación sucesiva, columnas de densidad estratificada y microfiltración (Minoletti et al., 2001; Stoll y Ziveri, 2002) han permitido la separación de fracciones de cocolitos muy restringidas o casi monoespecíficas. Aunque estas nuevas técnicas requieren mucho tiempo, evitan la necesidad de factores correctores para las asociaciones variables y suponen la mejor estrategia para el estudio de asociaciones extintas cuyos efectos vitales no pueden ser estudiados mediante cultivos. La separación de fracciones monoespecíficas ofrece además, por primera vez, la posibilidad de calibrar dos indicadores de temperatura a partir de dos medidas diferentes de un mismo organismo, es decir, la fase de carbono orgánica e inorgánica de la G. oceanica o E. huxleyi. En concreto, la tasa de subsaturación de las alquenonas y el isótopo estable del oxígeno.

Finalmente, si se confirma la relación entre el fraccionamiento isotópico y los procesos de calcificación y adquisición de carbono en cocolitóforos, los valores de los isótopos estables de los cocolitos del pasado podrían servir para entender los cambios de estos mecanismos en la historia geológica.

\subsection{Sr/Ca de los cocolitos como indicador de productividad}

El estroncio (Sr) presenta una carga y un radio iónico similar al del calcio, y es por ello que puede substituir a éste en la molécula del carbonato. Estudios en calcitas no biogénicas mostraron una fuerte correlación entre las tasas de crecimiento de los cristales y los ratios de $\mathrm{Sr} / \mathrm{Ca}$ (Lorens, 1981; Tesoriero y Pankow, 1996). Esta idea sirvió de base para el estudio pionero de Stoll y Schrag (2000) sobre el $\mathrm{Sr} / \mathrm{Ca}$ en la calcita de los cocolitos, en el que se propuso que el ratio $\mathrm{Sr} / \mathrm{Ca}$ podía reflejar la tasa de produción de cocolitos, correlacionada con la tasa de crecimiento celular, y servir así como indicador de la paleoproductividad de los cocolitóforos. 
Los estudios de sedimentos superficiales presentados en Stoll y Schrag (2000), fueron realizados en zonas de surgencia que presentan marcados gradientes de productividad y muestran que los ratios $\mathrm{Sr} / \mathrm{Ca}$ de la fracción dominada por cocolitos $(2,0$ a 2,4 $\mathrm{mmol} / \mathrm{mol})$ alcanzan valores hasta dos veces superiores a los de la fracción dominada por foraminíferos $(1,2 \mathrm{mmol} / \mathrm{mol})$ y que además, el rango de variabilidad del ratio $\mathrm{Sr} / \mathrm{Ca}$ es mucho mayor para los cocolitos (15\%) que para los foraminíferos (2 \%). La mayor variabilidad del $\mathrm{Sr} / \mathrm{Ca}$ de los cocolitos respecto al de los foraminíferos queda confirmada también en registros sedimentarios del Cuaternario (Stoll y Schrag, 2001) y el Paleoceno (Stoll y Bains, 2003), aunque no ha podido corroborarse en cultivos de laboratorio al no existir mediciones de $\mathrm{Sr} / \mathrm{Ca}$ para foraminíferos cultivados. Puesto que el ratio $\mathrm{Sr} / \mathrm{Ca}$ de los foraminíferos es mucho menor que el de los cocolitos, estudios en la fracción $\leq 20 \mu \mathrm{m}$ han de tomar medidas para minimizar la presencia de fragmentos de foraminíferos.

\begin{tabular}{|c|c|c|c|c|}
\hline Especie & $\begin{array}{l}\text { Factor } \\
\text { limitante }\end{array}$ & $\begin{array}{c}\text { Tasa de } \\
\text { crecimiento } \\
\text { (divisiones/día) }\end{array}$ & $\begin{array}{c}\mathrm{Sr} / \mathrm{Ca} \\
(\mathrm{mmol} / \mathrm{mol})\end{array}$ & Estudio \\
\hline E. huxleyi & Luz (cultivo) & $0,1-1,6$ & $\begin{array}{c}2,8-3,05 \\
(10 \%)\end{array}$ & Stoll et al., 2002a \\
\hline E. huxleyi & $\begin{array}{l}\text { Nutrientes } \\
\text { (cultivo) }\end{array}$ & $0,03-1,1$ & $\begin{array}{c}0,85-5 \\
(600 \%)\end{array}$ & Rickaby et al., 2002 \\
\hline G. oceanica & $\begin{array}{l}\text { ¿Nutrientes? } \\
\text { (Sedimentos) }\end{array}$ & $0,3-0,4$ & $\begin{array}{l}2,01-2,15 \\
\quad(6 \%)\end{array}$ & Stoll et al., 2002b \\
\hline
\end{tabular}

Tabla 4.4. Relaciones entre Sr/Ca y la tasa de crecimiento celular. Basada en Stoll y Ziveri, 2004.

Tanto los estudios con cultivos en laboratorio como los de sedimentos superficiales y registros sedimentarios han servido para la calibración de la señal de $\mathrm{Sr} / \mathrm{Ca}$ y confirman que altos ratios $\mathrm{Sr} / \mathrm{Ca}$ están correlacionados con incrementos de la tasa de crecimiento en respuesta a una mayor concentración de nutrientes, y por tanto, relacionados con periodos de aumento de la productividad de los cocolitóforos (Rickaby et al., 2002; Stoll et al., 2007b; 2002a; 2002b; 2007). De hecho, la correlación del ratio $\mathrm{Sr} / \mathrm{Ca}$ con la tasa de crecimiento celular es diferente según cuál sea el factor limitante del crecimiento en el cultivo, de modo que, si el factor limitante es la luminosidad, grandes incrementos ( 0,1 a 1,6 divisiones/día) en la tasa de crecimiento celular presentan respuestas modestas (10\%) del ratio $\mathrm{Sr} / \mathrm{Ca}$ (Stoll et al.,2002a; 2002b), mientras que si son los nutrientes el factor que regula el crecimiento celular, el ratio $\mathrm{Sr} / \mathrm{Ca}$ presenta un aumento de hasta el $600 \%$ (Rickaby et al., 2002).

Por otra parte, el ratio $\mathrm{Sr} / \mathrm{Ca}$ de las diferentes especies de cocolitos presenta diferencias tanto en los valores como en el rango de variabilidad (Stoll et al., 2007a), en concreto, los ratios $\mathrm{Sr} / \mathrm{Ca}$ de cocolitos pequeños como G. oceanica o $F$. profunda muestran una variabilidad entre el 6 y el $15 \%$ mientras que cocolitos mayores como los de C. leptoporus pueden ser más variables (23-55 \%) (Stoll et al. 2002b). 
El método pionero de selección picking de cocolitos individuales para su análisis en sonda iónica (Stoll et al., 2007a) ha permitido la determinación del ratio $\mathrm{Sr} / \mathrm{Ca}$ de muestras completamente monoespecífcas. Aplicando dicho método Auliaherliaty et al. (2009) han confirmado que los cocolitos de especies de mayor tamaño como Helicosphaera carteri y Calcidiscus leptoporus muestran, valores más altos y variables que los de especies más pequeñas como Emiliania huxleyi.

\subsubsection{Influencias secundarias en el $\mathrm{Sr} / \mathrm{Ca}$ de los cocolitos}

En cuanto a las influencias secundarias en el ratio $\mathrm{Sr} / \mathrm{Ca}$, su importancia es muy diferente. Por una parte, el ratio $\mathrm{Sr} / \mathrm{Ca}$ del agua del mar es homogéneo a lo largo de los diferentes océanos (de Villiers, 1999) y sólo registros superiores a $10^{6}$ años precisarían correcciones (Stoll et al., 1999).

Por el contrario, los cultivos de laboratorio revelan una significativa influencia de la temperatura en el ratio $\mathrm{Sr} / \mathrm{Ca}$ de los cocolitos, que aumenta un $1 \%$ por grado centígrado (Stoll et al., 2002a; 2002b), relación similar a la de las calcitas no biogénicas (Malone y Baker, 1999) y a la de los foraminíferos planctónicos (Lea et al., 1999).

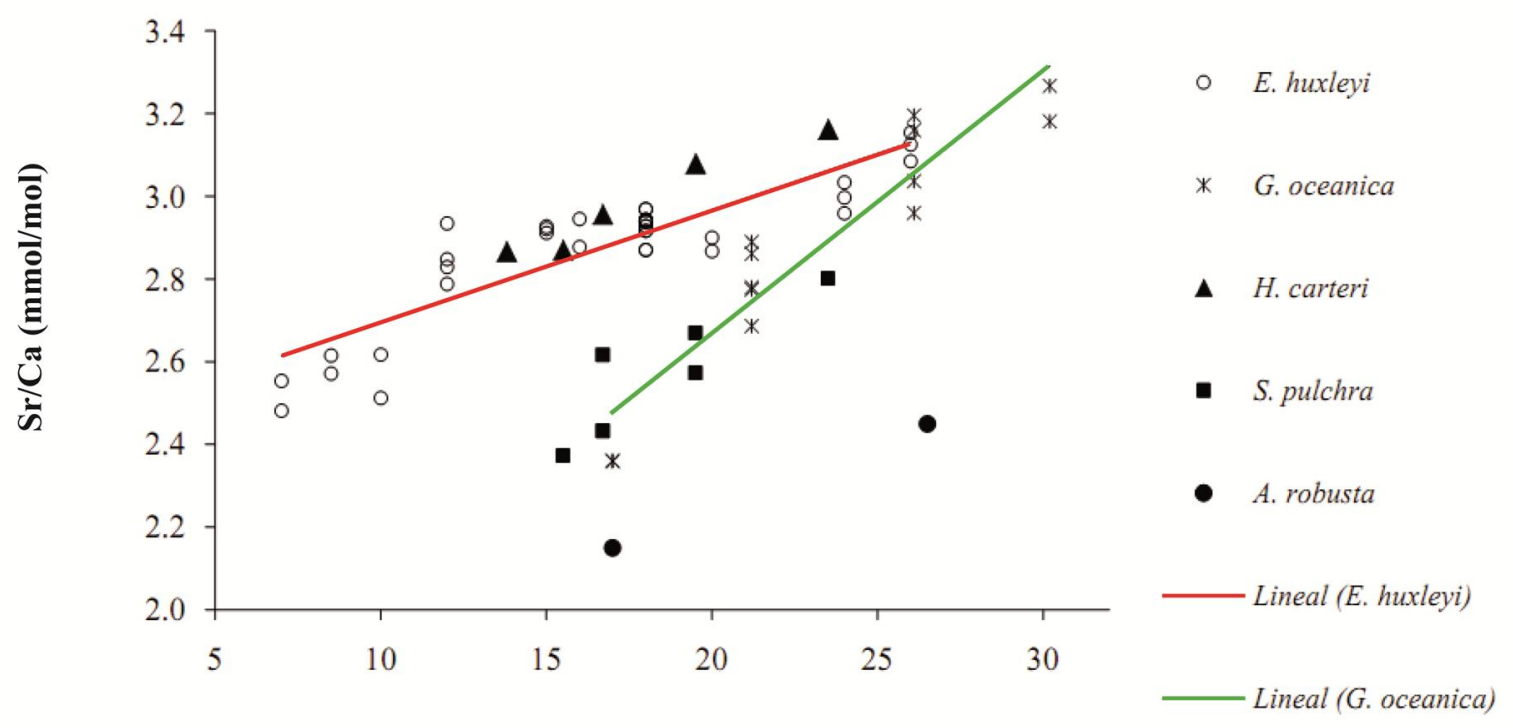

Temperatura $\left({ }^{\circ} \mathrm{C}\right)$

Figura 4.8. Valores de $\mathrm{Sr} / \mathrm{Ca}$ versus temperatura a partir de cultivos de cinco especies de cocolitóforos. Las líneas de tendencia corresponden a G. oceanica, que muestra la mayor pendiente y a E. huxleyi, con la menor. Adaptada de Stoll et al., 2002.

La influencia de la temperatura en el ratio $\mathrm{Sr} / \mathrm{Ca}$ de los cocolitos varía notablemente de unas especies a otras, de modo que el ratio $\mathrm{Sr} / \mathrm{Ca}$ de E. huxleyi presenta la menor dependencia termodinámica, mientras que G. oceanica muestra la pendiente más pronunciada (Fig. 4.8). Por tanto, el efecto de la temperatura en los $\mathrm{Sr} / \mathrm{Ca}$ ratios debe ser corregido para poder obtener el componente de la señal que puede ser atribuido a la productividad. 


\subsubsection{Aplicación paleoceanográfica del $\mathrm{Sr} / \mathrm{Ca}$ de cocolitos}

Una de las ventajas del ratio $\mathrm{Sr} / \mathrm{Ca}$ de los cocolitos respecto a otros indicadores clásicos de productividad, como el ópalo, el carbono orgánico o el carbonato, es que su uso no depende de la determinación de la tasa de acumulación y por tanto, no se verá afectado por una preservación diferencial de los materiales biogénicos.

Estudios recientes (D.Simon-Baile et al., para ser enviado, Stoll et al., enviado) confirman que la contribución de la temperatura en la variabilidad del $\mathrm{Sr} / \mathrm{Ca}$ es mucho menor que la de la productividad, y que su alcance puede ser calculado y corregido con el uso de indicadores independientes de paleotemperatura, de modo que no suponga una limitación en la determinación de la productividad a partir del $\mathrm{Sr} / \mathrm{Ca}$.

Por otra parte, aunque los cocolitóforos no son generalmente los mayores productores de carbono orgánico en las aguas superficiales, sin embargo, sí son los productores dominantes de carbonato. Puesto que la eficiencia en el transporte de carbono orgánico hasta el fondo oceánico viene controlada por el flujo de carbonato (Francois et al., 2002), cambios en la productividad de los cocolitóforos podrían ejercer un impacto importante en el flujo del carbono orgánico de una determinada región (Stoll y Ziveri, 2004). 



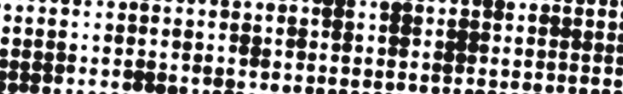

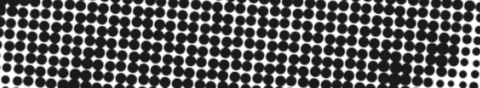

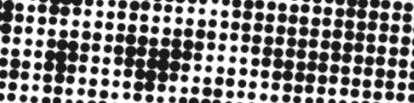

Capítulo 5:

Metodologia 

En este capítulo se explica en detalle la técnica de separación de fracciones de cocolitos que se decidió ampliar al ser parte esencial de la metodología aplicada en la tesis. El resto de metodología se describe en los apartados de methods correspondientes a cada uno de los artículos que se presentarán posteriormente.

\subsection{Separación de fracciones de cocolitos}

La metodología relativa al proceso de separación y concentración de fracciones de cocolitos de diferentes tamaños para su posterior análisis geoquímico incluye una preparación y limpieza de muestras, previa al propio proceso de separación de fracciones. Los procesos de limpieza de muestras y separación de fracciones se realizaron íntegramente en el laboratorio del Instituto de Ciencia y Tecnología Ambiental de la Universidad Autónoma de Barcelona según la técnica propuesta por Stoll y Ziveri (2002) y la técnica auxiliar de microfiltración (Minoletti et al., 2001; Stoll y Bains, 2003).

\subsubsection{Reactivos químicos}

- Agua tamponada (buffer). Se disuelven 0,1 gramos de carbonato de sodio anhidro al 99,5\% en 1 litro de agua destilada. Se deja homogeneizar la mezcla durante al menos 90 minutos en un agitador magnético y posteriormente se filtra con la bomba de vacío, utilizando un filtro de celulosa de $0,45 \mu \mathrm{m}$ que elimine los posibles restos de cristales del carbonato. Esta disolución se utiliza en todas las fases y reactivos del proceso como sustituta del agua destilada, se pretende con ello evitar posibles disoluciones de la muestra.

- Solución "MNX". Se prepara a partir de 50 gramos de hydroxilamina hidroclorida que se disuelven en $400 \mathrm{ml}$ de $\mathrm{NH}_{4} \mathrm{OH}$ al $25 \%$ y $600 \mathrm{ml}$ de agua tamponada (buffer). Esta es una solución reductora con la que se favorece el intercambio de iones.

- Solución "IONX". Consiste en la disolución de $65 \mathrm{ml} \mathrm{de} \mathrm{NH}_{4} \mathrm{OH}$ al $25 \%$ en 1 litro de agua tamponada. En una primera fase de 24 horas sirve para favorecer el intercambio iónico, aunque también será la solución utilizada durante todo el proceso de decantaciones sucesivas por considerarse un buen dispersante.

- Hipoclorito sódico ( $\mathrm{NaClO})$ al $3 \%$ (lejía) y peroxido de hidrógeno $\left(\mathrm{H}_{2} \mathrm{O}_{2}\right)$ al $30 \%$. Ambos reactivos se utilizan en la oxidación de la materia orgánica presente en la muestra.

- Ácido nítrico al $10 \%$ y solución de amoniaco al 0,2\%. Estos dos reactivos se utilizan en la limpieza del material utilizado en la filtración y microfiltración. El ácido nítrico destruye los restos de carbonato de la muestra anterior mientras que el amoniaco actúa como una base y equilibra el pH resultante de la limpieza con ácido, evitando así la disolución de la muestra siguiente.

- Etanol o metanol absoluto, utilizado para el almacenamiento de muestras. Evita la formación de agregados debidos al desarrollo bacteriano. 

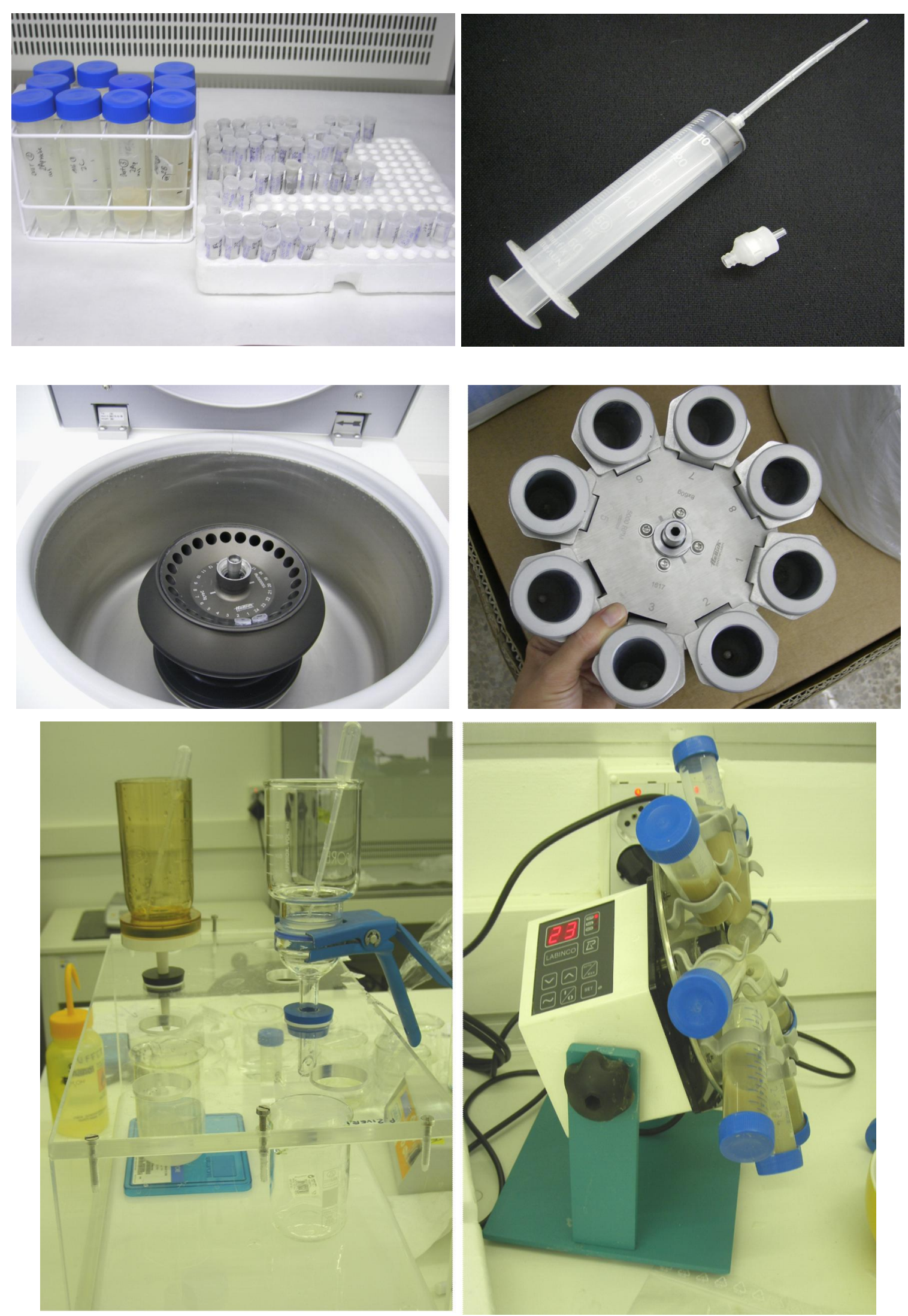

Figura 5.1. Tubos de polipropileno $(50 \mathrm{ml})$ y microtubos Eppendorf $(1,5 \mathrm{ml})$. Jeringa de polipropileno y adaptador de filtro de $10 \mathrm{~mm}$ de diámetro. Centrífuga con doble adaptador para tubos de $50 \mathrm{ml}$ y microtubos Eppendorf. Sistemas de filtración y agitador multimixer de $35 \mathrm{~cm}$ de diámetro, estilo Luckham MM1. 


\subsubsection{Preparación y limpieza de muestras}

Una de las limitaciones más importantes en la separación de fracciones restringidas de cocolitos es la formación de agregados, ya que las partículas con diámetro menor a $10 \mu \mathrm{m}$ de los sedimentos finos bien clasificados tienden a cohesionar y formar agregados (McCave et al., 1995). Sin embargo, las técnicas químicas y mecánicas más comunes en la minimización de agregados pueden dañar a los frágiles cocolitos. Por ejemplo, el uso de polifosfato sódico (0,1M Calgon), el dispersante de sedimentos de uso más común, resultaría enormemente corrosivo para las finas partículas de carbonato cálcico de los cocolitos, pudiendo llegar a disolver hasta $500 \mathrm{mg}$ de este carbonato por litro.

Con el fin de minimizar la formación de agregados preservando la frágil estructura de los cocolitos, se han sometido a las muestras a diferentes procesos. En primer lugar y anterior a la limpieza de las muestras, éstas fueron liofilizadas mediante un freeze-dryer o liofilizador Telstar Cryodos. El freezedrying elimina el agua de la muestra por sublimación en condiciones de vacío lo cual facilita el almacenamiento de la muestra, es necesario para pesar el sedimento seco y sobre todo, ayuda en la minimización de agregados (Charm, 1967).

Además del proceso habitual de oxidación de materia orgánica mediante peróxido de oxígeno e hipoclorito sódico (Bairbakhish et al., 1999), se optó por utilizar una solución de amoniaco al $2 \%$ (IONX), la cual favorece una alta dispersión de las partículas (Stoll y Ziveri, 2002).

Respecto a las técnicas mecánicas, los ultrasonidos son la más generalizada. Sin embargo, el uso de tiempos superiores a 60 segundos aumenta sustancialmente la fragmentación mientras que tiempos más cortos, no son suficientemente efectivos en la ruptura de agregados. Por otra parte, se ha comprobado que el uso de un carrusel rotativo en el que los tubos siguen un recorrido circular en el plano vertical a una velocidad entre 23 y $28 \mathrm{rpm}$ (revoluciones por minuto) durante 24 horas obtiene altas eficacias en la reducción del número de agregados sin dañar la estructura de los cocolitos (Nick McCave, comunicación personal, 2000). Por ello, se ha optado por combinar ultrasonidos en tiempos inferiores a 15 segundos con el carrusel rotativo durante 24 horas para las soluciones "MNX" e "IONX".

Los pasos a seguir en la preparación y limpieza de muestras serían los siguientes:

- Pesar en una balanza de precisión una cantidad aproximada de 0,6 gramos de sedimento seco para cada una de las muestras e introducirla en tubos de $50 \mathrm{ml}$ de polipropileno transparente con fondo cónico e indicados para pruebas con centrifugación.

- Añadir a cada tubo $3 \mathrm{ml}$ de agua tamponada. Homogeneizar el contenido del tubo y tomar una pequeña gota con la jeringa previamente llena con 2 ó $3 \mathrm{ml}$ de agua tamponada. Cambiar la 
punta de la jeringa por el adaptador de filtro, filtrar el contenido total de la jeringa y extraer el pequeño filtro de $10 \mathrm{~mm}$ de diámetro y $0,45 \mu \mathrm{m}$ de tamaño de poro para ser secado en el horno $\left(2\right.$ horas a $40{ }^{\circ} \mathrm{C}$ ). Una mitad del filtro se monta sobre un portaobjetos, se añade una gota de aceite de inmersión para hacerlo transparente y se coloca el cubreobjetos, quedando listo para su observación al microscopio óptico.

- Añadir $3 \mathrm{ml}$ de hipoclorito sódico (lejía) al $3 \%$, esperar unos segundos a que remita el burbujeo de la reacción y añadir otros $3 \mathrm{ml}$ de peroxido de hidrógeno al $30 \%$. Llevar al ultrasonidos entre 10 y 15 segundos y esperar 15 minutos. A continuación, añadir $1 \mathrm{ml}$ más de hipoclorito sódico, someter la muestra a ultrasonidos 10 ó 15 segundos y esperar de nuevo 15 min. Repetir este paso tres veces. Con esta fase se oxida la materia orgánica contenida en la muestra y se minimiza la formación de agregados, además se extraen los metales que no forman parte del carbonato.

- Filtrar el contenido del tubo (muestra $+3 \mathrm{ml}$ agua tamponada $+6 \mathrm{ml}$ lejía $+3 \mathrm{ml} \mathrm{H}_{2} \mathrm{O}_{2}$ ) a través de un filtro de celulosa de $47 \mathrm{~mm}$ de diámetro y $0,8 \mu \mathrm{m}$ de tamaño de poro colocado en un sistema de filtración conectado a una bomba de vacío.

- Recuperar el contenido del filtro de $0,8 \mu \mathrm{m}$ y trasvasarlo al tamiz de plástico con tamaño de poro de $20 \mu \mathrm{m}$. Este tamizado se realiza con agua tamponada y sirve para separar la fracción fina y eliminar de ella los foraminíferos o fragmentos de éstos. La fracción $>20 \mu \mathrm{m}$ se recupera y tras centrifugarla, se almacena en un microtubo Eppendorf de 1,5 $\mathrm{ml}$ con etanol.

- Recuperar la fracción fina $(<20 \mu \mathrm{m})$ y filtrarla de nuevo a través de un filtro de $0,8 \mu \mathrm{m}$. En este caso, la cantidad de líquido a filtrar puede ser de entre 100 y $200 \mathrm{ml}$, y la velocidad de filtración dependerá de la cantidad de partículas finas de la muestra. Si ésta es muy abundante, como en el caso de las muestras de Alborán, la filtración puede llevar casi un día y supondrá el uso de varios filtros, ya que éstos se saturan con más facilidad. Por otra parte, la eficiencia de la bomba disminuye con el tiempo al calentarse el agua de la misma, con lo que debemos sustituir continuamente esta agua por otra fría.

- Recuperar el material del filtro de $0,8 \mu \mathrm{m}$ y trasvasarlo a un tubo de $50 \mathrm{ml}$ que rellenaremos con solución MNX. Colocar el tubo en el agitador multimixer durante 24 horas. El carácter reductivo de la solución MNX favorece el intercambio iónico y actúa sobre las oxihidroxidas de Fe-Mn que toman los metales del agua marina.

- Centrifugar el tubo con MNX y extraer la fracción sobrenadante. Rellenar el mismo tubo con solución IONX y colocar de nuevo en el agitador multimixer durante otras 24 horas. Esta solución IONX se encarga de eliminar el estroncio adsorbido, además, constituye un buen dispersante para la fase de separación. Una vez transcurridas las 24 horas en el agitador, la muestra está lista para comenzar las decantaciones sucesivas. 


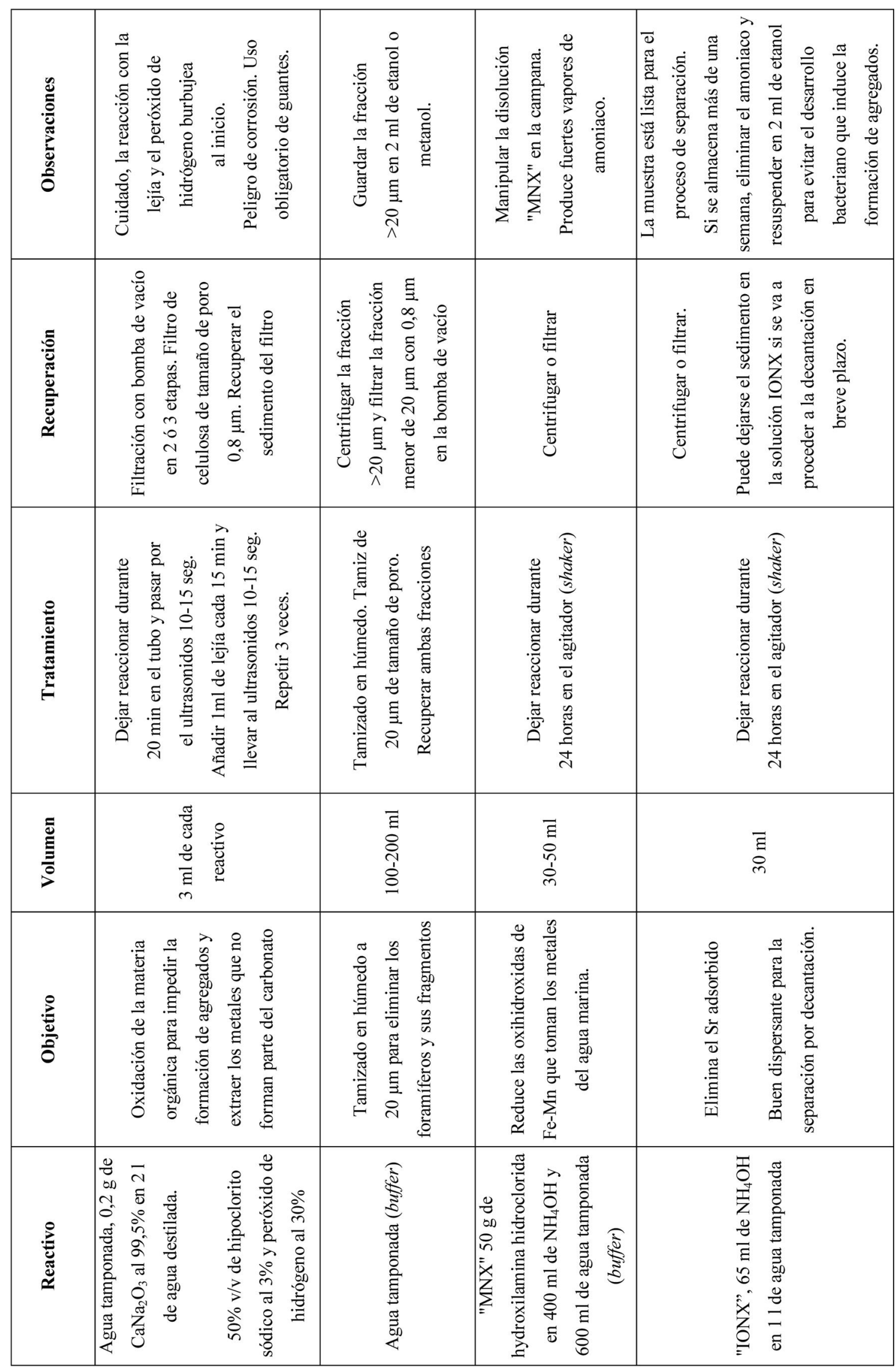




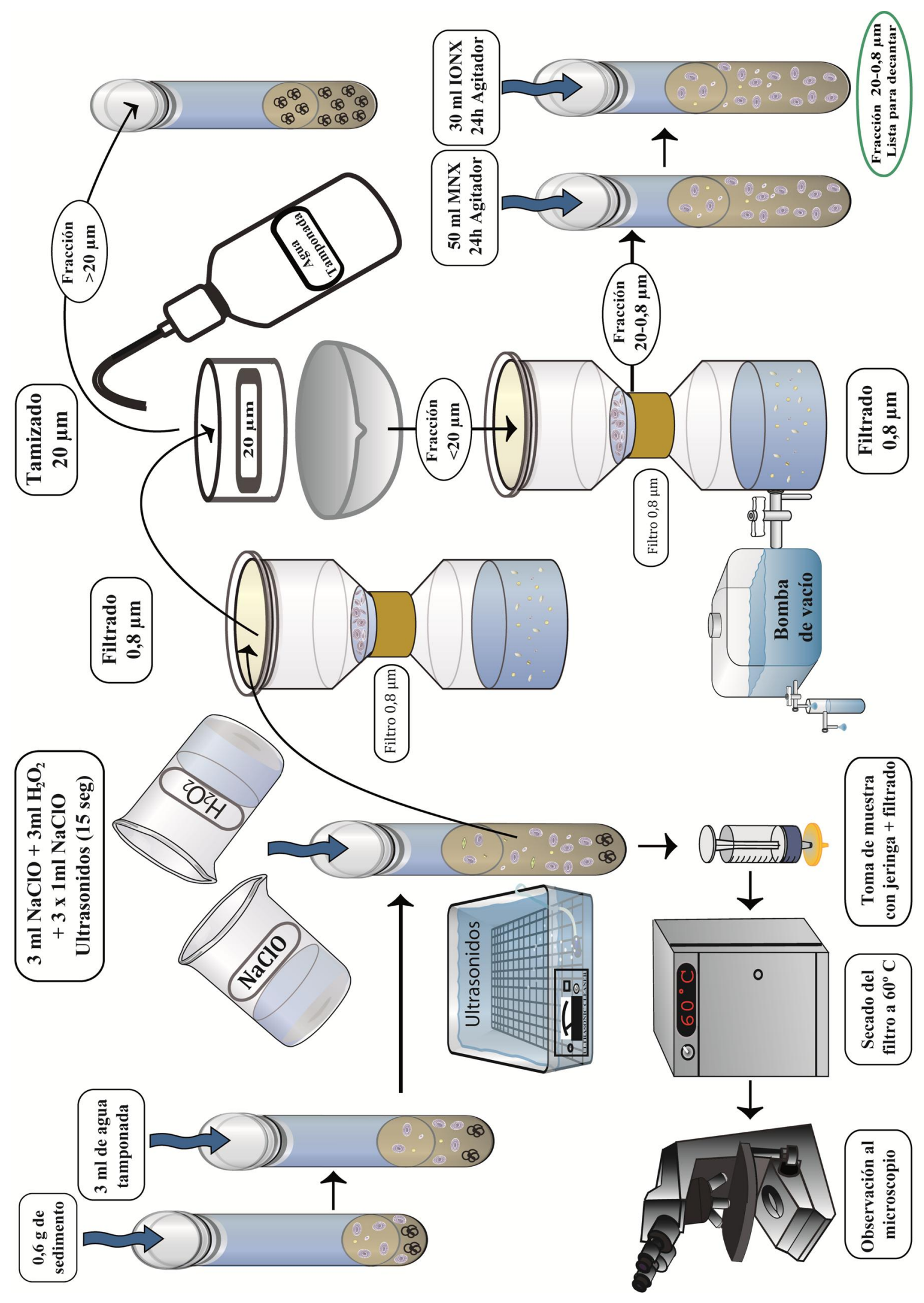

Figura 5.2. Esquema del proceso de preparación y limpieza de muestras para la separación de cocolitos. Tabla 5.1. Resumen del proceso de preparación y limpieza de muestras (página 71). 


\subsubsection{Antecedentes y mejoras en los métodos de separación}

Paull y Thierstein (1987) intentaron separar la fracción de carbonato menor de $38 \mu \mathrm{m}$ en diferentes subfracciones utilizando dispositivos automáticos de decantación como el Coulter counter, que es un aparato que sirve para contar partículas y cuantificar su tamaño. Los resultados del Coulter counter para la distribución de tamaños indicaron la existencia de cinco fracciones de composición distinta comprendidas entre los rangos de 2 y $32 \mu \mathrm{m}$. Las tres fracciones menores estaban dominadas por diferentes especies de cocolitos: G. oceanica, G. caribbeanica más E. huxleyi y F. profunda respectivamente. En cada fracción, la dominancia de las especies suponía entre un 50 y un $60 \%$ de la abundancia relativa, si bien, el porcentaje de carbonato de cada especie en su fracción correspondiente era menor y por tanto, la separación no resultaba útil para análisis geoquímicos.

Por ello, la separación de fracciones de cocolitos en el presente trabajo se basa en la novedosa metodología expuesta en Stoll y Ziveri (2002), Minoletti et al. (2001) y Stoll y Bains (2003) y propone el uso de decantaciones sucesivas combinado con microfiltración mediante membranas de policarbonato, aportando varias mejoras tanto en el desarrollo como en el seguimiento del proceso.

Tanto las decantaciones sucesivas como la microfiltración son completamente manuales y no requieren instrumentación especializada más allá del uso de la centrifugadora para eliminar el sobrenadante de las fracciones y del sistema de filtración y las membranas de microfiltración durante la microfiltración. Las separaciones se realizan a partir de la fracción fina $(20-0,8 \mu \mathrm{m})$ y se centran en el rango de tamaños menor, el comprendido entre 2 y 15 micras, al que pertenecen la mayoría de los cocolitos recientes.

Además de las modificaciones previas en la minimización de agregados, el método difiere en esencia de los métodos anteriores, ya que en lugar de separar todo el sedimento inicial en fracciones de diferente tamaño, se opta por tomar una subfracción de la columna de decantación en cada paso. Al final, la fracción seleccionada para una especie o grupo de especies de un tamaño determinado tendrá una cantidad de sedimento mucho menor que la que realmente existe en la fracción original, pero con este método se minimiza el número de pasos de la decantación con respecto a otros métodos.

En esencia, el objetivo de estas separaciones consiste en obtener una cantidad de sedimento suficiente para una fracción cuya contribución de carbonato esté dominada por una sola especie y contenga la menor cantidad de partículas que puedan interferir en la señal isotópica final. Según lo expuesto, en cada paso del proceso se selecciona la subfracción más adecuada para la separación de una especie aunque esa misma especie pueda estar presente también en alguna de las otras fracciones. 


\subsubsection{Calculo teórico del tiempo de decantación}

El fundamento teórico para los tiempos de las decantaciones se obtiene a partir de la ley de Stokes, basándose en las diferentes velocidades de decantación que presentan partículas con diferente morfología y tamaño. La ley se refiere a la fuerza de fricción experimentada por objetos esféricos moviéndose en el seno de un fluido viscoso en un régimen laminar. En general la ley de Stokes es válida en el movimiento de partículas esféricas pequeñas moviéndose a velocidades bajas.

Si las partículas están cayendo verticalmente en un fluido viscoso debido a su propio peso puede calcularse su velocidad de sedimentación igualando la fuerza de fricción con la de gravedad.

$$
V_{s}=\frac{2}{9} \frac{r^{2} g\left(\rho_{p}-\rho_{f}\right)}{\eta} \quad \text { donde }
$$

$V_{s}$ es la velocidad de caída de las partículas (velocidad límite)

$g$ es la aceleración de la gravedad

$\rho_{p}$ es la densidad de las partículas

$\rho_{f}$ es la densidad del fluido.

$\eta$ es la viscosidad del fluido y

$r$ es el radio de la esfera

Para el presente trabajo se realizaron cálculos teóricos de la distribución de partículas según tamaños para los distintos pasos de la decantación. Los cálculos se hicieron a partir de la ley de Stokes considerando como fluido el agua a $20^{\circ} \mathrm{C}$ y expresando los diámetros en micras de ESD (diámetro esférico equivalente). Estos cálculos se toman como una aproximación de los tiempos de sedimentación para los diferentes tamaños de las partículas. Puesto que la ley de Stokes se aplica a partículas esféricas, nuestra aproximación ha de considerar además las diferentes morfologías y reconocer que, por ejemplo, el tiempo de sedimentación de una partícula esférica de $10 \mu \mathrm{m}$ de diámetro será equivalente al tiempo de sedimentación de una partícula de morfología plana y un diámetro superior a $10 \mu \mathrm{m}$.

Aunque estos cálculos ofrezcan una idea orientativa de la distribución de tamaños para cada paso de la decantación, no debemos olvidar el carácter teórico de los mismos, ya que el porcentaje de partículas calculado para cada tamaño no se corresponde con la distribución real de tamaños en la muestra. Esto sólo se cumpliría si la muestra original presentara una distribución de partículas uniforme para cada uno de los tamaños, lo cual es poco frecuente. De hecho, la distribución de tamaños de las asociaciones de cocolitóforos suelen presentar los mayores porcentajes para las especies de menor tamaño y porcentajes mucho menores para las especies más grandes. 

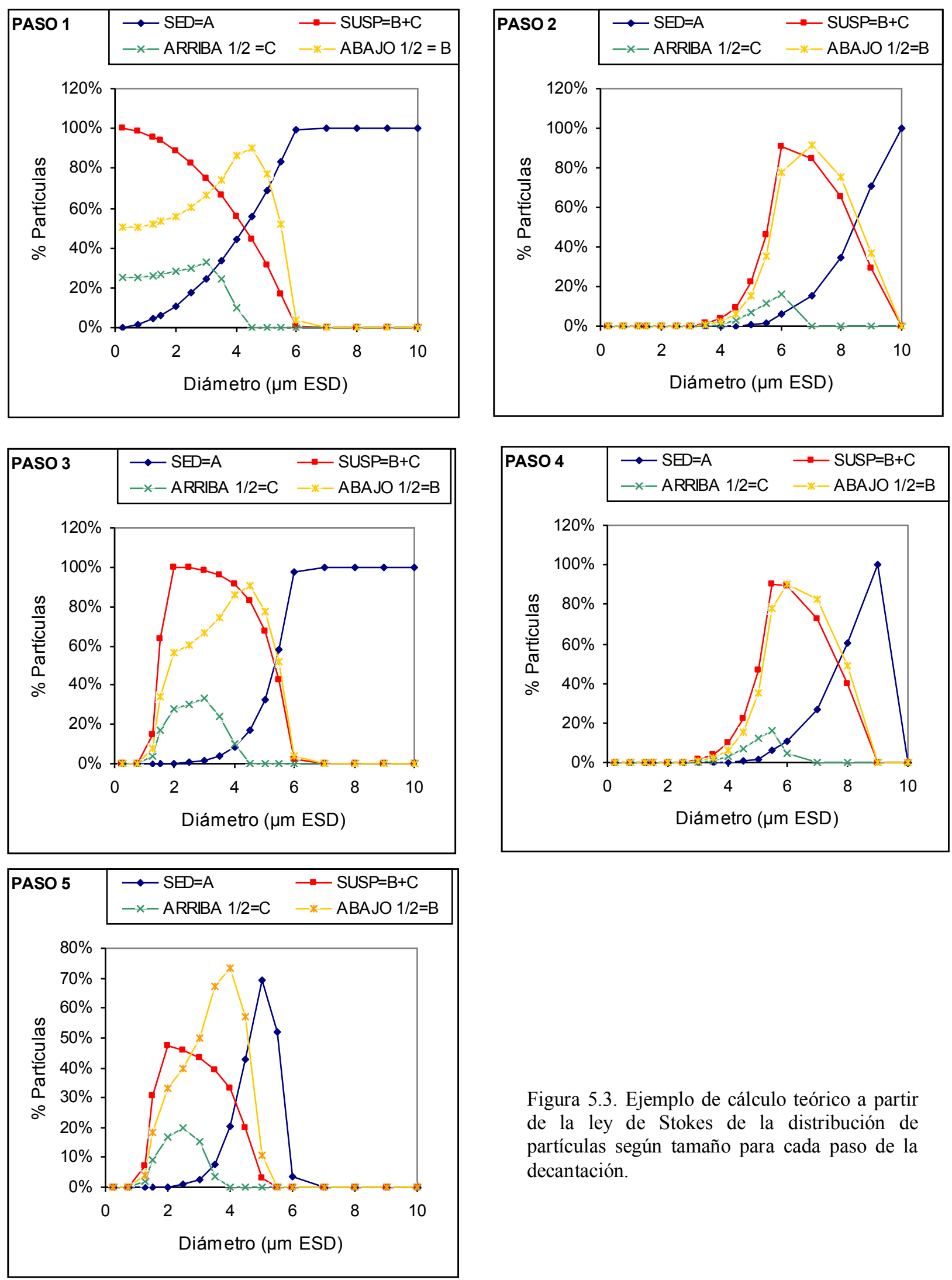

Figura 5.3. Ejemplo de cálculo teórico a partir de la ley de Stokes de la distribución de partículas según tamaño para cada paso de la decantación. 


\subsubsection{Decantaciones sucesivas}

Las decantaciones sucesivas se realizan manualmente dejando que una suspensión de $30 \mathrm{ml}$ decante en un tubo de centrifugado de $50 \mathrm{ml}$ y extrayendo las fracciones superiores mediante una jeringa en los tiempos seleccionados para cada paso. Los $30 \mathrm{ml}$ del tubo de centrifugado se corresponden con $5 \mathrm{~cm}$, que es la misma distancia de decantación para todos los pasos ya que utilizamos el mismo tipo de recipiente para todos ellos.

Tras cada paso de decantación, la muestra se subdivide en tres fracciones, el sedimento, denotado con la letra A, la mitad inferior de la suspensión (B) y la mitad superior de la suspensión (C).

Las fracciones sobrenadantes (B y C) se trasvasan cada una a un nuevo tubo de centrifugado. Todas las fracciones $\mathrm{B}$ y $\mathrm{C}$ resultantes de cada repetición se unen en su tubo correspondiente, y al final de la serie de repeticiones, los tubos con las fracciones B y C (que tendrán un volumen igual a $15 \mathrm{ml}$ por el número de repeticiones) se centrifugan para concentrar el sedimento y eliminar el sobrenadante.

El sedimento permanece en el tubo original de decantación y al inicio de cada repetición, se resuspende de nuevo con $30 \mathrm{ml}$ de solución IONX, que es la solución utilizada en todos los pasos de decantación. Se homogeneiza la muestra y se deja decantar el tiempo establecido, este proceso se repite varias veces. El número de repeticiones depende de la cantidad de sedimento de la fracción a decantar y de la fracción (sedimento o suspensión) que se pretenda concentrar, aunque suele oscilar entre 2 y 4 . El objetivo de las repeticiones es refinar el proceso de decantación resuspendiendo de nuevo partículas que podrían haber decantado en forma de agregados en una fracción diferente a la que le correspondería según su tamaño.

La selección de tiempos se basa en los cálculos teóricos a partir de la ley de Stokes, sin embargo, por sus limitaciones teóricas, requiere calibración experimental, por esto, a menudo se elige un tiempo de decantación y se realiza una sola repetición para comprobar si funciona, si las observaciones al microscopio confirman que ese tiempo de decantación es adecuado, entonces, se prosigue con más repeticiones del mismo paso.

Al finalizar cada paso de la decantación, se extrae una pequeña muestra de cada una de las fracciones resultantes (A, B y C) y se filtra con una jeringa a la que se adapta un filtro de $10 \mathrm{~mm}$ de diámetro que se deja secar al horno (ver preparación y limpieza de muestras punto 2). Este filtro se monta en un portaobjetos y se prepara para su observación al microscopio óptico.

Todo el proceso de separación requiere un trabajo simultáneo de observación al microscopio óptico, necesario para seleccionar la fracción o fracciones con las que se trabajará en los pasos sucesivos y para confirmar el éxito o no de la decantación. 


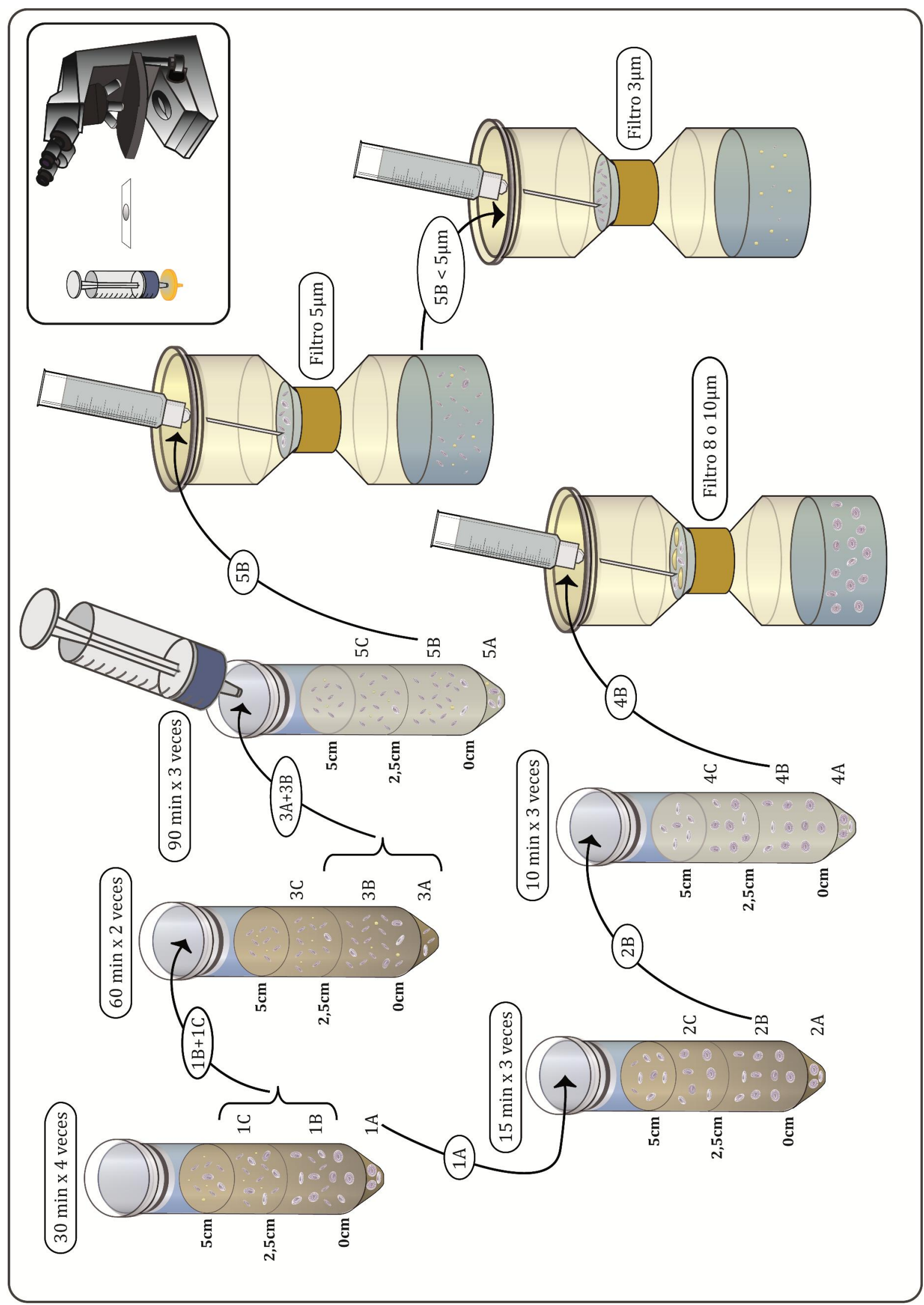

Figura 5.4. Esquema del proceso de separación de fracciones de cocolitos a partir de decantaciones sucesivas y microfiltración con membranas de policarbonato. 


\subsubsection{Microfiltración con membrana de policarbonato}

El método de decantaciones sucesivas se combina en su etapa final con el método de microfiltración. Normalmente, la microfiltración es la última etapa de la separación y sirve para refinar la fracción seleccionada del último paso de decantación.

Para la microfiltración se necesita un sistema de filtración adecuado y membranas de policarbonato especializadas de Millipore o Nuclepore de diferentes tamaños, en concreto, para los cocolitos recientes se utilizan los tamaños de $10,8,5$ y $3 \mu \mathrm{m}$.

La microfiltración requiere mucho tiempo, ya que los mejores resultados sólo se consiguen mediante continuas resuspensiones de la fracción superior. Para evitar que la membrana de policarbonato se sature añadimos una pequeña cantidad del sedimento a microfiltar y nos ayudamos de una pipeta Pasteur para resuspender la solución.

Es difícil calibrar la eficacia de la microfiltración por eso se continúa resuspendiendo hasta tener un volumen de aproximadamente $200 \mathrm{ml}$ en la fracción inferior. Por otra parte, la fracción de la que se parte para la microfiltración suele contener poco material al provenir de varios pasos de decantación, con lo que si filtramos un volumen de $200 \mathrm{ml}$, el sedimento se disolverá en él y será más difícil volver a concentrarlo, necesitando varias centrifugaciones sucesivas.

Si se realizan dos microfiltraciones sucesivas, por ejemplo, con 5 y 3 micras para obtener la fracción entre 5 y 3 micras, entonces, no serán necesarias estas centrifugaciones sucesivas ya que se recupera el sedimento directamente de la segunda membrana de policarbonato.

Al igual que para las decantaciones, al finalizar cada microfiltración, se toma una pequeña muestra de cada fracción y se prepara para observar al microscopio y comprobar la eficacia de la microfiltración.

\subsubsection{Consideraciones}

La observación al microscopio óptico de la muestra con la asociación original, nos dará idea de cuáles son las especies presentes y en que proporción, lo cual es básico para poder elegir los tiempos y número de repeticiones del proceso de decantaciones sucesivas, pero además nos informará de la presencia o no de partículas finas u otros elementos como los dinoflagelados, los cocolitos retrabajados o fragmentos de alguno de ellos. El éxito de la separación dependerá por tanto de diversos factores ligados o no a la asociación de cocolitóforos. 
En primer lugar, la separación final dependerá ulteriormente de las especies presentes en la asociación original pero sobre todo de la presencia de especies interferentes. Esto se refiere al grupo de especies con tamaños y morfologías parecidas, y que por tanto, decantarían a velocidades similares. Ejemplos clásicos son los casos de Calcidiscus leptoporus y Helicosphaera carteri para las especies de mayor tamaño $(9-6 \mu \mathrm{m})$ o de Emiliania huxleyi y Florisphera profunda para las especies de menor tamaño (5-3 $\mu \mathrm{m})$. Si una asociación presenta abundancias relativas semejantes para estos pares de especies, entonces la separación será más complicada o incluso no podrá llevarse a cabo de manera efectiva.

También han de separarse los cocolitos retrabajados por presentar valores isotópicos diferentes a los de los cocolitos actuales, sin embargo, la similitud de tamaños con los cocolitos actuales de mayor tamaño como Calcidiscus leptoporus, Helicosphaera carteri o incluso Coccolithus pelagicus, dificulta la separación.

Además de la composición de la asociación de nanofósiles, existen otros elementos que pueden complicar la separación. Una gran cantidad de partículas finas, además de ralentizar el proceso de filtrado durante la preparación de muestras, puede interferir con las especies de menor tamaño. Si su naturaleza es carbonatada será necesario eliminarlas para evitar una desviación de la señal isotópica. Para ello se requieren largas decantaciones que concentren estas partículas más finas en la fracción superior de la columna de decantación. Se han encontrado también dinoflagelados calcáreos (Thoracosphaera) en algunas de las fracciones de mayor tamaño (10-12 $\mu \mathrm{m})$. Estos dinoflagelados y sus fragmentos, deben ser separados de la fracción restringida ya que sus valores isotópicos difieren sustancialmente de los valores de los cocolitos. Normalmente pueden eliminarse de la fracción inferior o sedimento tras una decantación corta de unos 10 ó $12 \mathrm{~min}$, o de la fracción superior de una microfiltración con $10 \mu \mathrm{m}$.

\subsection{Análisis geoquímicos de isótopos estables y $\mathrm{Sr} / \mathrm{Ca}$}

Los análisis geoquímicos de isótopos estables y $\mathrm{Sr} / \mathrm{Ca}$ en las fracciones de cocolitos se explican en detalle en los apartados 7.3.1 y 8.3.1.

\subsection{Recuentos y estimación del carbonato de cocolitos}

Los recuentos de cocolitos y la estimación del carbonato tanto de las muestras originales como de las diferentes fracciones separadas se explica detalladamente en los apartados 7.3.2 y 8.3.2. 


\subsection{Estudios morfométricos de $C$. pelagicus y análisis factorial de datos morfométricos}

Los análisis morfométricos de la especie C. pelagicus se realizaron en el laboratorio de nanofósiles de la Universidad de Lisboa. No se realizaron mediciones del diámetro menor, ya que estudios anteriores (Parente, 2002) comprobaron la alta correlación entre el diámetro mayor y el menor $(\mathrm{R}=0,9714)$ medidos en un total de 3.479 cocolitos de $C$. pelagicus.

Para su posterior análisis estadístico, denominado Multivariate Morphon Analysis, las mediciones morfométricas fueron clasificadas en grupos de $1 \mu \mathrm{m}$ denominados morphons. Se utilizó el programa STATISTICA ${ }^{\circledR}$ versión 7 para realizar un análisis factorial de modo $\mathrm{R}$ sobre las mediciones morfométricas. El objetivo del análisis factorial es reducir el número de variables identificando los grupos de morphons con comportamiento correlacionable y combinándolos en factores que faciliten la interpretación de los datos originales. El modo R minimiza el efecto derivado de la comparación de morphons con un número elevado de especímenes con otros con un número muy bajo, y compara los morphons independientemente de su representatividad (Narciso et al., 2006). Además, se aplicó a los datos una rotación ortogonal varimax raw que rota los factores alineándolos con la dirección de máxima variabilidad y, maximiza la varianza.

En el apartado 9.3 se explica con mayor detalle la metodología referente a los estudios morfométricos de C. pelagicus y el análisis factorial de datos morfométricos. 


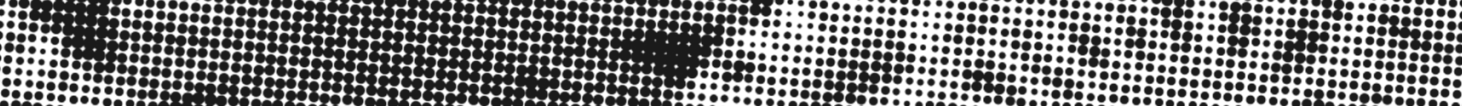

:

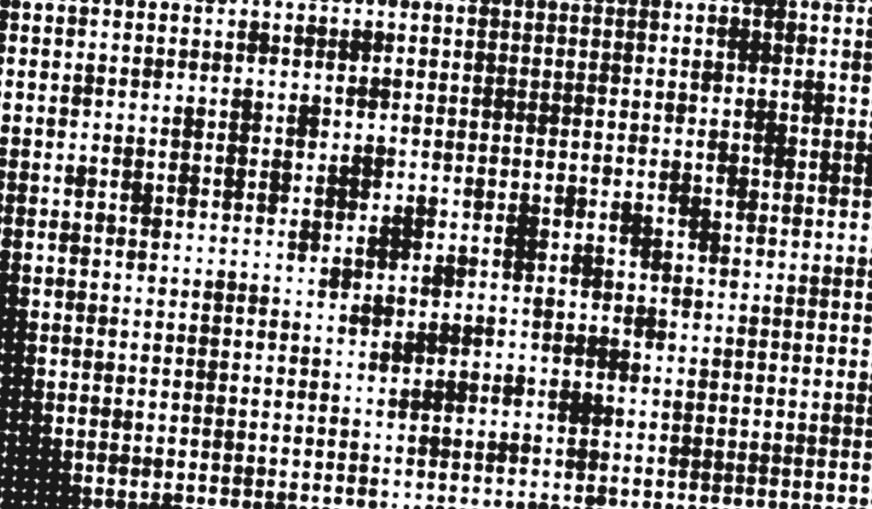

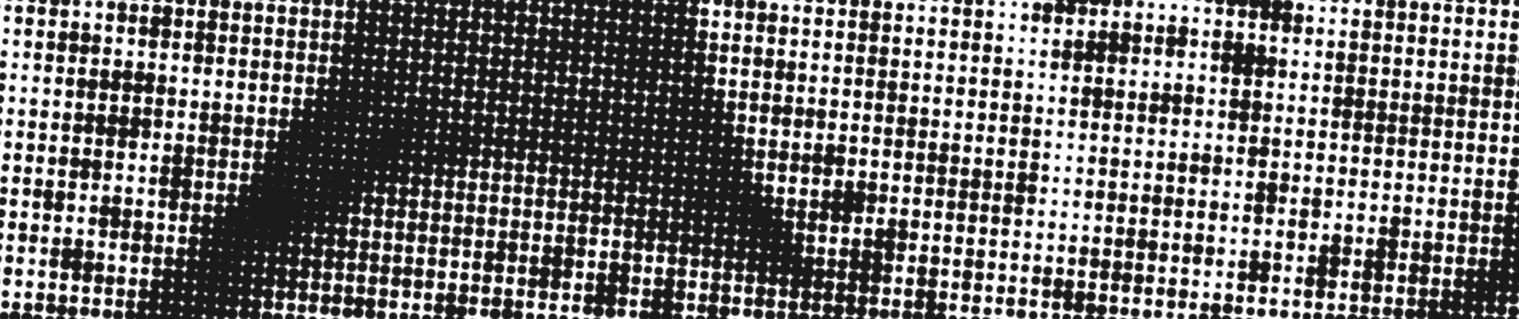

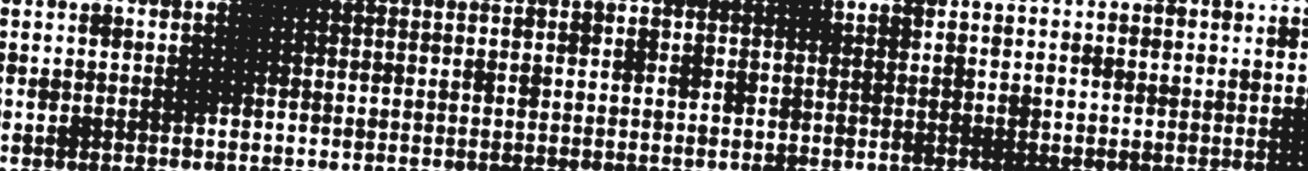

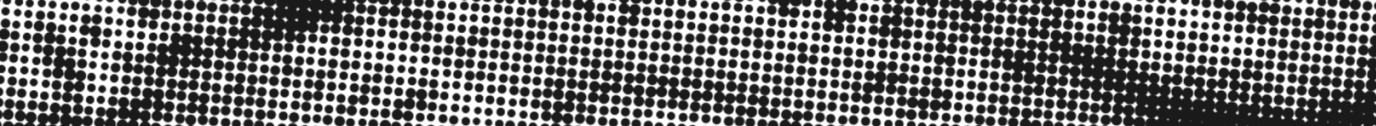

H.t.

H

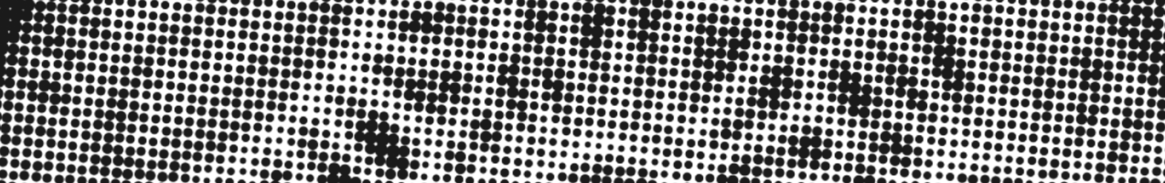

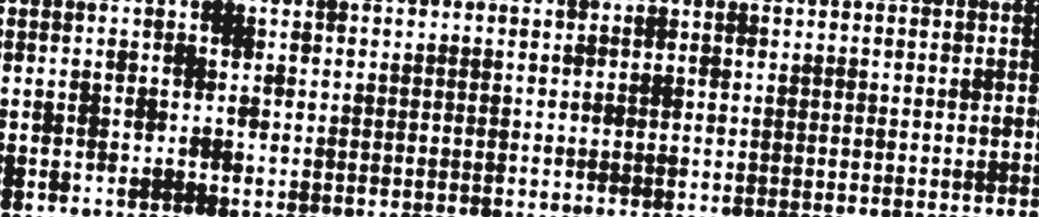

:

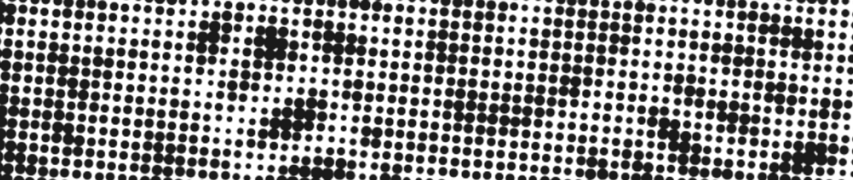

H.

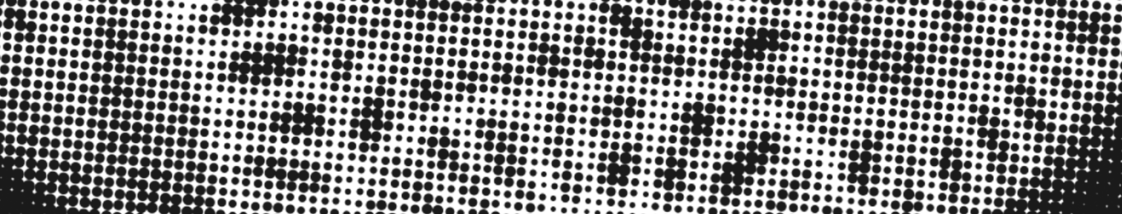

Hritom: 1

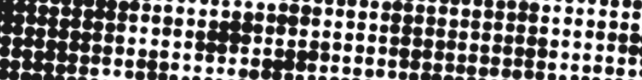

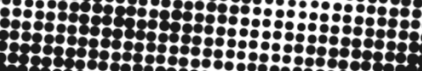
H:

H.t. TH:

Hิm:

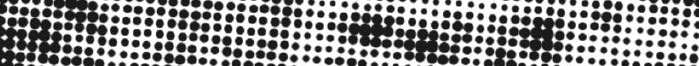

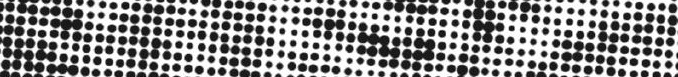

:

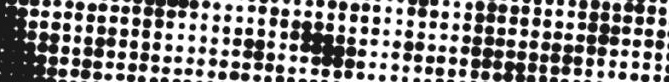
mim: TH

Capítulo 6:

Picking de cocolitos $y$ análisis de Sr/Ca en sonda iónica 



\subsection{Picking de cocolitos}

Además de la separación de cocolitos mediante la técnica combinada de decantaciones sucesivas y microfiltración, para el presente trabajo se realizó picking de cocolitos o selección de cocolitos individuales siguiendo la técnica descrita en (Stoll et al., 2007b). Los pasos a seguir son:

- $\quad$ Preparación de la muestra. Para ello, se prepara una suspensión del sedimento en etanol y se pipetea una gota sobre un portaobjetos extendiéndola con ayuda de la punta de la pipeta. La lámina se deja secar sin ser cubierta y se transporta horizontalmente. Para facilitar el picking posterior, la concentración del sedimento en la lámina ha de ser baja, en concreto, la distancia entre cocolitos ha de ser, al menos, el doble de su tamaño.

- $\quad$ Afilado de la aguja de tungsteno. Un pedazo de hilo de tungsteno se afila bajo una lámpara de alcohol al contacto con un cilindro sólido o stick de nitrato sódico para formar la aguja que se utilizará para el picking. Es muy importante obtener agujas de tungsteno muy afiladas, como ejemplo comparativo podría decirse que el hilo de tungsteno tiene el grosor de una mina de grafito de $0,5 \mathrm{~mm}$ y ha de afilarse hasta conseguir el grosor de un pelo humano.

- $\quad$ Alineación de la aguja. El picking se realiza bajo un microscopio invertido (Nikon Diaphot 300) al que se acopla un micromanipulador Narishige que puede moverse horizontal y verticalmente avanzando $250 \mu \mathrm{m}$ por cada giro de $360^{\circ}$ (Fig. 6.1). La aguja de tungsteno se coloca en un soporte que se acopla al micromanipulador y se centra con respecto al microscopio cambiando los objetivos desde el menor al de mayor aumento.

- $\quad$ Picking de cocolitos. El picking de cocolitos se realiza con un objetivo de 40x (Fig. 6.1), y bajo luz natural para poder ver la aguja, mientras que la identificación de los cocolitos, se realiza bajo luz polarizada y con un objetivo de mayor aumento.

Para el picking se utilizan dos láminas diferentes que se van alternando: la lámina con la muestra desde la que se tomarán los cocolitos y otra lámina "viscosa" o Tacky Dot (SPI Corp.) slide que contiene pequeños pozos viscosos o Tacky Dot wells de $75 \mu \mathrm{m}$ de diámetro donde se colocan los cocolitos seleccionados quedando adheridos. Primero se coloca la lámina con la muestra, se selecciona el cocolito y se hace descender la aguja para que toque suavemente el cocolito que se quedará adherido electrostáticamente. Después, se eleva la aguja con el cocolito adherido, se retira la lámina con la muestra, se coloca la lámina "viscosa" bajo el microscopio y se vuelve a bajar la aguja para depositar el cocolito en el correspondiente Tacky Dot well. El proceso se repite hasta conseguir colocar, lo más cerca posible, un total de entre 15 y 20 cocolitos en un único Tacky Dot well. 
Si la aguja está bien afilada y la especie de cocolito deseado es abundante, el picking de una población de 15 cocolitos de Helicosphaera carteri puede realizarse en 45 ó 60 minutos, mientras que para cocolitos de Gephyrocapsa oceanica, se empleará una hora y media o dos, ya que al ser más pequeños, se necesitan al menos 20 especímenes, que además, son más frágiles, y pueden romperse en contacto con la aguja. Puesto que los cocolitos se adhieren a la aguja de tungsteno electrostáticamente, es recomendable realizar el picking en invierno cuando la humedad ambiental es menor.

Hay que prestar especial atención en bajar la aguja de tungsteno suavemente para evitar que se doble en contacto con las láminas, e igualmente, para evitar el picking de partículas no deseadas.

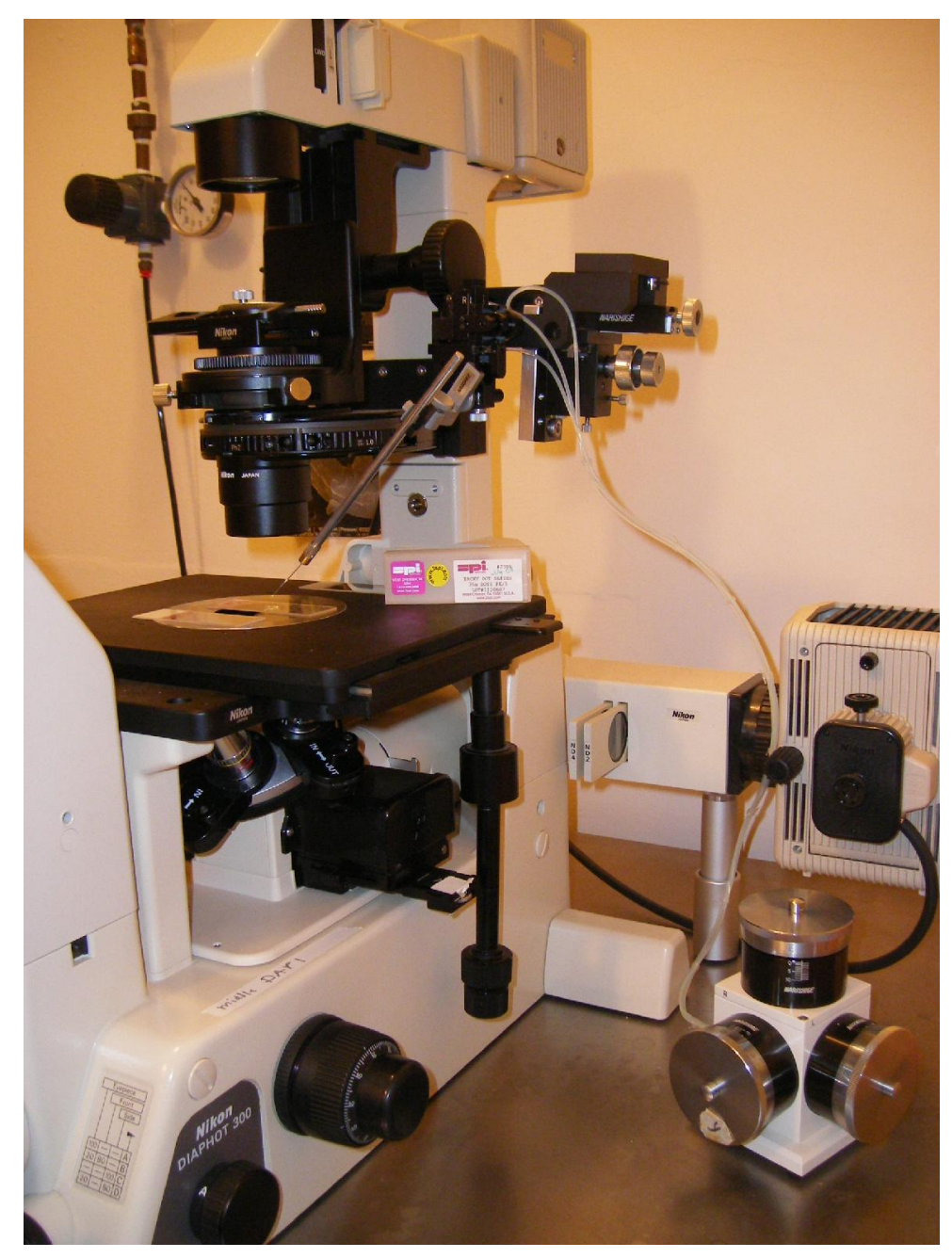

Figura 6.1. Estación de trabajo para el picking de cocolitos. Microscopio invertido (Nikon Diaphot 300), micromanipulador Narishige y aguja de tungsteno acoplada al micromanipulador.

- "Exposición" de los cocolitos. Una vez finalizado el picking, sobre el Tacky Dot slide, se coloca un cilindro de aluminio de $1,5 \mathrm{~cm}$ de diámetro sobre el que se vierte una resina (Buehler Epoxide) que se deja curar durante 24 horas a $35^{\circ} \mathrm{C}$, para después separar la Tacky Dot slide del cilindro con resina. A continuación comienza la "exposición" de cocolitos que es un proceso que requiere sumo cuidado y que consiste en disolver el polímero viscoso del Tacky Dot presente en el 
molde de resina mediante abrasión en una almohadilla empapada en etanol. Se puede confirmar la exposición progresiva de los cocolitos visualizándolos al microscopio.

Hay que ser especialmente cuidadoso en este paso, primero, porque la resina es muy delicada y ha de elaborarse siendo muy preciso en las proporciones (39/100) para que los cocolitos queden fuertemente adheridos a ella, y especialmente, durante la exposición, ya que las poblaciones de cocolitos se exponen a diferentes velocidades y pueden llegar a perderse varias de estas poblaciones. Una vez expuestas, las muestras se someten a un baño de oro para reducir las cargas en el posterior análisis en la sonda iónica.

\subsection{Análisis de $\mathrm{Sr} / \mathrm{Ca}$ en sonda iónica}

Los ratios $\mathrm{Sr} / \mathrm{Ca}$ de las muestras monoespecíficas de cocolitos fueron analizados en un espectrómetro de masas de iones secundarios (Cameca IMS3f) en el Northeast National Ion Microprobe Facility de Woods Hole. Un haz de iones de oxígeno cargados negativamente con una corriente de 2 nA se enfocó hacia un haz de $20 \mu \mathrm{m}$ que rasteó una superficie de $50 \mu \mathrm{m}$. Se usó una calcita estándar de referencia procedente del complejo de carbonatita Oka en Quebec (OKA-C) que en un periodo de dos años muestra una desviación estándar del 1,7 \% y los datos se recogieron a partir de tres análisis sucesivos.

\subsection{Potencial y limitaciones del método}

El picking de cocolitos permite seleccionar individuos bien preservados y analizar muestras totalmente monoespecíficas, evitando los problemas derivados de la presencia de especies de tamaño similar o de otras partículas de carbonato detrítico.

Además, es especialmente útil en los casos en que el material es muy limitado o la diversidad muy alta como para poder ser separado mediante decantaciones sucesivas o microfiltración, como ocurre generalmente con las trampas de sedimento.

Sin embargo, los análisis del ratio $\mathrm{Sr} / \mathrm{Ca}$ se realizan en un espectrómetro de masas de iones secundarios, que es un aparato de escasa disponibilidad (aproximadamente 9 en USA y 8 en Europa) que requiere una elevada inversión (50\$/hora) y en el que se pueden analizar un máximo de 8-10 muestras al día. Por tanto, la aplicación del picking de cocolitos, aún siendo una técnica totalmente innovadora y muy prometedora, se plantea como un recurso limitado en los estudios de geoquímica de cocolitos, debido a la escasa disponibilidad de la sonda iónica y al elevado precio de los análisis. 


\subsection{Aplicación del picking de cocolitos en sedimentos de California}

Se realizó picking de cocolitos sobre muestras procedentes de un box core recuperado de la Cuenca de Santa Bárbara (California) que presenta sedimentos varvados y abarca el periodo entre 1940 y 1998. La zona de estudio presenta una intensa surgencia con un máximo en primavera y verano. El objetivo era analizar el ratio $\mathrm{Sr} / \mathrm{Ca}$ de los cocolitóforos para evaluar los cambios de productividad primaria asociados con eventos climáticos interanuales como El Niño o La Niña (ENSO, El Niño-Southern Oscillation).

A raíz de los interpretaciones de los flujos de cocolitóforos del mismo box core presentados en De Bernardi et al. (2008), se decidió seleccionar las especies G. oceanica y H. carteri para el picking, adicionalmente, se seleccionó una muestra de C. leptoporus y otra de $C$. pelagicus para hacer comparaciones interespecíficas. Los datos de $\mathrm{Sr} / \mathrm{Ca}$ indican que las muestras de $H$. carteri presentan valores más altos que las muestras de G. oceanica, excepto para una muestra (1942) que presenta valores semejantes (Fig. 6.2). A su vez, el ratio $\mathrm{Sr} / \mathrm{Ca}$ de $H$. carteri es mayor que el de C. leptoporus correspondiente a la misma muestra, aunque es similar al de $C$. pelagicus, en este caso de muestras diferentes. Estas diferencias interespecíficas indican que las especies de menor tamaño presentan menor ratio $\mathrm{Sr} / \mathrm{Ca}$, lo cual coincide con los resultados sobre picking de cocolitos en trampas de sedimento de cuatro ubicaciones diferentes presentados en Auliaherliaty et al. (2009).

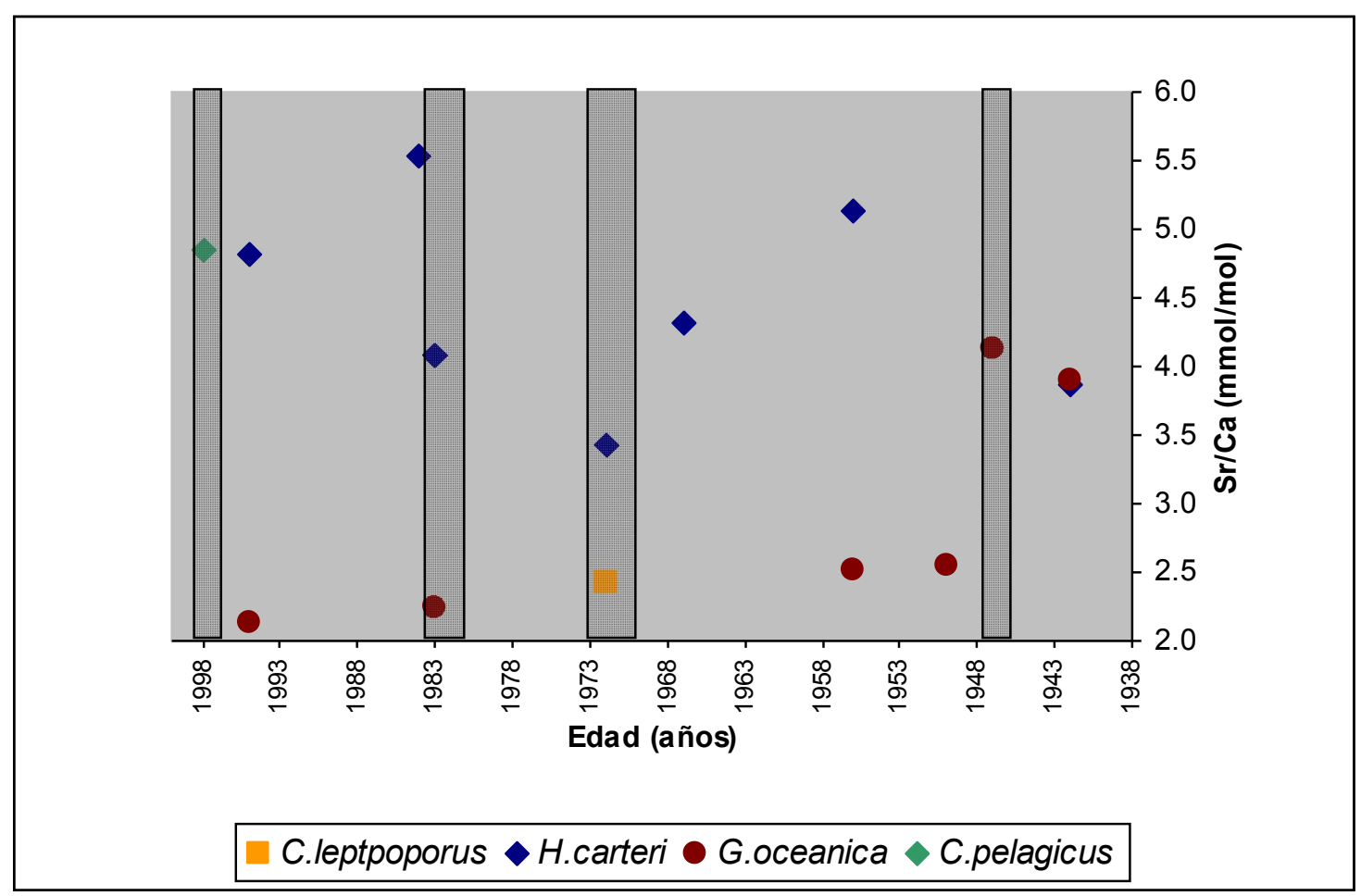

Figura 6.2. Variabilidad del ratio $\mathrm{Sr} / \mathrm{Ca}$ en diferentes especies de cocolitóforos registrados en sedimentos del box-core SABA9610J recuperado en la cuenca de Santa Bárbara (California) entre 1940 y 1998. Los eventos El Niño intensos están representados por barras sombreadas. 


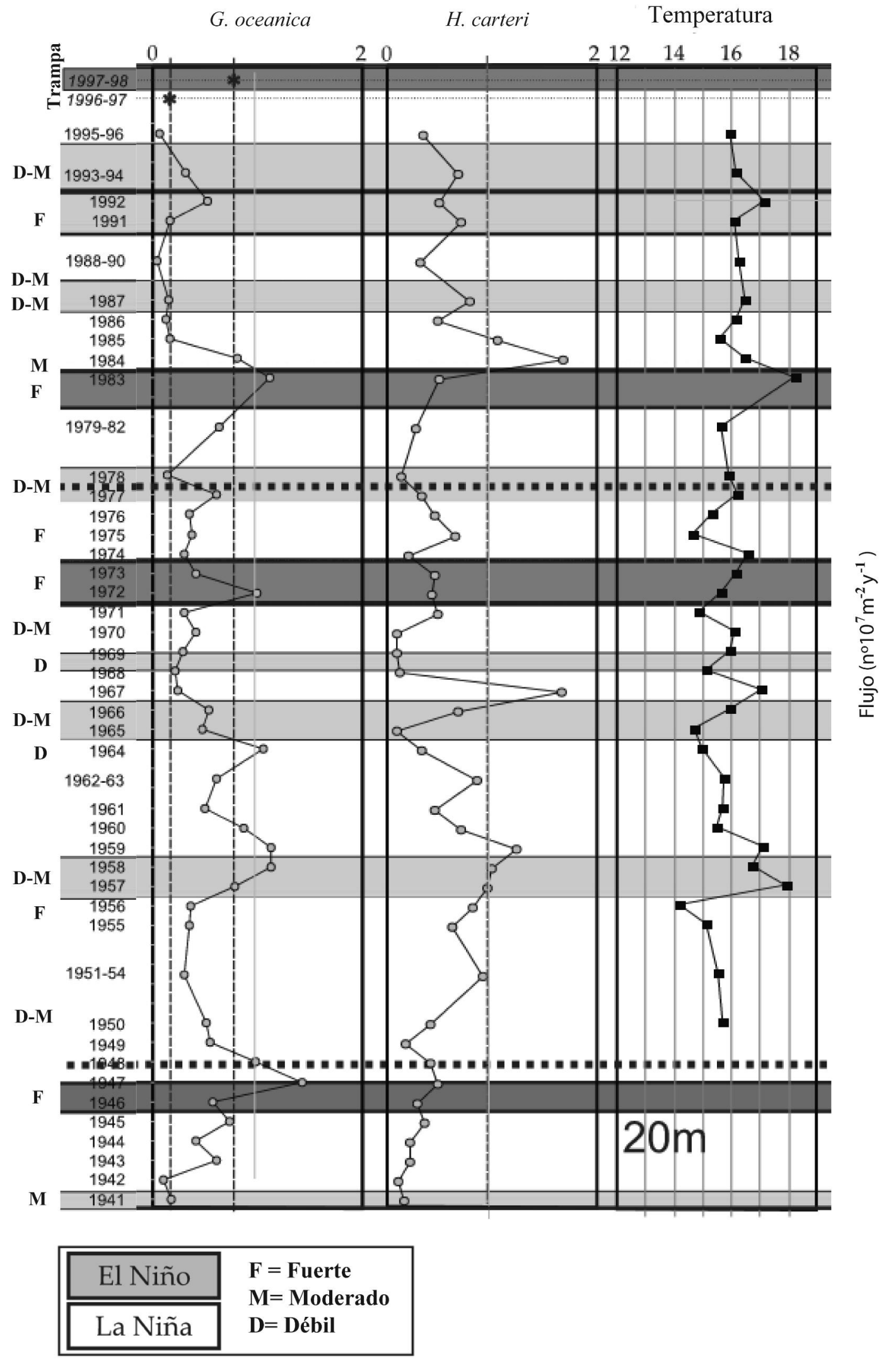

Figura 6.3. Flujos de las especies de cocolitóforos, G. oceanica y H. carteri registrados en el box core SABA9610J de la cuenca de Santa Bárbara entre 1940 y 1998. Comparación con la temperatura de las aguas superficiales. La intensidad de los eventos El Niño está representada por barras sombreadas (De Bernardi et al., 2008). 
Según De Bernardi et al. (2008), los flujos de G. oceanica aumentaban durante periodos El Niño en respuesta al incremento de temperaturas, la mayor disponibilidad de hierro y el descenso en la concentración de sílice. Por el contrario, los flujos de H. carteri aumentaban inmediatamente después de los eventos El Niño, cuando comenzaban a establecerse las condiciones de La Niña y se producía un descenso en las temperaturas y un incremento de las concentraciones de nitrato y fosfato (Fig. 6.3).

Nuestros resultados indican que en general, los valores de $\mathrm{Sr} / \mathrm{Ca}$ y por tanto de productividad, fueron más bajos durantes los periodos intensos de El Niño y ligeramente superiores durante eventos La Niña (Fig. 6.2). La menor productividad durante los eventos El Niño coincide con los valores totales de flujo de cocolitos (De Bernardi et al. 2008), que indican máximos durantes eventos La Niña y descensos relativos durante eventos E1 Niño. Varios estudios previos también sugieren un descenso de la productividad primaria durante eventos E1 Niño a lo largo de la costa californiana (Chavez et al., 2002a, 2002b; McGowan et al., 1998) junto con aumentos en la temperatura de las aguas superficiales. 




\title{
The last 20 ka paleoceanographic reconstruction of Alboran Sea (Western Mediterranean) from coccolith chemistry
}

\author{
Débora Simón-Baile ${ }^{1}$, Patrizia Ziveri ${ }^{2}$, Heather M. Stoll ${ }^{3}$, José A. Flores ${ }^{1}$, Francisco J. Sierro ${ }^{1}$. \\ 1. Área de Paleontologia, Departamento de Geologia, Universidad de Salamanca, 37008, Salamanca, Spain \\ 2. Institut de Ciència i Tecnologia Ambientals, Universitat Autónoma de Barcelona, 08193, Spain \\ 3. Departamento de Geología, Universidad de Oviedo, Oviedo, 33005, Spain
}

\begin{abstract}
The present work concerns the study of a well-dated core (MD95-2043) from the Alboran Sea, the westernmost basin of the Mediterranean Sea and therefore, the direct link between Atlantic and Mediterranean waters. This exceptional location was particularly sensitive to the abrupt and highfrequency climatic changes during the last glacial-interglacial transition. Repeated decanting and microfiltration techniques allowed the separation of restricted coccolith fractions that were analyzed for $\mathrm{Sr} / \mathrm{Ca}$ ratios and stable isotopes $\left(\delta^{18} \mathrm{O}\right.$ and $\left.\delta^{13} \mathrm{C}\right)$ to reconstruct productivity and sea surface conditions over the last $20 \mathrm{ka}$.
\end{abstract}

Our results confirm the sensibility of the area to climatic oscillations. The large paleoceanographic variations since last glacial maximum have been associated to changes in the atmospheric conditions, the intensity of the Atlantic inflow and the vertical mixing within the water column. These variations suggest a strong climatic connection of the Alboran Sea not only with North Atlantic perturbations but also with tropical dynamics. Changes in the coccolith $\delta^{18} \mathrm{O}$ trend were related to variations in the sea surface temperatures and to the entrance of iceberg meltwaters from the Atlantic during Heinrich 1. Such meltwaters may have caused strong stratification and hampered the upwelling of nutrients, reducing the coccolithophores productivity. During Younger Dryas, the southward displacement of the Intertropical Convergence Zone favoured the prevalence of low atmospheric pressure over the Western Mediterranean and the strengthening of the westerlies enhancing the inflow of Atlantic waters, the water mixing and the upwelling that altogether, were responsible for the high primary productivity. On the contrary, marine productivity during Bolling Allerod and early Holocene might have been low due to the weakening of the westerlies and reduced upwelling and Atlantic inflow. Such changes are related to a northward migration of the ITCZ and the establishment of a high pressure system over the region.

Keywords: Coccolith stable isotopes, $\mathrm{Sr} / \mathrm{Ca}$ ratios, paleoproductivity, Alboran Sea, Holocene/late glacial 


\subsection{Introduction}

The Mediterranean is a key region that can integrate processes running in both the North Atlantic and the Tropical areas. On one hand, Mediteranean thermohaline circulation has been affected by the arrival of cold and fresh water from the North Atlantic (Cacho et al., 2000; Sierro et al., 2005), and in turn, saline Mediterranean outflow has a significant impact on North Atlantic circulation, and hence, on global climate (Rogerson et al., 2006; Rogerson et al., 2005; Voelker et al., 2006). Alternatively, latitudinal migrations of the Intertropical Convergence Zone over North Africa influence the environmental conditions in the Mediterranean favouring the intensification of westerlies and Saharan dust input during cold events (Bárcena et al., 2001; Incarbona et al., 2008; Parrilla and Kinder, 1987; Rodrigo-Gámiz et al., 2011).

The Alboran Sea is the transition area between Atlantic and Mediterranean waters. This exceptional location is particularly sensitive to record the connections between both areas and, as a semienclosed basin, it amplifies the smallest climatic changes occurring at the mid-latitude regions (Cacho et al., 2002; Moreno et al., 2004).

The Western Mediterranean and specifically, core MD95-2043, have been extensively studied and provide a unique dataset for the detailed identification and interpretation of the oceanographic and atmospheric processes affecting the area (Cacho et al., 2002; 2000; 2006; Fletcher and Sánchez Goñi, 2008; Moreno et al., 2005; 2004; Penaud et al., 2011; Pérez-Folgado et al., 2003; Sánchez-Goñi et al., 2002). High sedimentation rates of core MD95-2043 allowed high resolution studies in previous studies (Sierro et al., 2005; Cacho et al., 1999; Colmenero-Hidalgo et al., 2004, Bárcena et al., 2001) which data on paleoproductivity and sea surface proxies is presented here for comparison. The present study aims to reconstruct the last 20 ka paleoceanography and paleoclimatology of the Alboran Sea from coccolith chemistry and to further confirm the potential and reliability of the application of coccolithophores geochemical records in the reconstruction of a time interval of abrupt and highfrequency climate changes.

Today, coccolithophores are one of the major components of the phytoplankton in the Mediterranean waters being well represented in the fossil record (Knappertsbusch, 1993). Coccolithophores directly depend on environmental conditions of surface waters and thus, provide valuable information to monitor the paleoceanographic variations occurred in this region during the last glacial period (Colmenero-Hidalgo et al., 2004; Flores et al., 1997; Weaver and Pujol, 1988). Despite its abundance in marine carbonate sediments, the small size of coccoliths hampers the picking of monospecific samples, and has been a basic limitation for the use of the coccolith calcite chemistry as paleoceanographic and paleoclimatic proxies (Stoll and Ziveri, 2004). Nevertheless, recent methods, although time consuming, allow the separation and concentration of near-monospecific coccoliths 
fractions (Minoletti et al., 2001; Minoletti et al., 2008; Stoll and Ziveri, 2002) whose analysis confirm that coccolithophores provide unique geochemical records that would likely differ from those of foraminifera because: (1) they are calcareous primary producers widely distributed throughout the ocean, (2) they produces calcite intracellularly, (3) they are the only marine organisms that provide indicators from both its organic and inorganic remains and, (4) they preserve especially well in sediments (Stoll and Ziveri, 2004; Stoll and Ziveri, 2002).

Although cultures of coccolithophores depicted a large (5\%) range of interespecific oxygen and carbon isotopic disequilibrium or vital effects, they confirm as well the constancy of species-specific isotopic fractionation, and in consequence, show that coccolith stable isotopes are reliable for the reconstruction of seawater chemistry and paleotemperatures, as long as monospecific fractions are analyzed (Ziveri et al., 2003). Field and culture data confirm the relationship between coccolith $\mathrm{Sr} / \mathrm{Ca}$ ratios and variations in coccolithopore productivity (Rickaby et al., 2002; Stoll et al., 2007a; 2007b; 2002a). Sr/Ca ratios are higher under nutrient-stimulated increases in growth rate and consequently, in periods of enhanced primary productivity. $\mathrm{Sr} / \mathrm{Ca}$ ratios also show a large array of interspecific variability (Stoll et al., 2007a), concretely, smaller coccoliths like Emiliania huxleyi, present both lower and less variable ratios than larger coccoliths such as Helicosphaera carteri and Calcidiscus leptoporus, as confirmed through analysis of $\mathrm{Sr} / \mathrm{Ca}$ ratios on samples of individually picked coccoliths (Auliaherliaty et al., 2009).

This contribution presents stable isotopes and $\mathrm{Sr} / \mathrm{Ca}$ ratios from restricted coccolith fractions that have been used to reconstruct seawater paleotemperatures and paleoproductivity during the last $20 \mathrm{ka}$, and to evaluate the interactions and climatic connection between the Western Mediterranean Sea and other regions, mainly the Atlantic Ocean, during this period.

\subsection{Climatic and oceanographic setting}

The Mediterranean is a semi-enclosed marginal sea which only connection with the open ocean is through the $\approx 14 \mathrm{~km}$ of the Strait of Gibraltar. Because evaporation exceeds precipitation (Béthoux, 1979), the basin shows an anti-estuarine circulation with the Mediterranean Outflow Water (MOW) flowing into the Atlantic at depth while the Modified Atlantic Water (MAW) is entering the Mediterranean as a surface current. The less saline (36.5\%) and nutrient-rich MAW flows into the Alboran Sea describing two almost permanent anticyclonic gyres and forming several upwelling cells (Heburn and La Violette, 1990; Parrilla and Kinder, 1987) that influence directly the location of core MD95-2043. Below the MAW, a relict of the high-saline $(\approx 38.5 \%$ ) Levantine Intermediate Water (LIW) is underlain by the Western Mediterranean Deep water (WMDW) that sink to depth in the Gulf of Lions due to the cooling of surface water by northwesterly winds (Millot, 1999). These water 
masses fed the MOW and outflow into the Intermediate Atlantic Ocean as a salty and warm injection (Fig. 7.1.)

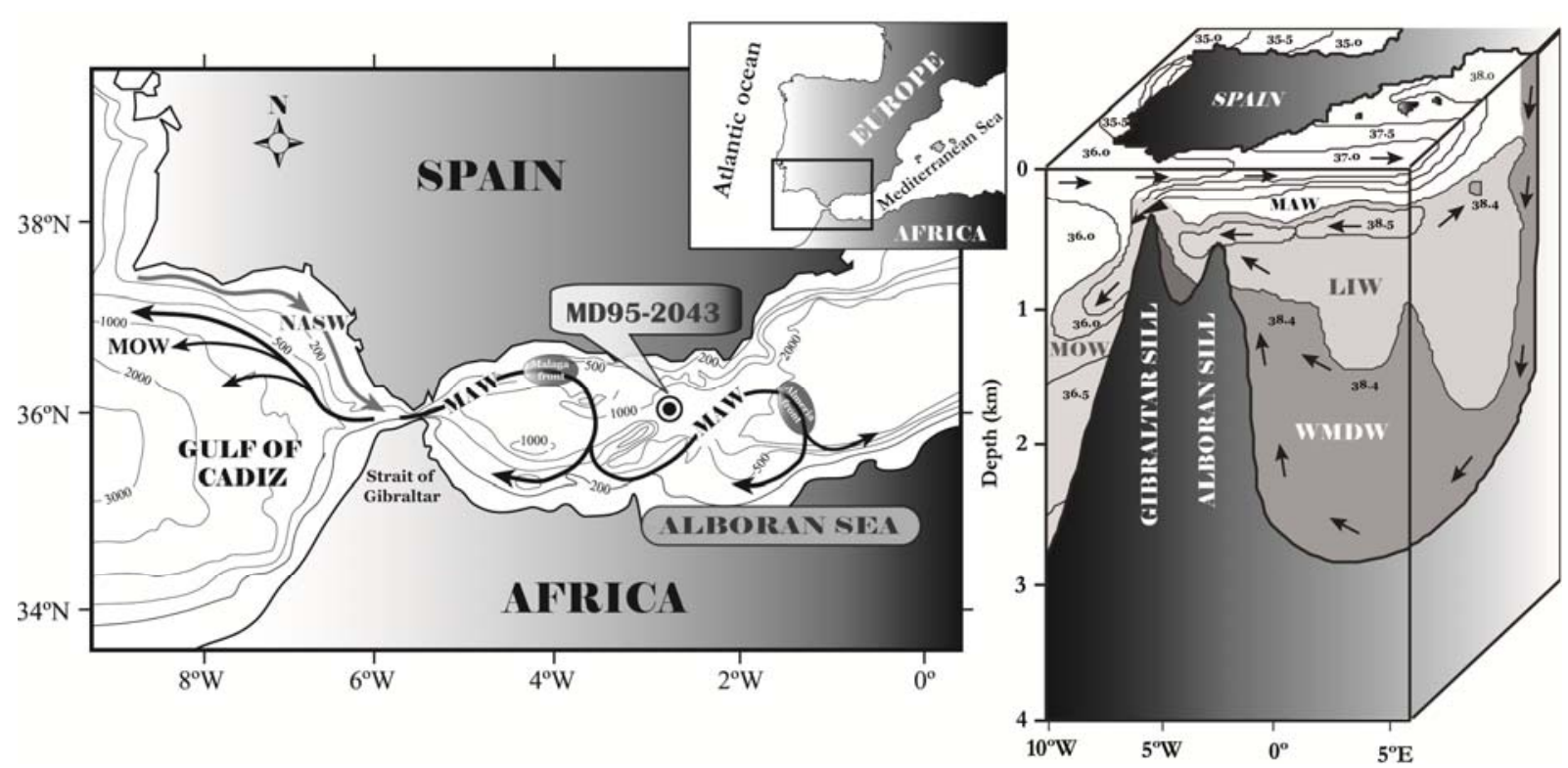

Figure 7.1. Location of core MD95-2043 in the Alboran Sea and surface circulation. Shaded areas represent present-day high productivity areas (left). Water masses circulation in the Western Mediterranean (right).

During summer, the Mediterranean climate is controlled by the subtropical belt of high-pressure and so, generally warm and dry (Sumner et al., 2001). In winters, the regional climate turns wetter due to the southward migration of the subtropical conditions and the entrance of humid fronts from the Atlantic. On a decadal time-scale, much of the modern rainfall variations in the Mediterranean area show a connection to the North Atlantic Oscillation (Goodess and Jones, 2002; Rodó et al., 1997). Low NAO index years are linked to enhanced precipitation in the Western Mediterranean and North Africa region, while high NAO index years are characterised by the export of humidity to central Europe due to a northward shift of the North Atlantic depression route (Moreno et al., 2004).

In contrast with the oligotrophy prevailing in most of the Mediterranean, the Alboran Sea exhibits a higher primary productivity mainly due to the interaction between inflowing nutrient-richer Atlantic waters and outflowing warmer and saltier Mediterranean waters. However, upwelling promotion and so, the onset of the anticyclonic gyres is also associated to stronger westerly winds link to the establishment of low-pressure conditions in the area determined by the southward migration of the Intertropical Convergence Zone (Bárcena et al., 2001). Additionally, proximity to landmasses favours aeolian and riverine nutrient supplies that further support greater productivity (Fabres et al., 2002). Satellite observations show higher transport of Saharan dust in spring and summer (Moulin et al., 1998) and the rivers flowing into the Alboran basin are of high importance as sediment feeders despite its small size (Liquete et al., 2005; Lobo et al., 2006), however, phosphate is still a limitating nutrient 
for primary productivity (Béthoux et al., 1998; Krom et al., 1991). Primary productivity in Alboran Sea presents a strong seasonality with a distinguished bloom period associated to the water column mixing from November to March and a low-productivity regime coincident with the strong summer stratification (May-September) (Garcia-Gorriz and Carr, 2001). Maximum planktonic fluxes show a seasonal pattern associated with the development of the surface gyres, vertical mixing and the subsequent activation of upwelling cells (Bárcena and Abrantes, 1998; Bárcena et al., 2004; Hernández-Almeida et al., 2010).

\subsection{Material \& Methods}

Calypso piston core MD95-2043 (36 ${ }^{\circ} 8^{\prime} \mathrm{N} ; 2^{\circ} 37^{\prime} \mathrm{W}$ ) was retrieved by the R/V Marion Dufresne during the IMAGES-I cruise in 1995. The core was recovered at $1841 \mathrm{~m}$ water depth in the Alboran Sea, the westernmost basin of the Mediterranean Sea. The sediment is mainly composed of calcareous oozes and clays (Plaza, 2001) and the record is continuous with $59.17 \mathrm{~cm} / \mathrm{ka}$ average sedimentation rate. Sedimentation rate is generally higher during Dansgaard/Oeschger interestadials, likely because these warmer and wetter periods foster riverine input (Moreno et al., 2002; Sánchez-Goñi et al., 2002).

Cacho et al., 1999 proposed two different chronostratigraphic models for core MD95-2043. The first of the two age models was constructed from $\mathrm{AMS}{ }^{14} \mathrm{C}$ ages measured on 21 monospecific samples of the planktonic foraminifera Globigerina bulloides (9) and Neogloboquadrina pachyderma (12) depending on their availability. Furthermore, the $\delta^{18} \mathrm{O}$ curve from $G$. bulloides was used to better constrain this stratigraphic framework through the identification of three isotopic events (Martinson et al., 1987). The present work adopted this first age model since radiocarbon ages and isotopic correlations are regarded to work/serve as independent and reliable age sources.

\subsubsection{Separation of coccoliths size fractions for geochemical analysis}

Recent methods consisting on repeated decanting (Stoll and Ziveri, 2002) and microfiltration (Minoletti et al., 2001; Stoll and Bains, 2003) allow the separation and concentration of different coccoliths size fractions dominated to high degrees by the coccolith carbonate of a single species that can subsequently be analyzed for $\mathrm{Sr} / \mathrm{Ca}$ ratio and stable isotopes $\left(\delta^{18} \mathrm{O}\right.$ and $\left.\delta^{13} \mathrm{C}\right)$.

For samples from core MD95-2043, a $0.6 \mathrm{~g}$ split of the freeze-dried sediment was massed and transferred to a $50 \mathrm{ml}$ centrifuge tube, the sediment was resuspended adding $3 \mathrm{ml}$ of buffered distilled water. Gentle mechanical disaggreagation together with chemical cleaning were performed aiming to minimize the formation of aggregates. Bleach and hyrdrogen peroxide $\left(\mathrm{NaClO}\right.$ and $\left.\mathrm{H}_{2} \mathrm{O}_{2}\right)$ were used to oxidize organic matter together with brief sonication (Bairbakhish et al., 1999) . 
After oxidation, the sediment was filtered under vacuum onto a $0.8 \mu \mathrm{m}$ cellulose nitrate filter and inmediately, wet sieved through a $20 \mu \mathrm{m}$ nylon mesh to remove the foraminifera and obtain the fine fraction $(<20 \mu \mathrm{m})$. The $<20 \mu \mathrm{m}$ fraction was then, recovered on a cellulose nitrate filter and resuspended in $5 \mathrm{ml}$ of a hydroxylamine $\mathrm{HCl}$ and dilute ammonia (12\%) solution that allows a reductive and ion exchange cleaning (Apitz, 1991). Finally, the suspended samples were subject to gentle mechanical disaggregation on a rotating carousel (Multimixer) for no less than $24 \mathrm{~h}$. Throughout the samples preparation and separation process, we avoided cross contamination among samples by rinsing the filtration equipment in a succession of diluted acid, distilled water and ammonia solution.

Following the technique proposed by Stoll and Ziveri (2002), a fraction enriched in the coarsest coccoliths was obtained through repeated decanting consisting on a settling distance of $5 \mathrm{~cm}$, repeated 3 times, and settling time between 7 and 30 minutes. The last step of these separations comprises microfiltration through 8 and $10 \mu \mathrm{m}$ polycarbonate membranes. The smallest coccoliths were concentrated from the $<20 \mu \mathrm{m}$ fraction through a combination of a set of repeated decanting steps (5 $\mathrm{cm}, 3$ times, $100 \mathrm{~min}$ ) with microfiltration using 3 and/or $5 \mu \mathrm{m}$ polycarbonate membranes.

Light microscope observations were performed in any given step throughout the separation procedure in order to identify the fractions containing the most restricted assemblages and verify the efficiency of separations. $\mathrm{Sr} / \mathrm{Ca}$ ratios analyses were also conducted on the total bulk fraction and the fine bulk fraction $(<20 \mu \mathrm{m})$ whereas the total bulk fraction was not analyzed for stable isotopes. We improved the resolution of the $\mathrm{Sr} / \mathrm{Ca}$ record of the fine bulk fraction $(<20 \mu \mathrm{m})$ by analysing 22 extra samples.

$\mathrm{Sr} / \mathrm{Ca}$ analyses were conducted at the University of Oviedo using Inductively Coupled Argon Plasma Spectrometry (Thermo ICAP DUO 6300). For that, splits of the fractions were dissolved in $0.1 \mathrm{M}$ acetic acid/ammonium acetate buffer, and diluted to be subsequently analyzed. Calibration was performed following the intensity ratio method as described in de Villiers et al. (2002). Stable isotopes were measured at Vrije University Amsterdam using the mass spectrometers Finnigan 252 equipped with an automated carbonate extraction line (Kiel Device) and Finnigan Gasbench with Delta ${ }^{+}$. Sample reproducibility and comparison of carbonate standard is better than $0.15 \%$ for $\delta^{18} \mathrm{O}$ with a standard deviation between 0.05 and 0.2 . The mean reproducibility of replicate analysis was $0.1 \%$. The results are relative to the Vienna Pee Dee Belemnite (VPDB).

\subsubsection{Quantification of coccoliths and coccolith carbonate contribution}

For the quantitative analysis of the separated fractions under light microscope, a wet split of each fraction was diluted with buffered distilled water and filtered under syringe onto a $0.45 \mu \mathrm{m}$ cellulose nitrate filter. The filter was oven dried and a segment was mounted on a glass slide and made 
transparent with a drop of inmersion oil. Alternatively, the original-bulk samples were prepared following a decantation method (Flores and Sierro, 1997). This method allows control of the area over which the sediment is uniformly distributed and the area observed in microscope and hence, an accurate calculation of the coccolith abundances per gram of sediment.

A total number of at least 400 coccoliths (precision $\geq 99 \%$ ) from the separated samples were counted at 1000x magnification using a polarized Light Microscope Leica DMRXE. The same counting routine was used for the original samples, although some of these samples were already analyzed in previous studies (Colmenero-Hidalgo et al., 2004).

Quantification of the coccolith carbonate contribution was determined using the formula given by Young and Ziveri (2000) that proposes the conversion of coccolith relative abundances into coccolithcarbonate relative mass by estimating the species-specific carbonate mass per coccolith. This coccolith carbonate mass estimation $\left(\mathrm{m}=2.7 \mathrm{k}_{\mathrm{s}} 1^{3}\right.$, in $\left.\mathrm{pg}\right)$ requires a species-specific shape factor $\left(\mathrm{k}_{\mathrm{s}}\right)$ and the average length of a species (1) in microns as well as the calcite density $\left(2.7 \mathrm{pg}^{\mathrm{m}} \mathrm{m}^{-3}\right)$.

The diameters of a minimum of 50 individuals of the most volumetrically abundant coccoliths species were measured at $1600 \mathrm{x}$ magnification under a light microscope. This morphometry analysis reduced the potential source of errors derived from size variation of individual species among samples in about 15-30\%. Moreover, in order to minimize an underestimation of the coccoliths volume due to variable size distribution of some of the species measured (C. leptoporus and C. pelagicus), we calculate the mean volume instead of using a simple mean length and avoided an error of up to $17 \%$.

Despite a certain degree of imprecision, the method proposed by Young and Ziveri (2000) is commonly used (Baumann et al., 2004; Fink et al., 2010; Sprengel et al., 2000) and provides a good estimation of the coccolith carbonate contribution.

\subsection{Results}

\subsubsection{Coccolith composition of size fractions and efficiency of separations}

Relative abundance and carbonate contribution of coccoliths in the original samples and the two separated fractions are presented in figures 7.2 and 7.3. Light microscope counts and carbonate contribution calculations were used to evaluate the efficiency of the separation procedure. The relevant indicator of separation efficiency for geochemical analysis is the carbonate contribution of a species, which differs from the relative abundance because different species contribute different amounts of carbonate per coccolith (Stoll and Ziveri, 2002). 
LM observations confirmed that the small coccoliths fraction was numerically dominated by $E$. huxleyi and Gephyrocapsa spp. in different proportions while the coarse coccoliths fraction did not show clear dominating species and varies among H. carteri, C. pelagicus and reworked coccoliths.

Despite the low abundance of some target species in the original samples, we managed to separate two representative size fractions from every sample. Concretely, H. carteri was highly concentrated from an abundance of $0.97 \%$ in the original sample to $82.7 \%$ in the separated fraction, while C. leptoporus enriched from $0.20 \%$ to $38 \%$ and C. pelagicus was concentrated, from $0.6 \%$ to almost $80 \%$ (Fig. 7.2). On the contrary, the numerical enrichment of the small coccoliths fractions was 1.2 on average, not relevant since small placoliths were already very abundant in the original samples. Regarding numerical abundances, the separation efficiency of the small coccoliths fractions is really good, and target species show values up to $88 \%$ on average whereas the efficiency of the fraction of coarse coccoliths presents high heterogeneity among the few separated samples, with two good separations and other poor ones. Specifically, there is a couple of samples showing a mix of species, one sample with a high percentage of $H$. carteri, another one dominated by $C$. pelagicus, and even one with high abundance of reworked coccoliths (Fig. 7.2). Nevertheless, when converting relative abundances into carbonate contribution (Young and Ziveri, 2000), the volumetric efficiency of the separation method of small and coarse coccoliths fractions behaves differentially. The volumetric efficiency of the coarse coccoliths fractions improves in general, especially for the samples with a mix of species, while the small coccoliths fractions one decreases from $88 \%$ to $74 \%$ (Fig. 7.3 ) because the few coarse coccoliths present in the small coccoliths fraction have much higher carbonate contribution. H. carteri maximum carbonate concentration is $91 \%$, C. pelagicus reaches $90 \%$ and a sample with small placoliths presents an exceptional high volumetric efficiency, with above $98 \%$ of the carbonate from a single species. In short, the coarse coccoliths fraction show large disparity (Fig. 7.2 and 7.3) and must be interpreted with caution, even when it confirms that is more probable to achieve higher carbonate concentration of a single species for a coarse coccoliths fraction. In any case, the small coccoliths fraction is more reliable, even after the decrease in the efficiency when converting percentages into carbonate contribution.

The presence of species of similar size and settling speeds, such as C. leptoporus and H. carteri, in the same sample strongly hampers the efficiency of separations. However, geochemical studies revealed that $C$. leptoporus and $H$. carteri present comparable oxygen isotopes values $(-0.1 \%$ and $-0.2 \%$ ) (Ziveri et al., 2003) and $\mathrm{Sr} / \mathrm{Ca}$ ratios (Stoll et al., 2002a; 2002b) and corroborate the reliability of mixed C. leptoporus-H. carteri size fractions. Additional obstacles in the separation process of samples from core MD95-2043 was the presence of reworked coccoliths in some samples and the high abundance of clay and other fine particles that required long decanting previous to the separation process itself. 


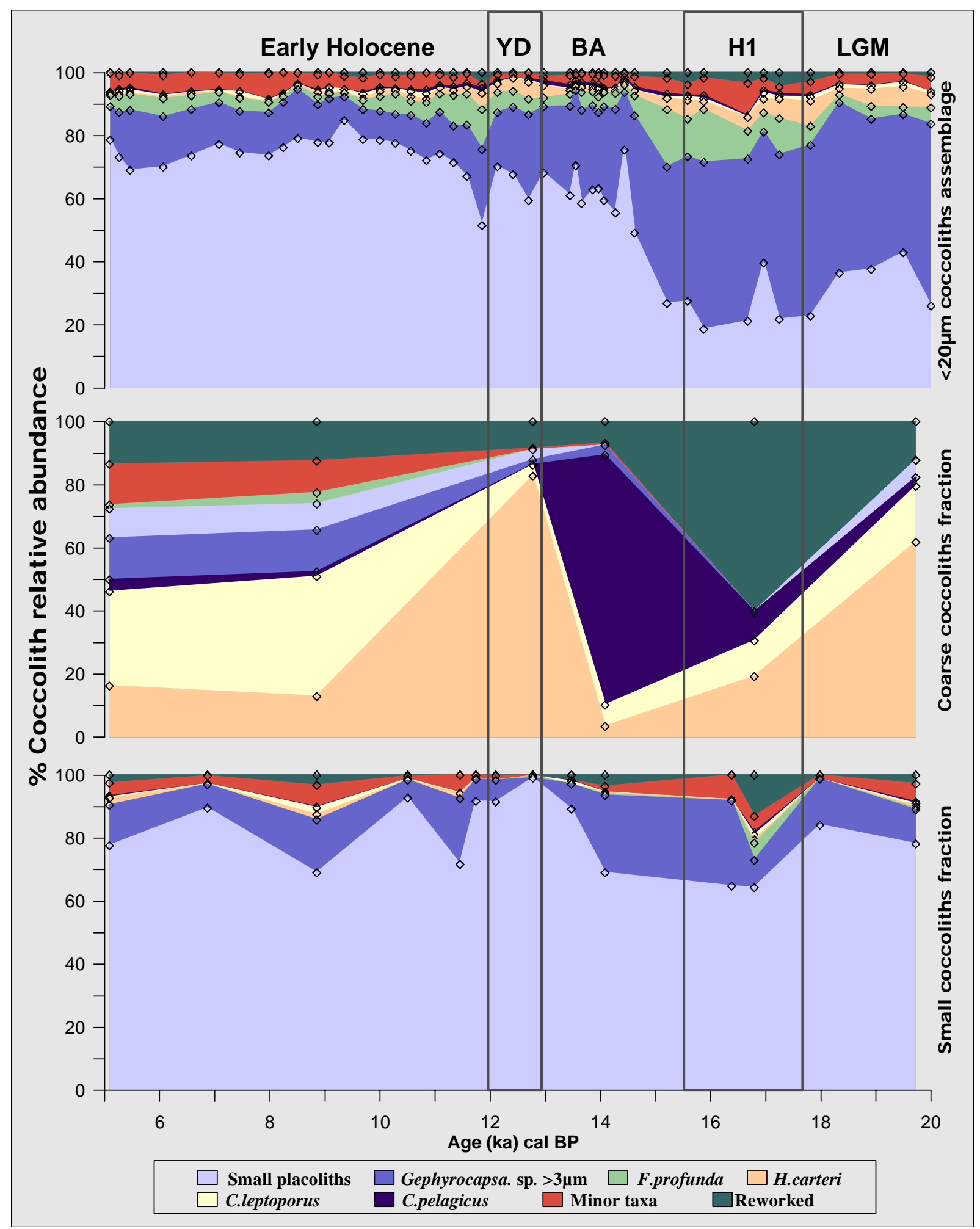

Figure 7.2. Temporal distribution of coccolith relative abundance from core MD95-2043. From top to bottom: $<20 \mu \mathrm{m}$ coccoliths original assemblage; coarse coccoliths separated fraction and small coccoliths separated fraction. Vertical bands represent Younger Dryas (YD), Bolling-Allerod (BA), Heinrich 1 (H1) and Last Glacial Maximum (LGM). 


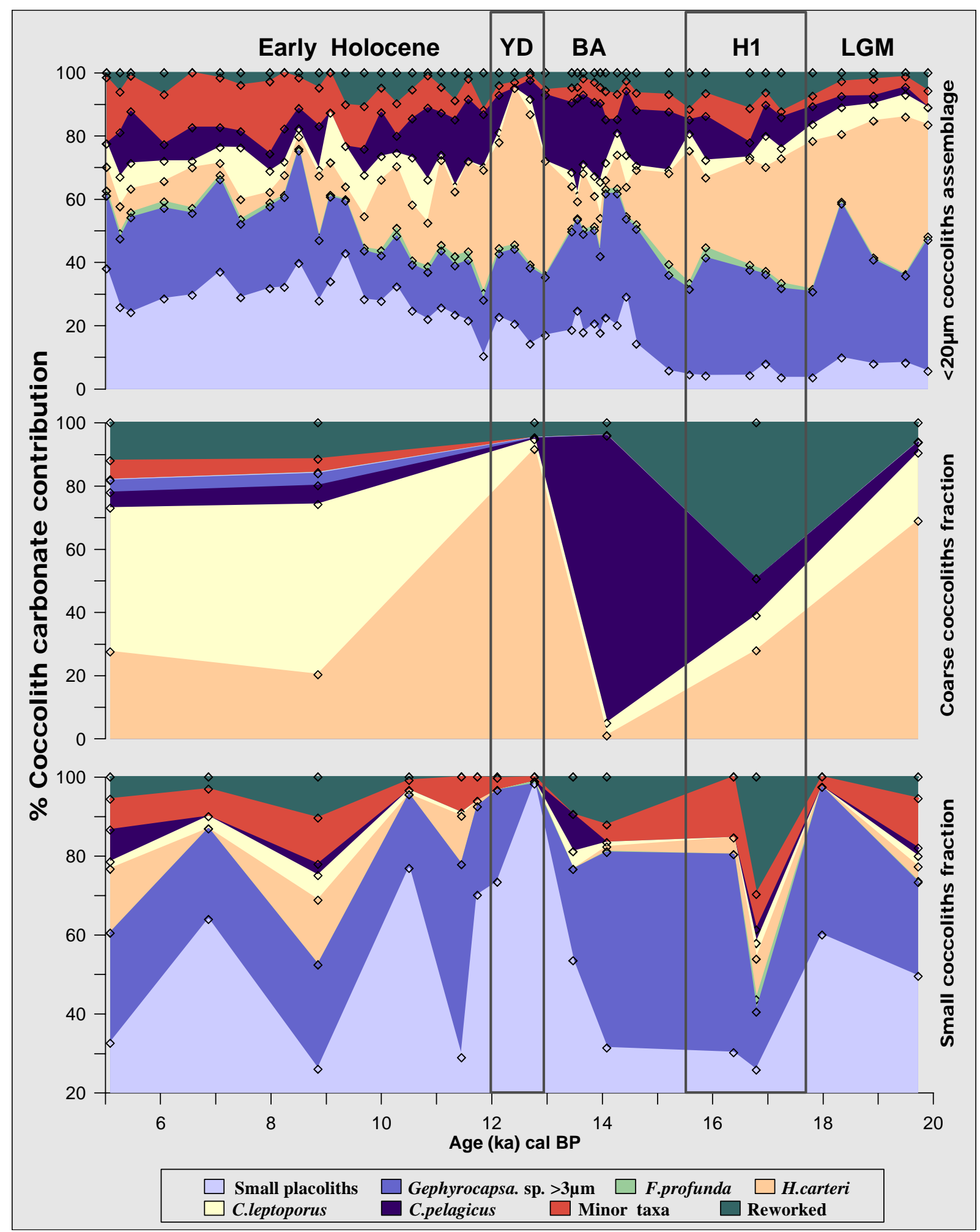

Figure 7.3. Temporal distribution of coccolith carbonate contribution from core MD95-2043. From top to bottom: $<20 \mu \mathrm{m}$ coccoliths original assemblage; coarse coccoliths separated fraction and small coccoliths separated fraction. Vertical bands represent Younger Dryas (YD), Bolling-Allerod (BA), Heinrich 1 (H1) and Last Glacial Maximum (LGM). 
The coccolith composition of a particular fraction is strongly dependent on the original sample composition and varies among samples from different sites but also in a single site due to assemblage variations through time. This is evident at YD times when the H. carteri shows its maxima, during the BA where there is a relative increase of $C$. pelagicus or with the higher abundance of reworked coccoliths during H1. All these variations in the original assemblage are consequently transferred to the corresponding separated fractions and imply an adaptation in the steps of the separation process. (See Fig. 7.3). LM images in plates 7.1 and 7.2 show isolated fractions from the surface dwellers $H$. carteri and C. pelagicus and the cosmopolitan E. huxleyi and Gephyrocapsa spp.

According to the counting data of the coccolithophore assemblage of core MD95-2043 (Colmenero et al., 2004), the relative abundances of E. huxleyi, Gephyrocapsa sps. and F. profunda account for the $91.4 \%$ (Fig. 2, up) of the assemblage while their carbonate contribution is about $48.65 \%$ (Fig. 3, up). Hence, in the Alboran Sea, both the small and the coarse coccolith contribute similarly to the coccolith carbonate budget.

\subsubsection{Coccolith stable isotopes and comparison with planktonic foraminifer records}

The oxygen isotope ratio of marine carbonate plankton is a function of two effects: (1) the sea surface temperature and (2) the oxygen isotope composition of the seawater in which they calcify that, in turn, depends on the sea surface salinity and the global ice volume.

Estimates of the $\delta^{18} \mathrm{O}$ of seawater were conducted by correcting the coccolith and planktonic foramimifer (Cacho et al., 1999; Sierro et al., 2005) $\delta^{18} \mathrm{O}$ data from variations in ice volume (Hanebuth et al., 2009; Lea et al., 2002; Peltier and Fairbanks, 2006; Toscano and Macintyre, 2003; Yokoyama et al., 2000) and surface temperature (Bemis et al., 1998; Ziveri et al., 2003). The alkenone-derived SST record (Cacho et al., 1999) was used for temperature corrections (Fig. 7.4).

Despite the low resolution of the isotopic records for the $<20 \mu \mathrm{m}$ coccolith fraction and the size fractions, the general trends of the coccolith $\delta^{18} \mathrm{O}$ and the G. bulloides $\delta^{18} \mathrm{O}$ correlate fairly well. Both coccoliths and planktonic foraminifera show higher $\delta^{18} \mathrm{O}$ values during colder periods such as the Last Glacial Maximum and the Younger Dryas and lower oxygen isotope ratios during warmer intervals like the Bolling Allerod or the Holocene itself. Furthermore, both present a $\delta^{18} \mathrm{O}$ decrease corresponding to the Heinrich 1. These oscillations in the $\delta^{18} \mathrm{O}$ indicate significant climatic changes throughout the last $20 \mathrm{ka}$. Concretely, the $\delta^{18} \mathrm{O}$ records of the $<20 \mu \mathrm{m}$ coccolith fraction and planktonic foraminifera display similar fluctuations of about $3 \%$ in response to glacial/interglacial variations, however, the small coccoliths fraction was found to be highly variable, its maximum glacial-interglacial amplitude being between $2.6 \%$ and $-3.1 \%$, with a total oscillation of $5.68 \%$. 


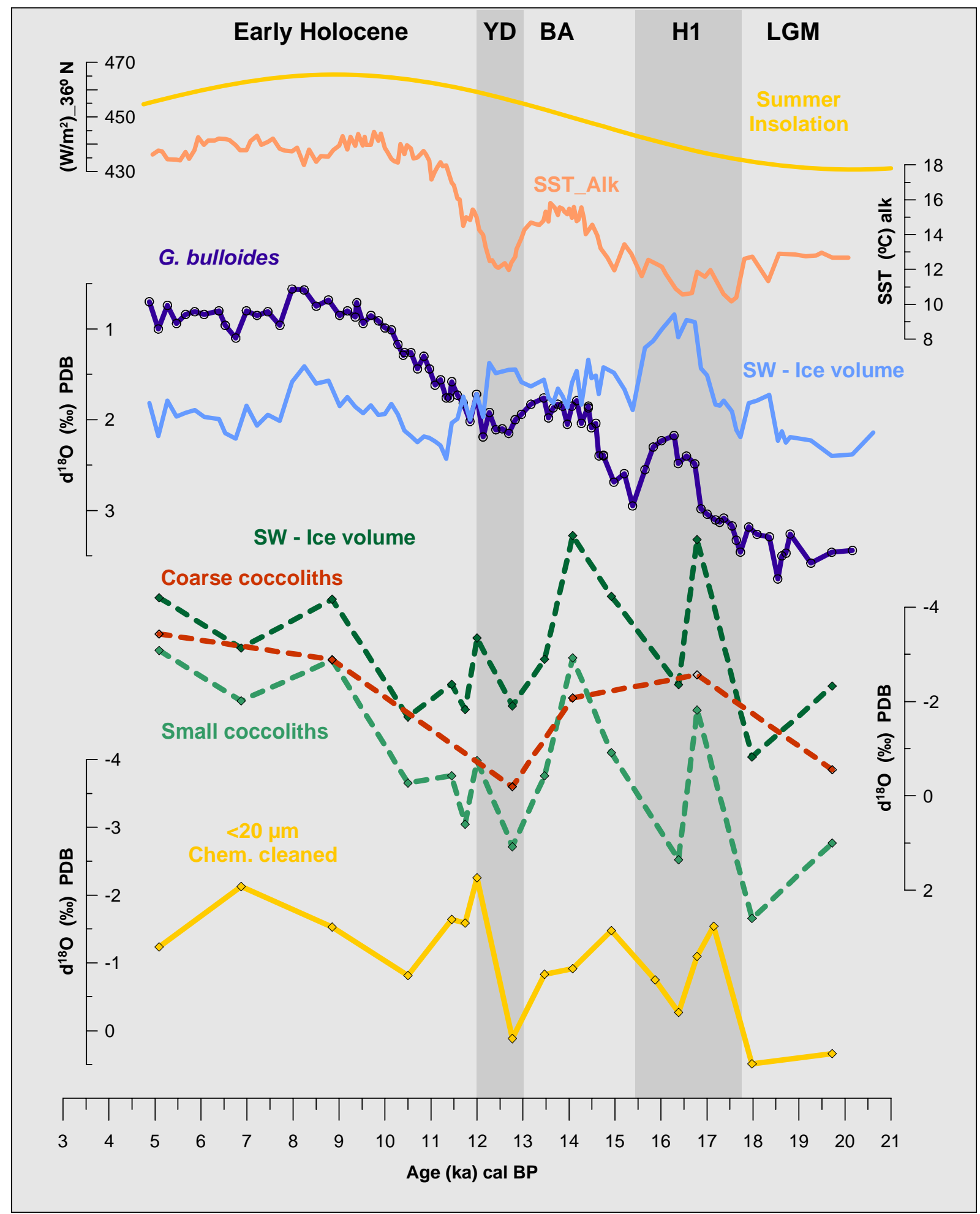

Figure 7.4. Temporal distribution of the coccolith oxygen isotope ratios $\left(\delta^{18} \mathrm{O}\right)$ from core MD95-2043. From bottom to top: Sieved fraction $(<20 \mu \mathrm{m})$ chemically cleaned. Separated fractions of coarse coccoliths and small coccoliths and the resulting calculated $\delta^{18} \mathrm{O}$ of surface water corrected for ice volume effect. And comparison with: $\delta^{18} \mathrm{O}$ of the planktonic foraminifera G. bulloides (Sierro et al., 2005; Cacho et al., 1999) and its calculated $\delta^{18} \mathrm{O}$ of surface water corrected for ice volume effect. Alkenone-derived surface sea temperature (Cacho et al., 1999) and boreal summer (JJA) average insolation for $36^{\circ} \mathrm{N}$ (Laskar et al., 2004). 
Although the foraminifer $\delta^{18} \mathrm{O}$ record exhibits an approximately continuous decrease for the last $20 \mathrm{ka}$, the coccolith $\delta^{18} \mathrm{O}$ record shows greater oscillations. Coccolith fractions present a more pronounced isotopic enrichment at YD times and lower $\delta^{18} \mathrm{O}$ during BA and $\mathrm{H} 1$ comparable to the Holocene values. However, a remarkable difference between foraminifera and coccoliths oxygen isotopic signals lies in their absolute values, because coccolith $\delta^{18} \mathrm{O}$ are mainly negative while foraminifer $\delta^{18} \mathrm{O}$ values are always positive. Such offsets might be related to differences in the isotopic disequilibrium among carbonate organisms since foraminifera exhibit a closer affinity to equilibrium and more limited expression of vital effects than coccolithophores (Spero et al., 1997; Stoll et al., 2007b; Zeebe et al., 2008) and/or to their different ecology, because G. bulloides is more abundant between 50 and $100 \mathrm{~m}$ although it can occupy deeper waters since it lacks symbionts (Hemleben et al., 1989) and because the vertical temperature gradient in the Mediterranean is higher than in other areas in the Atlantic on the same latitude. The negative values in the coccolith $\delta^{18} \mathrm{O}$ can also be due to the presence of detrital

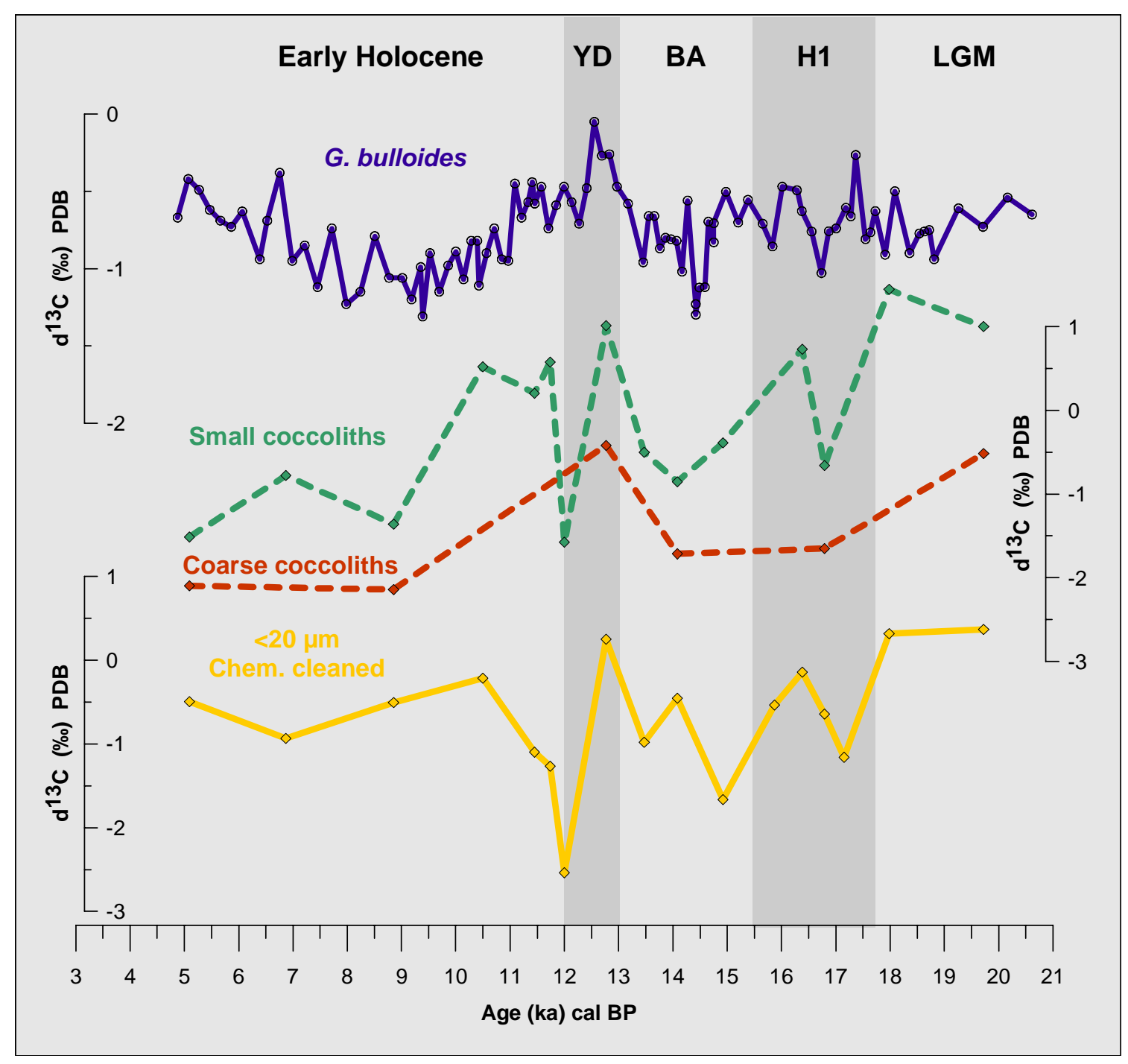

Figure 7.5. Temporal distribution of the coccolith $\delta^{13} \mathrm{C}$ from core MD95-2043. From bottom to top: Sieved fraction $(<20 \mu \mathrm{m})$ chemically cleaned. Separated fractions of coarse coccoliths and small coccoliths and comparison with: $\delta^{13} \mathrm{C}$ of the planktonic foraminifera G. bulloides. 
dolomite in the $<20 \mu \mathrm{m}$ fractions (Martinez-Ruiz, et al., 1999; Nieto-Moreno et al., 2007), which exhibit negative $\delta^{18} \mathrm{O}$ values. Such dolomites would be carried by the rivers flowing into the Alboran basin, which are of high importance as sediment feeders despite its small size (Liquete et al., 2005; Lobo et al., 2006). The latter is due to its torrential character, together with high soil erosion, the narrowness of the continental shelf and the broad dispersion of suspended sediment plumes (Liquette et al., 2005).

On the other hand, measurements of $\delta^{13} \mathrm{C}$ on coccolithophore size fractions have been conducted to estimate rate of nutrient utilization, because the carbon isotope ratios of marine carbonates are a function of the carbon isotopic composition of seawater, which is typically enriched in the surface due to the preferential extraction of ${ }^{12} \mathrm{C}$ during the photosynthesis and which decreases with depth because of remineralization of the organic matter. Upwelling brings these lower $\delta^{13} \mathrm{C}$ waters back to the surface. The trends of the coccolith size fractions $\delta^{13} \mathrm{C}$ and the G. bulloides $\delta^{13} \mathrm{C}$ (Fig. 7.5) are also reasonably similar. Both organisms show generally lower $\delta^{13} \mathrm{C}$ values during the Bolling Allerod and the Holocene while there is a synchronous peak at the Younger Dryas onset. Unlike $\delta^{18} \mathrm{O}$, the absolute values of coccoliths and G. bulloides $\delta^{13} \mathrm{C}$ record are within the same range, although coccolith $\delta^{13} \mathrm{C}$ exhibit higher amplitude of variability. Specifically, G. bulloides $\delta^{13} \mathrm{C}$ values have an amplitude of $1.26 \%$ whereas both $<20 \mu \mathrm{m}$ and small coccoliths fractions varies around $3 \%$.

Different coccolith size fractions from the same sample show slight offsets in the isotopic ratios, concretely, fractions enriched in E. huxleyi and Gephyrocapsa spp. show more positive $\delta^{18} \mathrm{O}$ and $\delta^{13} \mathrm{C}$ values than the coarse coccolith fractions dominated by Helicosphaera spp. and C. leptoporus, the offset being larger in the $\delta^{13} \mathrm{C}$. There is an exception in the $\delta^{18} \mathrm{O}$ of the coarse coccolith fraction around $14 \mathrm{ka}$ which is isotopically heavier than its corresponding small coccolith fraction because it is highly enriched in C.pelagicus whose oxygen isotope ratios are also positive (Ziveri et al., 2003). These differences are in agreement with previous culture observations that reported a wide range of interspecific disequilibrium effects (Dudley et al., 1986; Ziveri et al., 2003). Nevertheless, some of the $<20 \mu \mathrm{m}$ fractions does not exhibit intermediate values in between both separated fractions which indicates that they are not completely dominated by the coccolith assemblage. On the contrary, this suggests the presence of some interfering particles such as reworked coccoliths, biogenic calcite, aragonite fragments or clay as confirmed through light microscope observations.

\subsubsection{Sr/Ca ratios and constraint of the temperature effect}

Although coccolith $\mathrm{Sr} / \mathrm{Ca}$ ratios are primarily controlled by productivity, culture studies (Stoll et al., 2002a) reveal that temperature can exert a significant secondary influence on $\mathrm{Sr} / \mathrm{Ca}$ ratios and that the linear dependence between the two factors varies by a factor of two among different species. In 


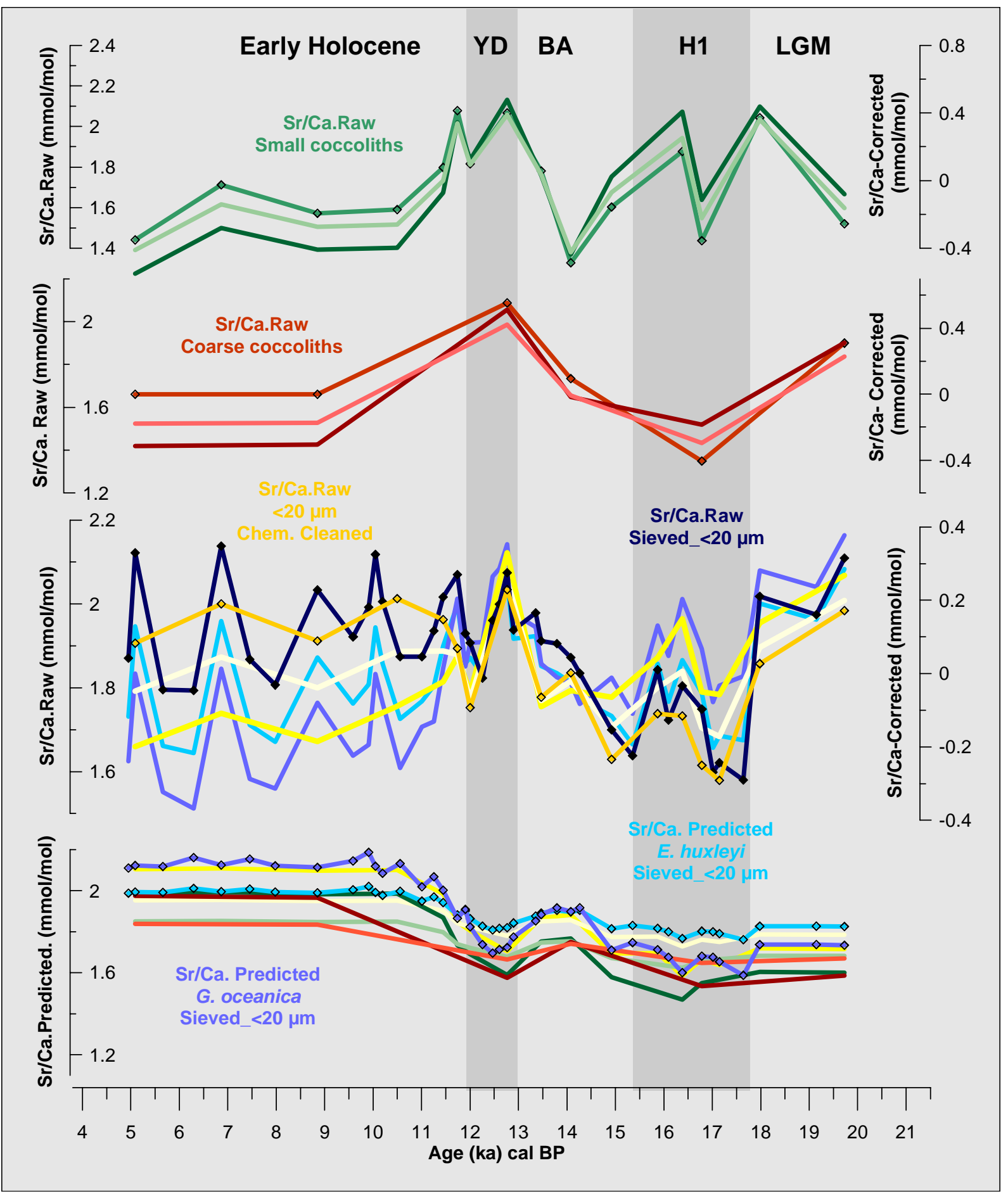

Figure 7.6. Sensitivity analysis of temperature influence on $\mathrm{Sr} / \mathrm{Ca}$ ratios in core MD95-2043 using the alkenonederived surface sea temperature (Cacho et al., 1999). From bottom to top: Predicted $\mathrm{Sr} / \mathrm{Ca}$ of four different fractions: Sieved fraction $(<20 \mu \mathrm{m})$ (blue), sieved fraction $(<20 \mu \mathrm{m})$ chemically cleaned (yellow), separated fractions of coarse coccoliths (red) and separated fractions of small placoliths (green). Raw-measured $\mathrm{Sr} / \mathrm{Ca}(\diamond)$ versus SST-corrected $\mathrm{Sr} / \mathrm{Ca}$ of the sieved fraction $(<20 \mu \mathrm{m})$ (blue) and the sieved fraction $(<20 \mu \mathrm{m})$ chemically cleaned (yellow). Raw-measured $\mathrm{Sr} / \mathrm{Ca}(\diamond)$ versus SST-corrected $\mathrm{Sr} / \mathrm{Ca}$ of separated fractions of coarse coccoliths (red). Raw-measured Sr/Ca $(\diamond)$ versus SST-corrected $\mathrm{Sr} / \mathrm{Ca}$ of separated fractions of small placoliths (green). SST-corrected Sr/Ca obtained using both G. oceanica (dark) and E. huxleyi (light) are shown. 
consequence, to ascertain to which extent temperature influence $\mathrm{Sr} / \mathrm{Ca}$ ratios is necessary to correct the measured record in order to obtain the signal that is likely dependent on productivity. Because coccolith carbonate contributors varies from one fraction to other but there are no available temperature calibrations for some dominant species, we performed a sensitivity analysis (Fig. 7.6) using the lowest (E. huxleyi) and the highest (G. oceanica) temperature dependencies (Stoll et al., 2002a). The alkenone-derived sea surface temperature record of core MD95-2043 (Cacho et al., 1999) was used for the $\mathrm{Sr} / \mathrm{Ca}$ temperature correction of the different fractions.

The temperature- $\mathrm{Sr} / \mathrm{Ca}$ species equations found in Stoll et al. (2002) permit the calculation of the temperature-predicted $\mathrm{Sr} / \mathrm{Ca}$ ratios that are subtracted from the raw-measured $\mathrm{Sr} / \mathrm{ca}$ ratios to obtain the residual or temperature-corrected $\mathrm{Sr} / \mathrm{Ca}$ ratio that is the component that can be attributed to paleoproductivity alone. The temperature correction of the $\mathrm{Sr} / \mathrm{Ca}$ signal is larger during the $\mathrm{H} 1$ event and especially, during the Holocene onset coinciding with greater SST changes. However, the trends in the raw $\mathrm{Sr} / \mathrm{Ca}$ and the temperature-corrected $\mathrm{Sr} / \mathrm{Ca}$ ratios of the four fractions are highly comparable, with small adjustments for the Holocene when the raw $\mathrm{Sr} / \mathrm{Ca}$ ratios show higher values than the SST-corrected $\mathrm{Sr} / \mathrm{Ca}$ ratios (Fig. 7.4). Likewise, the corrected $\mathrm{Sr} / \mathrm{Ca}$ curves resulting from the two extreme temperature dependencies of G. oceanica and E. huxleyi have similar patterns. Hence, we consider that the temperature control on $\mathrm{Sr} / \mathrm{Ca}$ ratios has been successfully constrained and that the temperature-corrected $\mathrm{Sr} / \mathrm{Ca}$ ratios are reliable paleoproductivity indicators.

The temperature-corrected coccolith $\mathrm{Sr} / \mathrm{Ca}$ ratios of the different analyzed fractions reflect significant oscillations in response to the coccolithophore productivity variations during the last $20 \mathrm{ka}$. Despite the lower resolution of the size fractions, all fractions show similar trends with higher ratios during the Last Glacial Maximum and the Younger Dryas (YD) onset and lower ratios during the Heinrich 1 onset, the Bolling-Allerod and the early Holocene.

\subsection{Discussion}

\subsubsection{Sea surface conditions: temperature and meltwater influences}

In agreement with previous studies in the Alboran Sea, oscillations in the coccolith $\delta^{18} \mathrm{O}$ during the last glacial-interglacial transition are related to changes in the sea surface temperature (Cacho et al., 1999; Martrat et al., 2004; Pérez-Folgado et al., 2003) and to meltwater supplies from the Atlantic that reduced surface salinities (Sierro et al., 2005). A decrease in the coccolith $\delta^{18} \mathrm{O}$ during the B-A and the Holocene is associated to warmer SSTs and to a greater freshwater input resulting in less salinity whereas higher coccolith $\delta^{18} \mathrm{O}$ values during LGM and the YD onset might derive from a cooling of surface waters and excess evaporation over precipitacion (Cacho et al., 2000; Sánchez-Goñi et al., 2002). The overall warming during Termination I was interrupted by a prominent and brief cooling 
event marked by a $4{ }^{\circ} \mathrm{C}$ drop and correlated with the Younger Dryas (Cacho et al., 1999). During YD, coccolith $\delta^{18} \mathrm{O}$ shows a more pronounced increase than foraminifera that reflects the transition from BA to YD with a marked shift from wet and warm conditions to cold and dry ones. Similar cold (Cacho et al., 2000; Martrat et al., 2004) and arid (Combourieu-Nebout et al., 2002; Sánchez-Goñi et al., 2002) environmental conditions prevailing at times of $\mathrm{H} 1$ should have result in high surface water densities and comparable high $\delta^{18} \mathrm{O}$ values, however, marked ${ }^{18} \mathrm{O}$ depletion during $\mathrm{H} 1$ contradict this pattern. Therefore, the lowering in $\delta^{18} \mathrm{O}$ values was likely due to an external freshwater input derived from melting icebergs from the North Atlantic (Sierro et al., 2005).

Iceberg melting at times of HE had a profound impact on North Atlantic oceanography although it might have also influenced southern latitudes (Schönfeld and Zahn, 2000; Shackleton et al., 2000). Sierro et al. (2005) suggest that during HE, meltwater from icebergs reached the Mediterranean and caused significant changes in its isotopic signature. At present, the Atlantic waters entering the Mediterranean show $\delta^{18} \mathrm{O}$ values around $0.7 \%$ which isotopic values increase gradually as they flow eastward and mix with the saltier and isotopically heavier Mediterranean waters reaching values around $1.2 \%$ in the Balearic basin (Pierre, 1999). This $\delta^{18} \mathrm{O}$ gradient might have been larger during the LGM when the lower sea level supported decreased water exchange between Mediterranean and Atlantic (Rohling and De Rijk, 1999), thus resulting in the amplification of the Mediterranean Sea as a concentration basin. Therefore, the entrance of Atlantic cold and fresh meltwater during H1 should have caused great contrasts of salinity and density with the Mediterranean outflow that may lead to reduced water mixing, and to a further injection of Atlantic waters into the Mediterranean (Sierro et al., 2005). Moreover, the larger salinity gradient between inflow and outflow waters ought to induce greater volume of water exchange and a more active circulation through the Gibraltar strait.

A detailed examination of the coccolith $\delta^{18} \mathrm{O}$ within the $\mathrm{H} 1$ allows the identification of two phases. The first phase shows lower $\delta^{18} \mathrm{O}$ values $(\approx 16.8 \mathrm{ka}$ ) likely associated to meltwater inputs whereas, by the middle of the $\mathrm{H} 1(\approx 16.3 \mathrm{ka})$ there is a relative increase in the coccolith oxygen isotopes that matches a peak in the polar species N. pachyderma (sin) (Sierro et al., 2005). This second phase, however, presents an offset with respect to the G. bulloides oxygen isotopes that may be due to the different seasonality of the organisms. G. bulloides is characteristic of upwelling conditions and in the Alboran Sea, may exhibit a strong unique bloom in May whereas coccolithphores such as G. oceanica and the small placoliths, the main components of the small coccoliths fraction, also present high fluxes in early summer and mid-fall (Bárcena et al., 2004; Hernández-Almeida et al., 2010). Since lower meltwater inputs may occur at summertimes, coccolithophores living at that season may register higher $\delta^{18} \mathrm{O}$ as a consequence of a freshwater decrease coincident with prevailing cold conditions.

In the Alboran Sea, the deglaciation is characterized by an intensive reorganization of the water dynamics due to the climatic transition from the last glacial to the present interglacial and the 
subsequent sea level and temperature rises. The different episodes of sea level rise and infill of the Mediterranean basin after the glacial lowstand seem to have generated a variety of scenarios in where SSTs, volume of water exchange and the degree of stratification of the upper layers of the water column controlled water and coccolithophore dynamics.

\subsubsection{Paleoproductiviy variations during the last $20 \mathrm{ka}$}

The coccolith $\mathrm{Sr} / \mathrm{Ca}$ curves of core MD95-2043 track the large coccolithophore productivity fluctuations in the Alboran Sea since the Last Glacial Maximum. All fractions exhibit decreases during warmer intervals like the Bolling-Allerod and the Holocene in contrast with significantly increases during the colder periods of the Last Glacial Maximum and the Younger Dryas (YD). The Heinrich 1 onset, however, presents low $\mathrm{Sr} / \mathrm{Ca}$ ratios (Fig. 7.7).

The lower $\mathrm{Sr} / \mathrm{Ca}$ ratios of both the $<20 \mu \mathrm{m}$ fractions and size fractions during the first part of $\mathrm{H} 1$ event indicate reduced coccolithophore productivity which is in full agreement with a decrease of coccolith $\delta^{13} \mathrm{C}$ and with previous geochemical (Cacho et al., 2000) and micropaleontological studies. On one hand, total organic carbon and total alkenones display a consistent pattern of decreased productivity during D-O stadials and Heinrich events (Moreno et al., 2004; 2005). On the other hand, both diatoms and coccolithopores reflect low abundances at $\mathrm{H} 1$ times coincident with a relative decrease in the $\mathrm{N}$ ratio (Bárcena et al., 2001; Colmenero-Hidalgo et al., 2004). The $\mathrm{N}$ ratio is the relationship between the main surface eutrophic species, E. huxleyi and Gephyrocapsa spp. $<3 \mu \mathrm{m}$, and the most abundant inhabitant of the lower photic zone, $F$. profunda, and has been used as a productivity and upwelling indicator (Beaufort et al., 2001; Beaufort et al., 1997; Flores et al., 2000). Lower Sr/Ca ratios during a first phase of $\mathrm{H} 1$ correlate with a decrease of coccolith and foraminifera $\delta^{18} \mathrm{O}$ (Fig. 7.4), therefore, low productivity might be the result of the entrance of meltwater from icebergs in the Atlantic that would induce strong stratification of the water column and hamper vertical mixing (Sierro et al., 2005). Although H1 temperatures in Alboran are not so different from LGM ones, the entrance of Atlantic meltwater during H1 supposed a drastic change in salinity values, which effect was amplified by the preexisting high salinity due to the LGM low sea level. It seems that, during this event, salinity changes had a more direct and immediate impact in Alboran area productivity than temperature variations did. A fresher, colder, and probably more turbid upper layer would have produced a deepening of the nutricline and favoured F. profunda growth. However, F. profunda is not a common taxon in the Western Mediterranean (Flores et al., 1997; Sbaffi et al., 2001), and its abundances during $\mathrm{H} 1$, despite a relative increase, are lower than $10.5 \%$ on average. It seems that low SST might have prevented this taxon from occurring in higher abundances (Colmenero-Hidalgo et al., 2004). The fact that $\mathrm{N}$ ratio values are always higher than 0.5 indicates that small placoliths, although decreasing, still dominate the assemblage during H1. Additionally, a wide range of studies on marine records 


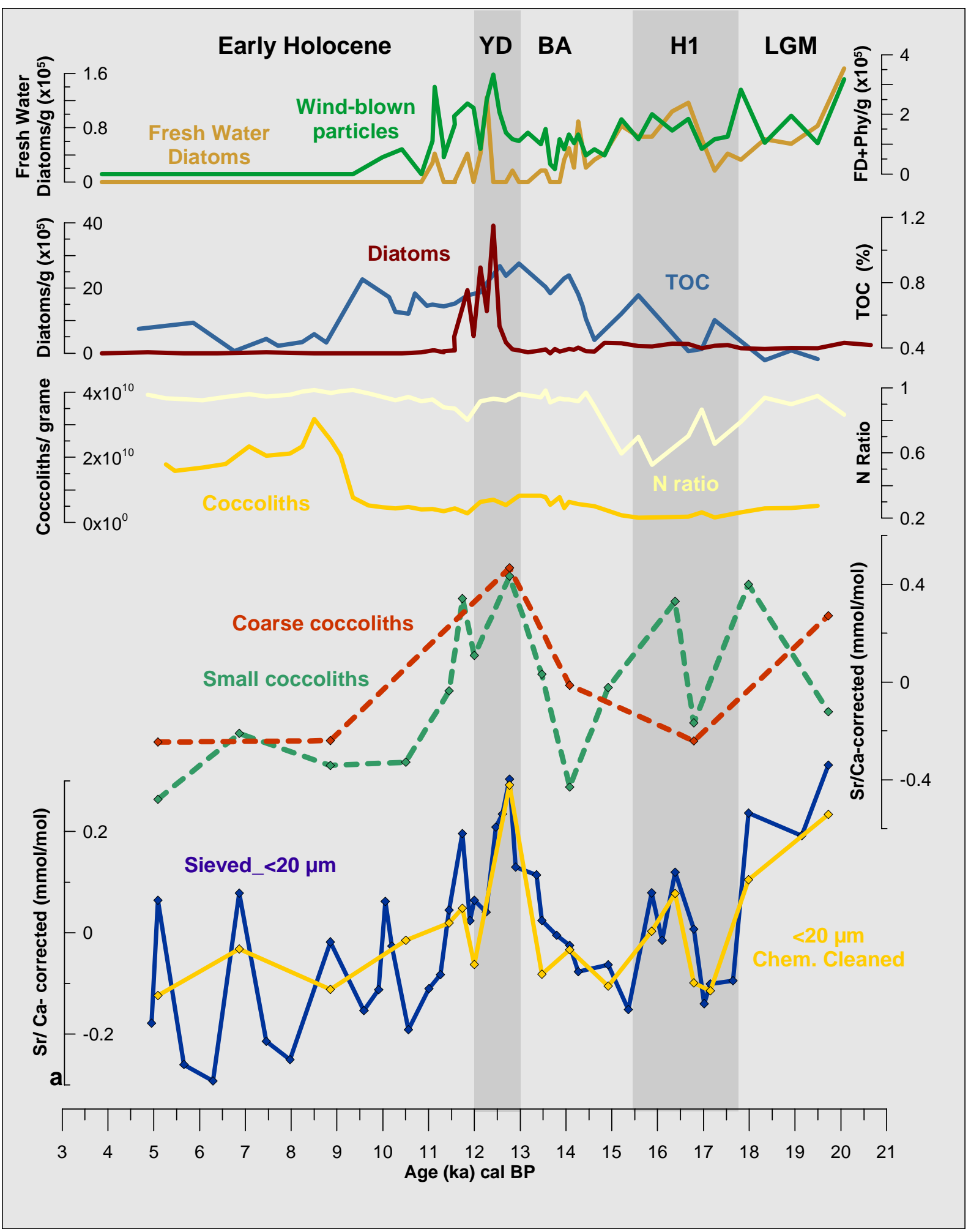

Figure 7.7. Temporal distribution of SST-corrected $\mathrm{Sr} / \mathrm{Ca}$ ratio $(\mathrm{mmol} / \mathrm{mol})$ from core MD95-2043. From bottom to top: Sieved fraction $(<20 \mu \mathrm{m})$ and sieved fraction $(<20 \mu \mathrm{m})$ chemically cleaned. Separated fractions of small cocoliths (Gephyrocapsa spp. + E. huxleyi) and coarse coccoliths (H. carteri + C. leptoporus) and comparison with: coccoliths absolute abundance (coccoliths/g), $\mathrm{N}$ ratio (ratio small placoliths $/ F$. profunda) (ColmeneroHidalgo et al., 2004), diatoms absolute abundance (diatoms/g), percentage of total organic carbon, fresh water diatoms absolute abundances and windblown particles absolute abundance $=$ fresh water diatoms + opal phytoliths (Bárcena et al., 2001). Vertical bands represent Younger Dryas (YD), Bolling-Allerod (BA), Heinrich 1 (H1) and Last Glacial Maximum (LGM). 
(Bárcena et al., 2001; Combourieu-Nebout et al., 2002; Fletcher and Sánchez Goñi, 2008; SánchezGoñi et al., 2002), and lakes (Bartov et al., 2003) reflect increase aridity and restricted rainfall and runoff during HE. Therefore, the combined effect of restricted access of nutrients to surface and lack of significant riverine nutrients supplies lead to limited nutrient availability in the upper photic zone and, hence, to low coccolithopore productivity during the $\mathrm{H} 1$ onset.

A close examination of the coccolith geochemical proxies within the $\mathrm{H} 1$ indicates a first phase of the $\mathrm{H} 1$ with lower $\mathrm{Sr} / \mathrm{Ca}$ ratios and coccolith $\delta^{13} \mathrm{C}$ and $\delta^{18} \mathrm{O}$ and a second phase with a relative increase of both $\mathrm{Sr} / \mathrm{Ca}$ ratios and coccolith stable isotopes that may indicate a decrease in the meltwater input, the reduction of the stratification and a relative increase in the coccolithophores productivity.

During the period between the $\mathrm{H} 1$ and the Bolling-Allerod, $\mathrm{Sr} / \mathrm{Ca}$ ratios of different fractions are generally low, consistent with low values of coccolith $\delta^{13} \mathrm{C}$ and coccolithophore and diatoms abundances but contrast with an increase of TOC (Fig. 7.7). However, previous studies (Cacho et al., 2002; Rogerson et al., 2008) suggest that the increase of TOC and alkenones concentrations around 14.5 ka marks the onset of the youngest organic rich layer in the Alboran Sea. This ORL has been mainly associated to poor bottom ventilation during the deglaciation, although, at least during the YD period, enhanced primary productivity may have contributed substantially to its formation (Bárcena et al., 2001; Cacho et al., 2002). Therefore, productivity during Termination Ia and B-A in the Alboran Sea might have been lower than during the previous (H1 phase 2) and subsequent (YD) intervals.

The Younger Dryas onset, in turn, is marked by a significant increase in the $\mathrm{Sr} / \mathrm{Ca}$ ratios and the $\delta^{13} \mathrm{C}$ of all the coccolith fractions and of the G. bulloides. This increase is in agreement with the trend of a wide range of paleoproductivity proxies from previous studies in the same core $\left(\mathrm{C}_{37}\right.$ alk, Cacho et al., 2000; TOC and diatoms, Barcena et al., 2001; N ratio, Colmenero-Hidalgo et al., 2004) and in nearby cores (TOC and $\mathrm{Ba}$ excess, Jimenez-Espejo et al., 2008; Martinez-Ruiz et al., 2004; Rodrigo-Gámiz et al., 2011). This common response of enhanced productivity is interpreted as an increase in the nutrient-richer Atlantic inflow and the prevalence of westerlies winds that induce higher water mixing and the subsequent development of the anticyclonic gyres and the upwelling cells.

During colder periods like the YD event, the ITCZ migrated southward and a low-pressure system established over the Western Mediterranean Sea together with stronger westerlies (Bárcena et al., 2001; COHMAP Members, 1988; Rodrigo-Gámiz et al., 2011) (Fig. 7.7, peak of wind-blown particles). The lower atmospheric pressure over the WMS has the direct effect of increasing the inflow of Atlantic waters through the Strait of Gibraltar resulting in a change in the size of the Western Alboran Gyre (Macías et al., 2008). Furthermore, the Azores Front penetrated eastward into the Gulf of Cadiz during the YD (Rogerson et al., 2004) which might have contributed to a highly fertilized Atlantic inflow since the AF is associated with vigorous frontal upwelling (Alves et al., 2002). Under 
these environmental conditions, opportunist species such as Gephyrocapsa sps. and E. huxleyi or species adapted to turbidity and changing environments like H. carteri (Giraudeau, 1992; Ziveri et al., 1995) proliferated (Colmenero-Hidalgo et al., 2004; Sprovieri et al., 2003) (See fig. 7.2).

On the other hand, some recent studies suggest increase of fluvial discharges during the YD (JimenezEspejo, 2007; 2008; Rodrigo-Gámiz et al., 2011) despite the dominant aridity conditions indicated by pollen studies (Fletcher and Sánchez Goñi, 2008; González-Sampériz et al., 2008; Sánchez-Goñi et al., 2002) and high abundances of fresh water diatoms (Bárcena et al., 2001; Fig. 7.7). Apart from an intra YD warm/wet event with sporadic rainfalls, one possible explanation would be freshwater injections derived from glacier melting in the high regional mountains around the Western Mediterranean basin that may have supplied additional nutrients supporting enhanced productivity (Bárcena et al., 2001; Jimenez-Espejo et al., 2008; Rodrigo-Gámiz et al., 2011; Sancetta, 1994; Schulte, 2002). However, since a possible melwater input is not reflected in the $\delta^{18} \mathrm{O}$ values, this hypothesis is still untested.

Concerning the early Holocene, since $12 \mathrm{ka}$, the coccolith $\mathrm{Sr} / \mathrm{Ca}$-derived productivity ratios are generally low although the $<20 \mu \mathrm{m}$ fraction shows a heterogeneous tendency with pronounced variations.

There is a large dataset of productivity proxies available from this core that is presented here for comparison and that shows rather different productivity signals for the early Holocene (Fig. 7.5 and 7.7). On one hand, coccolith $\mathrm{Sr} / \mathrm{Ca}$ ratios and $\delta^{13} \mathrm{C}$ of size fractions show general low values coincident with minima diatom abundances and a decrease of the TOC after 9 ka (Bárcena et al., 2001) related to the demise of the organic rich layer (Rogerson et al., 2008). These evidences indicate decreased productivity during the early Holocene that is in agreement with other paleoproductivity studies in the Alboran Sea (Abrantes, 1988; Jimenez-Espejo et al., 2008; Rodrigo-Gámiz et al., 2011). On the other hand, $\mathrm{N}$ ratios are constantly high during the early Holocene (11-5 ka) whereas the absolute coccolith abundances show a pronounced peak around $8.5 \mathrm{ka}$ and remain high until modern times although, the assemblage composition does not exhibit significant changes (Colmenero-Hidalgo et al., 2004).

Despite the contradictory productivity signals, the different studies (Colmenero-Hidalgo et al., 2004; Jimenez-Espejo et al., 2008; Jimenez-Espejo et al., 2007) suggest that the productivity variations around $8.5 \mathrm{ka}$ are related to the same climate change, the abrupt event about 8.2 ka when cold and dry conditions prevailed in broad northern-hemisphere regions (Alley and Ágústsdóttir, 2005). Colmenero-Hidalgo et al. (2004) suggest that the increase in coccolithophore abundances is due to the onset of the upweling cells in the Alboran Sea whereas Jimenez-Espejo et al. (2007) indicate that after the 8.2 event, the Western Mediterranean is characterised by hot and dry climatic conditions (Jalut et al., 2000) and low marine productivity. 
Our results support the interpretation that productivity in the Alboran Sea during the early Holocene was low due to the prevalence of warm and dry conditions associated to a stable high-pressure system that determined the reduction of the Atlantic inflow and the upwelling cells. Nonetheless, the explained discrepancies require further investigation to better constrain the productivity signal of the Alboran Sea during the Holocene.

\subsection{Conclusions}

Repeated decanting and microfiltration allowed the separation of size coccolith fractions highly enriched in the coccolith carbonate from target species with the small coccoliths (Gephyrocapsa spp. + E. huxleyi) fractions achieving carbonate concentrations of $75 \%$ on average.

Stable isotopes and $\mathrm{Sr} / \mathrm{Ca}$ ratios of restricted coccolith fractions were used to reconstruct sea surface conditions and productivity patterns throughout the last $20 \mathrm{ka}$ which oscillations may have been related to changes in the atmospheric conditions, the volume water exchange with the Atlantic and the vertical mixing of the water column. Such variations suggest that the Alboran Sea is strongly connected with both high and low latitudes and respond to climatic variability occurring either in the North Atlantic and/or in Tropical regions.

Variations in the coccolith $\delta^{18} \mathrm{O}$ since last glacial maximum were associated to changes in the SSTs and to meltwater inputs from the Atlantic during H1 that may have caused large density contrasts within the Mediterranean and a subsequent reduction of water mixing despite greater volume of water exchange and a more active circulation through the Gibraltar strait.

Despite the olygotrophy in most of the Mediterranean, mesotrophic scenarios occur in the Alboran Sea as a result of combined, interaction between Atlantic and Mediterranean waters and wind-induced upwelling. The Atlantic inflow increases nutrients availability whereas aeolian and fluvial inputs provide mineral nutrients.

During H1, the intense stratification blocked the upwelling and prevented Atlantic nutrients from moving upward and accessing the upper photic zone. At YD times, the southward migration of the ITCZ enabled the establishment of a low-pressure system and the intensification of the westerlies inducing a reactivation of water mixing and a shallower nutricline, that, together with extra riverine nutrients inputs, lead to high marine productivity. Productivity during Termination Ia and B-A and during early Holocene might have been low in the Alboran Sea as result of weaker westerlies and reduced Atlantic inflow and upwelling associated to a northward migration of the ITCZ and the prevalence of high atmospheric pressure over the Western Mediterranean. 

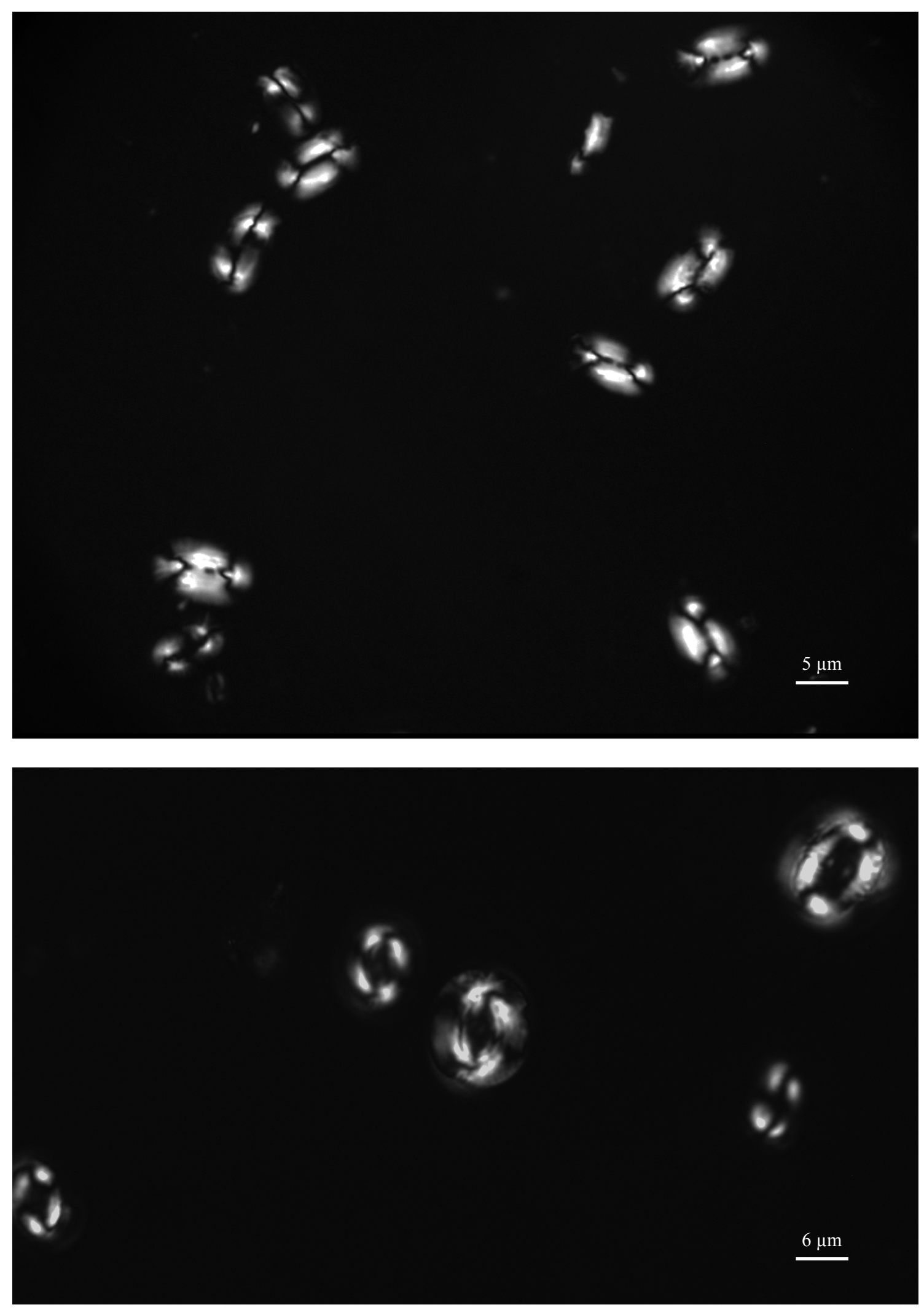

Plate 7.1. LM images of isolated fractions dominated by the surface dwellers Helicosphaera carteri (up) and Coccolitus pelagicus (down). 

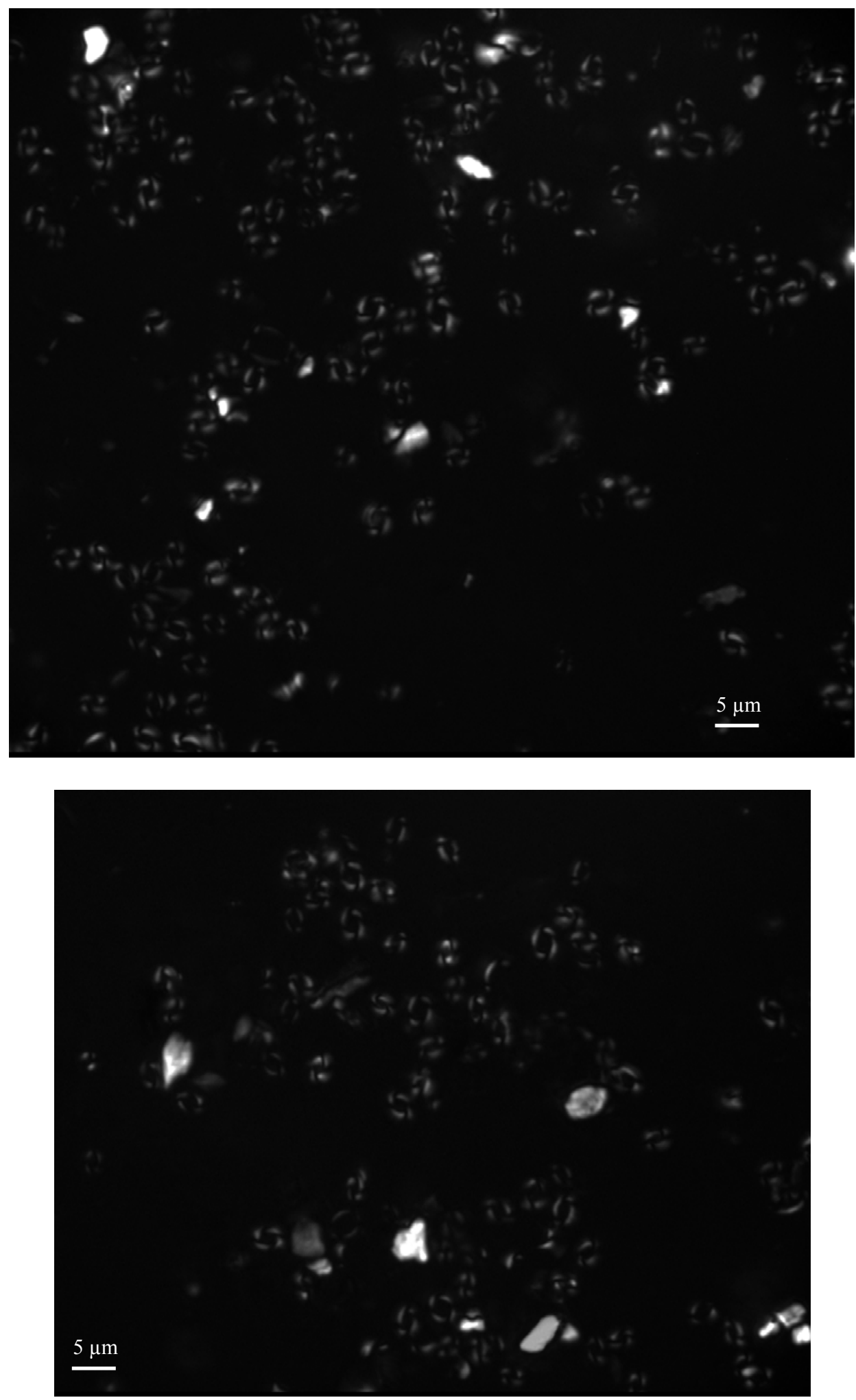

Plate 7.2. LM images of isolated fractions dominated by the cosmopolitan E. huxleyi and Gephyrocapsa spp. 




\title{
Variability in the coccolithophore geochemical imprint off NW Africa during the last 32 ka: the role of the Intertropical Convergence Zone
}

Débora Simón-Baile ${ }^{1}$, Heather M. Stoll ${ }^{2}$, Patrizia Ziveri ${ }^{3}$, José A. Flores ${ }^{1}$, Francisco J.Sierro ${ }^{1}$, María A. Bárcena ${ }^{1}$, Alejandra Mejía-Molina ${ }^{1}$.

1. Área de Paleontologia, Departamento de Geologia, Universidad de Salamanca, 37008, Salamanca, Spain

2. Departamento de Geología, Universidad de Oviedo, Oviedo, 33005, Spain

3. Institut de Ciència i Tecnologia Ambientals, Universitat Autónoma de Barcelona, 08193, Spain

\begin{abstract}
The present study undertook analyses of core MD03-2705, recovered from the Mauritanian margin and located under the direct influence of the Intertropical Convergence Zone (ITCZ) and within the Saharan dust plume. Enriched species-specific coccolith fractions were analyzed for $\mathrm{Sr} / \mathrm{Ca}$ ratio and $\delta^{18} \mathrm{O}$ to reconstruct changes in productivity and sea surface conditions during the last $32 \mathrm{ka}$. Repeated decanting and microfiltering techniques (Stoll and Ziveri, 2002) allowed the separation of two size fractions from every sample, dominated to high degrees by the coccolith carbonate from a single genera although, the efficiency of separations was better for the coarse coccoliths fractions $(91.5 \%$ on average) than for the small coccoliths fractions. A significant depletion in the $\delta^{18} \mathrm{O}$ between the Last Glacial Maximum-deglaciation and the onset of the Holocene marks the glacial/interglacial boundary. It seems that part of the glacial-Holocene temperature differences may be explained by a switch in the seasonal timing of coccolithophore proliferation, from summer during glacial times to a double peak in summer and winter at present. The $\mathrm{Sr} / \mathrm{Ca}$-derived productivity record shows generally low values during MIS 3 and LGM but pronounced changes and a larger instability during the deglaciation. Productivity variations in the area are determined by changes in wind stress and direction produced by the ITCZ latitudinal migration that drive fluctuations in the position and intensity of the upwelling cell as well as in its seaward extension. ITCZ seems to be a major controlling factor, a southward latitudinal shift may be responsible for the strong upwelling and increased productivity at Heinrich 1 times while a northward migration resulted in the stratification of surface waters and lower productivity during the early Holocene. High productivity during the Bolling Allerod might derive from the distinct ecological preferences of the group of coarse coccolithophore species (C. leptoporus and $H$. carteri) which proliferate in mesotrophic environments, whereas at Younger Dryas times, the massive dust input $(80 \%)$ from the neighbouring Sahara may have altered the isotopic signal and caused low productivity due to a drastic reduction of light availability.
\end{abstract}

Keywords: $\mathrm{Sr} / \mathrm{Ca}$ ratios, coccolith $\delta^{18} \mathrm{O}$, off Mauritania, ITCZ, upwelling, Saharan dust, deglaciation 


\subsection{Introduction}

Whereas Northern Atlantic is widely accepted to be the active trigger of both abrupt and long-term climatic changes, low-latitude regions have been largely considered to play a passive role during the last glacial/interglacial period (Alley and Clark, 1999). However, recent studies document that orbital scale and stadial/interstadial rearrangements in the tropical hydrological cycle would have a global impact on concentrations of water vapour affecting the heat transfer from tropics to northern latitudes and, ultimately, the emissions of greenhouse gas $\mathrm{CH}_{4}$ from wetland areas (Loulergue et al., 2008; van Huissteden, 2004) and point out the relevant role of the tropical regions in the global climatic regulation on the basis of a clear connection between high and low latitudes through the hydrological and atmospheric systems (Broecker, 2003; Ivanochko et al., 2005; Lea et al., 2003; Sirocko et al., 1996; Weldeab et al., 2007). Several reconstructions propose that cooling derived from massive iceberg discharge into the subarctic Atlantic could have been propagated into the subtropical Atlantic via the Canary current (Romero et al., 2008; Zhao et al., 1995). In parallel, Jullien et al. (2007) and Mulitza et al. (2008), identify a series of low-latitude "dusty" and arid events and suggest synchronicity between them and the classic high-latitude Heinrich events. This, being a remote response to a large-scale atmospheric and hydrological reorganization that could be amplified by a tropical phenomenon like the monsoon and would foster a subsequent shift in the mean position of the Intertropical Convergence Zone (Broccoli et al., 2006; deMenocal et al., 2000; Ivanochko et al., 2005; Tisserand et al., 2009).

In the Northwest African coast, ITCZ latitudinal displacements govern the regional climatic conditions and lead to intense seasonal changes which hydrologically, are mainly reflected in sea surface temperature variations (deMenocal et al., 2000). Likewise, ITCZ south migration drives a strengthening of the northeast trade winds and the resultant intensification of the coastal upwelling (Martinez et al., 1999; Romero et al., 2008). The seasonal range of ITCZ location changes could be extrapolated to a stadial/interstadial millennial-scale, with southward displacements during colder periods and northward during humid and warmer ones (Ivanochko et al., 2005; Jullien et al., 2007).

In order to gain better understanding of the nature of the NE Tropical Atlantic climatic scenarios variability during the last $32 \mathrm{ka}$, we need to identify the different marine and atmospheric processes involved, the linking between the underlying mechanisms and, their potential to propagate from a regional to a global scale. For this purpose, we undertook studies over a well-dated piston core (MD03-2705) from the Mauritanian margin directly influenced by the ITCZ and the tropical monsoon dynamics. Furthermore, the core is positioned within the summer African dust plume and provide a valuable record of the Saharan terrigenous supply and eolian transport already characterized by lithogenic data on dust (\%) and Ti/Al (Jullien et al., 2007). We present the calcareous nannoplankton 
and diatoms fluxes and integrate them, together with our innovative results from coccolith chemistry to trace the ITCZ fluctuations.

For the present work, restricted coccolith fractions were analyzed for $\mathrm{Sr} / \mathrm{Ca}$ ratio and stable isotopes $\left(\delta^{18} \mathrm{O}\right.$ and $\left.\delta^{13} \mathrm{C}\right)$ intending to reconstruct past changes in productivity and sea surface conditions during the last $32 \mathrm{ka}$ and to further assess the climatic processes that might drive such variations during this time interval. Coccolith calcite chemistry can provide valuable and innovative information, because, unlike foraminifera, coccolithophores are calcareous primary producers geographically widespread that have a direct link to the upwelling dynamics and because both organic and inorganic remains enjoy long term preservation in marine sediments (Stoll and Ziveri, 2004). Furthermore, they exhibit a specific seasonality cycle and a more restricted distribution within the water column that can serve to reconstruct the stratification of the water masses.

Field and culture studies document a strong dependence of coccolith calcification rate on $\mathrm{Sr}$ partitioning and this is useful for inferring past variations in coccolithophore productivity (Rickaby et al., 2002; Stoll et al., 2007a; 2002a; 2002b; 2007b). However, Sr/Ca ratios of different coccolith species present different absolute values as well as a distinct range of $\mathrm{Sr} / \mathrm{Ca}$ variation (Stoll et al., 2007). $\mathrm{Sr} / \mathrm{Ca}$ ratios obtained from monospecific picked samples (Auliaherliaty et al., 2009) confirm that larger coccoliths show both higher and more variable values than smaller coccoliths.

Stable isotopic measurements on coccoliths reveal the changes in salinity and temperatures of the waters at the depth and season of peak coccolithophore productivity. While coccolithophores cultures revealed a large (5\%) array of both oxygen and carbon isotopic fractionation among different species, they also corroborate constant and species-specific vital effects that seem to be first-order related to the volume-to-surface area ratio and therefore, confirm the reliability of monospecific coccolith stable isotopes in paleoceanographic reconstructions (Ziveri et al., 2003). Recent techniques, although time consuming, permit the separation and concentration of different species of coccoliths (Minoletti et al., 2001; Minoletti et al., 2008; Stoll and Ziveri, 2002).

\subsection{Climatic and oceanographic setting}

The present-day climatic scenario off Northwest Africa is primarily controlled by the latitudinal migration of the Intertropical Convergence Zone whose displacements are coupled with insolation changes. ITCZ is a major tropical feature that separates the dry subtropical air masses from the moonsonal moist system predominant in equatorial latitudes. 

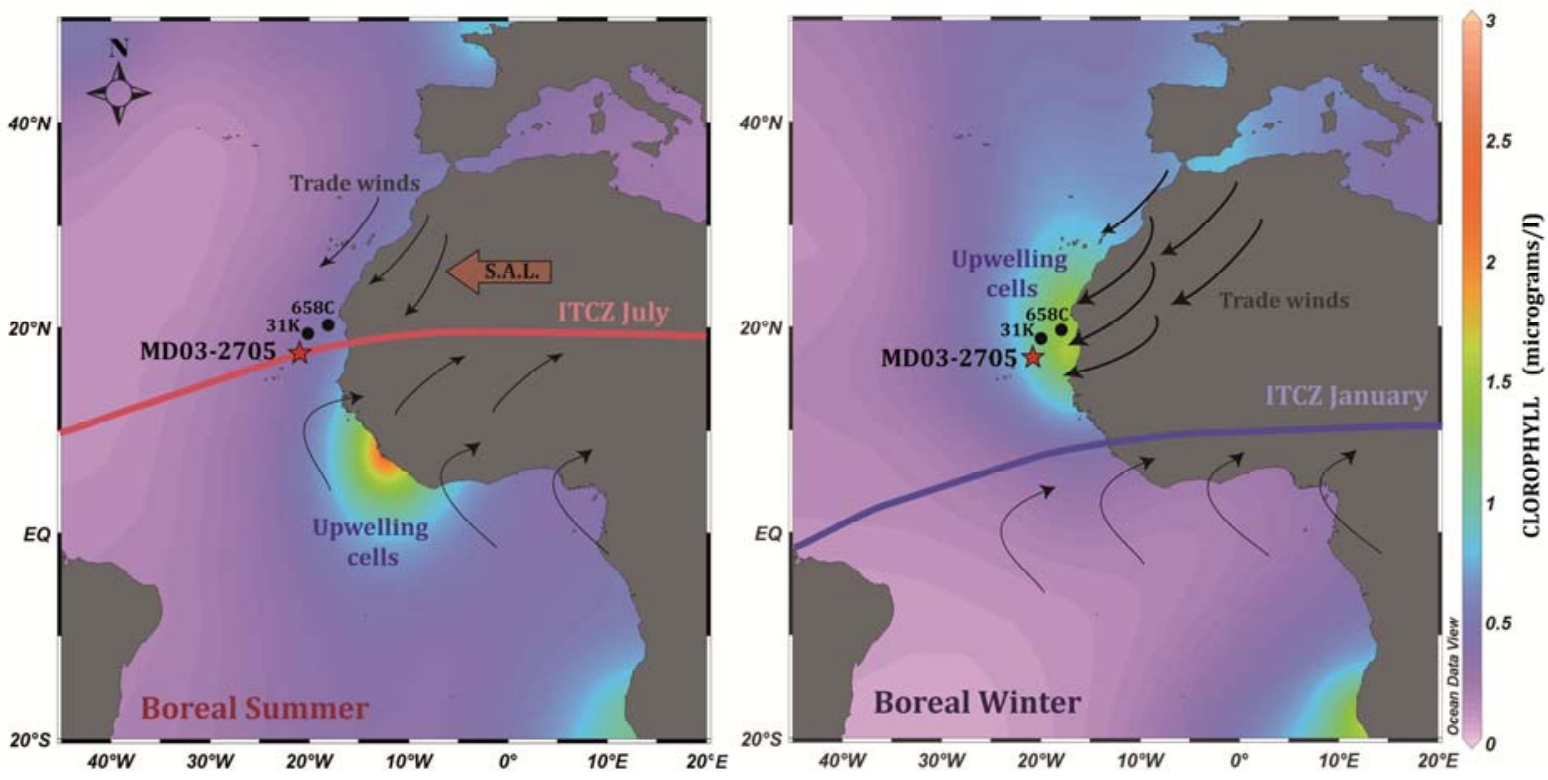

Figure 8.1. Location of core MD03-2705, clorophyll concentration and main atmospheric circulation in the NW African margin during summer (left) and winter (right). Cores ODP658C and BOFS 31K are also indicated.

During boreal summer, ITCZ reaches its most northerly position at $\approx 20^{\circ} \mathrm{N}$ and extends the humid monsoonal conditions northward into subtropical Africa. It confines dry trade winds and dust transport to northern Sahara and fosters the development of the Saharan Air Layer, a mass of dusty air that extends at higher altitudes (between 1500 and $6000 \mathrm{~m}$ ) and unloads dust over the Atlantic as far west as the Caribbean Sea (Dunion and Velden, 2004; Prospero and Lamb, 2003; Stuut et al., 2005). The summer African dust plume spreads between 15 and $25^{\circ} \mathrm{N}$ following the eastern direction of the transporting winds and blocked southerly by the ITCZ position.

In boreal winters, the African landmass cools faster than the ocean and induces regional atmospheric regime inversion. The equatorward migration of the ITCZ to $5^{\circ} \mathrm{N}$ enables the expansion of dry and strong NE trade winds to southern latitudes. Winter is the season when the Harmattan, a continental trade wind, blows southwestward at lower altitudes leading to the supply of more frequent and heavier eolian inputs into the ocean that fertilize the waters through mineral micronutrients (Chiapello et al., 1995). Site MD03-2705 is situated in the north boundary of the current winter Saharan dust plume (5$20^{\circ} \mathrm{N}$ ), but, directly below the axis of the summer dust plume which is the world's greatest source of dust to the atmosphere (Mulitza et al., 2010; Prospero et al., 2002) with almost half a billion tons per year.

In past climates, variations in maximum of insolation caused different interhemispheric temperature gradients and produced southward migrations of the ITCZ during colder periods (Broccoli et al., 2006; Tisserand et al., 2009). The ITCZ displacement exerts a strong influence on both the atmospheric and 
oceanic systems conditioning the strength and position of the trade winds and, therefore, the intensity and persistence of the upwelling off NW Africa.

The northeasterly trade winds off NW African margin induce surface water divergence and determine an intense coastal upwelling which exhibits a strong seasonal cycle and high Chl-a concentrations $\left(>1.0 \mathrm{mg} \mathrm{m}^{-3}\right.$ ) from January to June, typically peaking in Febraury-March (Pradhan et al., 2006). Upwelling persists throughout the year around $20^{\circ} \mathrm{N}$, where the Canary Current (CC) meets the North Equatorial Countercurrent and leaves the African coast. The $\mathrm{CC}$ flows south along the coast and is underlain by the South Atlantic Central Water (SACW), a less saline and nutrient-rich water mass that flows north between 200 and 600 m (Hernández-Guerra et al., 2005; Stramma et al., 2005). Beneath the SACW, and flowing southward, lies the saltier and nutrient-poorer North Atlantic Central Water (NACW). Resulting from the crossroad of water masses from both North and South Atlantic origin, upwelled waters, with SSTs below $17^{\circ} \mathrm{C}$ (Mittelstaedt, 1991), bring nutrients to surface and induce high biomasses and elevated primary productivity (Martinez et al., 1999; Romero et al.,2008). Although the upwelling is largely confined to coastal waters, its impact extends $300-600 \mathrm{~km}$ offshore, through Ekman flow, eddies and filaments (Hill et al., 1998; Pradhan et al., 2006).

\subsection{Materials \& Methods}

Core MD03-2705 was retrieved off the Mauritanian coast (18 $05 \mathrm{~N}, 21^{\circ} 09 \mathrm{~W} ; \approx 500 \mathrm{~km}$ offshore) during the IMAGES Calypso coring cruise onboard the R/V Marion Dufresne. The core was recovered at $3085 \mathrm{~m}$ water depth from a seamount connecting the Cabo Verde Archipielago to the African coast, and therefore, not disturbed neither by bottom current advection nor by fluvial discharge (Kolla et al., 1979; Moyes et al., 1976). This continuous marine record is made of two components, the major biogenic input, and the terrigenous aeolian fraction, largely constituted of Sahara/Sahel aerosols. The biogenic fraction is mostly composed of calcareous foraminifera and coccoliths, since the biogenic opal contribution is less than $5 \%$ (Adkins et al., 2006; deMenocal et al., 2000). Accordingly, $\%$ Dust $=100-\%$ carbonate $\left(\mathrm{CaCO}_{3}\right)$ (Jullien et al., 2007).

The age model for the last $31 \mathrm{ka}$ (Jullien et al., 2007) was built from eight AMS ${ }^{14} \mathrm{C}$ ages determined on monospecific samples of the planktonic foraminifera Globigerina bulloides. Additionally, the chronology of the core was better constrained by the correlation between the $\delta^{18} \mathrm{O} / \delta^{13} \mathrm{C}$ record of benthic foraminifera and the LR04 Stack (Lisiecki and Raymo, 2005), and by the $\delta^{18} \mathrm{O}$ benthic record of the neighbouring core ODP-658C (deMenocal et al., 2000). 


\subsubsection{Separation of coccoliths size fractions for inorganic chemistry analysis}

Recent techniques to separate different size fractions of coccoliths permit the concentration of sediment fractions dominated to high degrees by the coccolith carbonate of a single species.

Repeated decanting (Stoll and Ziveri, 2002) and microfiltration (Minoletti et al., 2001) allow separation and concentration of restricted coccolith assemblages to be analized for stable isotopes $\left(\delta^{18} \mathrm{O}\right.$ and $\left.\delta^{13} \mathrm{C}\right)$ and $\mathrm{Sr} / \mathrm{Ca}$ ratio. For samples from core MD03-2705, chemical cleaning and gentle mechanical disaggreagation were conducted in order to minimize the formation of aggregates following the protocol as in Stoll and Ziveri (2002).

A fraction enriched in the smallest coccoliths was obtained following the repeated decanting procedure of Stoll and Ziveri (2002), and using a settling distance of $5 \mathrm{~cm}$, repeated 3 times, with settling time between 100 and $300 \mathrm{~min}$.Some of the samples, were subsequently separated using a 3 and/or $5 \mu \mathrm{m}$ polycarbonate membranes. The largest coccoliths were concentrated from the $<20 \mu \mathrm{m}$ fraction by combining a set of repeated decanting steps $(5 \mathrm{~cm}, 3$ times, 7-30 min) with microfiltering through 8 and $10 \mu \mathrm{m}$ polycarbonate membranes. Light microscope analyses were conducted in any given step throughout the separation in order to monitor the progress of the separation techniques. In addition, the total bulk and the fine bulk fraction $(<20 \mu \mathrm{m})$ were analysed for $\mathrm{Sr} / \mathrm{Ca}$ ratios, although stable isotope data were not collected on the total bulk fraction. To increase resolution of the $\mathrm{Sr} / \mathrm{Ca}$ record, we analysed 60 additional samples of the $<20 \mu \mathrm{m}$ fraction with no oxidative or reductive cleaning steps.

For $\mathrm{Sr} / \mathrm{Ca}$ analyses, splits of the fractions were dissolved in $0.1 \mathrm{M}$ acetic acid/ammonium acetate buffer, and diluted to be measured via simultaneous dual ICP-AES (Thermo ICAP DUO 6300) at the University of Oviedo. Calibration was conducted following the intensity ratio method as described in de Villiers et al. (2002). Stable isotopes were measured at Vrije University Amsterdam using the mass spectrometers Finnigan 252 equipped with an automated carbonate extraction line (Kiel Device) and a Finnigan Gasbench with Delta ${ }^{+}$. Sample reproducibility and comparison of carbonate standard is better than $0.15 \%$ for $\delta^{18} \mathrm{O}$ with a standard deviation between 0.05 and 0.2 . The mean reproducibility of replicate analysis was $0.1 \%$. The results are relative to the Vienna Pee Dee Belemnite (VPDB).

\subsubsection{Coccolith assemblages and carbonate contribution}

For the separated fractions, a wet split of each fraction was filtered onto a $0.45 \mu \mathrm{m}$ cellulose nitrate filter that was successively oven dried. A portion of the filter was mounted on a glass slide and made transparent with immersion oil for light microscopy. On the other hand, the original-bulk samples were prepared for coccolith analyses following the settling technique of Flores and Sierro (1997). 
Coccolith counts (400 per sample) of both separated and original samples were performed under polarised Light Microscope Leica DMRXE at 1000x magnification.

The coccolith carbonate contribution was assessed following the method described in Young and Ziveri (2000) that comprises the calcite density $\left(2.7 \mathrm{pg} \mathrm{\mu m}^{-3}\right)$, a species-specific shape factor $\left(\mathrm{k}_{\mathrm{s}}\right)$ and the average length of a species in microns (1); (coccolith weight $(\mathrm{pg})=2.7 \mathrm{k}_{\mathrm{s}} 1^{3}$ ). To minimize potential source of errors due to size variation of individual species between samples, it is essential to calibrate the size range of at least the most volumetrically abundant coccoliths (Baumann et al., 2004; Sprengel et al., 2000; Young and Ziveri, 2000). The actual size of a mimimum of 50 specimens was measured by light microscopy at 1600x magnification, which reduced the volume error calculation of about $15-30 \%$. Given the different size distribution in some of the species measured (C. leptoporus and C. pelagicus), the mean volume was calculated instead of using a simple mean length. Otherwise the coccolith volume will have been underestimated with an error of up to $17 \%$

\subsection{Results}

\subsubsection{Efficiency of separations}

Species-specific coccolith relative abundance and carbonate contribution in the original samples and the separated fractions are shown in Figs. 8.2 and 8.3. The small coccolith species fraction was numerically dominated by E. huxleyi and Gephyrocapsa sp. in variable proportion, containing also some F. profunda, whereas the fraction of large-coarse coccoliths was clearly dominated, both numerically and volumetrically, by C. leptoporus and H. carteri. At least two representative fractions from every sample were separated despite the low abundance of the target species in the original samples. Specifically, it was possible to concentrate $H$. carteri from an abundance of $4.15 \%$ in the original sample to $68.5 \%$ in the separated fraction, whereas C. leptoporus was concentrated from 2.3 $\%$ to almost $87 \%$ or even from $1.33 \%$ to $54 \%$ (Fig. 8.2). Conversely, the numerical enrichment of the small coccoliths group presents an average value of 1.4 that is not significant due to the already high abundance of small placoliths in the original samples.

Considering numerical abundances, the separation efficiency for both small and coarse coccoliths fractions is generally good, and dominating species reach values of $\approx 80 \%$ abundance for a single species (Fig. 8.2). However, when converting numerical abundances into carbonate mass contribution (Young and Ziveri, 2000), the volumetric efficiency of the separation technique of small and coarse coccoliths fractions presents diverging behaviours. The volumetric efficiency of the coarse coccoliths fractions increases up to $91.5 \%$ on average whereas the small coccoliths fractions one declines from $74 \%$ to $58 \%$ (Fig. 8.3) due to the much higher carbonate contribution of the few coarse coccoliths that appear in the small coccoliths fraction. H. carteri maximum carbonate concentration is $84 \%$ and 


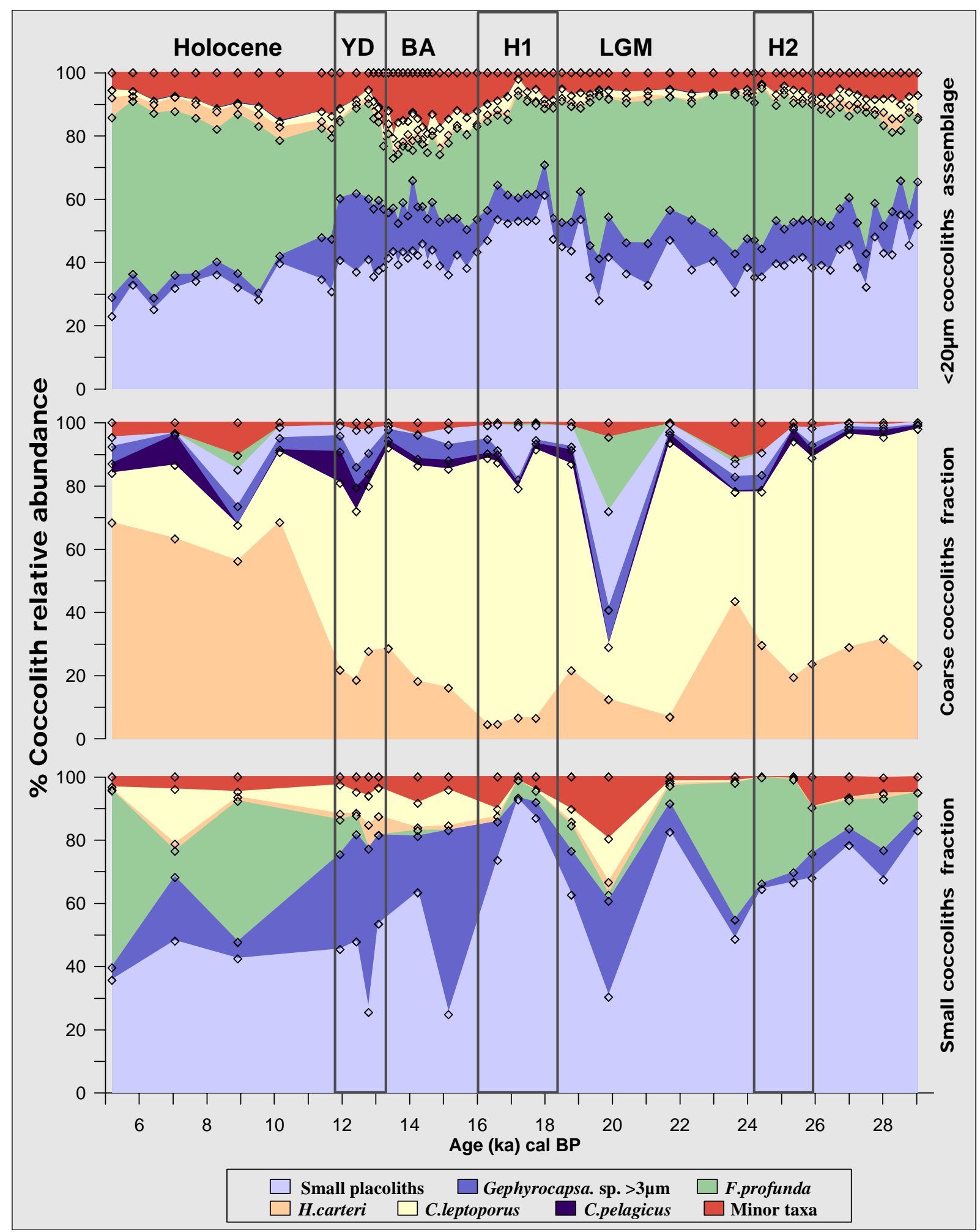

Figure 8.2.Temporal distribution of coccolith relative abundance from core MD03-2705. From top to bottom: $<20 \mu \mathrm{m}$ coccoliths original assemblage; coarse coccoliths separated fraction; small coccoliths separated fraction. Vertical bands represent Younger Dryas (YD), Bolling-Allerod (BA), Heinrich 1 (H1), Last Glacial Maximum (LGM) and Heinrich 2 (H2). 


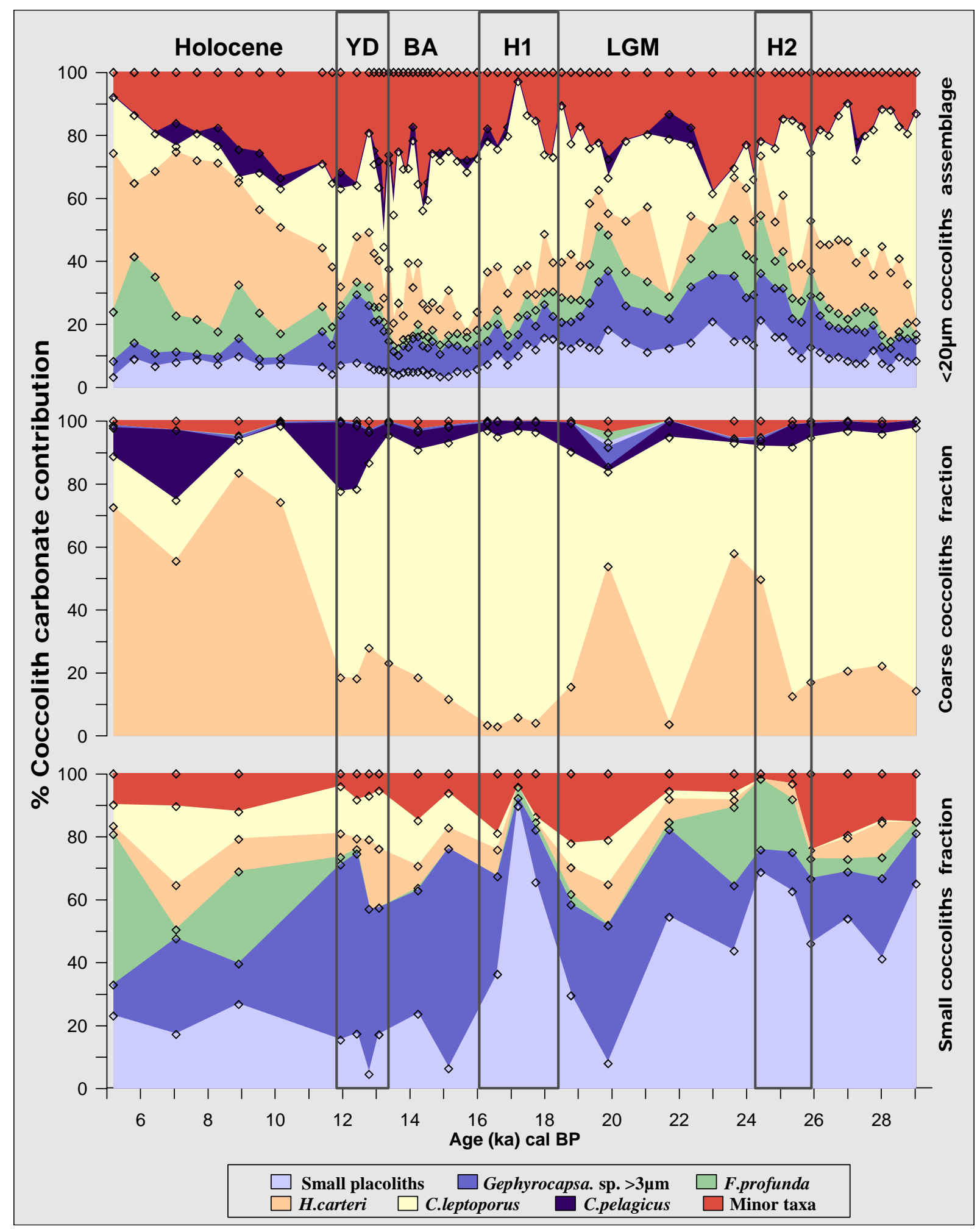

Figure 8.3.Temporal distribution of coccolith carbonate contribution from core MD03-2705. From top to bottom: $<20 \mu \mathrm{m}$ coccoliths original assemblage; coarse coccoliths separated fraction; small coccoliths separated fraction. Vertical bands represent Younger Dryas (YD), Bolling-Allerod (BA), Heinrich 1 (H1), Last Glacial Maximum (LGM) and Heinrich 2 (H2). 
C. leptoporus presents the highest separation efficiency, with above $90 \%$ of the carbonate from this species in five samples. In conclusion, size fractions with carbonate dominated by a single genera were produced more readily for the coarse size fractions than for the fine size fractions (Fig. 8.3)

The success of separation in a sample was conditioned by the presence of species of similar settling speeds and size, (so-called interfering), and so, the inability to separate interfering species such as $C$. leptoporus and $H$. carteri represent the most challenging limitation of the method. Nevertheless, culture experiments indicate that $C$. leptoporus and $H$. carteri have similar oxygen isotope vital effects $(-0.1 \%$ and $-0.2 \%$ ) (Ziveri et al., 2003) and comparable $\mathrm{Sr} / \mathrm{Ca}$ ratios (Stoll et al., 2002). These observations suggest that variations in the proportion of C. leptoporus and H. carteri in coarse fractions are not likely to introduce large variations in either isotopic or $\mathrm{Sr} / \mathrm{Ca}$ ratios. The dominating species in a particular fraction change due to the assemblage variations through time. This is noticeable for the small placoliths peak during the H1-like event, and especially remarkable from 12 ka onwards, when the assemblage undergoes several variations. Among them, the decrease of Gephyrocapsa spp. $>3 \mu \mathrm{m}$, the increase of F. profunda and the significant proliferation of $H$. carteri that replaces C. leptoporus. All of these changes in the original assemblage are consequently reflected on both separated fractions (Fig. 8.3) and the separation process has to be adapted to such variations.

According to the counting data for the coccolithophore assemblage of the core MD03-2705 (MejíaMolina et al. submitted), the relative abundance of E. huxleyi, Gephyrocapsa sps. and F. profunda account for more than $85.5 \%$ (Fig. 8.2) of the assemblage whereas their carbonate contribution is only about $26.7 \%$ (Fig. 8.3). Therefore, off Senegal, the numerical dominance of the small coccoliths contrast with their relatively minor contribution to the coccolith carbonate budget, whereas, the less abundant larger coccoliths (C. leptoporus, H. carteri) play a much important role in the carbonate flux to the deeper ocean.

\subsubsection{Isolating productivity variations in coccolith $\mathrm{Sr} / \mathrm{Ca}$ ratios:}

In the fine fraction $(<20 \mu \mathrm{m})$, the same overall temporal patterns are seen in the $\mathrm{Sr} / \mathrm{Ca}$ ratios of the cleaned as in the uncleaned splits (Fig. 8.6). For this core the overall similarities of the records are so strong that robust interpretations can be made from the high resolution uncleaned time series.

\subsubsection{Correction for temperature effect in $\mathrm{Sr} / \mathrm{Ca}$ ratios}

Despite the primary control of productivity, $\mathrm{Sr} / \mathrm{Ca}$ ratios are also secondarily influenced by temperature. According to a culture study presented by Stoll et al. (2002), coccolith $\mathrm{Sr} / \mathrm{Ca}$ ratios show a linear dependence on temperature which slope varies by a factor of two among different species. Hence, $\mathrm{Sr} / \mathrm{Ca}$ ratios must be corrected for temperature dependence in order to assess the component of 


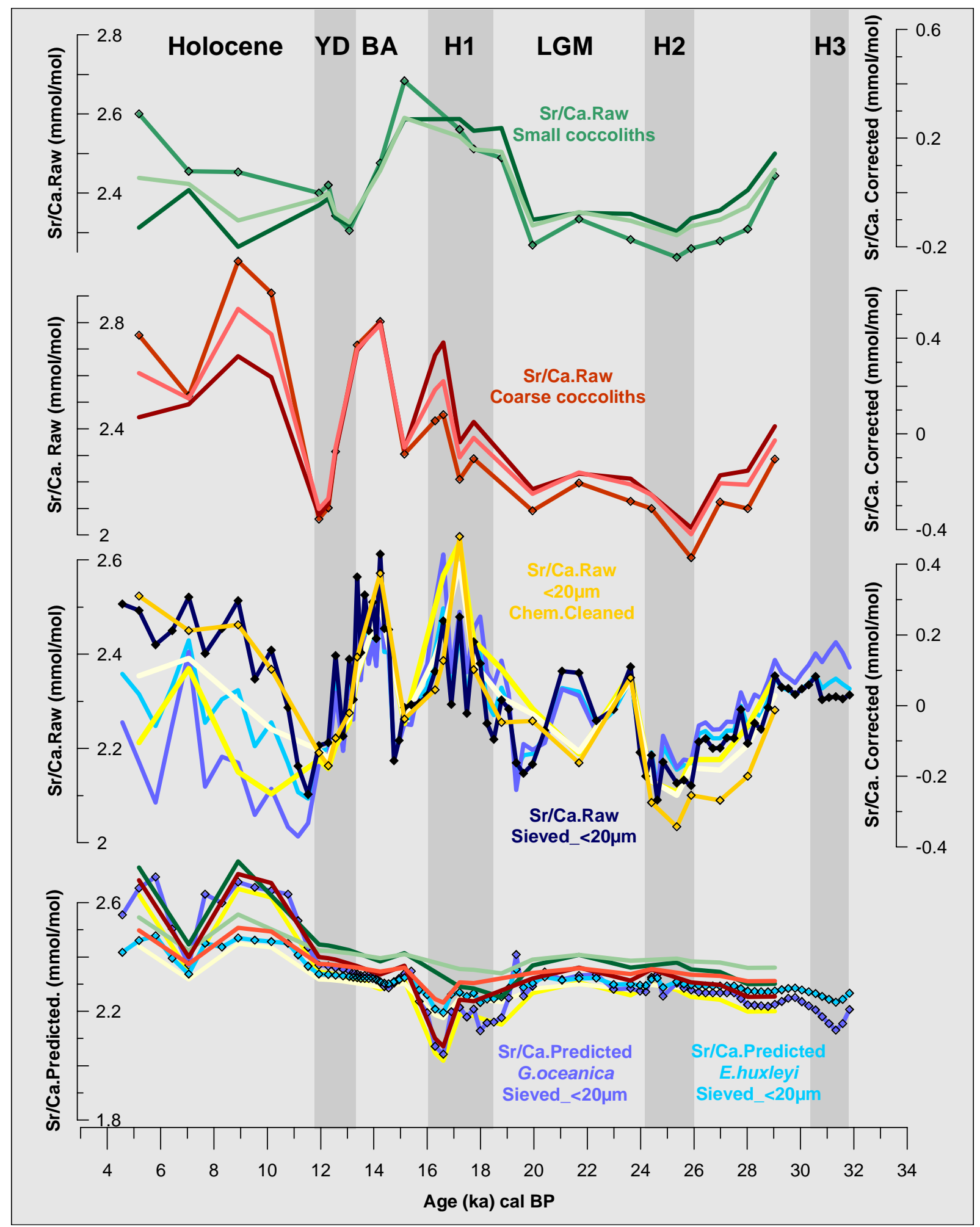

Figure 8.4. Sensitivity analysis of temperature influence on $\mathrm{Sr} / \mathrm{Ca}$ ratios in core MD03-2705 using the SST from planktonic foraminifera (Matsuzaki et al., 2010). From bottom to top: Predicted $\mathrm{Sr} / \mathrm{Ca}$ of four different fractions: Sieved fraction $(<20 \mu \mathrm{m})$ (blue), sieved fraction $(<20 \mu \mathrm{m})$ chemically cleaned (yellow), separated fractions of coarse coccoliths (red) and separated fractions of small placoliths (green). Raw-measured Sr/Ca $(\diamond)$ versus SSTcorrected $\mathrm{Sr} / \mathrm{Ca}$ of the sieved fraction $(<20 \mu \mathrm{m})$ (blue) and the sieved fraction $(<20 \mu \mathrm{m})$ chemically cleaned (yellow). Raw-measured Sr/Ca $(\diamond)$ versus SST-corrected Sr/Ca of separated fractions of coarse coccoliths (red). Raw-measured Sr/Ca $(\diamond)$ versus SST-corrected Sr/Ca of separated fractions of small placoliths (green). SSTcorrected $\mathrm{Sr} / \mathrm{Ca}$ obtained using both G. oceanica (dark) and E. huxley (light) are shown. 
the measured signal that is likely due to productivity. Since carbonate contributors change among the different fractions and there are no available temperature calibrations for some dominant species, we opted to conduct a sensitivity analysis (Fig. 8.4) using the two extreme temperature dependencies of $E$. huxleyi (lowest) and G. oceanica (highest) (Stoll et al., 2002a). The site sea surface temperature reconstruction made from planktonic foraminifera (Matsuzaki et al., 2011) has been used for the $\mathrm{Sr} / \mathrm{Ca}$ temperature correction of the different fractions. The residual or temperature-corrected $\mathrm{Sr} / \mathrm{Ca}$ ratios represent the signal that can be attributed to paleoproductivity alone. The temperature correction is most significant for the Holocene onset and the $\mathrm{H} 1$ event but still a minor effect on the trends since the raw $\mathrm{Sr} / \mathrm{Ca}$ and the temperature-corrected $\mathrm{Sr} / \mathrm{Ca}$ ratios of the different fractions present very similar trends for the whole time range (Fig. 8.4).

\subsubsection{Sr/Ca ratios of different coccolith size fractions}

Temperature-corrected $\mathrm{Sr} / \mathrm{Ca}$ ratios of the two separated-size fractions differ in the amplitude of $\mathrm{Sr} / \mathrm{Ca}$ variation as well as in the magnitude (Stoll et al., 2007). The coarse coccolith fraction (Helicosphaera spp.+ Calcidiscus spp.) shows $\mathrm{Sr} / \mathrm{Ca}$ variations of a greater amplitude than that seen in the small coccoliths fraction. This supports previous studies of Stoll et al. (2002b), which revealed that $\mathrm{Sr} / \mathrm{Ca}$ ratios in large coccoliths show variability ranges between 23 and $55 \%$ whereas, smaller coccoliths such as F. profunda or G. oceanica have lower values and are much less variable (6-15\%). Hence, $\mathrm{Sr} / \mathrm{Ca}$ of larger species appears to show a more dynamic response to environmental variations (Stoll and Ziveri, 2002).

Furthermore, in the coarse coccolith fraction there are significant variations in the proportion of $H$. carteri and C. leptoporus. Concretely, around the Holocene onset, H. carteri displaces C. leptoporus, as the most abundant species of the coarse coccoliths fraction, reaching carbonate contribution of H.carteri of $83.4 \%$ (Fig. 8.3.) This is coincident with the highest $\mathrm{Sr} / \mathrm{Ca}$ ratio of the coarse liths fraction recorded also at the Holocene. Analyses of individually picked coccoliths of a single species in a Secondary Ion Mass Spectrometer (ion probe) show that in modern sediment traps, $\mathrm{Sr} / \mathrm{Ca}$ ratios of H. carteri are on average $13 \%$ higher than those of C. leptoporus (Auliaherliaty et al., 2009). Since this difference is not representative it suggests that the variation in the relative contribution of $H$. carteri and C. leptoporus is not the major cause of varying $\mathrm{Sr} / \mathrm{Ca}$ in this fraction.

Regarding the temporal variability of the temperature-corrected $\mathrm{Sr} / \mathrm{Ca}$ ratios, all the fractions show general low values during the older glacial and the Last Glacial Maximun that contrast with the high variable trends of the last deglaciation. During this interval, there are synchronous higher $\mathrm{Sr} / \mathrm{Ca}$ ratios at Heinrich 1 times and a decrease of all fractions during YD event, however, the two size fractions present opposite patterns during the Bolling Allerod and the Early Holocene. 


\subsubsection{Coccoliths isotopic signal}

Since the first work of Emiliani (1954), the oxygen isotopic ratio of calcareous marine organisms has been widely applied to interpret paleotemperature changes, as well as to deduce the oxygen isotope composition of the seawater in which they are precipitated which varies with the regional evaporation/precipitation balance and global ice volume (Shackleton, 1987).

At present, sea surface temperature near the site changes throughout the year whereas salinity (SSS) remains fairly constant at around $\approx 36 \%$ (Boyer et al., 2006; Levitus and Boyer, 1994). Freshwater input from rivers seems negligible in the vicinity of the core since it is situated $\approx 500 \mathrm{~km}$ offshore out of the influence of any significant fluvial discharge (Tisserand et al., 2009). Moreover, the rainfall offshore Mauritania during the summer monsoon presents low values (20-25 $\mathrm{mm}$ on average) (Oberhuber, 1988) if compared to the typical monsoonal values that can reach $300 \mathrm{~mm} / \mathrm{month}$ (Murgese et al., 2008), therefore, it does not produce a strong seasonal salinity contrast at the sea surface (Tisserand et al., 2009). Although present salinity influence is small, the $\delta^{18} \mathrm{O}$ variability over the last 32 ka may be due to synchronized changes in temperature, ice volume and salinity during specific geological periods such as last deglaciation.

The amplitude of $\delta^{18} \mathrm{O}$ change in coccoliths between the Last Glacial Maximum and the onset of the Holocene that marks the glacial/interglacial boundary is on the order of $2 \%$ (Fig.8.5). This is perfectly evident for the chemically cleaned, fine fraction $<20 \mu \mathrm{m}$ and the small cocoliths fraction and correlates well with the $\delta^{18} \mathrm{O}$ record of the planktonic foraminifera Globigerina bulloides from the neighbouring core BOFS $31 \mathrm{~K}$ (Chapman et al., 1996). Considering that the variation derived from ice volume changes would account for $\approx 1 \%$, and assuming very low salinity changes between the LGM and the early Holocene, it seems that a depletion in the oxygen isotope of $\approx 1 \%$ would be mainly due to SST changes. Converted to a temperature difference, this would correspond to a warming of about $4.3^{\circ} \mathrm{C}$ (Kim and O'Neil, 1997; O'Neil et al., 1969) which is in agreement with the SST reconstruction of Matsuzaki et al. (2011) regarding the absolute shift in SST between the LGM and the Holocene, if the $\mathrm{H} 1$ interval is not considered.

Estimates of the $\delta^{18} \mathrm{O}$ of seawater were conducted by correcting the $\delta^{18} \mathrm{O}$ data of the small coccoliths fraction from variations in: (1) sea surface temperature, using a culture calibration for G. oceanica (Ziveri et al., 2003) and the SST reconstruction made from planktonic foraminifera (Matsuzaki et al., 2011) and (2) ice volume by applying the correction of $+0.008 \%$ per meter dropping of sea level (Schrag et al., 1996) to different sea level data (Hanebuth et al., 2009; Lea et al., 2002; Peltier and Fairbanks, 2006; Toscano and Macintyre, 2003; Yokoyama et al., 2000) (Fig. 8.5). Modern mean annual $\delta^{18} \mathrm{O}$ of surface seawater in the area (LeGrande and Schmidt, 2006) exhibits values around 0.54 $\%$ (PDB) whereas all the values for the calculated $\delta^{18} \mathrm{O}_{\mathrm{SW} \text {-ice volume }}$ are more negative than the modern 


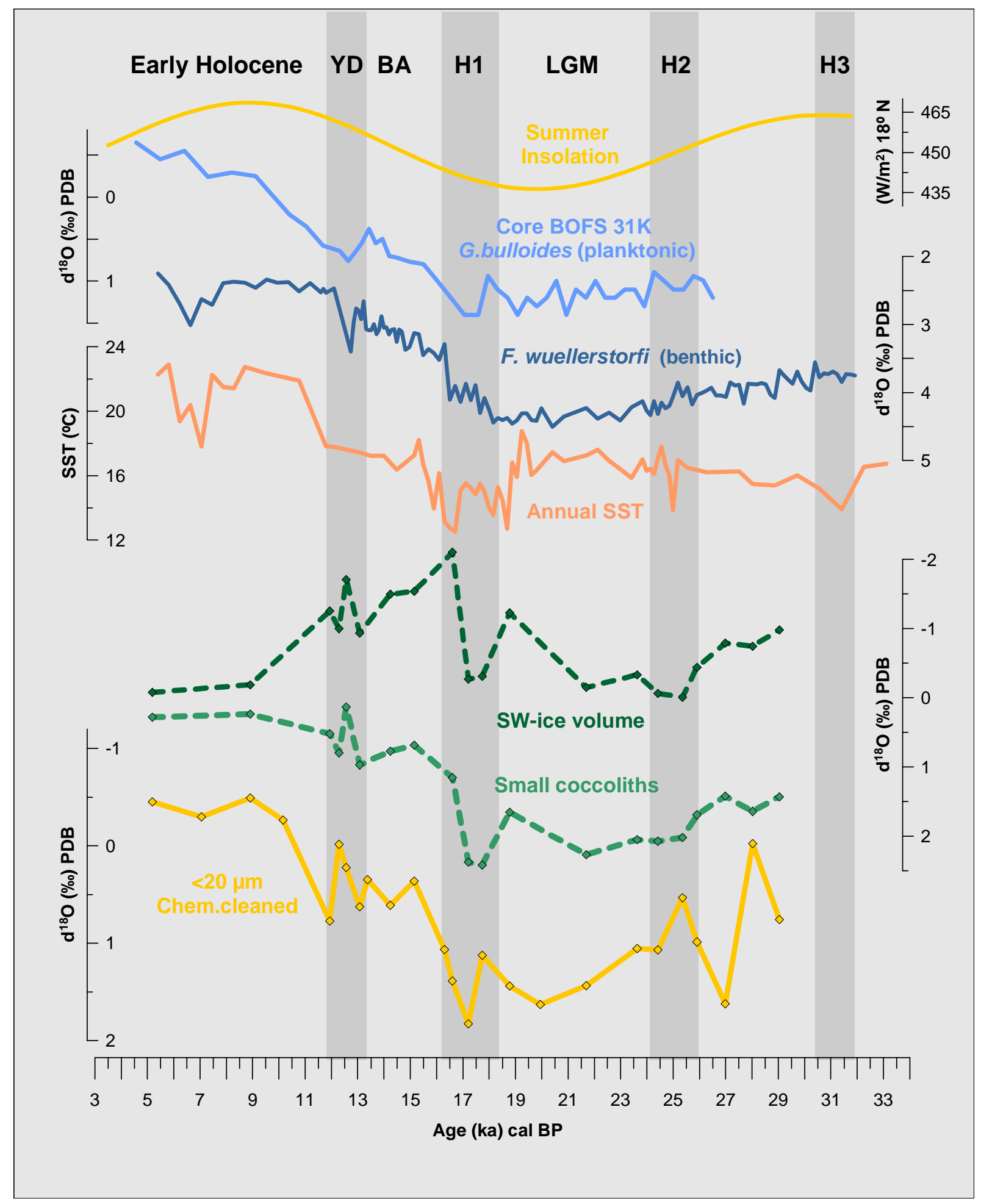

Figure 8.5. Temporal distribution of oxygen isotopic ratios $\left(\delta^{18} \mathrm{O}\right)$ from core MD03-2705. From bottom to top. Sieved fraction $(<20 \mu \mathrm{m})$ chemically cleaned. Separated fractions of small coccoliths (Gephyrocapsa spp. + E. huxleyi), and $\delta^{18} \mathrm{O}$ of sea water calculated with the equation for $G$. oceanica: $\delta^{18} \mathrm{O}_{\text {water (SMOw) }}=\delta^{18} \mathrm{O}_{\text {calcite (PDB) }}$ $4.93+0.22 \cdot \mathrm{T}$ (Ziveri et al., 2003) and corrected for the ice volume effect. Reconstruction of annual SST from planktonic foraminifera (Matsuzaki et al., 2010). $\delta^{18} \mathrm{O}$ record of benthic foraminifera (Fombotia wuellerstorfi). $\delta^{18} \mathrm{O}$ record of planktonic foraminifera (Globigerina bulloides) from core BOFS 31K (Chapman et al., 1996) and boreal summer (JJA) average insolation for $18^{\circ} \mathrm{N}$ (Laskar et al., 2004). 
value (Fig. 8.5) indicating that surface waters during the last $30 \mathrm{ka}$ might have been always fresher than today. The calculated $\delta^{18} \mathrm{O}_{\mathrm{SW} \text {-ice volume }}$ shows the most negative values during the deglaciation, in particular, during the end of $\mathrm{H} 1$ while its values are less negative and more similar to present conditions between 26 and $22 \mathrm{ka}$, at the $\mathrm{H} 1$ onset and during the early Holocene.

Regarding the $\delta^{18} \mathrm{O}$ interspecific variability among coccoliths, different fractions from the same sample show slight offsets in the isotopic ratios consistent with those of non-equilibrium effects observed in previous culture experiments of Dudley et al (1986) and Ziveri et al. (2003). In agreement with culture observations, the small placoliths fraction mainly made up of E. huxleyi and Gephyrocapsa spp. presents isotopically heavier values than the $<20 \mu \mathrm{m}$ fraction that it is mainly dominated by the coccolith assemblage with minimum percentage of allocthonus components.

\subsection{Discussion. Paleoceanography off NW Africa}

The new $\mathrm{Sr} / \mathrm{Ca}$ productivity record, together with independent indicators (Fig. 8.6), suggest that although MD03-2705 today's location is slightly westward diverted from the main Cap Blanc upwelling cell, the upwelling influence on our core during last $32 \mathrm{ka}$ has been variable and depended on several factors like the intensity, the latitudinal migrations and the seaward extent of the upwelling cell. Overall, the general good correlation of the $\mathrm{Sr} / \mathrm{Ca}$ record with the coccolithopores assemblages and accumulation rate indicates that the different variables are interdependent and respond to common changes in the upwelling dynamics. In particular, the ratio of small placoliths/deep dwelling $F$. profunda ( $\mathrm{N}$ ratio) often used as an upwelling indicator, parallels the main changes in $\mathrm{Sr} / \mathrm{Ca}$ ratios. Diatom fluxes peak during the first coccolith upwelling response of $\mathrm{H} 1$, but the subsequent productivity peak at the end of the $\mathrm{B} / \mathrm{A}$ appears to affect predominantly coccolithophores and results in a major increase in biogenic $\mathrm{CaCO}_{3}$ accumulation. Whereas productivity during older glacial and LGM seems to have been generally low with short sporadic increases, special attention should be paid to the last deglaciation, with both the larger variability and more extreme values that seem to be the result of the abrupt and large climatic variations happening at this time (Harris et al., 1996, Zhao et al., 2006).

\subsubsection{Latitudinal migrations of the upwelling center during the LGM}

The inference of lower productivity for MD03-2705 during the LGM from low $\mathrm{Sr} / \mathrm{Ca}$, coccolith flux and $\mathrm{N}$ ratios (Fig. 8.6), is consistent with several studies in the region (Bertrand et al., 1996; Henderiks and Bollmann, 2004; Martinez et al., 1999; Romero et al., 2008; Sicre et al., 2001; Ternois et al., 2000; Zhao et al., 2000). These inferences diverge from classic model that the Last Glacial 


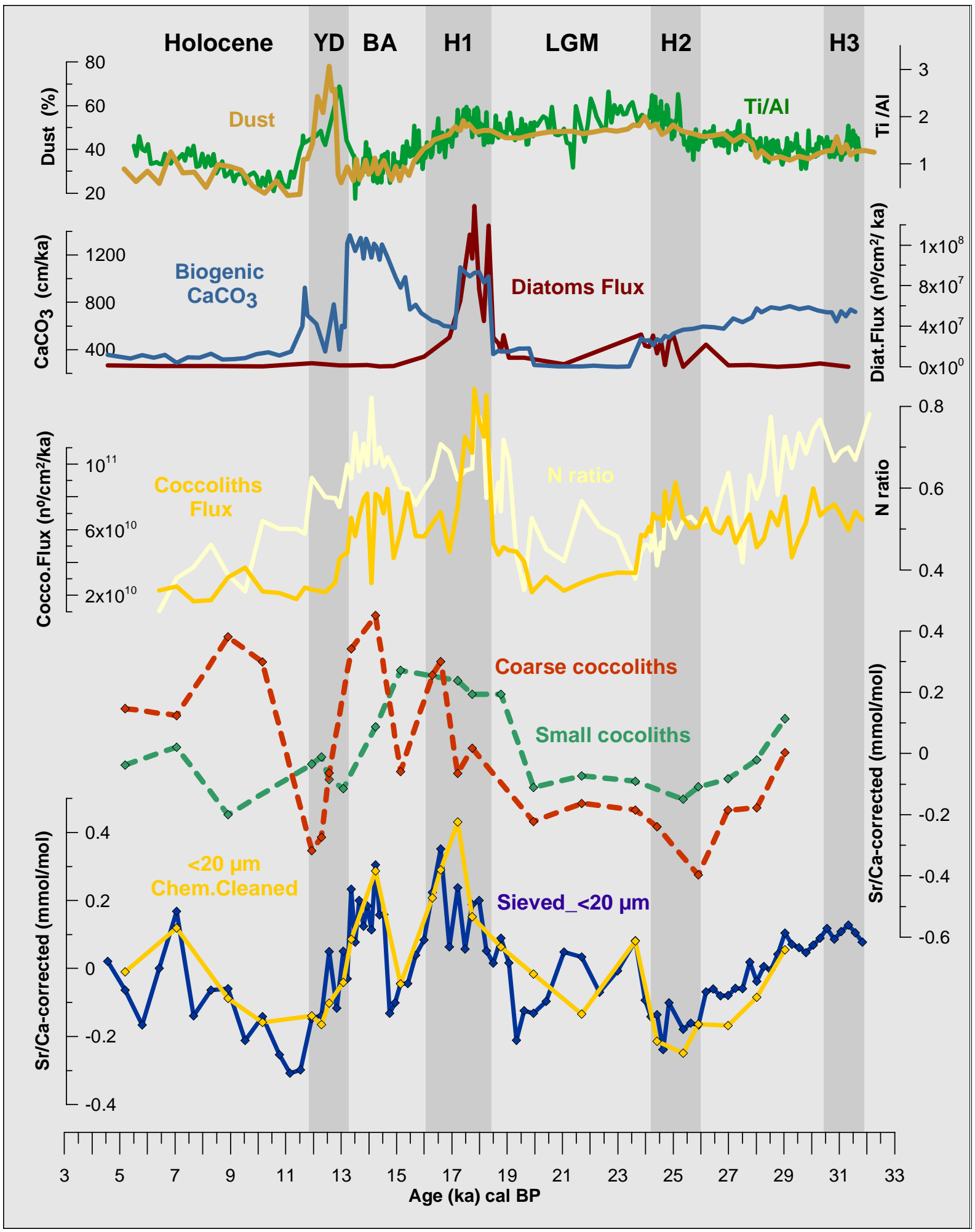

Figure 8.6. Temporal distribution of SST-corrected $\mathrm{Sr} / \mathrm{Ca}$ ratio $(\mathrm{mmol} / \mathrm{mol})$ from core MD03-2705. From bottom to top: Sieved fraction $(<20 \mu \mathrm{m})$ and sieved fraction $(<20 \mu \mathrm{m})$ chemically cleaned. Separated fractions of small cocoliths (Gephyrocapsa spp.+ E. huxleyi) and coarse coccoliths $(H$. carteri + C. leptoporus) and comparison with: coccoliths flux (coccoliths $/ \mathrm{cm}^{2} / \mathrm{ka}$ ), $\mathrm{N}$ ratio (ratio small placoliths $/ F$.profunda), diatoms flux (diatoms $/ \mathrm{cm}^{2} / \mathrm{ka}$ ), biogenic $\mathrm{CaCO}_{3}$ accumulation rate, dust percentage and Ti/Al ratio (Jullien et al., 2007). Vertical bands represent Younger Dryas (YD), Bolling-Allerod (BA), Heinrich 1 (H1), Last Glacial Maximum (LGM), Heinrich 2 (H2) and Heinrich 3 (H3). 
Maximum featured enhanced upwelling and productivity with large terrigenous input due to increased continental aridity and strong winds (Hooghiemstra, 1988; Sarnthein et al., 1992; 1981; 1982). In part, the diverging interpretations may arise from heterogeneous response within the upwelling system off NW Africa, with opposite signals between northern and southern locations (Bertrand et al., 1996). This latitudinal heterogeneity would derive from a combination of changes in sea level, morphology of continental shelf and wind strength and direction that might provoke shifts in the upwelling position. Recent work suggests that the NETW intensified at the LGM in the northernmost latitudes $\left(24-36^{\circ} \mathrm{N}\right)$ along NW African coast whereas SAL dominated in latitudes southern of Cap Blanc $\left(21^{\circ} \mathrm{N}\right)$ as indicated by the seaward migration of desert dunes in Sahara (Lancaster et al., 2002). Hence, during LGM, site MD03-2705 should not have been influenced by the main upwelling filament, placed further north, but, might have received SAL dust load as suggested by the high dust and Ti/Al values.

\subsubsection{Upwelling intensification and offshore extension during early deglaciation}

The abrupt massive discharge of icebergs invading the North Atlantic during H1 induced such a cooling and salinity disturbance (Bond et al., 1992; Clark et al., 2001) that Meridional Overturning Circulation (MOC) collapsed (McManus et al., 2004), hampering, in turn, NADW formation. The space left by NADW along the Atlantic water column might have enabled nutrient richer SACW to reach northern latitudes than usual and became the prevailing upwelling waters during H1 off Mauritania (Romero et al., 2008).

The onset of $\mathrm{H} 1$ is characterised by a significant peak of $\mathrm{Sr} / \mathrm{Ca}<20 \mu \mathrm{m}$-fraction ratio that perfectly match with the high $\mathrm{N}$ ratio as well as with the maxima coccolith flux. Besides coccoliths indicators, independent proxies such as an evident diatom maximum indicate a clear common response of enhanced productivity. The high biological productivity during $\mathrm{H} 1$ would be a consequence of enhanced nutrient availability in upwelled waters (SACW), intensified NE trade winds, and the subsequent larger intensity and offshore extent of the upwelling cell. In addition, the heaviest coccolith $\delta^{18} \mathrm{O}$ around $17 \mathrm{ka}$ (Fig. 8.5) correlates well with similar abrupt SST decreases from elsewhere in the North Atlantic associated with Heinrich 1 event. This Heinrich-like event is in good agreement with the SST reconstruction from planktonic foraminifera from the same core (Matsuzaki et al., 2011) and would also be supported by the interpretation of Zhao et al. (1995) about ODP 658C, according to which, cool meltwater produced during Heinrich events was transmitted southward by the Canary current exerting a considerable influence on SSTs in the subtropical eastern Atlantic. The negative values of the calculated $\delta^{18} \mathrm{O}_{\text {SW-ice volume }}$ by the end of the $\mathrm{H} 1$ indicate that these meltwaters might have also had an impact on salinity that resulted in fresher surface waters.

Furthermore, enhanced dust content in the sediments together with a higher Ti/Al ratios suggest greater supply of terrigenous material via stronger continental winds allowing the uplift and transport 
of coarser eolian particles to the African margin (Jullien et al., 2007). This support the idea that aridity in NW Africa were linked to reduced MOC associated with Heinrich Stadials (Mulitza et al., 2008)

All the results presented above support a southward displacement of the ITCZ during H1 and a substantial reduction in monsoon intensity, that are consistent with previous regional studies (Romero et al., 2008; Jullien et al., 2007; Ivanochko et al., 2005).

\subsubsection{Enhanced productivity despite reduced upwelling}

High $\mathrm{Sr} / \mathrm{Ca}$ ratios of the $<20 \mu \mathrm{m}$-fraction comparable to those observed during $\mathrm{H} 1$ are registered during the $\mathrm{B} / \mathrm{A}$ and match a period of high $\mathrm{N}$ ratio and high biogenic $\mathrm{CaCO}_{3}$ accumulation. However, the peak in $\mathrm{N}$ ratio is related to minima in the F. profunda abundance and not to an increase of the small placoliths (Mejia-Molina et al., submitted). Furthermore, a close examination to the different response of the two separated fractions reveals that the small coccoliths $\mathrm{Sr} / \mathrm{Ca}$ ratio exhibit moderate values but with a clear decreasing trend whereas coarse coccoliths $\mathrm{Sr} / \mathrm{Ca}$ presents a marked peak. This peak coincides with the significant increase in the number of coarser and warmer species, especially of $C$. leptoporus, that reaches its highest abundance for the last $25 \mathrm{ka}$. Unlike for $\mathrm{H} 1$, the $\mathrm{Sr} / \mathrm{Ca}$ of the $<20 \mu \mathrm{m}$-fraction would mainly derive from the coarse coccoliths $\mathrm{Sr} / \mathrm{Ca}$, that act as the greater carbonate contributors.

Hence, higher productivity during B/A could not be related to enhanced upwelling that would have benefited diatoms and the eutrophic small placoliths, but is more likely due to mesothrophic conditions favourable for the proliferation of species like C. leptoporus. Coccolith $\delta^{18} \mathrm{O}$ suggests warmer water temperatures during the B/A that may have especially favoured these taxa while the decline of both dust and Ti/Al ratio supports continental humidity and the weakening of the wind system (Lancaster et al., 2002; Swezey, 2001). As deglaciation continues, the heat transfer from tropics to North Atlantic would have lead to a feedback process of transition to warm B/A conditions, and to the extension of ITCZ far into the Sahara (Romero et al., 2008).

\subsubsection{Influence of the continent: Saharan dust episodes}

The most striking feature that characterizes the onset of YD at MD03-2705 site is the abrupt and high magnitude intensification of the eolian activity, since the terrigenous proxy values (80\%; Fig. 8.6) are almost twice as high as those of any other time (Jullien et al., 2007). Such a sharp increase requires enhanced aridity over the nearby continent and the intensification of winds throughout Northern Africa (Gasse, 2000; Lancaster et al., 2002; Mulitza et al., 2008).

One could expect that such NETW strengthening would increase upwelling and result in higher biological productivity, however the massive terrigenous supply at YD may have drastically reduced 
water transparency and light availability in the Upper Photic Zone and hence, inhibited coccolithophores development, as supported by the synchronous decrease of $\mathrm{Sr} / \mathrm{Ca}$ ratios of all fractions.

On the other hand, the three analyzed fractions show lighter $\delta^{18} \mathrm{O}$ values coinciding with the YD event. Although slight, such depletion would be, however, unexpected for a colder period. Therefore, a possible explanation for such an "unexpected" ${ }^{18} \mathrm{O}$ depletion is that the great amount of dust reaching the site at this moment would have contained inorganic carbonates originally part of dolostones, which are isotopically light. According to Shields et al. (2007) and Porter et al. (2004), basins like that of Taoudéni, in Mauritania and Mali, comprise dolostones that form an isotopically distinct group with consistent low $\delta^{18} \mathrm{O}$ values down to $-6 \%$. These basins were identified by Jullien et al. (2007) as possible source areas for the dust supplied to the region of core MD03-2705. Further semi-quantitative SEM microanalyses regarding suspected dolostones crystals (Appendix II. SEM photos) confirm this hypothesis by revealing a composition of $50 \% \mathrm{Ca}$ and $17 \% \mathrm{Mg}$ on average.

In agreement with many previous studies (Dupont et al., 2004; Lea et al., 2003; Partridge et al., 2004; Romero et al., 2008; Stuut et al., 2004; Talbot et al., 2007), we believe that ITCZ migrated southward at YD times, although this terrigenous anomaly should have altered both the expected high productivity and the coccoliths $\delta^{18} \mathrm{O}$ signal.

\subsubsection{Stratification of surface waters and seasonality changes during early Holocene}

Although the $\mathrm{Sr} / \mathrm{Ca}$ signal for early Holocene resembles that previously discussed for $\mathrm{B} / \mathrm{A}$, in this case, the $\mathrm{Sr} / \mathrm{Ca}$ of the coarse coccoliths fraction shows a peak at around 9 ka that was linked to the highest proportion of H. carteri (Fig. 8.3). The small coccoliths fraction exhibits a reduction of the eutrophic small placoliths and a substantial increase of the deep-dwelling $F$. profunda that reaches its maximum (58\%) at around $6 \mathrm{ka}$ (Mejia-Molina et al. submitted) (Fig. 8.2). This is reflected in the $\mathrm{N}$ ratio, whose low values indicate stratified waters with a deep nutricline and thermocline. Additionally, the sharp and abrupt simultaneous decrease in accumulation rate, dust abundance and Ti/Al by the end of YD points to the weakening of the regional wind regime and increased moisture (Adkins et al., 2006).

Despite some degree of interannual and seasonal variability of coccolithophore fluxes recorded in sediment traps deployed in the area (Müller and Fischer, 2001; Sprengel et al., 2002; Sprengel et al., 2000), recently, Köbrich and Baumann (2009) reported that present coccolithophore fluxes off Senegal coast present two peaks, with high values in summer and a maxima in winter. In consequence, present coccoliths $\delta^{18} \mathrm{O}$ should record temperatures of the mixed layer during both summer and winter. 
It seems that part of the glacial-Holocene temperature differences may be explained by a switch in the seasonal timing of coccolithophore major proliferation, from summer during glacial times to a double peak in summer and winter in the modern ocean. This interpretation is supported by Chapman et al. (1996) in their SST reconstruction from a combined application of alkenones and foraminifera transfer function in the neighbouring core BOFS $31 \mathrm{~K}$.

The general low values of the different proxies indicate the prevalence of warm well-stratified waters and reduced upwelling and mark a major climatic boundary between the last deglaciation and the warm and stable Holocene. This climate transition is probably related to a northward migration of the ITCZ around $3^{\circ}-5^{\circ}$ north of its current mean position (Gasse and Roberts, 2005) and triggered the reinvigoration of monsoon circulation with an expansion of monsoon belt (Hoelzmann et al., 2004).

\subsubsection{Regional upwelling gradients}

Additional evidence on the upwelling variations can be obtained by comparing the productivity and accumulation rate signals and contrasting them with data from ODP Site $658 \mathrm{C}$, situated in the vicinity of MD03-2705 but right within the upwelling filament off Senegal (See Fig. 8.1). Whereas core 658C shows rather constant accumulation rate through time (Zhao et al., 1995), with higher average values of around $18 \mathrm{~cm} / \mathrm{ka}$ (deMenocal et al., 2000), core MD03-2705 presents large variations in the accumulation rate spanning the last $32 \mathrm{ka}$ and an average rate of $11.4 \mathrm{~cm} / \mathrm{ka}$ (Jullien et al.,2007). Site MD03-2705 registers lower accumulation rates for both glacial $(9 \mathrm{~cm} / \mathrm{ka})$ and Holocene $(4.7 \mathrm{~cm} / \mathrm{ka})$ periods but significant higher values during the deglaciation, similar to ODP $658 \mathrm{C}$ values, and with a maximum of $20.6 \mathrm{~cm} / \mathrm{ka}$ at $\mathrm{H} 1$. The steady high sedimentation rate of site ODP $658 \mathrm{C}$ derives from its location right below the productive upwelling cell while the pronounced deglacial increase in accumulation rate at MD03-2705 suggest an upwelling-related productivity origin and confirm that productivity differences were primarily driven by fluctuations in regional upwelling position and extent. Consequently, we can conclude that, during the deglaciation, the main upwelling filament spread towards the position of MD03-2705 location.

\subsection{Conclusions}

The separation of restricted coccolith fractions through repeated decanting and microfiltering is a reliable method to investigate coccolith calcite chemistry as verified by the high species-specific coccolith carbonate contribution obtained in the separated fractions. However, this technique is more useful to achieve greater carbonate concentration of target species for coarse coccoliths fractions, with $91.5 \%$ on average.

Whereas productivity during MIS 3 and LGM is generally low with short sporadic increases, pronounced changes in productivity and a larger instability is recorded during the deglaciation. 
Variations in the conditions of waters overlying site MD03-2705 seem to result from the interplay of a wide variety of oceanographic and atmospheric processes. Fluctuations in the position and intensity of the upwelling cell together with a seaward enlargement and variable nutrient content of the upwelled waters derived from a dynamic hydrographic system were probably responsible for the large changes in productivity during the deglaciation and early Holocene. These fluctuating scenarios were likely the consequence of changes in wind stress and direction and linked to migrations of the ITCZ. Furthermore, punctual massive dust inputs from the neighbouring Sahara may have altered the productivity and isotopic signal.

A southward latitudinal shift of the ITCZ seems to be a major controlling factor that explains the upwelling intensification and enhanced productivity observed during $\mathrm{H} 1$ whereas an early Holocene northward migration resulted in the stratification of the water column and lower productivity. The paleoceanographic reconstruction for the $\mathrm{B} / \mathrm{A}$ and the YD is more complex, other processes besides ITCZ have to be considered. Changes in coccolith calcite chemistry during the B/A might derive from the distinct ecological preferences of the group of coarse coccolithophore species (C. leptoporus and $H$. carteri) which prefer mesotrophic environments, whereas during YD, the massive terrigenous supply ( $80 \%$ ) may have drastically reduced light availability in the Upper Photic Zone and hence, inhibited the coccolithophores growth. 





\title{
Morphometric variability of $C$. pelagicus and its paleoceanographic significance in the Northeast Atlantic and Western Mediterranean during the last deglaciation
}

\author{
Débora Simón-Baile ${ }^{1}$, Mário Cachão ${ }^{2}$, José A. Flores ${ }^{1}$, Aurea Narciso ${ }^{2}$, Francisco J. Sierro ${ }^{1}$. \\ 1. Área de Paleontologia, Departamento de Geologia, Universidad de Salamanca, 37008, Salamanca, Spain \\ 2. Departamento Geologia, Faculdade de Ciências, Universidade de Lisboa, 1749-016, Lisboa, Portugal
}

\begin{abstract}
Morphometry studies of $C$. pelagicus were conducted on 64 samples from cores MD95-2043 and MD03-2705, retrieved from the Alboran Sea and off Mauritania respectively. Subsequent statistical morphometric analysis (Multivariate Morphon Analysis) allowed to characterize the presence of the three morphotypes previously described in Parente et al. (2004) and to asses the relative importance of each morphotype during the last deglaciation. However, further comparison with two additional cores shows that the presence of a specific morphotype and its size boundaries, vary latitudinally indicating either adaptations to the environmental conditions of each location, evolution or, most probably, an interplay of both.
\end{abstract}

Results from Multivariate Morphon Analysis, when compared with other independent proxies such as $\%$ N. pachyderma (sin.), SST reconstructions, $\mathrm{Sr} / \mathrm{Ca}$ ratios and $\mathrm{N}$ ratios, helped connecting the influence of specific water masses to the occurrence of each morphotype. In addition, they revealed that the Alboran Sea seems to amplify paleoceanographic variations and thus be more sensitive to climatic oscillations than the NW African margin.

At site MD95-2043, the significant increase in the importance of the smaller morphotype, C. pelagicus subsp. pelagicus during Heinrich 1 indicates the arrival of subarctic waters as far south as the Mediterranean Sea, whereas the relative predominance of the intermediate morphotype, C. pelagicus subsp. braarudii during Younger Dryas suggest enhanced upwelling in the Alboran Sea. Alternatively, the dominance of the large morphotype, C. pelagicus subsp. azorinus, during both H1 and YD in the core off Mauritania may result from the intensification of the Azores Current due to a combined effect of the polar front shift and to an increase of Mediterranean outflow waters.

Keywords: Morphometry, C. pelagicus, factor analysis, Alboran Sea, off Mauritania, last deglaciation, paleoceanography. 


\subsection{Introduction and objectives}

Size variation patterns of several coccolithophores species have been investigated for taxonomy, biostratigraphy, palaeoecology and paleoclimate studies (Baumann and Sprengel, 2000; Baumann, 1995; Bollmann, 1997; Colmenero-Hidalgo et al., 2002; Flores et al., 2010; Knappertsbusch et al., 1997; Renaud et al., 2002; Tremolada et al., 2008; Young, 1990).

Heterococcoliths are particularly useful for morphometric studies because are entirely formed by an intracellular process before being extruded to produce the coccosphere that surrounds the cell (Winter and Siesser, 1994; Young et al., 1999; Young and Henriksen, 2003). Therefore, their dimensions may be considered to be an intrinsic property of a particular species or ecophenotype (Narciso et al., 2006; Parente et al., 2004). Morphometry variations through time, however, would indicate either evolution, environmental change or, most likely, a combination of both (Bollmann, 1997).

Coccolithus pelagicus, one of the first extant coccolithophores described (Wallich, 1877), produces large and highly robust coccoliths favouring their preservation during diagenesis and thus allowing more robust paleoecological interpretations (Cachão and Moita, 2000). Coccolithus pelagicus has been widely interpreted as a cold-water proxy, found in waters at temperatures between -1.7 and $15{ }^{\circ} \mathrm{C}$ (Andruleit, 1997; Baumann, 1995; McIntyre and Bé, 1967b; Okada and McIntyre, 1979; Raffi and Rio, 1981; Winter et al., 1994). Nevertheless, Cachão and Moita (2000) demonstrated that its biogeography also includes upwelling areas, such as the upwelling system off Portugal. This duality in behaviour was further supported by Geisen et al. (2002) that presented life cycle evidences for the existence of two subspecies of $C$. pelagicus: . pelagicus subsp. pelagicus, the smaller $(7-10 \mu \mathrm{m})$ subarctic form, and C. pelagicus subsp. braarudii, the temperate form with sizes between 10 and 16 microns. In 2003, Saéz et al. reported genetic differences between these two subspecies and corroborated the hypothesis of discrete genetic entities with independent life-cycles and different ecological preferences.

Further detailed morphometric studies performed on surface and downcore sediments (Narciso et al., 2006; Parente et al., 2004) confirmed the existence of these two morphotypes and found evidences for an additional third morphtype, with distinct ecological preferences. According to these studies, the smaller morphotype, equivalent to C. pelagicus subsp. pelagicus may be used as a cold water proxy, the intermediate morphotype, proposed as C. pelagicus subsp. braarudii would be related to upwelling conditions, and a larger new morphotype defined as C. pelagicus subsp. azorinus (Jordan et al., 2004; Parente et al., 2004) invoked as a possible proxy of the influence of the Azores current. 
The last deglaciation was characterized by a series of abrupt, high-frequency, millennial-scale climate oscillations (Clement and Peterson, 2008). The most prominent deglacial events of the Northern Hemisphere are the Heinrich event 1 (H1) and Younger Dryas (YD) cold periods and the BøllingAllerød warm event (B/A) (Alley and Clark, 1999). Nevertheless, the ages, durations and characteristics of these climate events were not globally uniform (Xiang et al., 2007). For instance, the magnitude of the Younger Dryas climate anomaly (cooler/drier) increases with latitude in the Northern Hemisphere (Shakun and Carlson, 2010). We intend to gain better understanding of the drivers behind this natural variability and of the distinct spatial response of the climate system to these millennialscale events through the morphometric study of the species $C$. pelagicus.

Hence, the specific objectives of the present study are: (1) to identify the presence of the three distinct morphotypes of $C$. pelagicus in two cores in the Alboran Sea and off NW Mauritania during the last deglaciation, (2) to associate the dominance of each morphotype to the influence of specific water masses and oceanographic mechanisms by comparing them with other independent proxies and, (3) to interpret the latitudinal variations regarding morphotypes presence and morphometric boundaries and intervals through the comparison of four cores within a transect from tropical to temperate regions.

\subsection{Cores location and oceanographic setting}

The present study focus on two Calypso piston cores retrieved onboard the R/V Marion Dufresne. Core MD95-2043 (36 ${ }^{\circ} 8^{\prime} \mathrm{N}, 2^{\circ} 37^{\prime} \mathrm{W}$; $1841 \mathrm{~m}$ water-depth) was obtained from the Alboran Sea during the IMAGES-I coring cruise, whereas core MD03-2705 was recovered off the Mauritanian coast $\left(18^{\circ} 05^{\prime} \mathrm{N}, 21^{\circ} 09^{\prime} \mathrm{W} ; 3085 \mathrm{~m}\right.$ water-depth) during the DUST expedition.

The Alboran Sea is the westernmost basin of the Mediterranean, and therefore, the crossroad of inflow Atlantic waters and outflow Mediterranean ones. The fresher and nutrient-rich Atlantic waters enter the Alboran Sea describing two anticyclonic gyres (Heburn and La Violette, 1990; Parrilla and Kinder, 1987) and leading to the development of upwelling cells under which direct influence is situated the core MD95-2043. The interaction of different water masses together with the strenghtening of westerly winds and the aeolian and riverine fertilization (Fabres et al., 2002) are responsible for the relatively higher primary productivity of the Alboran Sea that contrast with the oligotrophy of most of the Mediterranean.

Alternatively, the northwest African coast is a highly productive region where NE trade winds induce a coastal upwelling whereas eolian supplies from the nearby Sahara fertilize the waters. Even when the most intense and persistent upwelling is confined to coastal waters around $20^{\circ} \mathrm{N}$ (Martinez et al., 1999; Romero et al., 2008), its influence can extend to offshore areas reaching site MD03-2705. Nevertheless, the upwelling influence at this site presents a strong seasonality controlled by the 
latitudinal migrations of the Intertropical Convergence Zone (ITCZ). In winters, ITCZ shifts southward driving the enhancement of the upwelling and the increase of terrigenous inputs (Chiapello et al., 1995) at site MD03-2705. Hydrologically, this area lies under the influence of the Canary Current, the Eastern branch of the Subtropical North Atlantic Gyre.

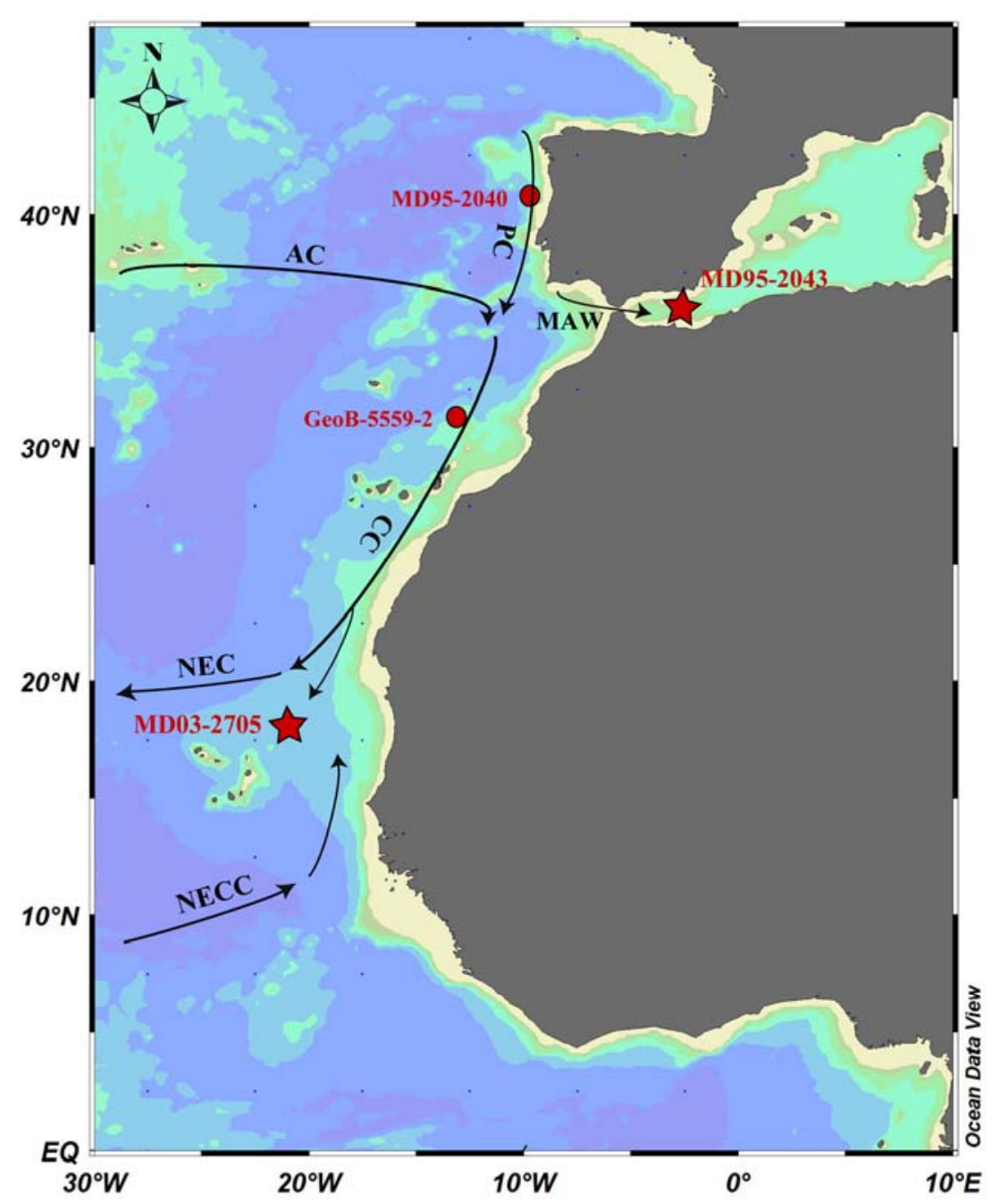

Figure 9.1. Location of the studied cores: MD95-2043 in the Alboran Sea and MD03-2705, off Mauritania. Positions of cores MD95-2040 and GeoB-5559-2 are also shown. Black arrows represent the pathway of the main oceanographic surface currents with, PC: Portugal Current, AC: Azores Current, CC: Canary Current, NEC: North Equatorial Current, NECC: North Equatorial Counter Current, and the MAW: Modified Atlantic Waters.

Moreover, further interpretations were based on the comparison of the two previous cores with two extra cores. Core MD95-2040, was recovered from the Portuguese margin (40 $34^{\prime} \mathrm{N}, 9^{\circ} 5^{\prime} \mathrm{W} ; 2465 \mathrm{~m}$ water-depth), an area influenced by the Portugal current and by the upwelling system that develops in summers driven by the strengthening of northerly winds as result of the westward shift of the Azores

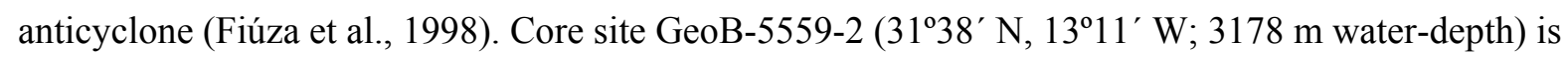


located under the influence of the Cape Ghir upwelling filament, in a productivity gradient from the coast to the open ocean (Moreno et al., 2002) where the main surface current is the Canary Current (Fig. 9.1).

\subsection{Chronology \& Methods}

The chronology for the last $21 \mathrm{ka}$ of core MD95-2043 was built from $17 \mathrm{AMS}{ }^{14} \mathrm{C}$ ages (Cacho et al., 1999). The program Calib 4.1 (Stuiver and Reimer, 1993; Stuiver et al., 1998) was used to correct for a reservoir effect of 400 year (Bard et al., 1994) and to convert AMS ages into calendar ages. On the other hand, the age model for core MD03-2705 (Jullien et al., 2007) was constructed from 8 AMS ${ }^{14} \mathrm{C}$ ages obtained from the analyses of planktonic foraminifera. Further correlation between the $\delta^{18} \mathrm{O}$ record of benthic foraminifera and the LR04 Stack (Lisiecki and Raymo, 2005), and the $\delta^{18}$ O benthic record of the nearby core ODP-658C (deMenocal et al., 2000) helped to better constrain this chronology.

A total of 64 samples, 33 from core MD95-2043 and 31 from core MD03-2705 were selected and analyzed in a morphometry study covering the last deglaciation of both cores, from the onset of Heinrich 1 event to the end of the Younger-Dryas.

Samples were prepared following the settling method of Flores and Sierro (1997) and observed under a LEITZ.ORTHOLUX-II POL BK polarized light microscope at 1000x magnification, connected to an OLYMPUS DP12 digital camera. One hundred specimens of $C$. pelagicus were randomly chosen in each sample, captured by the digital camera and measured.

As in Parente et al. (2004) and Narciso et al. (2006), the image analysis program Scion-Image, equipped with a suite of routines (www.nhm.ac.uk/hosted_sites/ina/CODENET/Coccobiom) and adapted to PC, allowed to: (1) create a composite mosaic of 25 images that permits the visualization of multiple coccoliths simultaneously, (2) measure the distal shield length of each placcolith directly on frame-grabber captured digital images at $\approx 2500 \mathrm{x}$ magnification and, (3) copy the measurements to a spreadsheet to be analyzed statistically. The associated error of measurements is \pm 0.1 microns. For the subsequent statistical analysis, denominated Multivariate Morphon Analysis (MMA) (Narciso et al., 2006), measurements were tabulated into $1 \mu \mathrm{m}$ size intervals, hereafter referred to as morphons. Therefore, morphon 9 would comprise all specimens whose length are within the interval [9.0, 10.0[ $\mu \mathrm{m}$. The program STATISTICA ${ }^{\circledR}$ version 7 was used for the MMA, an R-mode Factor Analysis performed on the morphometric measurements matrix, where samples were in rows and morphons in columns. A factor was considered relevant when its variance within the initial data matrix was higher than $10 \%$. 
This method, proposed by Parente et al. (2004), enables to: (1) statistically determine the presence of distinct morphotypes in a data set, (2) delimitate their morphometric boundaries and intervals and, (3) assess the relative dominance of each morphotype along the time series. Information for (1) and (2) derives from factor loadings while (3) does from factor scores.

The main advantage of the integrated approach provided by the MMA procedure with respect to the classical histograms is that it avoids the inconvenience of the representation and analysis of a large number of graphics. Furthermore, MMA enables the identification of morphometric boundaries even when they show some degree of overlapping because it evaluates the behaviour of the morphons along a time series, and not on a single sample (Narciso et al., 2006). However, since the MMA method is based on the behaviour of the morphons, it can not be applied to a single or to a limited number of samples. To obtain statistically relevant results, the number of samples must be equal or higher to the number of morphons considered for a particular species (Narciso et al., 2006).

\subsection{Results}

\subsubsection{Multivariate Morphon Analysis on core MD95-2043 (Alboran Sea)}

\subsubsection{Identification of $C$. pelagicus morphotypes and its boundaries from factor loadings}

MMA was performed on the $C$. pelagicus morphometric dataset correspondent to the last deglaciation $(\approx 11.5$ to $\approx 18.5 \mathrm{ka}$ ) (Fig. 9.2). Factor 1 (F1) explains almost $65 \%$ of the total variance while factor 2 only retains $5 \%$. Thus, only one single factor is considered significant for the MMA. According to F1 there are two morphotypes each characterized by a set of contiguous morphons with high loadings $(>|0.7|)$ : a smaller morphotype with high positive loadings (morphons 6 to 10) and a larger morphotype, here designated intermediate following the terminology of Narciso et al. (2006) and Parente et al. (2004) with high negative loadings (morphons 12 to 15). This factor is defined by the opposite behaviour between the small and the intermediate morphotypes, associated to C. pelagicus subsp. pelagicus and C. pelagicus subsp. braarudii, respectively. The low loadings of morphon 11 for F1 mark the morphometric boundary between the small and the intermediate morphotypes.

The MMA for this dataset did not reflect the appearance of a big morphotype, instead, it defines an intermediate morphotype characterized by a broad size range, even when morphon 15 shows relatively lower loadings. 
Figure 9.2. Factor loadings for MD95-2043 (11.5-18.5 ka)

\begin{tabular}{l|c|c}
\hline Variable & Factor 1 & Factor 2 \\
\hline Morphon 5 & 0.60 & 0.03 \\
Morphon 6 & $\mathbf{0 . 9 4 *}$ & -0.01 \\
Morphon 7 & $\mathbf{0 . 9 6 *}$ & 0.19 \\
Morphon 8 & $\mathbf{0 . 9 8 *}$ & 0.02 \\
Morphon 9 & $\mathbf{0 . 9 2 *}$ & 0.1 \\
Morphon 10 & $\mathbf{0 . 7 9 *}$ & -0.27 \\
Morphon 11 & -0.30 & -0.59 \\
Morphon 12 & $\mathbf{- 0 . 9 3 *}$ & -0.07 \\
Morphon 13 & $\mathbf{- 0 . 9 4 *}$ & -0.07 \\
Morphon 14 & $\mathbf{- 0 . 8 9 *}$ & 0.19 \\
Morphon 15 & $\mathbf{- 0 . 7 2}$ & 0.29 \\
Morphon 16 & -0.16 & 0.21 \\
\hline Expl. Var & 7.79 & 0.64 \\
Prp. Totl & $\mathbf{0 . 6 5}$ & $\mathbf{0 . 0 5}$
\end{tabular}

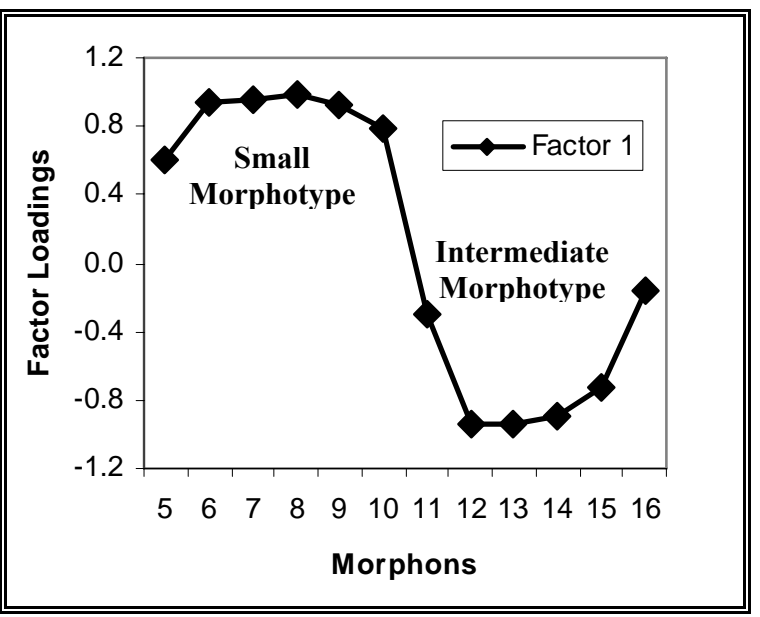

Extraction: Principal factors (comm. $=$ multiple R-square) with varimax raw. Marked loadings * are $>|0.7|$.

\subsubsection{C. pelagicus behaviour on MD95-2043 from factor scores and comparison with other proxies}

Further information from the MMA factor analysis can be derived from the factor scores, which indicate the relative importance of each morphotype through a period of time according to the morphotype associated loadings. In this case, since the small morphotype is characterized by positive F1 loadings and the intermediate is related to negative F1 loadings, a sample with positive F1 scores has dominance of the small morphotype whereas a sample with negative F1 scores reflects importance of the intermediate morphotype. In turn, low F1 scores means similar abundances of both morphotypes.

F1 scores were plotted against age in order to investigate the relationship between the small and the intermediate morphotype during the last deglaciation (Fig. 9.3). The higher positive F1 scores are concentrated during the $\mathrm{H} 1$ event while negative $\mathrm{F} 1$ scores dominate at $\mathrm{YD}$ times. Intermediate scores are recorded between $\mathrm{H} 1$ and YD. Therefore, the small morphotype, C. pelagicus subsp. pelagicus, presents clear dominance at $\mathrm{H} 1$ times but loses importance dramatically at the end of the Heinrich event being substituted by the intermediate morphotype, C. pelagicus subsp. braarudii towards the YD event. The very high scores (up to 10) of MD95-2043 MMA analysis indicate that certain samples during a specific time slice are strongly correlated with a particular morphotype. Furthermore, they show an abrupt temporal shift in the importance of the small and the intermediate morphotypes. 
Further relationships were investigated through the performance of an R-mode Factor Analysis on the MMA F1 scores and five other proxies (Table 9.1): $\mathrm{N}$ ratio, total coccolith abundance (ColmeneroHidalgo et al., 2004), $\delta^{18} \mathrm{O}$ of the planktonic foraminifera G. bulloides (Cacho et al., 1999; Sierro et al., 2005), alkenone derived SSTs (Cacho et al., 1999) and the relative abundance of $N$. pachyderma (sin) (Sierro et al., 2005).

Table 9.1. MMA factor scores $v s$. other proxies of MD95-2043

\begin{tabular}{l|c|c}
\hline Variable & Factor 1 & Factor 2 \\
\hline MMA. F1 scores & $\mathbf{- 0 . 5 4 *}$ & -0.16 \\
N ratio & $\mathbf{0 . 8 8 *}$ & 0.23 \\
Coccoliths/grame & $\mathbf{0 . 8 3 *}$ & 0.44 \\
$\boldsymbol{\delta}^{\mathbf{1 8}}$ O. G. bulloides & -0.25 & $\mathbf{- 0 . 8 3}^{*}$ \\
SST $\left({ }^{\circ}\right.$ C) & 0.36 & $\mathbf{0 . 8 4 *}$ \\
\% . pachyderma $($ sin) & -0.31 & $\mathbf{- 0 . 6 2 *}^{*}$. \\
\hline Expl. Var & 2.51 & 2.49 \\
\hline Prp. Totl & 0.36 & 0.35 \\
\hline & &
\end{tabular}

Extraction: Principal factors (com.= multiple R-square) with varimax raw. Marked loadings * are $>|0.5|$.

According to results in table 9.1, the last three proxies (SST, foraminifer $\delta^{18} \mathrm{O}$ and $\% N$. pachyderma (sin)) are not correlated with the MMA F1 scores, being strongly correlated among them, whereas the $\mathrm{N}$ ratio, and the coccoliths total abundance are indeed anticorrelated with F1 scores. Statistical analysis between the morphometric data and the coccoliths $\mathrm{Sr} / \mathrm{Ca}$ ratios from separated and $<20 \mu \mathrm{m}$ fractions were not possible due to their different sampling resolution, but, the visual comparison of the proxies records in the graphs (Fig. 9.3) indicates similarities worthy to be considered. Although statistical analysis show no clear correlation between the morphometric data and some of the other compared proxies $\left(\mathrm{SST}, \delta^{18} \mathrm{O}\right.$ and $\% N$. pachyderma $\left.(\sin )\right)$, there are, however, significant agreements when considering specific time ranges. For instance, at H1 times, F1 scores present two peaks, the older one coincident with a similar increase on $\% N$. pachyderma $(\sin$.) and with a decrease of $\mathrm{N}$ ratio while the later one is synchronized to $\delta^{18} \mathrm{O}$ and with a second $\mathrm{N}$ ratio decrease during the last half of $\mathrm{H} 1$. Likewise, the general trends of N. pachyderma (sin.) record and F1 scores are highly comparable (Fig. 9.3).

Note that a factor does not necessarily define a single morphotype, in fact, MMA F1 scores of MD952043 indicate the relative importance of two C. pelagicus morphotypes (the small and the intermediate) with different ecological requirements. Therefore, their correlation with other proxies will vary through time as the dominance of each morphotype does. 


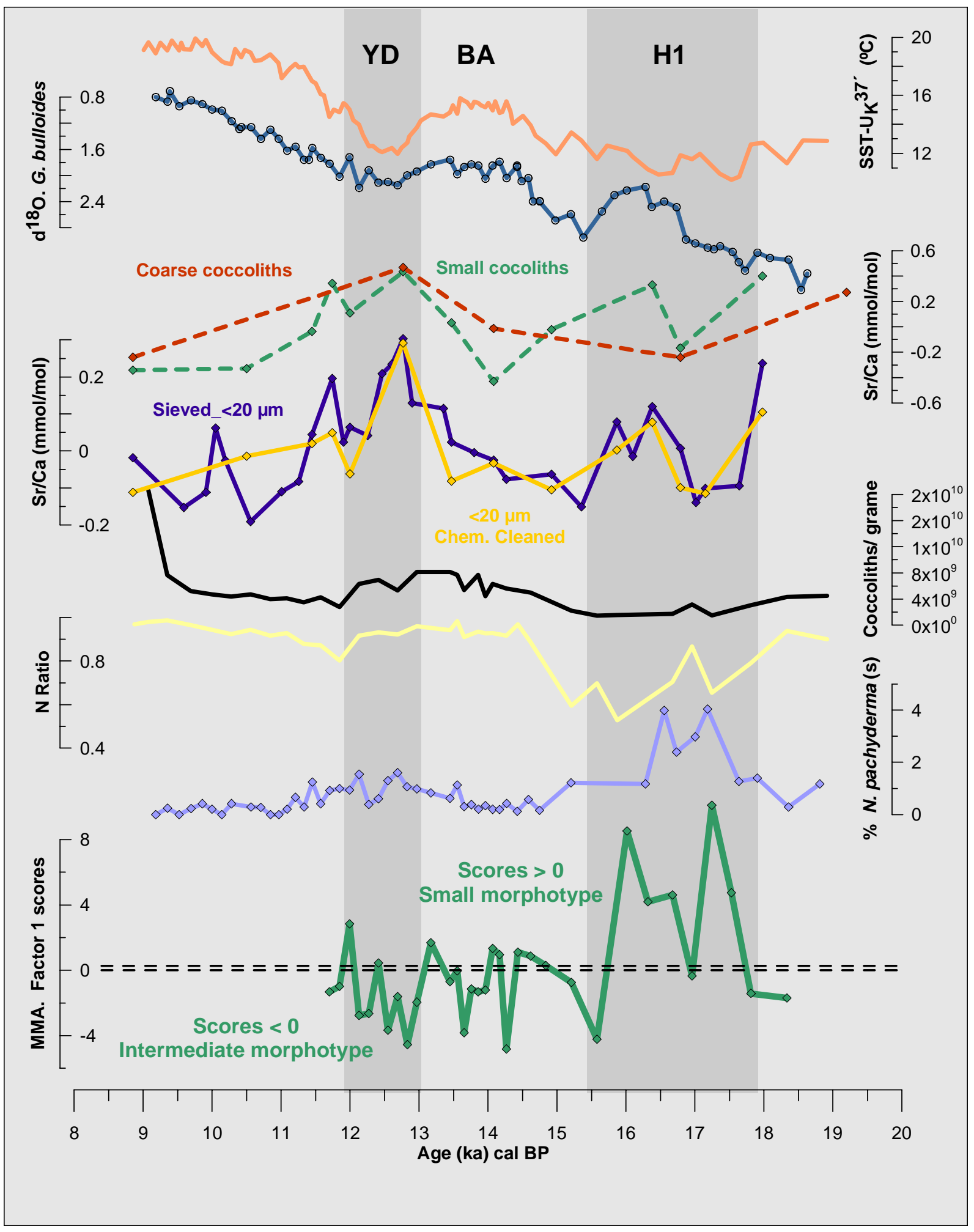

Figure 9.3. Comparison of the scores of MMA Factor 1, indicating the relative dominance of the small and the intermediate morphotypes of C. pelagicus, with some selected proxies from core MD95-2043. From bottom to top: MMA Factor 1 scores, \% N. pachyderma $(\sin )$ (Sierro et al., 2005), N ratio, total coccolith abundance (Colmenero-Hidalgo et al., 2004), SST-corrected $\mathrm{Sr} / \mathrm{Ca}$ ratios $(\mathrm{mmol} / \mathrm{mol})$ of the sieved fraction $(<20 \mu \mathrm{m})$, the sieved fraction $(<20 \mu \mathrm{m})$ chemically cleaned and separated fractions of small cocoliths and coarse coccoliths (Simon-Baile et al., to be submitted), $\delta^{18} \mathrm{O}$ of $G$. bulloides (Cacho et al., 1999; Sierro et al., 2005) and alkenone derived SSTs (Cacho et al., 1999). Grey bands indicate Heinrich 1 (H1) and Younger Dryas (YD). BollingAllerod (BA) is also shown. 


\subsubsection{Multivariate Morphon Analysis on core MD03-2705 (off Mauritania)}

\subsubsection{Identification of $C$. pelagicus morphotypes and its boundaries from factor loadings}

Figure 9.4. Factor loadings for MD03-2705 (11.5-18 ka)

\begin{tabular}{l|c|c}
\hline Variable & Factor 1 & Factor 2 \\
\hline Morphon 9 & 0.01 & 0.29 \\
Morphon 10 & 0.65 & -0.19 \\
Morphon 11 & $\mathbf{0 . 6 8 *}$ & 0.40 \\
Morphon 12 & $\mathbf{0 . 8 1 *}$ & 0.26 \\
Morphon 13 & 0.01 & $\mathbf{- 0 . 9 5 *}$ \\
Morphon 14 & $\mathbf{- 0 . 8 4 *}$ & 0.19 \\
Morphon 15 & $\mathbf{- 0 . 8 9 *}$ & -0.03 \\
Morphon 16 & $\mathbf{- 0 . 7 4 *}$ & 0.06 \\
\hline Expl. Var & 3.58 & 1.30 \\
Prp. Totl & $\mathbf{0 . 4 5}$ & $\mathbf{0 . 1 6}$
\end{tabular}

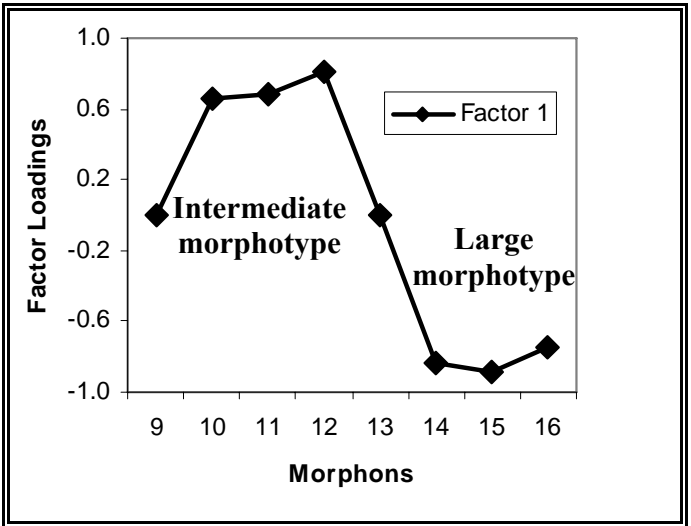

Extraction: Principal factors (comm. = multiple R-square)

with varimax raw. Marked loadings* are $>|0.7|$.

MMA conducted on MD03-2705 data matrix (Fig. 9.4) reveals two factors with high loadings. Factor 1 (F1) explains $44.8 \%$, almost half of the total variance and is strongly influenced by two sets of morphons with opposite behaviour to each other, each defining a distinct morphotype. The first set of morphons between 10 and 12, has high positive loadings and is related to the intermediate morphotype whereas the second set (morphons 14 to 16) with high negative loadings defines the larger morphotype.

Factor 2 (F2) with $16.3 \%$ of variance is strongly influenced by the single morphon 13 whose low loading on factor 1 suggests that it could simply represent the transition between the intermediate and large morphotype. However, the importance it has on factor 2 led to a more careful analysis. Thus, morphon 13 was subsequently subdivided into 5 smaller units of 0.2 micron size interval each. MMA performed on this new morphometric matrix disclosed that: (1) the size boundary between intermediate and large morphotypes should be repositioned on sub-morphon 13.4-13.6 (i.e. around 13.5 microns) and, (2) sizes between 13-13.4 and 13.6-14 microns would generally correlate with the intermediate and the large morphotypes respectively although the scores for time interval $\mathrm{H} 1$ show some incoherencies with the rest of the core interval. This last point requires further research that, due to methodological limitations of MMA, needs higher sampling resolution.

Factor analysis performed on the last deglaciation MD03-2705 samples allows the identification of $C$. pelagicus subsp. braarudii, the intermediate morphotype, and a larger morphotype that has been proposed as C. pelagicus subsp. azorinus (Parente et al., 2004) however, it does not disclose the occurrence of the small morphotype. 


\subsubsection{C. pelagicus behaviour on MD03-2705 from factor scores and comparison with other proxies}

MMA factor 1 scores (Fig. 9.5) provide information about the behaviour of the previously identified morphotypes through the period between H1 and YD events. (Note that the intermediate morphotype loadings and scores are positive for this core while they were negative for the Alboran core).

Fig. 9.5 shows that negative F1 scores, the large morphotype, are mainly related to both H1 and YD events. However, during these two time intervals they exhibit opposite trends, increasing during $\mathrm{H} 1$ and decreasing during YD. In turn, positive F1 scores predominate between $\mathrm{H} 1$ end and the onset of $\mathrm{YD}$, with the highest scores centred in the $\mathrm{B} / \mathrm{A}$ when the intermediate morphotype, C. pelagicus subsp. braarudii reaches higher importance.

The absolute values of F1 scores for MD03-2705 are homogeneously moderate, which indicates that the different samples through the whole time range show similar importance and that the temporal shift between morphotypes is more gradual than compared to MD95-2043 core.

An R-mode Factor Analysis (Table 9.2) allowed to decipher the correlations between MMA F1 scores of MD03-2705 and other available data from the same core such as: $\mathrm{N}$ ratio, total coccolith abundance, coccolith accumulation rate (Mejia-Molina et al., submitted), $\delta^{18} \mathrm{O}$ of the benthic foraminifera $F$. wuellerstorfi (Jullien et al., 2007), SST reconstruction from planktonic foraminifera (Matsuzaki et al., 2011) and coccolith raw and temperature-corrected $\mathrm{Sr} / \mathrm{Ca}$ ratios from $<20 \mu \mathrm{m}$ fractions (Simon-Baile et al., to be submitted). This factor analysis (Table 9.2) resulted in two factors, the first one characterised by the high anticorrelation between the SST signal and coccolith total abundance, coccolith flux and benthic $\delta^{18} \mathrm{O}$ and the second factor revealing a positive correlation between the MMA F1 scores, the $\mathrm{N}$ ratio and both $\mathrm{Sr} / \mathrm{Ca}$ ratios.

Both cores reveal good correlation between the MMA F1 scores and the $\mathrm{N}$ ratio, but, unlike in the Alboran Sea core, MD03-2705 shows lower correlation between this pair of proxies and the coccolith total abundance and flux, that appear in a different factor in the core off NW Africa.

Since the signal of the scores depends on its loadings, this would condition a positive or negative correlation with other proxies. This explains why MMA factor 1 scores are correlated to $\mathrm{N}$ ratio off NW Africa whereas the same two proxies are anticorrelated in the Alboran core. 


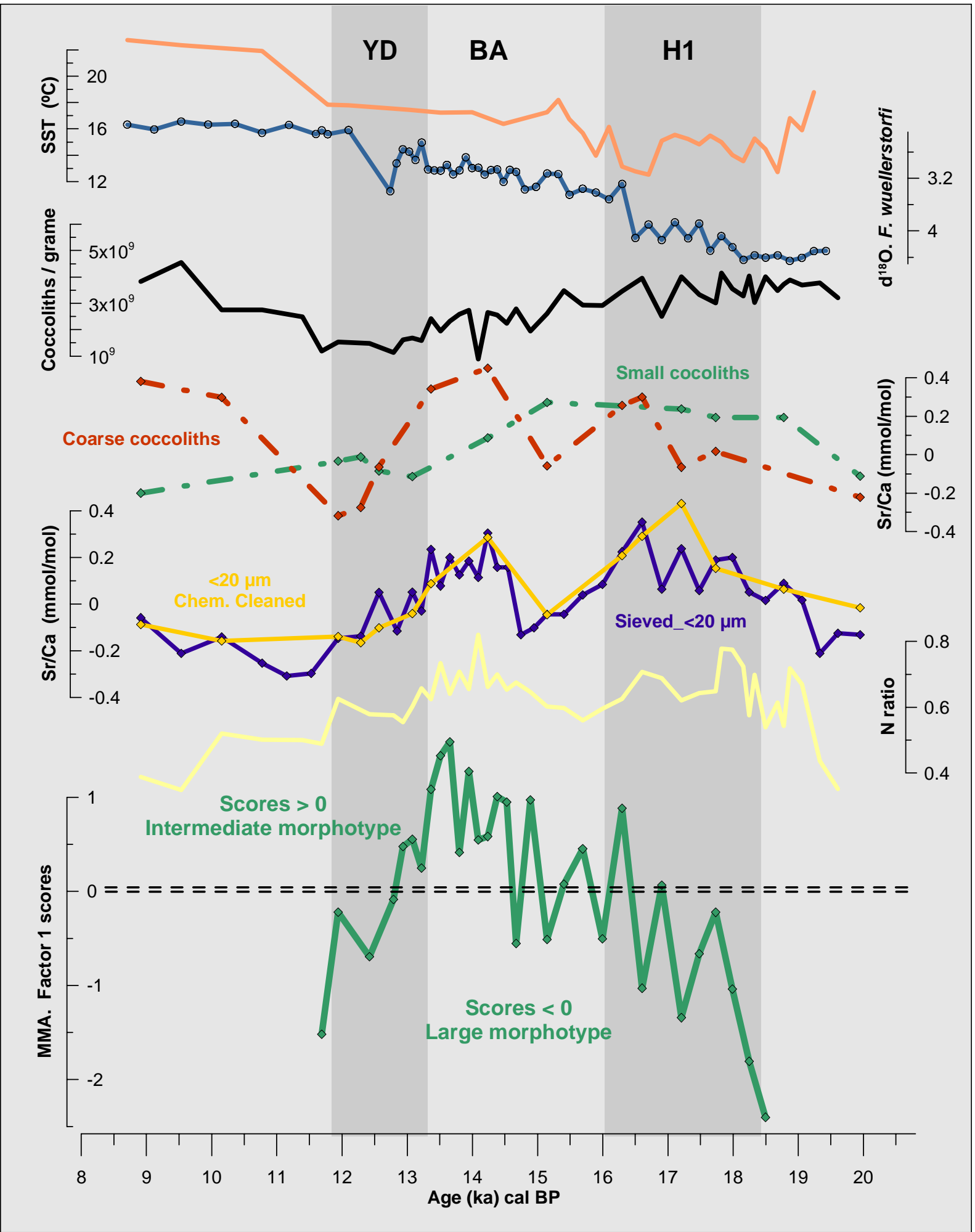

Figure 9.5. Comparison of the scores of MMA Factor 1, indicating the relative dominance of the intermediate and the large morphotypes of $C$. pelagicus, with some selected proxies from core MD03-2705. From bottom to top: MMA Factor 1 scores, N ratio (Mejia-Molina et al., submitted), SST-corrected $\mathrm{Sr} / \mathrm{Ca}$ ratios (mmol/mol) of the sieved fraction $(<20 \mu \mathrm{m})$, the sieved fraction $(<20 \mu \mathrm{m})$ chemically cleaned and separated fractions of small cocoliths and coarse coccoliths (Simon-Baile et al., to be submitted), total abundance of coccoliths (MejiaMolina et al., submitted), $\delta^{18} \mathrm{O}$ of the benthic foraminifera $F$. wuellerstorfi (Jullien et al., 2007) and SST reconstruction from planktonic foraminifera (Matsuzaki et al., 2011). Grey bands indicate Heinrich 1 (H1) and Younger Dryas (YD). Bolling-Allerod (BA) is also shown. 
Table 9.2. MMA Factor scores vs. other proxies of MD03-2705

\begin{tabular}{l|c|cl}
\hline Variable & Factor 1 & Factor 2 & \\
\cline { 1 - 3 } MMA. F1 scores & -0.44 & $\mathbf{0 . 6 3}$ & \\
N ratio & 0.09 & $\mathbf{0 . 8 2}^{*}$ & \\
Coccoliths/grame & $\mathbf{0 . 9 0 *}$ & -0.06 & \\
Coccolith flux & $\mathbf{0 . 7 3}^{*}$ & 0.17 & Extraction: Principal factors \\
$\boldsymbol{\delta}^{\mathbf{1 8}}$ O. Benthic & $\mathbf{0 . 8 8}^{*}$ & -0.08 & (com.= multiple R-square) with varimax raw. \\
SST $\left({ }^{\mathbf{0}}\right.$ C) & $\mathbf{- 0 . 8 7 *}^{*}$ & -0.04 & Marked loadings* are $>|0.6|$. \\
Raw Sr/Ca & 0.22 & $\mathbf{0 . 8 0 *}$ & \\
Corrected Sr/Ca & 0.59 & $\mathbf{0 . 6 9 *}$ & \\
\cline { 1 - 2 } Expl. Var & 3.70 & 3.09 & \\
Prp. Totl & $\mathbf{0 . 3 7}$ & $\mathbf{0 . 3 1}$ &
\end{tabular}

\subsection{Discussion}

\subsubsection{Paleoecological and paleoceanographic reconstruction from $C$. pelagicus morphotypes during the last deglaciation}

\subsubsection{Alboran Sea}

High F1 scores indicating dominance of $C$. pelagicus subsp. pelagicus during $\mathrm{H} 1$ event is in full agreement with the trend of other proxies reflecting SST decrease, like the alkenone-SSTs and the high abundance of $N$. pachyderma (sin), a polar water species that was only present in the Mediterranean during Heinrich events (Cacho et al., 1999; Pérez-Folgado et al., 2003). A close examination to F1 scores during $\mathrm{H} 1$ reveals large oscillations and two marked peaks, the older one perfectly matching with maxima in \% N. pachyderma $(\sin )$ but the other one not.

We believe that this reflects the different biogeographic distribution of the two taxa, since, at present, $N$.pachyderma ( $\sin )$ occupies polar areas (Bauch et al., 2003; Hemleben et al., 1989) whereas $C$. pelagicus subsp. pelagicus is mainly found in the Subarctic region (Geitzenauer et al., 1977; McIntyre and Bé, 1967a; Okada and McIntyre, 1977; Okada and McIntyre, 1979; Samtleben and Schröder, 1992; Winter et al., 1994), and therefore, optimum growth of $N$. pachyderma ( $\sin )$ corresponds to colder waters.

Detailed analysis of the SST-alkenones record at $\mathrm{H} 1$ times confirms that synchronized increases of $N$. pachyderma ( $\sin$ ) and C. pelagicus subsp. pelagicus correlate with minima SST during H1 onset while its second peak would correspond to a relative increase of SST that may have provoked a decrease of N. pachyderma (sin.) at an earlier age. By the end of H1 event, SST should have been "too warm" for the polar N. pachyderma (sin), but still cold enough for the development of C. pelagicus subsp. pelagicus, a subarctic species, hence, it seems that the polar province retreated while the subarctic influence remained. 
Moreover, the synchronous decrease of primary productivity indicated by low $\mathrm{Sr} / \mathrm{Ca}$ and $\mathrm{N}$ ratios is coincident with the MMA results that show an opposite behaviour between C. pelagicus subsp. pelagicus and C. pelagicus subsp. braarudii, the latter, with a preference for upwelling conditions (Blasco et al., 1980; Cachão and Moita, 2000; Giraudeau et al., 1993; Narciso et al., 2006; Parente et al., 2004a; Ziveri et al., 2004).

The remarkable increase in the abundance and dominance of the smaller morphotype at site MD952043 during H1 suggests the extension of its spatial distribution towards temperate latitudes. Heinrich events have been widely characterised by a large discharge of icebergs in the North Atlantic, whose melting provokes significant disturbances in the temperature and salinity signals at these latitudes (Cortijo et al., 1997; Elliot et al., 1998; Elliot et al., 2001; Grousset et al., 1993; Heinrich, 1988) but that affected also most meridional locations (Grousset et al., 1993; Schönfeld and Zahn, 2000; Schönfeld et al., 2003; Shackleton et al., 2000) as far as the Mediterranean Sea (Cacho et al., 2000; Sierro et al., 2005). Large salinity differences between Atlantic and Mediterranean waters might have intensified water exchange through the Gibraltar strait resulting in the arrival of great volumes of cooler (Cacho et al., 2000; Martrat et al., 2004) and fresher (Sierro et al., 2005) waters to the Alboran Sea, the westernmost basin within the Mediterranean Sea. Besides the cooling trend, H1 event in the Alboran Sea has also been described as a scenario of higher instability since this basin presents high sensitivity to oceanographic changes and more drastic responses to climatic fluctuations (ColmeneroHidalgo et al., 2004). The previously described scenario for H1 would match with the arrival to the Alboran Sea of the smaller morphotype, C. pelagicus subsp. pelagicus, a proxy of the influence of subpolar Atlantic water masses (Parente et al., 2004) and instable conditions (Narciso et al., 2006).

The small morphotype loses dominance drastically by the end of $\mathrm{H} 1$ and is replaced by the intermediate morphotype. C. pelagicus subsp. braarudii shows greater relevance for the rest of the record, from Termination Ia onwards, with a maximum during the YD onset.

C. pelagicus subsp. braarudii exhibits some sporadic peaks between $\mathrm{H} 1$ end and YD onset. In particular, the most negative score before $14 \mathrm{ka}$ coincides with a SST increase and a $\delta^{18} \mathrm{O}$ decrease indicating the onset of warm BA conditions and with the recovery of high $\mathrm{N}$ ratios and a progressive increase of $\mathrm{Sr} / \mathrm{Ca}$ ratios reflecting the disappearance of stratification in the water column.

At YD times, the SST decrease does not correlate with high F1 scores, on the contrary, they show low values related with the dominance of the intermediate morphotype, an upwelling indicator. It implies that during YD event, the relevance of upwelling enhancement prevails over the cooling trend, what is supported by the strong correlation between F1 scores and high $\mathrm{Sr} / \mathrm{Ca}$ and $\mathrm{N}$ ratios. Several studies in the Alboran Sea report high productivity during YD times (Bárcena et al., 2001; Jimenez-Espejo et al., 2007; Rodrigo-Gámiz et al., 2011). This may be linked to a larger inflow of nutrient-richer Atlantic 
waters and to stronger westerly winds fostering upwelling and the development of the anticyclonic gyres. In parallel, there might have been larger nutrient riverine inputs from glacier melting in the mountains surrounding the Mediterranean (Bárcena et al., 2001; Sancetta, 1994).

\subsubsection{Off Mauritania}

At site MD03-2705, we identified the presence of the intermediate and the large morphotypes of $C$. pelagicus. The large morphotype dominates during both cold events (H1 and YD) whereas the intermediate morphotype prevails around $\mathrm{B} / \mathrm{A}$ event.

During the $\mathrm{YD}$, there is a synchronized decline of the different indicators of primary productivity $(\mathrm{Sr} / \mathrm{Ca}$ ratio, $\mathrm{N}$ ratio and coccolith flux) that is in agreement with the MMA factors, which define an opposite behaviour between C. pelagicus subsp. azorinus and the upwelling-related C. pelagicus subsp. braarudii (Narciso et al., 2006; Parente et al., 2004). However, during H1, there is a dominance of C. pelagicus subsp. azorinus despite the clear common response of enhanced upwelling inferred from the high values of the primary productivity proxies. It seems that during the H1, the importance of the influence of water masses from the Azores region is greater than the upwelling intensification.

Parente (2002) reported the prevalence of the larger morphotype of $C$. pelagicus in samples from around the Azores islands. The presence of the larger morphotype, proposed as C. pelagicus subsp. azorinus, at a site as far as off Mauritania seems to indicate the influence of water masses driven directly from the Azores region towards those distant locations and the migration of larger specimens through the Azores current (Parente et al., 2004). The Azores current, which is a recirculation of the Gulf Stream, marks the northeastern boundary of the North Atlantic subtropical gyre (Rogerson et al., 2004). Along its eastward-flowing component, the Azores Current bifurcates into three major branches (Klein and Siedler, 1989), the easternmost branch turning southwards to feed the Canary Current (Meggers et al., 2002; New et al., 2001; Stramma, 1984), the surface current that reaches site MD032705.

During cold events like H1 and YD, the polar front migrated southward almost as far south as the Mediterranean Sea. Because the polar front was at the northern edge of the Gulf Stream, this was forced to turn eastward, flow toward the Azores, and then southward, keeping the path of the Azores and the Canary currents and increasing substantially the influence of Azores waters along the NW African Coast.

On the other hand, recent studies suggest that the outflow of salty water from the Mediterranean Sea plays a role in strengthening the Azores Current (Jia, 2000; Özgökmen et al., 2001) and that stronger outflow occurred during northern hemisphere coolings such as Heinrich events and the Younger Dryas (Voelker et al., 2006). 
Therefore, we believe that the increase of the large morphotype at site MD03-2705 during H1 and YD may derive from the intensification of the Azores Current due to a combined effect of the polar front shift and to an strengthening of the Mediterranean outflow (Sierro et al., 2005; Voelker et al., 2006) as a consequence of the large density gradient between Atlantic and Mediterranean waters. At YD times, C. pelagicus subsp. azorinus is less dominant because the salinity differences between Atlantic and Mediterranean waters decrease, and so does the outflow influence in the Azores current transport.

Alternatively, the intermediate morphotype, C. pelagicus subsp. braarudii, clearly dominates during the $\mathrm{B} / \mathrm{A}$ and correlates well with high $\mathrm{Sr} / \mathrm{Ca}$ ratios indicating an increase in primary productivity. However, previous interpretation of the upwelling influence in core MD03-2705 (Simón-Baile et al., to be submitted) suggested that high $\mathrm{Sr} / \mathrm{Ca}$ ratios of the $<20 \mu \mathrm{m}$-fraction are mainly linked to the proliferation of coarser and warmer species, especially of C. leptoporus, and to a lesser extent, to an increase of the eutrophic small placoliths. Therefore, higher productivity during B/A might reflect the predominance of mesothrophic conditions rather than strong upwelling, as supported by the low small coccoliths $\mathrm{Sr} / \mathrm{Ca}$ ratios and the reduced terrigenous inputs (Jullien et al., 2007).

Although it could seem to contradict the interpretation of C. pelagicus subsp. braarudii as an upwelling indicator, this may be due to the different upwelling intensities between the Alboran Sea and off NW Africa. Since the upwelling intensity off Mauritania is much stronger, what we previously considered enhanced upwelling in the Mediterranean Sea, could be, of similar intensity to what we are considering mesotrophic conditions at site MD03-2705. A comparison of the values of the $\mathrm{Sr} / \mathrm{Ca}$ ratios in both locations supports the foregoing, because, even the highest $\mathrm{Sr} / \mathrm{Ca}$ ratio of any fraction of the Alboran Sea core is lower than the lowest $\mathrm{Sr} / \mathrm{Ca}$ ratio of the core off Mauritania. In any case, when interpreting the same specimen in different locations based on an oceanographic process as the upwelling, we should consider the particular intensity of such process in each site.

\subsubsection{Latitudinal variations of the $C$. pelagicus morphotypes}

We compared results for the last deglaciation from the MMA performed on the C. pelagicus of four cores covering a transect from tropical areas to temperate sites including the Western Mediterranean Sea (See fig. 9.1). The cores compared are the two here presented, MD03-2705 at $18^{\circ} \mathrm{N}$ and MD952043 located at $36^{\circ} \mathrm{N}$ in the Alboran Sea, and two additional cores, MD95-2040 recovered off the Portugal coast at $40^{\circ} \mathrm{N}$ (Narciso et al., 2006) and GeoB 5559-2 located at $31^{\circ} \mathrm{N}$, north of the Canary Islands. Together they disclose an overall pattern of latitudinal variations (Fig. 9.6) although results from core GeoB 5559-2 should be considered with caution since its sample interval is slightly different. 


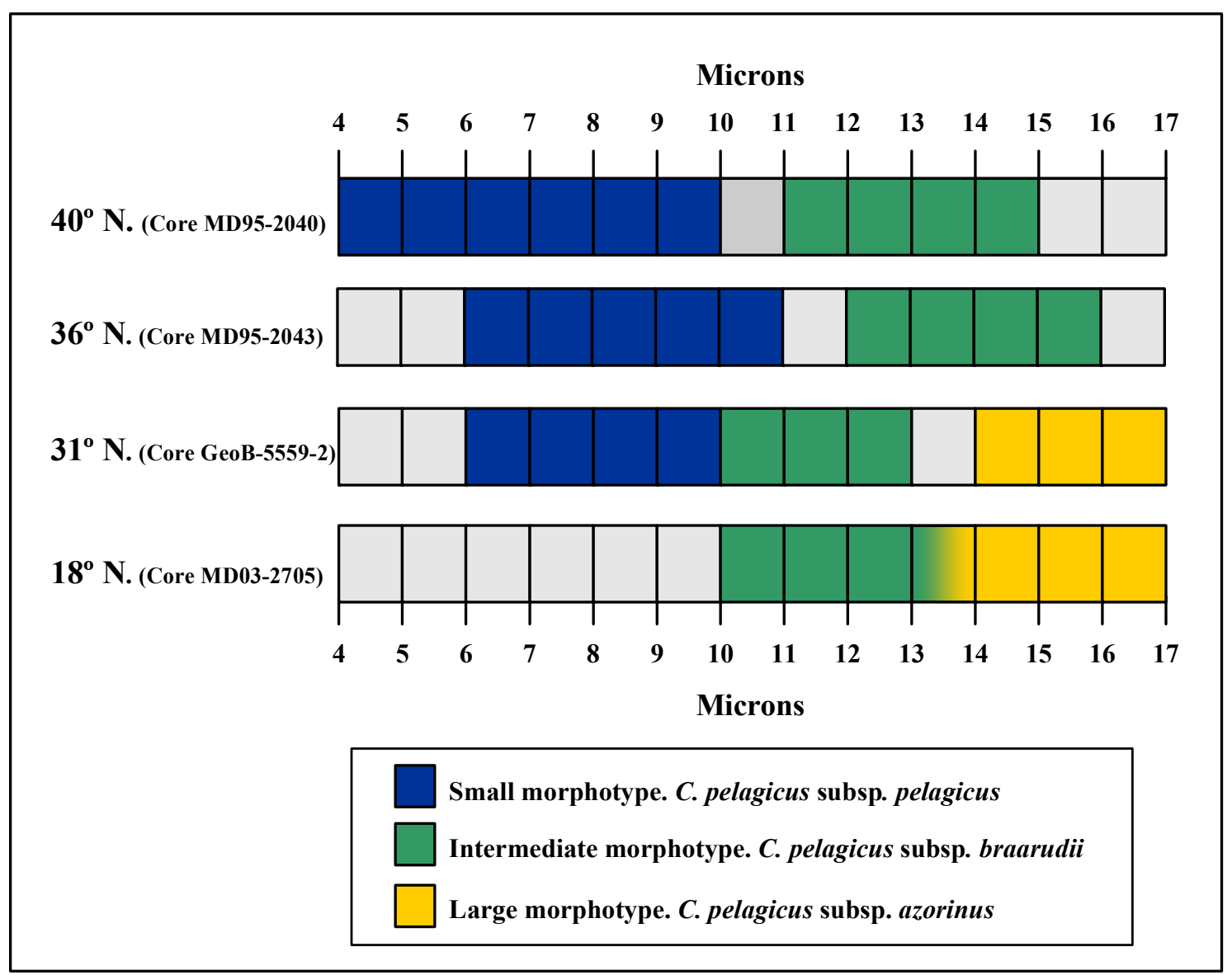

Figure 9.6. Latitudinal variation of the three distinct morphotypes of $C$. pelagicus in a transect from tropical areas to temperate sites including the Western Mediterranean Sea (see Fig. 9.1). Results are based in the MMA loadings of four different cores. Each rectangle represents a morphon, equivalent to a size interval of $1 \mu \mathrm{m}$. Grey rectangles represent morphons with no statistical meaning.

The latitudinal differences regarding the $C$. pelagicus morphotypes correspond to three aspects: (1) the present morphotypes in a particular latitude, (2) the morphometric boundaries between morphotypes and, (3) the morphometric interval of each morphotype.

First, concerning the presence of a specific morphotype, we observe that the three morphotypes only appear together in core GeoB 5559-2. The larger morphotype was only identified on the most meridional cores (at $18^{\circ} \mathrm{N}$ and $31^{\circ} \mathrm{N}$ ), whereas the smaller morphotype is absent in the southernmost core. The smaller morphotype (C. pelagicus subsp. pelagicus) optimum growth conditions are between 2 and $12{ }^{\circ} \mathrm{C}$ (Okada and McIntyre, 1979; Winter et al., 1994). Therefore, the tropical MD032705 site would be out of its geographical distribution because the core SST reconstruction (Matsuzaki et al., 2011) indicates temperatures higher than $12{ }^{\circ} \mathrm{C}$ for the last deglaciation. The larger morphotype, $C$.pelagicus subsp. azorinus is not found in the cores located in the Alboran Sea and off Oporto because they are out of the path followed by the Azores current. 
Secondly, the data show differences among the four analyzed cores when regarding the morphometric boundaries between morphotypes. Most of the limits are well-defined in a size range while few are more ambiguous and with some degree of overlapping. Specifically, the boundary between the smaller and the intermediate morphotype is clearly fixed around the morphon 10 in the northernmost and GeoB 5559-2 cores, but shifts to morphon 11 in the Alboran Sea core. In the case of the intermediate and the large morphotype, in 2006, Narciso et al. reported for other time slices that the morphometric boundary between these two morphotypes was less clear defined due to a higher degree of overlapping and that the large morphotype appears in a different factor, thus, its behaviour was unrelated to the other two morphotypes. However, both at sites GeoB 5559-2 and MD03-2705, we found the opposite, with the limit between the intermediate and the large morphotypes unambiguously set around morphon 13 and both morphotypes been described in the same factor and hence, reflecting a relationship. The overlapping of morphometric boundaries may reflect a younger phylogenetic separation (Narciso et al., 2006). According to this, the populations of small and intermediate morphotypes in GeoB 5559-2 core were still in the process of individualization because the environmental conditions required for the evolution towards separated populations, in this case, the cold conditions necessary for the development of the small morphotype, may have had an occasional and irregular influence.

Finally, the morphometric interval of the small morphotype is always broader than the intermediate one and at the same time, broadens from south to north, in such a way that the small morphotype in the northernmost core is defined by a set of 6 morphons, almost twice the morphometric interval at $31^{\circ} \mathrm{N}$. In turn, the morphometric interval of the intermediate morphotype is defined by four morphons in both cores of the Portugal coast and the Alboran Sea, and hardly narrows from north to south, still including three morphons in the cores off NW Africa. The morphometric interval of the large morphotype remains almost constant through latitude. As regards the small morphotype, a broader morphometric interval in northern latitudes could be related to a stronger and more frequent influence of subarctic cold waters which impact decreases towards southern locations. Under higher frequency of such conditions, the small morphotype populations might have experienced a longer evolution process, evolving towards smaller specimens. Within the range of $C$. pelagicus morphotypes, the small morphotype would have higher capacity for adaptation to unstable conditions and proliferate under the changeable conditions prevailing at sites located further north evolving faster and faster towards smaller forms. In turn, the large morphotype would be related to the more stable conditions prevailing in the Azores region, and hence, with smaller size changes. The intermediate morphotype may be halfway between the small and the large, experiencing slight variations in the intermediate size of its placolith. 
In short, it is evident that the existence of a specific morphotype and both its morphometric interval and boundaries, vary latitudinally because the subspecies overcome a series of adaptations to the particular environmental conditions of each location.

\subsection{Conclusions}

Statistical morphometric analysis (MMA) performed on the C. pelagicus dataset of cores MD95-2043 and MD03-2705 during the last deglaciation allowed the identification of the small and the intermediate morphotypes in the Alboran Sea core and of the intermediate and the large morphotypes in the core off Mauritania. On both cases, the two present morphotypes show opposite behaviour to each other. The absolute values of F1 scores for MD03-2705 are homogeneously moderate, and never higher than |2.4|, whereas for MD95-2043 core they can reach values up to $|10|$. This reveals that the Alboran Sea is more sensitive to climatic variations and has the capacity to amplifies oceanographic changes, as previous studies suggest (Cacho et al., 2002; Moreno et al., 2004).

The significant increase in the importance of the smaller morphotype, C. pelagicus subsp. pelagicus at site MD95-2043 during H1 suggests that the influence of subarctic waters broadened as far as the Mediterranean Sea. On the contrary, the polar province that also extended to the Alboran Sea during the H1, might have retreated before according to the abundance of $N$. pachyderma ( $\sin$.). During the YD event, the intermediate morphotype, C. pelagicus subsp. braarudii gained importance and correlated well with high $\mathrm{Sr} / \mathrm{Ca}$ and $\mathrm{N}$ ratios indicating increased upwelling and higher primary productivity in the Alboran Sea that probably resulted from the combination of larger inflow of nutrient-richer Atlantic waters and stronger wind-induced upwelling. At site MD03-2705, the dominance of the large morphotype during cold events H1 and YD may result from the intensification of the Azores Current due to a combined effect of the polar front southward migration and to an increase of Mediterranean outflow waters (Sierro et al., 2005; Voelker et al., 2006) as a consequence of the large density gradient between Atlantic and Mediterranean waters.

Comparison of morphometric datasets of C. pelagicus in four cores within a transect from tropical to temperate regions disclose an overall pattern of latitudinal variations. Specifically, the smaller morphotype is absent in the core off Mauritania because SSTs at this site are higher than its optimum growth conditions. Likewise, the larger morphotype is not found in the cores located in the Alboran Sea and off Oporto because they are out of the influence of the Azores current. Some degree of overlapping in the morphometric boundaries between morphotypes may reflect a younger phylogenetic separation. Moreover, morphometric interval of the small morphotype broadens from south to north and is broader than those of larger morphotypes, which hardly varies latitudinally. Thus, the small morphotype latitudinal size changes may result from its adaptation to more unstable conditions. 



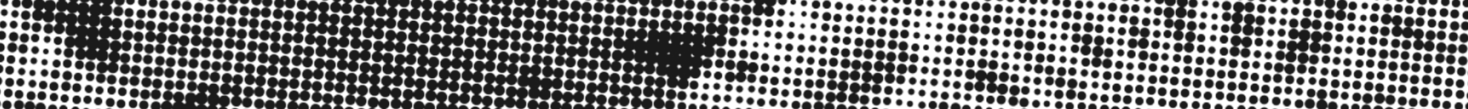

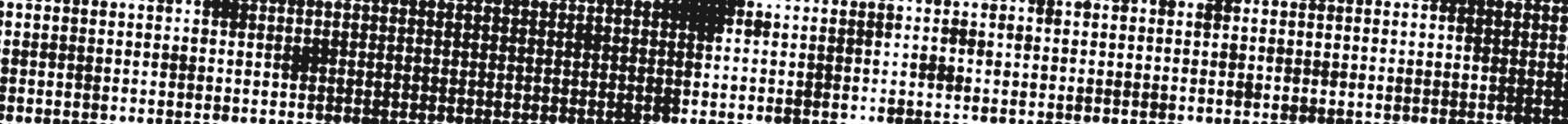

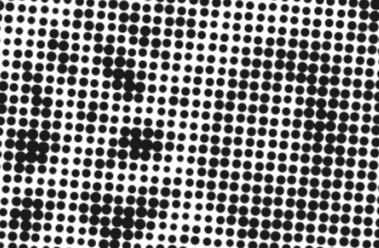
t3:

:mam 



\section{Conclusiones}

La presente tesis doctoral aporta nuevos registros sobre la química de los cocolitos que se complementan con datos de morfometría procedentes de testigos obtenidos en el mar de Alborán y en el margen noroccidental africano (costa de Mauritania). Ambas fuentes han permitido identificar diferentes patrones de variabilidad oceanográfica y climática, y profundizar en nuestro conocimiento sobre el papel que los cocolitóforos han desempeñado en el clima a lo largo de la última transición glacial-interglacial. Las conclusiones pueden agruparse atendiendo a las cuatro secciones en las que se divide la tesis:

- En el primer trabajo, se realizó picking de cocolitos para el análisis de ratios $\mathrm{Sr} / \mathrm{Ca}$ mediante sonda iónica SIMS. Las cuatro especies investigadas, G. oceanica, H. Carteri, C. leptoporus y C.pelagicus, mostraron diferencias interespecíficas aunque, en general, los valores de $\mathrm{Sr} / \mathrm{Ca}$ y por tanto de productividad, fueron menores durante los eventos El Niño ocurridos en la última mitad del siglo XX.

-En la segunda y tercera sección se abordó la separación de fracciones restringidas de cocolitos mediante decantaciones sucesivas y microfiltración. Se trata de un método eficaz para investigar la química de la calcita de los cocolitos como demuestra la elevada contribución de carbonato de una única especie obtenida en las fracciones separadas. No obstante, la eficiencia de las dos fracciones separadas fue diferente para cada testigo. En el testigo del mar de Alborán, las fracciones de cocolitos más robustos fueron demasiado heterogéneas y las fracciones de cocolitos de menor tamaño resultaron más fiables, alcanzando concentraciones de carbonato de un $75 \%$ en promedio, $16 \%$ mayores que para el testigo de la costa de Mauritania. En el testigo del margen norafricano, se obtuvieron más fácilmente fracciones cuyo carbonato está dominado por una única especie para las fracciones de cocolitos más robustos, con un promedio del $91,5 \%$. Por otro lado, en la asociación original de cocolitóforos del mar de Alborán, tanto los cocolitos pequeños como los gruesos contribuyeron de forma similar al contenido de carbonato mientras que en la zona del testigo MD03-2705, la fracción de cocolitos pequeños presenta una menor contribución al total del carbonato, siendo en torno a un $22 \%$ menos que en el testigo del mar de Alborán.

Los isotopos estables $\left(\delta^{18} \mathrm{O}\right.$ y $\left.\delta^{13} \mathrm{C}\right)$ y los ratios $\mathrm{Sr} / \mathrm{Ca}$ de la fracción $<20 \mu \mathrm{m}$ y las fracciones restringidas de cocolitos se emplearon en la reconstrucción de las condiciones superficiales del océano y los patrones de productividad en el Mediterráneo occidental y el margen noroccidental de África. Las diferencias en la señal geoquímica entre ambas fracciones separadas fueron significativas para las costas del noroeste de África, siendo moderadas para el Mediterráneo occidental.

En el mar de Alborán, las fluctuaciones paleoceanográficas a lo largo de los últimos 20 ka estuvieron probablemente relacionadas con cambios en las condiciones atmosféricas, la intensidad del flujo de entrada desde el Atlántico, y la mezcla vertical en la columna de agua. Tales variaciones sugieren que 
el mar de Alborán se encuentra fuertemente conectado a altas y bajas latitudes y responde a los cambios climáticos que ocurren tanto en el Atlántico Norte como en las regiones tropicales. Las variaciones en el $\delta^{18} \mathrm{O}$ de los cocolitos desde el último máximo glaciar se asociaron a cambios en las temperaturas superficiales del mar (TSM) y a los aportes de agua de deshielo desde el Atlántico durante el Heinrich 1 que pudieron causar considerables contrastes en la densidad del Mediterráneo y la consecuente reducción en la mezcla de masas de agua a pesar de un mayor intercambio de aguas y de una circulación más activa a través del estrecho de Gibraltar. A pesar de la oligotrofía que caracteriza la mayor parte del Mediterráneo, el mar de Alborán presenta condiciones mesotróficas como consecuencia del efecto combinado entre la interacción de las aguas mediterráneas con las aguas atlánticas más ricas en nutrientes, y los afloramientos o upwellings inducidos por los vientos. Durante el H1, la intensa estratificación evitó que los nutrientes orgánicos del Atlántico ascendieran a la superficie y alcanzaran la zona fótica superior, por lo que la productividad marina disminuyó. En el intervalo YD, la migración de la ZCIT hacia zonas más meridionales permitió el establecimiento de un sistema de bajas presiones y la intensificación de los vientos del oeste, lo que indujo una reactivación de la mezcla de aguas y una nutriclina más somera que, junto con aportes extra de nutrientes de origen fluvial, condujo a una elevada productividad primaria. La productividad durante la Terminación Ia y el evento B-A y durante los inicios del Holoceno fue probablemente baja en el mar de Alborán como consecuencia del debilitamiento de los vientos del oeste y de una reducción del flujo de entrada del Atlántico y de la surgencia oceánica, asociados a una migración de la ZCIT hacia posiciones más septentrionales y a la prevalencia de altas presiones atmosféricas sobre el Mediterráneo occidental.

En las costas de Mauritania, la productividad durante el MIS 3 y el Último Máximo Glacial fue generalmente baja con pequeños incrementos esporádicos, pero mostró cambios pronunciados y una mayor inestabilidad durante la deglaciación. Las variaciones en las condiciones de las aguas sobre el testigo MD03-2705 parecen deberse a la interacción de una amplia variedad de procesos oceanográficos y atmosféricos. Las fluctuaciones en la posición y la intensidad de la surgencia oceánica junto a su expansión hacia el océano abierto y al contenido variable de los nutrientes en las aguas que afloran, fueron responsables de los grandes cambios en la productividad a lo largo de la deglaciación. Estos escenarios fluctuantes fueron probablemente consecuencia de un cambio en la fuerza y dirección del viento relacionado con migraciones en la ZCIT. Además, masivos aportes puntuales de polvo procedente del desierto del Sahara pudieron alterar la productividad y la señal isotópica. El desplazamiento hacia el sur de la ZCIT parece ser un factor determinante a la hora de explicar la intensificación de las surgencia oceánica y el incremento de la productividad observado durante el H1 mientras que una migración hacia posiciones más norteñas en el Holoceno temprano dio lugar a una estratificación de la columna de agua y una menor productividad. La reconstrucción paleoceanográfica para el B/A y el YD es más compleja y para ello, deben tenerse en cuenta otros procesos además de la ZCIT. Los cambios en la química de la calcita de los cocolitos durante el 
evento B/A pudieran derivarse de las diferentes preferencias ecológicas del grupo de especies de mayor tamaño de cocolitóforos (C. leptoporus y H. carteri), los cuales prefieren ambientes mesotróficos, mientras que, durante el YD, el aporte masivo de terrígenos $(80 \%)$ pudo haber reducido drásticamente la disponibilidad de luz en la zona fótica superior y, en consecuencia, inhibir el crecimiento de los cocolitóforos.

-La última sección se dedica al análisis estadístico de los datos morfométricos de C. pelagicus en los testigos MD95-2043 y MD03-2705 durante la última deglaciación. Este análisis ha permitido la identificación de los morfotipos pequeño e intermedio en el testigo del mar de Alborán y los morfotipos intermedio y grande en el testigo del margen norafricano. Los valores absolutos de los scores del factor 1 para el testigo MD03-2705 son homogéneamente moderados, y nunca mayores a |2.4|, mientras que para el testigo MD95-2043 pueden alcanzar valores superiores a |10|. Esto revela que el mar de Alborán es más sensible a las variaciones climáticas y que posee la capacidad de amplificar los cambios oceanográficos. El incremento significativo de la importancia del morfotipo más pequeño, C. pelagicus subsp. pelagicus, en la zona del testigo MD95-2043 durante el H1 sugiere que la influencia de las aguas subárticas se expandió llegando hasta el Mediterráneo. Por el contrario, la influencia de las condiciones polares que también se habían extendido hasta el mar de Alborán durante el H1, pudo haberse retirado con anterioridad de acuerdo a la abundancia de $N$. pachyderma (sin.). Durante el evento YD, el morfotipo intermedio, C. pelagicus subsp. braarudii, ganó importancia y su buena correlación con altos ratios $\mathrm{Sr} / \mathrm{Ca}$ y $\mathrm{N}$, indica una intensificación de la surgencia oceánica y una elevada productividad en el mar de Alborán. En el área del testigo MD032705, el predominio del morfotipo grande durante los eventos fríos H1 y YD pudo ser el resultado de la intensificación de la corriente de las Azores debido al efecto combinado de la migración al sur del frente polar y del incremento del flujo de salida de aguas del Mediterráneo como consecuencia del elevado gradiente de densidad entre las aguas del Atlántico y el Mediterráneo.

La comparación de datos morfométricos de C. pelagicus en cuatro testigos a lo largo de un transecto desde regiones tropicales a templadas revela un patrón general de variaciones latitudinales. Concretamente, el morfotipo más pequeño no está presente en el testigo de Mauritania puesto que las TSM de esta zona son superiores a sus condiciones óptimas de crecimiento. Así mismo, el morfotipo más grande no se encontró en los testigos del mar de Alborán y la costa de Oporto ya que estas regiones están fuera de la influencia de la corriente de las Azores. Un cierto grado de solapamiento en los límites entre morfotipos pudiera ser el reflejo de una separación filogenética más reciente. Además, el intervalo morfométrico del morfotipo pequeño aumenta de sur a norte y es más amplio que los de los morfotipos de mayor tamaño, que apenas varían latitudinalmente. Así, los cambios latitudinales en el tamaño del morfotipo pequeño pudieran ser el resultado de su adaptación a condiciones de mayor inestabilidad. 


\section{Conclusions}

The present thesis provides new records of coccolith chemistry and complements them with morphometry data from cores from the Alboran Sea and off Mauritania that allowed us to identify different patterns of oceanographic and climatic variability and to further understand the role of coccolithophores in the climate over the last glacial-interglacial transition. The conclusions obtained in this thesis can be divided according to the main four sections:

-In a first work, we picked individual coccoliths for analysis of $\mathrm{Sr} /$ ca ratios using SIMS ion probe. The four coccolith species investigated, G. oceanica, H. Carteri, C. leptoporus and C.pelagicus exhibit interspecific differences, although, in general, the $\mathrm{Sr} / \mathrm{Ca}$-derived productivity values are lower during the strongest El Niño-Southern Oscillation events occurring over the last half century.

-The second and third sections deal with the separation of restricted coccolith fractions through repeated decanting and microfiltering. This is a reliable method to investigate coccolith calcite chemistry as verified by the high species-specific coccolith carbonate contribution obtained in the separated fractions. However, the efficiency of the two separated fractions was different in each core. In the Alboran core, the coarse coccolith fractions were too heterogenous and the small coccolith fractions were more reliable achieving carbonate concentrations of $75 \%$ on average, $16 \%$ higher than for the core off NW Africa. In the core off Mauritania, size fractions with carbonate dominated by a single species were produced more readily for the coarse size fractions, with $91.5 \%$ on average. On the other hand, in the original coccolithophore assemblage of the Alboran Sea, both the small and the coarse coccolith contribute similarly to the coccolith carbonate budget whereas at site MD03-2705 the small coccoliths fraction has a minor contribution to the assemblage carbonate, being around $22 \%$ lower than in the Alboran Sea core.

Stable isotopes $\left(\delta^{18} \mathrm{O}\right.$ and $\left.\delta^{13} \mathrm{C}\right)$ and $\mathrm{Sr} / \mathrm{Ca}$ ratios of $<20 \mu \mathrm{m}$ and restricted coccolith fractions were used to reconstruct sea surface conditions and productivity patterns in the Western Mediterranean and off NW Africa. Differences in the geochemical signal between both separated fractions are significant off NW Africa, being moderate in the Western Mediterranean.

In the Alboran Sea, paleoceanographic fluctuactions throughout the last 20 ka may have been related to changes in the atmospheric conditions, the intensity of the Atlantic inflow and the vertical mixing within the water column. Such variations suggest that the Alboran Sea is strongly connected with both high and low latitudes and respond to climatic changes occurring either in the North Atlantic or in Tropical regions.

Variations in the coccolith $\delta^{18} \mathrm{O}$ since last glacial maximum were associated to changes in the SSTs and to meltwater inputs from the Atlantic during H1 that may have caused large density contrasts 
within the Mediterranean and a subsequent reduction of water mixing despite greater volume of water exchange and a more active circulation through the Gibraltar strait.

Despite the olygotrophy in most of the Mediterranean, mesotrophic scenarios occur in the Alboran Sea as a result of combined interaction between Mediterranean and nutrient-richer Atlantic waters and wind-induced upwelling. During H1, the intense stratification prevented organic Atlantic nutrients from moving upward and accessing the upper photic zone and the marine productivity decreased. At YD times, the southward migration of the ITCZ enabled the establishment of a low-pressure system and the intensification of the westerlies inducing a reactivation of water mixing and a shallower nutricline, that, together with extra riverine nutrients inputs, lead to high primary productivity. Productivity during Termination Ia and B-A and during early Holocene might have been low in the Alboran Sea as result of weaker westerlies and reduced Atlantic inflow and upwelling associated to a northward migration of the ITCZ and the prevalence of high atmospheric pressure over the Western Mediterranean.

Off Mauritania, the productivity during MIS 3 and LGM was generally low with short sporadic increases, but it shows pronounced changes and a larger instability during the deglaciation. Variations in the conditions of waters overlying site MD03-2705 seem to result from the interplay of a wide variety of oceanographic and atmospheric processes. Fluctuations in the position and intensity of the upwelling cell together with a seaward enlargement and variable nutrient content of the upwelled waters were responsible for the large changes in productivity during the deglaciation. These fluctuating scenarios were likely the consequence of changes in wind stress and direction and linked to migrations of the ITCZ. Furthermore, punctual massive dust inputs from the neighbouring Sahara may have altered the productivity and isotopic signal.

A southward latitudinal shift of the ITCZ seems to be a major controlling factor that explains the upwelling intensification and enhanced productivity observed during H1 whereas an early Holocene northward migration resulted in the stratification of the water column and lower productivity. The paleoceanographic reconstruction for the $\mathrm{B} / \mathrm{A}$ and the $\mathrm{YD}$ is more complex and other processes besides ITCZ have to be considered. Changes in coccolith calcite chemistry during the B/A might derive from the distinct ecological preferences of the group of coarse coccolithophore species $(C$. leptoporus and $H$. carteri) which prefer mesotrophic environments, whereas, during the YD, the massive terrigenous supply ( $80 \%$ ) may have drastically reduced light availability in the upper photic zone and hence, inhibited the coccolithophores growth.

-The last section is dedicated to statistical morphometric analysis performed on the C. pelagicus dataset of cores MD95-2043 and MD03-2705 during the last deglaciation. It allowed the identification of the small and the intermediate morphotypes in the Alboran Sea core and of the intermediate and the 
large morphotypes in the core off Mauritania. The absolute values of F1 scores for MD03-2705 are homogeneously moderate, and never higher than |2.4|, whereas for MD95-2043 core they can reach values up to $|10|$. This reveals that the Alboran Sea is more sensitive to climatic variations and has the capacity to amplify oceanographic changes.

The significant increase in the importance of the smaller morphotype, C. pelagicus subsp. pelagicus at site MD95-2043 during H1 suggests that the influence of subarctic waters broadened as far as the Mediterranean. On the contrary, the polar province that also extended to the Alboran Sea during H1, might have retreated before according to the abundance of $N$. pachyderma ( $\sin$.). During YD event, the intermediate morphotype, C. pelagicus subsp. braarudii gained importance and correlated well with high $\mathrm{Sr} / \mathrm{Ca}$ and $\mathrm{N}$ ratios indicating increased upwelling and high productivity in the Alboran Sea.

At site MD03-2705, the dominance of the large morphotype during cold events H1 and YD may result from the intensification of the Azores Current due to a combined effect of the polar front southward migration and to an increase of Mediterranean outflow waters as a consequence of the large density gradient between Atlantic and Mediterranean waters.

Comparison of morphometric datasets of $C$. pelagicus in four cores within a transect from tropical to temperate regions disclose an overall pattern of latitudinal variations. Specifically, the smaller morphotype is absent in the core off Mauritania because SSTs at this site are higher than its optimum growth conditions. Likewise, the larger morphotype is not found in the cores located in the Alboran Sea and off Oporto because they are out of the influence of the Azores current. Some degree of overlapping in the morphometric boundaries between morphotypes may reflect a younger phylogenetic separation. Moreover, morphometric interval of the small morphotype broadens from south to north and is broader than those of larger morphotypes, which hardly vary latitudinally. Thus, the small morphotype latitudinal size changes may result from its adaptation to more unstable conditions. 



\section{Bibliografía}

Abrantes, F., 1988. Diatom productivity peak and increased circulation during latest Quaternary: Alboran Basin (Western Mediterranean). Marine Micropaleontology, 13(1): 79-96.

Abrantes, F., Meggers, H., Nave, S., Bollman, J., Palma, S., Sprengel, C., Henderiks, J., Spies, A., Salgueiro, E., Moita, T. and Neuer, S. 2002. Fluxes of micro-organisms along a productivity gradient in the Canary Islands region $\left(29^{\circ} \mathrm{N}\right)$ : implications for paleoreconstructions. Deep-Sea Research II, 49: 3599-3629.

Adkins, J., deMenocal, P. and Eshel, G., 2006. The "African humid period" and the record of marine upwelling from excess 230Th in Ocean Drilling Program Hole 658C. Paleoceanography, 21.

Ahagon, N., Tanaka, Y. and Ujiié, H., 1993. Florisphaera profunda, a possible nannoplankton indicator of late Quaternary changes in sea-water turbidity at the northwestern margin of the Pacific. Marine Micropaleontology, 22(3): 255-273.

Alley, R.B. and Ágústsdóttir, A.M., 2005. The 8k event: cause and consequences of a major Holocene abrupt climate change. Quaternary Science Reviews, 24(10-11): 1123-1149.

Alley, R.B. and Clark, P.U., 1999. The deglaciation of the Northern Hemisphere: A Global Perspective. Annual Review of Earth and Planetary Sciences, 27: 149-182.

Álvarez, M.C., Flores, J.A., Sierro, F.J., Diz, P., Francés, G., Pelejero, C. y Grimalt, J.O. 2002. Dinámica superficial en la Ría de Vigo durante los últimos 3000 años puesta de manifiesto a través de los cocolitofóridos y biomarcadores. Geogaceta, 32: 207-210.

Alves, M., Gaillard, F., Sparrow, M., Knoll, M. and Giraud, S., 2002. Circulation patterns and transport of the Azores Front-Current system. Deep Sea Research Part II: Topical Studies in Oceanography, 49(19): 3983-4002.

Anderson, T. and Steinmetz, J., 1983. Stable isotopes in calcareous nannofossils: potential application to deep-sea paleoenvironmental reconstructions during the Quaternary. In: J. Meulenkamp (Editor), Reconstruction of Marine Paleoenvironments. Micropaleontol Bull, Utrecht pp. 189-204.

Anderson, T.F. and Cole, S.A., 1975. The stable isotope geochemistry of marine coccoliths: a preliminary comparison with planktonic foraminifera. Journal of Foraminiferal Research 5: 188-192.

Andruleit, H., 1997. Coccolithophore fluxes in the Norwegian-Greenland Sea: Seasonality and assemblage alterations. Marine Micropaleontology, 31(1-2): 45-64.

Apitz, S.E., 1991. The lithification of Ridge Flank Basal carbonates: characterization and implications for $\mathrm{Sr} / \mathrm{Ca}$ and $\mathrm{Mg} / \mathrm{Ca}$ in marine chalks and limestones, University of California, San Diego, CA.

Armstrong, H.A. and Brasier, M.D., 2005. Microfossils. Blackwell Publishing, Oxford, 304 pp.

Aubry, M.-P., 2009. A sea of Lilliputians. Palaeogeography, Palaeoclimatology, Palaeoecology, 284(1-2): 88-113.

Auliaherliaty, L., Stoll, H.M., Ziveri, P., Malinverno, E., Triantaphyllou, M., Stravrakakis, S. and Lykousis, V., 2009. Coccolith $\mathrm{Sr} / \mathrm{Ca}$ ratios in the eastern Mediterranean: Production versus export processes. Marine Micropaleontology, 73(3-4): 196-206.

Bains, S., Corfield, R. and Norris, R., 1999. Mechanims of climate warning at the end of the Paleocene. Science, 285: 724-727.

Bairbakhish, A.N., Bollmann, J., Sprengel, C. and Thierstein, H.R., 1999. Disintegration of aggregates and coccospheres in sediment trap samples. Marine Micropaleontology, 37(2): 219-223.

Bárcena, M.A. and Abrantes, F., 1998. Evidence of a high-productivity area off the coast of Málaga from studies of diatoms in surface sediments. Marine Micropaleontology, 35(1-2): 91-103. 
Bárcena, M.A., Cacho, I., Abrantes, F., Sierro, F.J., Grimalt, J.O. and Flores, J.A., 2001. Paleoproductivity variations related to climatic conditions in the Alboran Sea (western Mediterranean) during the last glacial-interglacial transition: the diatom record. Palaeogeography, Palaeoclimatology, Palaeoecology, 167(3-4): 337-357.

Bárcena, M.A., Flores, J.A., Sierro, F.J., Pérez-Folgado, M., Fabres, J., Calafat, A. and Canals, M., 2004. Planktonic response to main oceanographic changes in the Alboran Sea (Western Mediterranean) as documented in sediment traps and surface sediments. Marine Micropaleontology, 53(3-4): 423-445.

Bard, E., Arnold, M., Mangerud, J., Paterne, M., Labeyrie, L., Duprat, J., Mélières, M.-A., Sønstegaard, E. and Duplessy, J.-C., 1994. The North Atlantic atmosphere-sea surface 14C gradient during the Younger Dryas climatic event. Earth and Planetary Science Letters, 126(4): 275-287.

Bartov, Y., Goldstein, S.L., Stein, M. and Enzel, Y., 2003. Catastrophic arid episodes in the Eastern Mediterranean linked with the North Atlantic Heinrich events. Geology, 31(5): 439-442.

Bauch, D., Darling, K., Simstich, J., Bauch, H.A., Erlenkeuser, H. and Kroon, D., 2003. Palaeoceanographic implications of genetic variation in living North Atlantic Neogloboquadrina pachyderma. Nature, 424: 299-302.

Baumann, K.H. and Sprengel, C., 2000. Morphological variations of selected coccolith species in a sediment trap north of the Canary Islands. Journal of Nannoplankton Research, 22: 185-193.

Baumann, K.H., 1995. Morphometry of Quaternary Coccolithus pelagicus coccoliths from Northern North Atlantic and its paleoceanographical significance., Proceedings 5th INA Conference, Salamanca, Spain, pp. 11-21.

Baumann, K.H., Andruleit, H. and Samtleben, C., 2000. Coccolithophores in the Nordic Seas: comparison of living communities with surface sediment assemblages. Deep Sea Research Part II: Topical Studies in Oceanography, 47(9-11): 1743-1772.

Baumann, K.H., Boeckel, B. and Frenz, M., 2004. Coccolith contribution to South Atlantic carbonate sedimentation. In: H.R. Thierstein and J.R. Young (Editors), Coccolithophores: from molecular processes to global impact. Springer, Heidelberg, Germany, pp. 367-402.

Baumann, K.H., Cepek and Kinkel, H., 1999. Coccolithophores as indicators of ocean water masses, surface-water temperature, and paleoproductivity-examples from the South Atlantic. In: G. Fischer and G. Wefer (Editors), Use of Proxies in Paleoceanography: Examples from the South Atlantic. Springer, Berlin-Heidelberg, pp. 117-144.

Beaufort, L., de Garidel-Thoron, T., Mix, A.C. and Pisias, N.G., 2001. ENSO-like forcing on oceanic primary production during the Late Pleistocene. Science, 293(5539): 2440-2444.

Beaufort, L., Lancelot, Y., Camberlin, P., Cayre, O., Vincent, E., Bassinot, F. and Labeyrie, L., 1997. Insolation cycles as a major control of Equatorial Indian Ocean primary production. Science, 278(5342): 1451-1454.

Bemis, B.E., Spero, H.J., Bijma, J. and Lea, D.W., 1998. Reevaluation of the oxygen isotopic composition of planktonic foraminifera: experimental results and revised paleotemperature equations. Paleoceanography, 13.

Berger, W.H. and Roth, P.H., 1975. Oceanic Micropaleontology: Progress and Prospect. Reviews in Geophysics, 13.

Bertrand, P. et al., 1996. The glacial ocean productivity hypothesis: the importance of regional temporal and spatial studies. Marine Geology, 130(1-2): 1-9.

Béthoux, J.P., 1979. Budgets of the Mediterranean Sea. Their dependence on the local climate and on the characteristics of the Atlantic waters. Oceanologica Acta, 2: 157-163. 
Béthoux, J.P., Morin, P., Chaumery, C., Connan, O., Gentili, B. and Ruiz-Pino, D., 1998. Nutrients in the Mediterranean Sea, mass balance and statistical analysis of concentrations with respect to environmental change. Marine Chemistry, 63(1-2): 155-169.

Bijma, J., Spero, H. and Lea, D., 1991. Reassessing foraminiferal stable isotopes geochemistry: impact of the oceanic carbonate system (Experimental Results). In: G. Fischer, Wefer, G. (Editors), Use of Proxies in Paleoceanography: Examples from the South Atlantic. Springer-Verlag Berlin Heidelberg, pp. 489-512.

Billard, C. and Inouye, I., 2004. What is new in coccolithophore biology? In: H.R. Thierstein and J.R. Young (Editors), Coccolithophores: From Molecular Processes to Global Impact. Springer, Berlin, pp. $1-30$.

Blasco, D., Estrada, M. and Jones, B., 1980. Relationship between the phytoplankton distribution and composition and the hydrography in the northwest African upwelling region near Cabo Corbeiro. Deep Sea Research Part A. Oceanographic Research Papers, 27(10): 799-821.

Boeckel, B., 2003. Present and past coccolith assemblages in the South Atlantic: Implications for species ecology, carbonate contribution and palaeoceanograhic applicability, Universität Bremen, Bremen, $157 \mathrm{pp}$.

Bollmann, J., 1997. Morphology and biogeography of Gephyrocapsa coccoliths in Holocene sediments. Marine Micropaleontology, 29(3-4): 319-350.

Bollmann, J., Baumann, K.H. and Thierstein, H.R. 1998. Global dominance of Gephyrocapsa coccoliths in the Late Pleistocene: selective dissolution, evolution, or global environmental change? Paleoceanography, 13 (5): 517-529.

Bond, G. et al., 1992. Evidence for massive discharges of icebergs into the North Atlantic ocean during the last glacial period. Nature, 360: 245-249.

Bornemann, A., Aschwer, U. and Mutterlose, J., 2003. The impact of calcareous nannofossils on the pelagic carbonate accumulation across the Jurassic-Cretaceous boundary. Palaeogeography, Palaeoclimatology, Palaeoecology, 199(3-4): 187-228.

Bouvier-Soumagnac, Y. and Duplessy, J.-C., 1985. Carbon and oxygen isotopic composition of planktonic foraminifera from laboratory culture, plankton tows and Recent sediment: implications for the reconstruction of paleoclimatic conditions and of the global carbon cycle. Foraminiferal Research, 15:302-320.

Bown, P., Lees, J.A. and Young, J.R., 2004. Calcareous nannoplankton evolution and diversity through time. In: Thierstein H.R. and Young, J.R. (Editors), Coccolithophores: from molecular processes to global impact. Springer, Berlin-Heidelberg,Germany, pp. 481-508.

Boyer, P. et al., 2006. World Ocean Database 2005. NOAA Atlas NESDIS 60. U.S. Government Printing Office, Washington, D.C., 190 pp.

Bralower, T.J., Bown, P.R. and Siesser, W.G., 1991. Significance of Upper Triassic nannofossils from the Southern Hemisphere (ODP Leg 122, Wombat Plateau, N.W. Australia). Marine Micropaleontology, 17(1-2): 119-154.

Brand, L.E. 1994. Physiological ecology of marine coccolithophores. In: Coccolithophores Winter, A. and Siesser, W.G. (Editors).Cambridge University Press, Cambridge: 39-49.

Brand, L.E., 1994. Physiological ecology of marine coccolithophores. In: A. Winter and W.G. Siesser (Editors), Coccolithophores. Cambridge University Press, Cambridge, pp. 39-49.

Brassell, S.C., Eglinton, G., Marlowe, I.T., Pflaumann, U. and Sarnthein, M., 1986. Molecular stratigraphy: a new tool for climatic assessment. Nature, 320: 129-133.

Bratbak, G., Wilson, W. and Heldal, M., 1996. Viral control of Emiliania huxleyi blooms? Journal of Marine Systems, 9(1-2): 75-81. 
Broccoli, A.J., Dahl, K.A. and Stouffer, R.J., 2006. Response of the ITCZ to Northern Hemisphere cooling. Geophys. Res. Lett., 33.

Broecker, W., 2003. Does the trigger for abrupt climate change reside in the ocean or in the atmosphere?. Science, 300: 1519-1522.

Broecker, W.S., 1971. A kinetic model for the chemical composition of sea water. Quaternary Research, 1(2): 188-207.

Brownlee, C. and Taylor, A., 2004. Calcification in coccolithopores: a cellular perspective. In: H.R. Thierstein and J.R. Young (Editors). Coccolithophores: From Molecular Processes to Global Impact. Springer Verlag. pp. 31-50.

Cachão, M. and Moita, M.T., 2000. Coccolithus pelagicus, a productivity proxy related to moderate fronts off Western Iberia. Marine Micropaleontology, 39(1-4): 131-155.

Cacho, I., Grimalt, J.O. and Canals, M., 2002. Response of the Western Mediterranean Sea to rapid climatic variability during the last 50,000 years: a molecular biomarker approach. Journal of Marine Systems, 33-34: 253-272.

Cacho, I., Grimalt, J.O., Pelejero, C., Canals, M., Sierro, F.J., Flores, J.A. and Shackleton, N., 1999. Dansgaard-Oeschger and Heinrich event imprints in Alboran Sea paleotemperatures. Paleoceanography, 14: 698-705.

Cacho, I., Grimalt, J.O., Sierro, F.J., Shackleton, N. and Canals, M., 2000. Evidence for enhanced Mediterranean thermohaline circulation during rapid climatic coolings. Earth and Planetary Science Letters, 183(3-4): 417-429.

Cacho, I., Shackleton, N., Elderfield, H., Sierro, F.J. and Grimalt, J.O., 2006. Glacial rapid variability in deep-water temperature and 180 from the Western Mediterranean Sea. Quaternary Science Reviews, 25(23-24): 3294-3311.

Castradori, D., 1993. Calcareous Nannofossils and the Origin of Eastern Mediterranean Sapropels. Paleoceanography, 8(4): 459-471.

Cavalier-Smith T. 1981. Eucaryote kingdoms, seven or nine? BioSystems, 14 : 461-481.

Cavalier-Smith, T., 1998. A revised six-kingdom system of life. Biological Reviews of the Cambridge Philosophical Society, 73: 203-266.

Chapman, M.R., Shackleton, N.J., Zhao, M. and Eglinton, G., 1996. Faunal and Alkenone Reconstructions of Subtropical North Atlantic Surface Hydrography and Paleotemperature Over The last 28 kyr. Paleoceanography, 11.

Charm, W.B., 1967. Freeze drying as a rapid method of disaggregating silts and clays for dry particle size analysis. Journal of Sedimentary Petrology, 37(3) 970-971.

Chavez, F. P., Collins, C. A., Huyer, A. and Mackas, D. L., 2002a. El Niño along the West Coast of North America.Progress of Oceanography, 54, 1-5,doi:10.1016/S0079-6611(02)00040-X.

Chavez, F. P., Pennington, J. T., Castro, C. G. , Ryan, J. P., Michisaki, R. P., Schlining, B., Walz, P.,Buck, K., McFadyen, A. and Collins, C. A., 2002b. Biological and chemical consequences of the 1997- 1998 El Niño in central California waters. Progress of Oceanography, 54, 205-232, doi:10.1016/S0079-6611(02)00050-2

Chiapello, I. et al., 1995. An additional low layer transport of Sahelian and Saharan dust over the northeastern tropical Atlantic. Geophys. Res. Lett., 22: 3191-3194.

Chiapello, I., Bergametti, G., Gomes, L., Chatenet, B., Dulac, F., Pimenta, J. and Santos Soares, E., 1995. An additional low layer transport of Sahelian and Saharan dust over the northeastern tropical Atlantic. Geophysical Research Letters, 22: 3191-3194.

Clark, P.U. et al., 2001. Freshwater Forcing of Abrupt Climate Change During the Last Glaciation. Science, 293(5528): 283-287. 
Clement, A.C. and Peterson, L.C., 2008. Mechanisms of abrupt climate change of the last glacial period. Reviews of Geophysics, 46(4): RG4002.

COHMAP Members, 1988. Climatic changes of the last 18,000 years: observations and model simulations. Science, 241: 1043-1052.

Colmenero-Hidalgo, E., 2004. Respuesta de las asociaciones de cocolitofóridos a los cambios climáticos del Cuaternario final, Universidad de Salamanca, 255 pp.

Colmenero-Hidalgo, E., Flores, J.A. and Sierro, F.J., 2002. Biometry of Emiliania huxleyi and its biostratigraphic significance in the Eastern North Atlantic Ocean and Western Mediterranean Sea in the last 20.000 years. Marine Micropaleontology, 46(3-4): 247-263.

Colmenero-Hidalgo, E., Flores, J.A., Sierro, F.J., Bárcena, M.Á., Löwemark, L., Schönfeld, J. and Grimalt, J.O., 2004. Ocean surface water response to short-term climate changes revealed by coccolithophores from the Gulf of Cadiz (NE Atlantic) and Alboran Sea (W Mediterranean). Palaeogeography, Palaeoclimatology, Palaeoecology, 205(3-4): 317-336.

Combourieu-Nebout, N., Turon, J.L., Zahn, R., Capotondi, L., Londeix, L. and Pahnke, K., 2002. Enhanced aridity and atmospheric high-pressure stability over the western Mediterranean during the North Atlantic cold events of the past 50 k.y. Geology, 30(10): 863-866.

Cortés, M.Y. and Bollmann, J., 2002. A new combination coccosphere of the heterococcolith species Coronosphaera mediterranea and the holococcolith species Calyptrolithophora hasleana. European Journal of Phycology, 37(1): 145-146.

Cortés, M.Y., 2000. Further evidence for the heterococcolith-holococcolith combination Calcidiscus leptoporus - Crystallolithus rigidus. Marine Micropaleontology, 39(1-4): 35-37.

Cortijo, E., Labeyrie, L., Vidal, L., Vautravers, M., Chapman, M., Duplessy, J.-C., Elliot, M., Arnold, M., Turon, J.-L. and Auffret, G., 1997. Changes in sea surface hydrology associated with Heinrich event 4 in the North Atlantic Ocean between $40^{\circ}$ and $60^{\circ} \mathrm{N}$. Earth and Planetary Science Letters, 146(1-2): 29-45.

Craig, H. and Gordon, L.I., 1965. Deuterium and oxygen 18 variations in the ocean and marine atmosphere. In: E. Tongiorgi (Editor), Stable isotopes in oceanographic studies and paleotemperatures. Consiglio Nazionale delle Ricerche, Laboratorio di Geologia Nucleare, Pisa, pp. 9-130.

Cros, L. and Fortuño, J.M., 2002. Atlas of the Northwestern Mediterranean coccolithophores. Scientia Marina, 66. Institut de Ciències del Mar, CMIMA-CSIC, Barcelona, Spain, 194 pp.

Cros, L., Kleijne, A., Zeltner, A., Billard, C. and Young, J.R., 2000. New examples of holococcolithheterococcolith combination coccospheres and their implications for coccolithophorid biology. Marine Micropaleontology, 39(1-4): 1-34.

Crudeli, D., Young, J.R., Erba, E., Geisen, M., Ziveri, P., de Lange, G.J. and Slomp, C.P., 2006. Fossil record of holococcoliths and selected hetero-holococcolith associations from the Mediterranean (Holocene-late Pleistocene): Evaluation of carbonate diagenesis and palaeoecologicalpalaeocenographic implications. Palaeogeography, Palaeoclimatology, Palaeoecology, 237(2-4): 191212.

Dafner, E.V., Sempéré, R. and Bryden, H.L., 2001. Total organic carbon distribution and budget through the Strait of Gibraltar in April 1998. Marine Chemistry, 73(3-4): 233-252.

Dansgaard, W. et al., 1993. Evidence for general instability of past climate from a 250-kyr ice-core record. Nature, 364: 218-220.

Dansgaard, W., 1961. Isotope systematics in high latitude precipitation. Tellus, 16: 437-468.

De Bernardi, B., Ziveri, P., Erba, E. and Thunell, R.C., 2008. Calcareous phytoplankton response to the half century of interannual climatic variability in Santa Barbara Basin (California). Paleoceanography, 23(2): PA2215. 
de Villiers, D., Graves, S. and Elderfield, H., 2002. An intensity ratio calibration method for the accurate determination of $\mathrm{Mg} / \mathrm{Ca}$ and $\mathrm{Sr} / \mathrm{Ca}$ of marine carbonates by ICP-AES. Geochemistry, Geophysics, Geosystems, 3(1): 1001-1015.

de Villiers, S., 1999. Seawater strontium and $\mathrm{Sr} / \mathrm{Ca}$ variability in the Atlantic and Pacific oceans. Earth and Planetary Science Letters, 171(4): 623-634.

deMenocal, P., Ortiz, J., Guilderson, T., Adkins, J., Sarnthein, M., Baker, L. and Yarusinsky, M., 2000. Abrupt onset and termination of the African Humid Period:: rapid climate responses to gradual insolation forcing. Quaternary Science Reviews, 19(1-5): 347-361.

Di Nocera, S. and Scandone, P., 1977. Triassic nannoplankton limestones of deep basin origin in the central mediterranean region. Palaeogeography, Palaeoclimatology, Palaeoecology, 21(2): 101-111.

Dickens, G., 2001. Carbon addition and removal during the Late Paleocene Thermal Maximum: basic theory with a preliminary treatment of the isotope record at ODP site 1051, Blake Nose. In: N.R. Kroon, D. and Klaus, A. (Editors), Western North Atlantic Paleogene and Cretaceous Paleoceanography. Geological Society of London Spec pub, pp. 293-305.

Dudley, W., Duplessy, J., Blackwelder, P., Brand, L. and Guillard , R., 1980. Coccoliths in Pleistocene-Holocene nannofossil assemblages. Nature, 285: 222-223.

Dudley, W.C. and Goodney, D.E., 1979. Oxygen isotope content of coccoliths grown in culture. Deep Sea Research Part A. Oceanographic Research Papers, 26(5): 495-503.

Dudley, W.C. and Nelson, C.S., 1989. Quaternary surface-water stable isotope signal from calcareous nannofossils at DSDP Site 593, southern Tasman Sea. Marine Micropaleontology, 13(4): 353-373.

Dudley, W.C., Blackwelder, P., Brand, L. and Duplessy, J.C., 1986. Stable isotopic composition of coccoliths. Marine Micropaleontology, 10(1-3): 1-8.

Dunion, J.P. and Velden, C.S., 2004. The impact of the Saharan Air Layer on Atlantic tropical cyclone activity. Bull. Amer. Meteor. Soc, 85: 353-365.

Dupont, L.M., Kim, J.-H., Schneider, R.R. and Shi, N., 2004. Southwest African climate independent of Atlantic sea surface temperatures during the Younger Dryas. Quaternary Research, 61(3): 318-324.

Elliot, M., Labeyrie, L., Bond, G., Cortijo, E., Turon, J.-L., Tisnerat, N. and Duplessy, J.-C., 1998. Millennial-scale iceberg discharges in the Irminger Basin during the Last Glacial Period: relationship with the Heinrich Events and environmental settings. Paleoceanography, 13(5): 433-446.

Elliot, M., Labeyrie, L., Dokken, T. and Manthé, S., 2001. Coherent patterns of ice-rafted debris deposits in the Nordic regions during the last glacial (10-60 ka). Earth and Planetary Science Letters, 194(1-2): 151-163.

Emiliani, C., 1954. Depth habitats of some species of pelagic foraminifera as indicated by oxygen isotopes ratios. American Journal of Science, 252: 149-158.

Epstein, S. and Mayeda, T., 1953. Variation of O18 content of waters from natural sources. Geochimica et Cosmochimica Acta, 4(5): 213-224.

Epstein, S., Buchsbaum, R., Lowenstam, H.A. and Urey, H.C., 1953. Revised carbonate-water isotopic temperature scale. Geological Society of America Bulletin, 64: 1315-1325.

Erez, J. and Luz, B., 1983. Experimental paleotemperature equation for planktonic foraminifera. Geochimica et Cosmochimica Acta, 47: 1025-1031.

Fabres, J., Calafat, A., Sanchez-Vidal, A., Canals, M. and Heussner, S., 2002. Composition and spatiotemporal variability of particle fluxes in the Western Alboran Gyre, Mediterranean Sea. Journal of Marine Systems, 33-34: 431-456.

Fink, C., Baumann, K.-H., Groeneveld, J. and Steinke, S., 2010. Strontium/Calcium ratio, carbon and oxygen stable isotopes in coccolith carbonate from different grain-size fractions in South Atlantic surface sediments. GeoBios, 43(1): 151-164. 
Fiúza, A.F.G., Hamann, M., Ambar, I., Diaz del Rio, G., González, N. and Cabanas, J.M., 1998. Water masses and their circulation off western Iberia during May 1993. Deep Sea Research Part I: Oceanographic Research Papers, 45(7): 1127-1160.

Fletcher, W.J. and Sánchez Goñi, M.F., 2008. Orbital and sub-orbital-scale climate impacts on vegetation of the western Mediterranean basin over the last 48,000 yr. Quaternary Research, 70(3): 451-464.

Flores J.A., Marino M., Sierro, F.J., Hodell, D.A. and Charles C.D. 2003. Calcareous plankton dissolution pattern and coccolithophore assemblages during the last $600 \mathrm{kyr}$ at ODP Site 1089 (Cape Basin, South Atlantic): paleoceanographic implications. Palaeogeography, Palaeoclimatology, Palaeoecology, 196: 409-426.

Flores, J.A. and Sierro, F.J., 1997. Revised technique for calculation of calcareous nannofossil accumulation rates. Micropaleontology, 43(3): 321-324.

Flores, J.A. and Sierro, F.J., 1997. Revised technique for calculation of calcareous nannofossil accumulation rates. Micropaleontology, 43(3): 321-324.

Flores, J.A. and Sierro, F.J., 2007. Coccoliths. In: E.A. Scott (Editor), Encyclopedia of Quaternary Science. Elsevier, Amsterdam, pp. 1634-1647.

Flores, J.A., Bárcena, M.A. and Sierro, F.J., 2000. Ocean-surface and wind dynamics in the Atlantic Ocean off Northwest Africa during the last 140000 years. Palaeogeography, Palaeoclimatology, Palaeoecology, 161(3-4): 459-478.

Flores, J.-A., Colmenero-Hidalgo, E., Mejía-Molina, A.E., Baumann, K.-H., Henderiks, J., Larsson, K., Prabhu, C.N., Sierro, F.J. and Rodrigues, T., 2010. Distribution of large Emiliania huxleyi in the Central and Northeast Atlantic as a tracer of surface ocean dynamics during the last 25,000 years. Marine Micropaleontology, 76(3-4): 53-66.

Flores, J.-A., Gersonde, R. and Sierro, F.J., 1999. Pleistocene fluctuations in the Agulhas Current Retroflection based on the calcareous plankton record. Marine Micropaleontology, 37(1): 1-22.

Flores, J.A., Sierro, F.J., Francés, G., Vázquez, A. and Zamarreno, I., 1997. The last 100,000 years in the western Mediterranean: sea surface water and frontal dynamics as revealed by coccolithophores. Marine Micropaleontology, 29(3-4): 351-366.

Frada, M., Percopo, I., Young, J., Zingone, A., de Vargas, C. and Probert, I., 2009. First observations of heterococcolithophore-holococcolithophore life cycle combinations in the family Pontosphaeraceae (Calcihaptophycideae, Haptophyta). Marine Micropaleontology, 71(1-2): 20-27.

Francois, R., Honjo, S., Krishfield, R. and Manganini, S., 2002. Factors controlling the flux of organic carbon to the bathypelagic zone of the ocean. Global Biogeochemistry Cycles, 16(4): 1087.

Garcia-Gorriz, E. and Carr, M.-E., 2001. Physical control of phytoplankton distributions in the Alboran Sea: A numerical and satellite approach. Journal of Geophysical Research, 106: 1679516806.

Gasse, F. and Roberts, C.N., 2005. Late Quaternary hydrologic changes in the arid and semiarid belt of northern Africa. In: H.F. Diaz and R.S. Bradley (Editors), The Hadley Circulation: Present, Past and Future. Elsevier, New York, pp. 313-345.

Gasse, F., 2000. Hydrological changes in the African tropics since the Last Glacial Maximum. Quaternary Science Reviews, 19(1-5): 189-211.

Geisen, M., Billard, C., Broerse, A.T.C., Cros, L., Probert, I. and Young, J.R., 2002. Life-cycle associations involving pairs of holococcolithophorid species: intraspecific variation or cryptic speciation? European Journal of Phycology, 37(4): 531-550.

Geisen, M., Young, J., Probert, I., Sáez, A.G., Baumann, KH., Sprengel, C., Bollmann, J., Cros, L., De Vargas, C. and Medlin, L.K. 2004. Species level variation in coccolithopores. In: Thierstein, H. and 
Young, J. (eds). Coccolithophores: From Molecular Processes to Global Impact. Springer Verlag. : 327-366.

Geitzenauer, K.R., Roche, M.B. and McIntyre, A., 1977. Coccolith biogeography from North Atlantic and Pacific surface sediments; a comparison of species distribution and abundances. In: A.T.S. Ramsay (Editor), Oceanic Micropaleontology. Academic Press, London, pp. 973-1008.

Giraudeau, J., 1992. Distribution of Recent nannofossils beneath the Benguela system: Southwest African continental margin. Marine Geology, 108(2): 219-237.

Giraudeau, J., Monteiro, P.M.S. and Nikodemus, K., 1993. Distribution and malformation of living coccolithophores in the northern Benguela upwelling system off Namibia. Marine Micropaleontology, 22(1-2): 93-110.

González-Sampériz, P., Valero-Garcés, B.L., Moreno, A., Morellón, M., Navas, A., Machín, J. and Delgado-Huertas, A., 2008. Vegetation changes and hydrological fluctuations in the Central Ebro Basin (NE Spain) since the Late Glacial period: Saline lake records. Palaeogeography, Palaeoclimatology, Palaeoecology, 259(2-3): 157-181.

Goodess, C.M. and Jones, P.D., 2002. Links between circulation and changes in the characteristics of Iberian rainfall. International Journal of Climatology, 22(13): 1593-1615.

Goodney, D.E., Margolis, S.V., Dudley, W.C., Kroopnick, P. and Williams, D.F., 1980. Oxygen and carbon isotopes of Recent calcareous nannofossils as paleoceanographic indicators. Marine Micropaleontology, 5: 31-42.

Grousset, F.E., Labeyrie, L., Sinko, J.A., Cremer, M., Bond, G., Duprat, J., Cortijo, E. and Huon, S., 1993. Patterns of Ice-Rafted Detritus in the Glacial North Atlantic $\left(40-55^{\circ} \mathrm{N}\right)$. Paleoceanography, $8(2)$ : 175-192.

Hanebuth, T.J.J., Stattegger, K. and Bojanowski, A., 2009. Termination of the Last Glacial Maximum sea-level lowstand: The Sunda-Shelf data revisited. Global and Planetary Change, 66(1-2): 76-84.

Harris, R.P., 1994. Zooplankton grazing on the coccolithophore Emiliania huxleyi and its role in inorganic carbon flux. Marine Biology, 119(3): 431-439.

Heburn, G.W. and La Violette, P.E., 1990. Variations in the structure of the anticyclonic gyres found in the Alboran Sea. Journal of Geophysical Research, 95: 1599-1613.

Heinrich, H., 1988. Origin and consequences of cyclic ice rafting in the northeast Atlantic Ocean during the past 130,000 years. Quaternary Research, 29: 143-152.

Hemleben, C., Spindler, M. and Anderson, O.R. (Editors), 1989. Modern Planktonic Foraminifera., $363 \mathrm{pp}$.

Henderiks, J. and Bollmann, J., 2004. The Gephyrocapsa sea surface palaeothermometer put to the test: comparison with alkenone and foraminifera proxies off NW Africa. Marine Micropaleontology, 50(3-4): 161-184.

Hernández-Almeida, I., Bárcena, M.A., Flores, J.A., Sierro, F.J., Sanchez-Vidal, A. and Calafat, A., 2010. Microplankton response to environmental conditions in the Alboran Sea (Western Mediterranean): One year sediment trap record. Marine Micropaleontology, 78(1-2): 14-24.

Hernández-Guerra, A. et al., 2005. Canary Current and North Equatorial Current from an inverse box model. J. Geophys. Res., 110(C12): C12019.

Hibberd, D., 1976. The ultrastructure and taxonomy of the Chrysophyceae and Prymnesiophyceae (Haptophyceae): a survey with some new observations on the ultrastructure of the Crysophyceae. Botanical Journal of the Linnaean Society, 72: 55-80.

Hill, A.E. et al., 1998. Eastern ocean boundaries. Coastal segment (E). In: A.R. Robinson and K.H. Brink (Editors), The Sea, the Global Coastal Ocean: Regional Studies and Syntheses, Wiley, New York pp. 29-67. 
Hoelzmann, P., Gasse, F., Dupont, L., Salzmann, U., Staubwasser, M., Leuscher, D.C. and Sirocko, F., 2004. Palaeoenvironmental changes in the arid and sub-arid belt (Sahara-Sahel_Arabian Peninsula) from $150 \mathrm{kyr}$ to present. In: R.W. Battarbee, F. Gasse and C.E. Stickley (Editors), Past Climatic Variability Through Europe and Africa. Springer, New York, pp. 219-256.

Honjo, S., 1976. Coccoliths: Production, transportation and sedimentation. Marine Micropaleontology, 1: $65-79$.

Hooghiemstra, H., 1988. Changes of major wind belts and vegetation zones in NW Africa $20,000 \pm 5,000$ yr BP., as deduced from a marine pollen record near Cap Blanc. Review of Palaeobotany and Palynology, 55: 101-140.

Husar, R.B., Prospero, J.M. and Stowe, L.L., 1997. Characterization of tropospheric aerosols over the oceans with the NOAA Advanced Very High Resolution Radiometer Optical Thickness Operational Product. Journal of Geophysical Research 102: 889-909.

Huybers, P. and Wunsch, C., 2004. A depth-derived Pleistocene age model: Uncertainty estimates, sedimentation variability, and nonlinear climate change. Paleoceanography, 19(1): PA1028.

Imbrie, J. et al., 1984. The orbital theory of Pleistocene climate: Support from a revised chronology of the marine d18O record. In: A. Berger, J. Imbrie, H. Hays, G. Kukla, and B. Saltzman (Editors), Milankovitch and Climate Part 1. Springer, New York, pp. 269-305.

Incarbona, A., Di Stefano, E., Sprovieri, R., Bonomo, S., Censi, P., Dinarès-Turell, J. and Spoto, S., 2008. Variability in the vertical structure of the water column and paleoproductivity reconstruction in the central-western Mediterranean during the Late Pleistocene. Marine Micropaleontology, 69(1): 2641 .

Ivanochko, T.S., Ganeshram, R.S., Brummer, G.-J.A., Ganssen, G., Jung, S.J.A., Moreton, S.G. and Kroon, D., 2005. Variations in tropical convection as an amplifier of global climate change at the millennial scale. Earth and Planetary Science Letters, 235(1-2): 302-314.

Jalut, G., Esteban Amat, A., Bonnet, L., Gauquelin, T. and Fontugne, M., 2000. Holocene climatic changes in the Western Mediterranean, from south-east France to south-east Spain. Palaeogeography, Palaeoclimatology, Palaeoecology, 160(3-4): 255-290.

James, R., 2005. Marine biogeochemical cycles, Oxford.

Jia, Y., 2000. Formation of an Azores Current due to Mediterranean overflow in a modeling study of the North Atlantic. Journal of Physical Oceanography, 30: 2342-2358.

Jimenez-Espejo, F.J., 2007. Climatic variability in the Western Mediterranean during the Last Glacial cycle: impact on human cultural evolution in the South of the Iberian Peninsula, University of Granada, Granada.

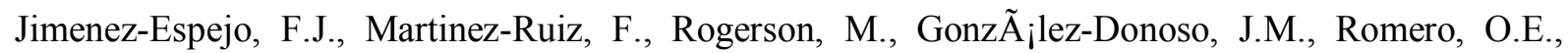
Linares, D., Sakamoto, T., Gallego-Torres, D., Rueda Ruiz, J.L., Ortega-Huertas, M. and Perez Claros, J.A., 2008. Detrital input, productivity fluctuations, and water mass circulation in the westernmost Mediterranean Sea since the Last Glacial Maximum. Geochemistry, Geophysics, Geosystems, 9.

Jimenez-Espejo, F.J., Martinez-Ruiz, F., Sakamoto, T., Iijima, K., Gallego-Torres, D. and Harada, N., 2007. Paleoenvironmental changes in the western Mediterranean since the last glacial maximum: High resolution multiproxy record from the Algero-Balearic basin. Palaeogeography, Palaeoclimatology, Palaeoecology, 246(2-4): 292-306.

Jordan, R.W. and Chamberlain, A.H.L., 1997. Biodiversity among haptophyte algae. Biodiversity and Conservation, 6(1): 131-152.

Jordan, R.W., Cros, L. and Young, J.A. 2004. A revised classification scheme for living haptophytes. Micropaleontology, 50: 55-79.

Jordan, R.W., Zhao, M., Elington, G. and Weaver, P.P.E. 1996. Coccolith and alkenone stratigraphy and paleoceanography at an upwelling site off NW Africa (ODP 658C) during the last 130,000 years. 
In: Microfossils and Oceanic Environments. R. Whatley y A. Moguilevsky, (Editors), Univ. Wales, AberystwythPress, Aberystwyth: 111-130.

Jullien, E., Grousset, F., Malaizé, B., Duprat, J., Sanchez-Goni, M.F., Eynaud, F., Charlier, K., Schneider, R., Bory, A., Bout, V. and Flores, J.A., 2007. Low-latitude "dusty events" vs. high-latitude "icy Heinrich events". Quaternary Research, 68(3): 379-386.

Karner, D.B., Levine, J., Medeiros, B.P. and Muller, R.A., 2002. Constructing a stacked benthic D.18 O record. Paleoceanography, 17(3): 1030.

Keller, K. and Morel , F., 1999. A model of carbon isotope discrimination and active carbon uptake in phytoplankton. Marine Ecology Progress Series, 182: 295-298.

Kelly, D.C., Norris, R.D. and Zachos, J.C. 2003. Deciphering the paleoceanographic significance of Early Oligocene Braarudosphaera chalks in the South Atlantic. Marine Micropaleontology, 49: 49-63.

Kim, S.-T. and O'Neil, J.R., 1997. Equilibrium and non equilibrium oxygen isotope effects in synthetic carbonates. Geochimica et Cosmochimica Acta, 61: 3461-3475.

Kinkel, H., Baumann, K.H. and Cepek, M. 2000. Coccolithopores in the ecuatorial Atlantic Ocean: response to seasonal and Late Quaternary surface water availability. Marine Micropaleontology, 39: 87-112.

Klein, B.a. and Siedler, G., 1989. On the origin of the Azores Current. Journal of Geophysical Research, 94: 6159-6168.

Knappertsbusch, M., 1993. Geographic distribution of living and Holocene coccolithophores in the Mediterranean Sea. Marine Micropaleontology, 21(1-3): 219-247.

Knappertsbusch, M., Cortes, M.Y. and Thierstein, H.R., 1997. Morphologic variability of the coccolithophorid Calcidiscus leptoporus in the plankton, surface sediments and from the Early Pleistocene. Marine Micropaleontology, 30(4): 293-317.

Köbrich, M.I. and Baumann, K.-H., 2009. Coccolithophore flux in a dsediment trap off Cape Blanc (NW Africa) Journal of Nannoplankton Research, 30 (2): 83-96.

Kolla, V., Biscaye, P.E. and Hanley, A.F., 1979. Distribution of quartz in late Quaternary Atlantic sediments in relation to climate. Quaternary Research, 11(2): 261-277.

Krom, M.D., Brenner, S., Kress, N. and Gordon, L.I., 1991. Phosphorus limitation of primary productivity in the E. Mediterranean Sea. Limonology and Oceanography, 36: 424-432.

Kroopnick, P.M., 1985. The distribution of 13C of [Sigma]CO2 in the world oceans. Deep Sea Research Part A. Oceanographic Research Papers, 32(1): 57-84.

Lancaster, N., Kocurek, G., Singhvi,A., Pandey, V., Deynoux, M., Ghienne, J-F., Lô, K., 2002. Late Pleistocene and Holocene dune activity and wind regimes in the western Sahara Desert of Mauritania. Geology, 30: 991-994.

Lancis Sáez, C. 1998. El nanoplancton calcáreo de las cuencas neógenas orientales de la Cordillera Bética. Tesis doctoral, Universidad de Alicante, Alicante : 1-841.

Laskar, J., Robutel, P., Joutel, F., Gastineau, M., Correia, A.C.M. and Levrard, B., 2004. A long term numerical solution for the insolation quantities of the Earth. Astronomy and Astrophysics 428: 261285.

Lea, D.W., Martin, P.A., Pak, D.K. and Spero, H.J., 2002. Reconstructing a 350 ky history of sea level using planktonic $\mathrm{Mg} / \mathrm{Ca}$ and oxygen isotope records from a Cocos Ridge core. Quaternary Science Reviews, 21(1-3): 283-293.

Lea, D.W., Mashiotta, T.A. and Spero, H.J., 1999. Controls on magnesium and strontium uptake in planktonic foraminifera determined by live culturing. Geochimica et Cosmochimica Acta, 63(16): 2369-2379. 
Lea, D.W., Pak, D.K., Peterson, L.C. and Hughen, K.A., 2003. Synchroneity of Tropical and HighLatitude Atlantic Temperatures over the Last Glacial Termination. Science, 301: 1361-1364.

LeGrande, A.N. and Schmidt, G.A., 2006. Global gridded data set of the oxygen isotopic composition in seawater. Geophysical Reearch Letters, 33 L12604.

Levitus, S. and Boyer, T.P., 1994. World Ocean Atlas 1994. Temperature, NOAA Atlas NESDIS, 4. NOAA, Silver Spring, Md.

Liquete, C., Arnau, P., Canals, M. and Colas, S., 2005. Mediterranean river systems of Andalusia, southern Spain, and associated deltas: A source to sink approach. Marine Geology, 222-223: 471-495.

Lisiecki, L.E. and Raymo, M.E., 2005. A Pliocene-Pleistocene stack of 57 globally distributed benthic D. 18. O records. Paleoceanography, 20(1): PA1003.

Liu, C., Wang, P., Tian, J. and Cheng, X., 2008. Coccolith evidence for Quaternary nutricline variations in the southern South China Sea. Marine Micropaleontology, 69(1): 42-51.

Liu, H., Probert, I., Uitz, J., Claustre, H., Aris-Brosou, S., Frada, M., Not, F. and de Vargas, C., 2009. Extreme diversity in noncalcifying haptophytes explains a major pigment paradox in open oceans. Proceedings of the National Academy of Sciences, 106 (31): 12803-12808.

Lobo, F.J., Fernández-Salas, L.M., Moreno, I., Sanz, J.L. and Maldonado, A., 2006. The sea-floor morphology of a Mediterranean shelf fed by small rivers, northern Alboran Sea margin. Continental Shelf Research, 26(20): 2607-2628.

Lorens, R.B., 1981. Sr, Cd, Mn and Co distribution coefficients in calcite as a function of calcite precipitation rate. Geochimica et Cosmochimica Acta, 45(4): 553-561.

Loulergue, L., Schilt, A., Spahni, R., Masson-Delmotte, V., Blunier, T., Lemieux, B., Barnola, J.-M., Raynaud, D., Stocker, T. and Chappellaz , J., 2008. Orbital and millennial-scale features of atmospheric CH4 over the past 800,000 years. Nature, 453: 383-386.

Macías, D., Bruno, M., Echevarría, F., Vázquez, A. and García, C.M., 2008. Meteorologically-induced mesoscale variability of the North-western Alboran Sea (southern Spain) and related biological patterns. Estuarine, Coastal and Shelf Science, 78(2): 250-266.

Malone, M. and Baker, P., 1999. Temperature dependence of the strontium distribution coefficient in calcite: an experimental study from $40^{\circ}$ to $200^{\circ} \mathrm{C}$ and application to natural diagenetic calcites. Journal of Sedimentary Research, 69: 228-235.

Marchant, H.J. and Thomsen, H.A., 1994. Haptophytes in polar waters. In: J.C. Green, Leadbeater, B.S.C (Editors). The Haptophyte Algae. Systematics Association. Clarendon Press, Oxford.

Margolis, S.V., Kroopnick, P.M., Goodney, D.E., Dudley, W.C. and Mahoney, M.E., 1975. Oxygen and carbon isotopes from calcareous nannofossils as paleoceanographic indicators. Science, 189: 555557.

Martinez, P., Bertrand, P., Shimmield, G.B., Karen, C., Jorissen, F.J., Foster, J. and Dignan, M., 1999. Upwelling intensity and ocean productivity changes off Cape Blanc (northwest Africa) during the last 70,000 years: geochemical and micropalaeontological evidence. Marine Geology, 158(1-4): 57-74.

Martinez-Ruiz, F., Gonzalez-Donoso, J.M., Linares, D., Jimenez-Espejo, F.J., Gallego-Torres, D., Romero, O. and Paytan, A., 2004. Respuesta de la productividad biológica marina al cambio climático: registro de alta resolución de la cuenca del mar de Alborán. Geotemas 6: 128-128.

Martinson, D.G., Pisias, N.G., Hays, J.D., Imbrie, J., Moore, T.C. and Shackleton, N.J., 1987. Age dating and the orbital theory of the ice ages: Development of a high-resolution 0 to 300,000-year chronostratigraphy. Quaternary Research, 27(1): 1-29.

Martrat, B., Grimalt, J.O., Lopez-Martinez, C., Cacho, I., Sierro, F.J., Flores, J.A., Zahn, R., Canals, M., Curtis, J.H. and Hodell, D.A., 2004. Abrupt temperature changes in the Western Mediterranean over the Past 250,000 Years. Science, 306(5702): 1762-1765. 
Matsuzaki, K.M.R., Eynaud, F., Malaizé, B., Grousset, F.E., Tisserand, A., Rossignol, L., Charlier, K. and Jullien, E., 2011. Paleoceanography of the Mauritanian margin during the last two climatic cycles: From planktonic foraminifera to African climate dynamics. Marine Micropaleontology, 79(3-4): 6779.

McCave, I.N., Manighetti, B. and Robinson, S.G., 1995. Sortable silt and fine sediment size/composition slicing: parameters for palaeocurrent speed and palaeoceanography. Paleoceanography, 10(3): 593-610.

McConnaughey, T., 1989a. ${ }^{13} \mathrm{C}$ and ${ }^{18} \mathrm{O}$ isotopic disequilibrium in biological carbonates: I. Patterns. Geochimica et Cosmochimica Acta, 53(1): 151-162.

McConnaughey, T., 1989b. ${ }^{13} \mathrm{C}$ and ${ }^{18} \mathrm{O}$ isotopic disequilibrium in biological carbonates: II. In vitro simulation of kinetic isotope effects. Geochimica et Cosmochimica Acta, 53(1): 163-171.

McConnaughey, T.A., Burdett, J., Whelan, J.F. and Paull, C.K., 1997. Carbon isotopes in biological carbonates: Respiration and photosynthesis. Geochimica et Cosmochimica Acta, 61(3): 611-622.

McCrea, J., 1950a. On the isotipic chemistry of carbonates and a paleotemperature scale. Journal of Chemical Physics, 18: 849-857.

McGowan, J.A., Cayan, D.R. and M. Dorman, L.-R., 1998. Climate-ocean variability and ecosystem response in the northeast Pacific. Science, 281:210-217.

McIntyre A., Bé A.W.H., Roche, M.B. 1970. Modern Pacific Coccolithophorida: a paleontological thermometer. Transactions of the New York Academy of Sciences Series II, 32 (6): 720-731.

McIntyre, A. 1967. Coccoliths as paleoclimatic indicators of Pleistocene glaciation. Science, 158: 1314-1317.

McIntyre, A. and Bé, A.W.H., 1967a. Modern coccolithophoridae of the Atlantic Ocean. Placoliths and Cyrtoliths. Deep-Sea Research, 14: 561-597.

McIntyre, A. and Molfino, B., 1996. Forcing of atlantic equatorial and subpolar millennial cycles by precession. Science, 274(5294): 1867-1870.

McManus, J.F., Francois, R., Gherardi, J.M., Keigwin, L.D. and Brown-Leger, S., 2004. Collapse and rapid resumption of Atlantic meridional circulation linked to deglacial climate changes. Nature, 428(6985): 834-837.

Meggers, H., Freudenthal, T., Nave, S., Targarona, J., Abrantes, F. and Helmke, P., 2002. Assessment of geochemical and micropaleontological sedimentary parameters as proxies of surface water properties in the Canary Islands region. Deep Sea Research Part II: Topical Studies in Oceanography, 49(17): 3631-3654.

Millot, C., 1999. Circulation in the Western Mediterranean Sea. Journal of Marine Systems, 20(1-4): 423-442.

Minoletti, F., Gardin, S., Nicot, E., Renard, M. and Spezzaferri, S., 2001. Mise au point d'un protocole experimental de separation granulometrique d'assemblages de nannofossiles calcaires; applications paleoecologiques et geochimiques. Bulletin Societié Geologique France, 172: 437-446.

Minoletti, F., Hermoso, M. and Gressier, V., 2008. Separation of sedimentary micron-sized particles for palaeoceanography and calcareous nannoplankton biogeochemistry. Nature Protocols, 4(1): 14-24.

Mittelstaedt, E., 1991. The ocean boundary along the Northwest African coast: circulation and oceanographic properties at the sea surface. Prog. Oceanogr., 26: 307-355.

Mix, A.C. et al., 2003. Proceedings of the Ocean Drilling. Program. Southeast Pacific paleoceanographic transects, Initial Reports, 202: College Station TX (ODP), 145 pp.

Molfino, B. and McIntyre, A., 1990. Nutricline variation in the equatorial atlantic coincident with the Younger Dryas. Paleoceanography, 5(6): 997-1008. 
Moreno, A., Cacho, I., Canals, M., Grimalt, J.O. and Sanchez-Vidal, A., 2004. Millennial-scale variability in the productivity signal from the Alboran Sea record, Western Mediterranean Sea. Palaeogeography, Palaeoclimatology, Palaeoecology, 211(3-4): 205-219.

Moreno, A., Cacho, I., Canals, M., Grimalt, J.O., Sánchez-Goñi, M.F., Shackleton, N. and Sierro, F.J., 2005. Links between marine and atmospheric processes oscillating on a millennial time-scale. A multi-proxy study of the last 50,000 yr from the Alboran Sea (Western Mediterranean Sea). Quaternary Science Reviews, 24(14-15): 1623-1636.

Moreno, A., Cacho, I., Canals, M., Prins, M.A., Sánchez-Goñi, M.-F., Grimalt, J.O. and Weltje, G.J., 2002.Saharan dust transport and high-latitude glacial climatic variability: the Alboran Sea record. Quaternary Research, 58(3): 318-328.

Moreno, A., Nave, S., Kuhlmann, H., Canals, M., Targarona, J., Freudenthal, T. and Abrantes, F., 2002. Productivity response in the North Canary Basin to climate changes during the last $250000 \mathrm{yr}$ : a multi-proxy approach. Earth and Planetary Science Letters, 196(3-4): 147-159.

Moulin, C., Lambert, C.E., Dayan, U., Masson, V., Ramonet, M., Bousquet, P., Legrand, M., Balkanski, Y.J., Guelle, W., Marticorena, B., Bergametti, G. and Dulac, F., 1998. Satellite climatology of African dust transport in the Mediterranean atmosphere. Journal of Geophysical Research, 103(D11): 13137-13144.

Moyes, J. et al., 1976. Etude stratigraphique et sédimentologique. Geochimie organique des sédiments marins profonds, Orgon II, Atlantique N. In: E. Brésil (Editor), Paris, pp. 105-156.

Müller, C. 1976. Tertiary and Quaternary calcareous nannoplankton in the Norwegian-Greenland Sea, DSDP, Leg 38. In: Initial Reports of the Deep-Sea Drilling Project, 38 .M. Talwani, G. Udintsev et al., (Editors). U. S. Government Printing Office, Washington: 823-841.

Müller, P.J. and Fischer, G., 2001. A 4-year sediment trap record of alkenones from the filamentous upwelling region off Cape Blanc, NW Africa and a comparison with distributions in underlying sediments. Deep Sea Research Part I: Oceanographic Research Papers, 48(8): 1877-1903.

Mulitza, S. et al., 2008. Sahel megadroughts triggered by glacial slowdowns of Atlantic meridional overturning. Paleoceanography, 23(4): PA4206.

Mulitza, S. et al., 2010. Increase in African dust flux at the onset of commercial agriculture in the Sahel region. Nature, 466: 226-228.

Murgese, D.S., De Deckker, P., Spooner, M.I. and Young, M., 2008. A 35,000 year record of changes in the eastern Indian Ocean offshore Sumatra. Palaeogeography, Palaeoclimatology, Palaeoecology, 265(3-4): 195-213.

Narciso, A., Cachão, M. and de Abreu, L., 2006. Coccolithus pelagicus subsp. pelagicus versus Coccolithus pelagicus subsp. braarudii (Coccolithophore, Haptophyta): A proxy for surface subarctic Atlantic waters off Iberia during the last $200 \mathrm{kyr}$. Marine Micropaleontology, 59(1): 15-34.

New, A.L., Jia, Y., Coulibaly, M. and Dengg, J., 2001. On the role of the Azores Current in the ventilation of the North Atlantic Ocean. Progress in Oceanography, 48: 163-194.

Oberhuber, J.M., 1988. An Atlas based on the COADS data set: The budgets of heat, buoyancy and turbulent kinetic energy at the surface of the global ocean. Report No. 15, Max-Planck Institut für Meteorology

Okada, H. and Honjo, S., 1973. The distribution of oceanic coccolithophorids in the Pacific. Deep-Sea Research 20: 355-374.

Okada, H. and McIntyre, A., 1977. Modern coccolithophores of the Pacific and North Atlantic oceans. Micropaleontology, 23(1): 1-54.

Okada, H. and McIntyre, A., 1979. Seasonal distribution of modern coccolithophores in the western North Atlantic Ocean. Marine Biology, 54(4): 319-328. 
Okada, H. and Wells, P. 1997. Late Quaternary nannofossil indicators of climate change in two deepsea cores associated with the Leeuwin Current off Western Australia. Palaeogeography, Palaeoclimatology, Palaeoecology, 131 (3-4): 413-432.

O'Neil, J.R., Clayton, R.N. and Mayeda, T.K., 1969. Oxygen isotope fractionation in divalent metal carbonates. Journal of Chemical Physics, 51: 5547-5558.

Ostund, H., Craig, H., Broecker, W. and Spenser, D., 1987. Geosecs Atlantic, Pacific and Indian ocean expehitions. In: T.r.N.S. Found. (Editor), Washington D.C.

Özgökmen, T.M., Chassignet, E.P. and Rooth, C.G.H., 2001. On the connection between the Mediterranean Outflow and the Azores Current. Journal of Physical Oceanography, 31: 461-480.

Paasche, E., 1962. Coccolith Formation. Nature, 193(4820): 1094-1095.

Paillard, D.L., Labeyrie, L. and Yiou, P., 1996. Macintosh program performs time-series analyses. EOS, Transactions American Geophysical Union, 77(39): 379.

Parente, A., 2002. Contribuçao para o estudo morfométrico de nanofósseis calcários durante os últimos 4 Ma. Master Thesis Thesis, Universidade de Lisboa, Lisboa, 158 pp.

Parente, A., Cachao, M., Baumann, K.-H., de Abreu, L. and Ferreira, J., 2004. Morphometry of Coccolithus pelagicus s.l. (Coccolithophore, Haptophyta) from offshore Portugal, during the last 200 kyr. Micropaleontology, 50(1): 107-120.

Parrilla, G. and Kinder, T.H., 1987. Oceanografía física del mar de Alborán. Boletin Instituto Español Oceanografia, 4: 133-165.

Partridge, T.C., Scott, L. and Schneider, R.R., 2004. Between Agulhas and Benguela: Responses of Southern African climates of the Late Pleistocene to current fluxes, orbital precession and the extent of the Circum-Antarctic vortex. In: F.G. R. W. Battarbee, and C. E. Stickley (Editor), Past Climatic Variability Through Europe and Africa. Springer, New York, pp. 45-68.

Paull, C.K. and Thierstein, H.R., 1987. Stable isotopic fractionation among particles in Quaternary coccolith-sized deep-sea sediments. Paleoceanography, 2(4): 423-429.

Peleo-Alampay, A.M., Mead, G.A. and Wei, W. 1999. Unusual Oligocene Braarudosphaera-rich layers of the South Atlantic and their paleoceanographic implications. Journal of Nannoplankton Research, 21 (1): 17-26.

Peltier, W.R. and Fairbanks, R.G., 2006. Global glacial ice volume and Last Glacial Maximum duration from an extended Barbados sea level record. Quaternary Science Reviews, 25(23-24): 33223337.

Penaud, A., Eynaud, F., Sánchez-Goñi, M., Malaizé, B., Turon, J.L. and Rossignol, L., 2011.Contrasting sea-surface responses between the western Mediterranean Sea and eastern subtropical latitudes of the North Atlantic during abrupt climatic events of MIS 3. Marine Micropaleontology, 80(1-2): 1-17.

Perch-Nielsen, K. 1972. Remarks on Late Cretaceous to Pleistocene coccoliths from the North Atlantic. In: Initial Reports of the Deep-Sea Drilling Project, 12 .A.S. Laughton, W.A. Berggren et al., (Editors). U.S. Government Printing Office, Washington: 1003-1069.

Perch-Nielsen, K. 1985a. Mesozoic calcareous nannofossils. In: Plankton Stratigraphy. H.M. Bolli, J.B.Saunders y K. Perch-Nielsen, (Editors). Cambridge University Press, Cambridge: 329-426.

Pérez-Folgado, M., Sierro, F.J., Flores, J.A., Cacho, I., Grimalt, J.O., Zahn, R. and Shackleton, N., 2003. Western Mediterranean planktonic foraminifera events and millennial climatic variability during the last 70 kyr. Marine Micropaleontology, 48(1-2): 49-70.

Pienaar, R.N., 1994. Ultrastructure and calcification of coccolithophores. In: E. A. Winter and W. G. Siesser (Editors), Coccolithophores. Cambridge University Press, Cambridge, pp. 13-39. 
Pierre, C., 1999. The oxygen and carbon isotope distribution in the Mediterranean water masses. Marine Geology, 153: 41-55.

Pierre, C., Vangriesheim, A. and Laube-Lenfant, E., 1994. Variability of water masses and of organic production-regeneration systems as related to eutrophic, mesotropic and oligotrophic conditions in the northeast Atlantic Ocean. Journal of Marine Systems, 5(2): 159-170.

Plaza, A.M., 2001. Estudio paleoceanográfico de los testigos TG-7 (dorsal de Nazca-Pacífico) y MD95-2043 (mar de Alborán-Mediterráneo). Universidad Politécnica de Cataluña, Barcelona, 285 pp.

Popp, B.N., Laws, E.A., Bidigare, R.R., Dore, J.E., Hanson, K.L. and Wakeham, S.G., 1998. Effect of Phytoplankton Cell Geometry on Carbon Isotopic Fractionation. Geochimica et Cosmochimica Acta, 62(1): 69-77.

Porter, S.M., Knoll, A.H. and Affaton, P., 2004. Chemostratigraphy of Neoproterozoic cap carbonates from the Volta Basin, West Africa. Precambrian Research, 130(1-4): 99-112.

Pradhan, Y., Lavender, S.J., Hardman-Mountford, N.J. and Aiken, J., 2006. Seasonal and inter-annual variability of chlorophyll-a concentration in the Mauritanian upwelling: Observation of an anomalous event during 1998-1999. Deep Sea Research Part II: Topical Studies in Oceanography, 53(14-16): 1548-1559.

Prahl, F.G. and Wakeham, S.G., 1987. Calibration of unsaturation patterns in long-chain ketone compositions for palaeotemperature assessment. Nature, 330(6146): 367-369.

Prahl, F.G., Muehlhausen, L.A. and Zahnle, D.L., 1988. Further evaluation of long-chain alkenones as indicators of paleoceanographic conditions. Geochimica et Cosmochimica Acta, 52(9): 2303-2310.

Prospero, J.M. and Lamb, P.J., 2003. African droughts and dust transport to the Caribbean: climate change implications. Science, 302: 1024-1027.

Prospero, J.M., Ginoux, P., Torres, O., Nicholson, S.E. and Gill, T.E., 2002. Environmental characterization of global sources of atmospheric soil dust identified with the NIMBUS 7 Total Ozone Mapping Spectrometer (TOMS) absorbing aerosol product. Rev. Geophys., 40.

Pujos, A. 1992. Calcareous nannofossils of Plio-Pleistocene sediments from the northwestern margin of tropical Africa. In: Upwelling Systems: Evolution since the Early Miocene (C.P. Summerhayes, WL. Prell , KC. Emeis, eds), Geological Society Special Publication, Londres, 64: 343-359.

Pujos-Lamy A. 1977. Emiliania et Gephyrocapsa (nannoplancton calcaire): biométrie et intérêt biostratigraphique dans le Pleistocène Supérieur marin des Açores. Revista Española de Micropaleontología, 9: 69-84.

Quinn, P.S., Cortés, M.Y.and Bollmann, J. 2005. Morphological variation in the deep ocean-dwelling coccolithopore Florisphaera profunda (Haptophyta). European Journal of Phycology, 40, num.1: 123133.

Raffi, I. and Rio, D., 1981. Coccolithus pelagicus (Wallich): a paleotemperature indicator in the late Pliocene Mediterranean deep sea record. In: F.C. Wezel (Editor), Sedimentary basins of Mediterranean margins. C.N.R. Ital. Proj. Oceanog, Bolonha, pp. 187-190.

Renaud, S. and Klaas, C., 2001. Seasonal variations in the morphology of the coccolithophore Calcidiscus leptoporus off Bermuda (N. Atlantic). Journal of Plankton Research, 23(8): 779-795.

Renaud, S., Ziveri, P. and Broerse, A.T.C., 2002. Geographical and seasonal differences in morphology and dynamics of the coccolithophore Calcidiscus leptoporus. Marine Micropaleontology, 46(3-4): 363-385.

Reynolds, R.W., Rayner, N.A., Smith, T.M., Stokes, D.C. and Wang, W., 2002. An improved in situ and satellite SST analysis for climate. Journal of Climate, 15: 1609-1625.

Rickaby, R.E.M., Schrag, D.P., Zondervan, I. and Riebesell, U., 2002. Growth rate dependence of Sr incorporation during calcification of Emiliania huxleyi. Global Biogeochem. Cycles, 16. 
Rigual-Hernández, A.S., 2011. Registro del plancton silíceo y calcáreo en trampas de sedimento del Mediterráneo Occidental durante el periodo 1993-2006, Universidad de Salamanca.

Rodó, X., Baert, E. and Comin, F.A., 1997. Variations in seasonal rainfall in Southern Europe during the present century: relationships with the North Atlantic Oscillation and the El Niño-Southern Oscillation. Climate Dynamics, 13: 275-284.

Rodrigo-Gámiz, M., Martínez-Ruiz, F., Jiménez-Espejo, F.J., Gallego-Torres, D., Nieto-Moreno, V., Romero, O. and Ariztegui, D., 2011. Impact of climate variability in the western Mediterranean during the last 20,000 years: oceanic and atmospheric responses. Quaternary Science Reviews, 30(15-16): 2018-2034.

Rogerson, M., Cacho, I., Jimenez-Espejo, F., Reguera, M.I., Sierro, F.J., Martinez-Ruiz, F., Frigola, J. and Canals, M., 2008. A dynamic explanation for the origin of the western Mediterranean organic-rich layers. Geochemistry, Geophysiscs, Geosystems, 9(7): Q07U01.

Rogerson, M., Rohling, E.J. and Weaver, P.P.E., 2006. Promotion of meridional overturning by Mediterranean-derived salt during the last deglaciation. Paleoceanography, 21(4): PA4101.

Rogerson, M., Rohling, E.J., Weaver, P.P.E. and Murray, J.W., 2004. The Azores Front since the Last Glacial Maximum. Earth and Planetary Science Letters, 222(3-4): 779-789.

Rogerson, M., Rohling, E.J., Weaver, P.P.E. and Murray, J.W., 2005. Glacial to interglacial changes in the settling depth of the Mediterranean Outflow plume. Paleoceanography, 20(3): PA3007.

Rohling, E. and Cooke, S., 2003. Stable oxygen and carbon isotopes in foraminiferal carbonate shells. In: B.K.S.Gupta (Editor), Modern Foraminifera. Springer Netherlands, pp. 239-258.

Rohling, E.J. and De Rijk, S., 1999. Holocene Climate Optimum and Last Glacial Maximum in the Mediterranean: the marine oxygen isotope record. Marine Geology, 153(1-4): 57-75.

Romero, O.E., Kim, J.-H. and Donner, B., 2008. Submillennial-to-millennial variability of diatom production off Mauritania, NW Africa, during the last glacial cycle. Paleoceanography, 23: PA3218.

Rosenthal, Y., Stoll, H.M., Wyman, K. and Falkowski, P., 2000. Growth related variations in carbon isotopic fractionation and coccolith chemistry in Emiliania huxleyi, Trans. AGU,81, Ocean Sciences Meeting, EOS, Washington, DC.

Rost, B. and Riebesell, U., 2004. Coccolithophore calcification and the biological pump: response to environmental changes. In: H.R. Thierstein and J.R. Young (Editors), Coccolithophores: from molecular processes to global impact. Springer, Berlin-Heidelberg, Germany, pp. 99-125.

Rost, B., Zondervan, I. and Riebesell, U., 2002. Light-dependent carbon isotope fractionation in the coccolithophorid Emiliania huxleyi. Limonology and Oceanography, 47: 120-128.

Roth, P.H. 1974. Calcareous Nannoplancton from the Northwestern Indian Ocean, Leg 24, Deep Sea Drilling Program. In: Initial Reports of the Deep-Sea Drilling Project, 24 .R.L. Fisher, E.T. Bunce et al. (Editors).U. S. Government Printing Office, Washington: 969-994.

Roth, P.H. and Thierstein, H.R. 1972. Calcareous Nannoplakton: Leg 14 of the Deep Sea Drilling Program. In: Initial Reports of the Deep-Sea Drilling Project, 14 .D.E. Hayes, A.C. Pimm et al. (Editors). U. S.Government Printing Office, Washington: 421-486.

Roth, P.H., 1994. Distribution of coccoliths in oceanic sediments. In: A. Winter and W.G. Siesser, (Editors), Coccolithophores. Cambridge University Press, Cambridge, pp. 199-218.

Rowson, J.D., Leadbeater, B.S.C. and Green, J.C., 1986. Calcium carbonate deposition in the motile (Crystallolithus) phase of Coccolithus pelagicus (Prymnesiophyceae). British Phycological Journal, 21:359-370.

Ruddiman, W.F., 2001. Earth's Climate: past and future. W. H. Freeman and Company, New York, $465 \mathrm{pp}$. 
Saavedra-Pellitero, M. 2009. Reconstrucción de las características ambientales de las masas de agua superficiales del Pacífico y Atlántico del último ciclo climático mediante el desarrollo de una función de análogos modernos. Tesis doctoral. Universidad de Salamanca.266 pp.

Saavedra-Pellitero, M., Flores, J.A. and Sierro, F.J., 2007. Nuevas aportaciones a la biogeografía de cocolitóforos en el Pacífico ecuatorial y suroriental. Geogaceta, 42: 91-94.

Saéz, A.G., Probert, I., Geisen, M., Quinn, P., Young, J.R. and Medlin, L.K., 2003. Pseudo-cryptic speciation in coccolithophores. Proceedings of the National Academy of Sciences of the United States of America, 100: 7163-7168.

Samtleben, C. and Schröder, A., 1992. Living coccolithophore communities in the NorwegianGreenland Sea and their record in sediments. Marine Micropaleontology, 19(4): 333-354.

Sancetta, C., 1994. Mediterranean sapropels: seasonal stratification yields high production and carbon flux. Paleoceanography, 9.

Sánchez-Goñi, M.F., Cacho, I., Turon, J.L., Guiot, J., Sierro, F.J., Peypouquet, J.-P., Grimalt, J.O. and Shackleton, N., 2002. Synchroneity between marine and terrestial responses to millennial scale climatic variability during the last glacial period in the Mediterranean region. Climate Dynamics, 19: 95-105.

Sarnthein, M. et al., 1982. Atmospheric and oceanic circulation patterns off Northwest Africa during the past 25 million years. In: U. von Rad, K. Hinz, M. Sarnthein and E. Seibold (Editors), Geology of the Northwest African Continental Margin. Springer-Verlag, Berlin, pp. 545- 603.

Sarnthein, M., Pflaumann, U., Ross, R., Tiedemann, R. and Winn, K., 1992. Transfer functions to reconstruct ocean palaeoproductivity: a comparison. In: C.P. Summerhayes, W.L. Prell and K.C. Emeis (Editors), Upwelling Systems: Evolution since the Early Miocene. Geological Society Special Publication, The Geological Society,London, pp. 411-427.

Sarnthein, M., Tetzla, G., Koopmann, B., Wolter, K. and Pflaumann, U., 1981. Glacial and interglacial wind regimes over the eastern subtropical Atlantic and North-West Africa. Nature, 293: 193-196.

Sbaffi, L., Wezel, F.C., Kallel, N., Paterne, M., Cacho, I., Ziveri, P. and Shackleton, N., 2001. Response of the pelagic environment to palaeoclimatic changes in the central Mediterranean Sea during the Late Quaternary. Marine Geology, 178(1-4): 39-62.

Schlizer, R., 2009. Ocean Data View, http://odv.awi.de.

Schneider, R.R., Müller, P.J. and Ruhland, G., 1995. Late Quaternary surface circulation in the east equatorial South Atlantic: Evidence from alkenone sea surface temperatures. Paleoceanography, 10 (2): 197-219.

Schönfeld, J. and Zahn, R., 2000. Late Glacial to Holocene history of the Mediterranean Outflow. Evidence from benthic foraminiferal assemblages and stable isotopes at the Portuguese margin. Palaeogeography, Palaeoclimatology, Palaeoecology, 159(1-2): 85-111.

Schönfeld, J., Zahn, R. and de Abreu, L., 2003. Surface and deep water response to rapid climate changes at the Western Iberian Margin. Global and Planetary Change, 36(4): 237-264.

Schrag, D.P., Hampt, G. and Murray, D.W., 1996. Pore Fluid Constraints on the Temperature and Oxygen Isotopic Composition of the Glacial Ocean. Science: 1930-1932.

Schulte, L., 2002. Climatic and human influence on river systems and glacier fluctuations in southeast Spain since the Last Glacial Maximum. Quaternary International, 93-94: 85-100.

Shackleton, N.J., 1974. Attainment of isotopic equilibrium between ocean water and the benthonic foraminifera genus Uvigerina: Isotopic changes in the ocean during the last glacial. Colloques Internationaux Centre National de la Recherche Scientifique 219: 203-209.

Shackleton, N.J., 1987. Oxygen isotopes, ice volume and sea level. Quaternary Science Reviews, 6(34): 183-190. 
Shackleton, N.J., Hall, M.A. and Pate, D., 1995. Pliocene stable isotope stratigraphy of ODP Site 846, Proceedings Ocean Drilling Program Scientific Results, pp. 337- 356.

Shackleton, N.J., Hall, M.A. and Vincent, E., 2000. Phase relationships between millennial-scale events 64,000-24,000 years ago. Paleoceanography, 15.

Shakun, J.D. and Carlson, A.E., 2010. A global perspective on Last Glacial Maximum to Holocene climate change. Quaternary Science Reviews, 29(15-16): 1801-1816.

Shields, G.A., Deynoux, M., Strauss, H., Paquet, H. and Nahon, D., 2007. Barite-bearing cap dolostones of the Taoudéni Basin, northwest Africa: Sedimentary and isotopic evidence for methane seepage after a Neoproterozoic glaciation. Precambrian Research, 153(3-4): 209-235.

Sicre, M.-A., Ternois, Y., Paterne, M., Martinez, P. and Bertrand, P., 2001. Climatic changes in the upwelling region off Cap Blanc, NW Africa, over the last 70 kyear: a multi-biomarker approach. Organic Geochemistry, 32(8): 981-990.

Sierro, F.J., Bárcena, M.A., Flores, J.-A., Cacho, I., Pelejero, C., Grimalt, J.O. and Shackleton, N.J., 1998. Origin of the youngest western Mediterranean organic-rich layer: productivity or stagnation. In: F. Abrantes (Editor), 6th International Conference on Paleoceanography, Lisbon, pp. 211.

Sierro, F.J., Hodell, D.A., Curtis, J.H., Flores, J.A., Reguera, I., Colmenero-Hidalgo, E., Bárcena, M.A., Grimalt, J.O., Cacho, I., Frigola, J. and Canals, M., 2005. Impact of iceberg melting on Mediterranean thermohaline circulation during Heinrich events. Paleoceanography, 20.

Siesser, W.G. and Winter, A., 1994. Composition and morphology of coccolithophore skeletons. In: A. Winter and W.G. Siesser (Editors), Coccolithophores. Cambridge University Press, Cambridge, pp. 51-62.

Sirocko, F., Garbe-Schönberg, D., McIntyre, A. and Molfino, B., 1996. Teleconnections Between the Subtropical Monsoon and High-Latitude Climates During the Last Deglaciation. Science, 272: 526529.

Spero, H.J., Bijma, J., Lea, D.W. and Bemis, B.E., 1997. Effect of seawater carbonate concentration on foraminiferal carbon and oxygen isotopes. Nature, 390: 497-500.

Sprengel, C., Baumann, K.-H. and Neuer, S., 2000. Seasonal and interannual variation of coccolithophore fluxes and species composition in sediment traps north of Gran Canaria $\left(29^{\circ} \mathrm{N} 15^{\circ} \mathrm{W}\right)$. Marine Micropaleontology, 39(1-4): 157-178.

Sprengel, C., Baumann, K.-H., Henderiks, J., Henrich, R. and Neuer, S., 2002. Modern coccolithophore and carbonate sedimentation along a productivity gradient in the Canary Islands region: seasonal export production and surface accumulation rates. Deep Sea Research Part II: Topical Studies in Oceanography, 49(17): 3577-3598.

Sprovieri, R., Di Stefano, E., Incarbona, A. and Gargano, M.E., 2003. A high-resolution record of the last deglaciation in the Sicily Channel based on foraminifera and calcareous nannofossil quantitative distribution. Palaeogeography, Palaeoclimatology, Palaeoecology, 202(1-2): 119-142.

Steinmetz, J.C., 1994. Sedimentation of coccolithophores. In: A. Winter and W.G. Siesser (Editors), Coccolithophores. Cambridge University Press, Cambridge, pp. 179-197.

Stocker, T.F., 1998. Climate change: The Seesaw Effect. Science, 282(5386): 61-62.

Stoll, H. and Ziveri, P., 2004. Coccolithophorid-based geochemical proxies. In: H.R. Thierstein and J. Young (Editors), Coccolithophores: From Molecular Processes to Global Impact. Springer, Berlin, pp. 529-562.

Stoll, H.M. and Bains, S., 2003. Coccolith Sr/Ca records of productivity during the Paleocene-Eocene thermal maximum from the Weddell Sea. Paleoceanography, 18.

Stoll, H.M. and Schrag, D.P., 2000. Coccolith $\mathrm{Sr} / \mathrm{Ca}$ as a new indicator of coccolithophorid calcification and growth rate. Geochemistry, Geophysiscs, Geosystems, 1: 1-24. 
Stoll, H.M. and Schrag, D.P., 2001. Sr/Ca variations in Cretaceous carbonates: relation to productivity and sea level changes. Palaeogeography, Palaeoclimatology, Palaeoecology, 168(3-4): 311-336.

Stoll, H.M. and Shimizu, N., 2009. Micropicking of nannofossils in preparation for analysis by secondary ion mass spectrometry. Nature Protocols, 4(7): 1038-1043.

Stoll, H.M. and Ziveri, P., 2002. Separation of monospecific and restricted coccolith assemblages from sediments using differential settling velocity. Marine Micropaleontology, 46(1-2): 209-221.

Stoll, H.M. and Ziveri, P., 2004. Coccolithophorid-based geochemical proxies. In: H.R. Thierstein and J. Young (Editors), Coccolithophores: from molecular processes to global impact. Springer, Berlin, pp. 529-562.

Stoll, H.M., Arevalos, A., Burke, A., Ziveri, P., Mortyn, G., Shimizu, N. and Unger, D., 2007a. Seasonal cycles in biogenic production and export in Northern Bay of Bengal sediment traps. Deep Sea Research Part II: Topical Studies in Oceanography, 54(5-7): 558-580.

Stoll, H.M., Klaas, C.M., Probert, I., Ruiz Encinar, J. and Garcia Alonso, J.I., 2002a. Calcification rate and temperature effects on $\mathrm{Sr}$ partitioning in coccoliths of multiple species of coccolithophorids in culture. Global and Planetary Change, 34(3-4): 153-171.

Stoll, H.M., Rosenthal, Y. and Falkowski, P., 2002b. Climate proxies from $\mathrm{Sr} / \mathrm{Ca}$ of coccolith calcite: calibrations from continuous culture of Emiliania huxleyi. Geochimica et Cosmochimica Acta, 66(6): 927-936.

Stoll, H.M., Schrag, D.P. and Clemens, S.C., 1999. Are seawater $\mathrm{Sr} / \mathrm{Ca}$ variations preserved in quaternary foraminifera? Geochimica et Cosmochimica Acta, 63(21): 3535-3547.

Stoll, H.M., Shimizu, N., Arevalos, A., Matell, N., Banasiak, A. and Zeren, S., 2007b. Insights on coccolith chemistry from a new ion probe method for analysis of individually picked coccoliths. Geochemistry, Geophysiscs, Geosystems, 8.

Stoll, H.M., Ziveri, P., Shimizu, N., Conte, M. and Theroux, S., 2007c. Relationship between coccolith $\mathrm{Sr} / \mathrm{Ca}$ ratios and coccolithophore production and export in the Arabian Sea and Sargasso Sea. Deep Sea Research Part II: Topical Studies in Oceanography, 54(5-7): 581-600.

Stramma, L., 1984. Geostrophic transport in the warm water sphere of the eastern subtropical North Atlantic. Journal of Marine Research, 42: 537-558.

Stramma, L., Hüttl, S. and Schafstall, J., 2005. Water masses and currents in the upper tropical northeast Atlantic off northwest Africa. J. Geophys. Res., 110(C12): C12006.

Stuiver, M. and Reimer, P.J., 1993. Extended ${ }^{14} \mathrm{C}$ database and revised Calib.3.0 ${ }^{14} \mathrm{C}$ age calibration program. Radiocarbon, 35: 215-230.

Stuiver, M., Reimer, P.J., Bard, E., Beck, W., Burr, G.S., Hughen, K.A., Kromer, B., McCormac, F.G., van der Plicht, J. and Spurk, M., 1998. INTCAL98 radiocarbon age calibration, 24000-0 cal BP. Radiocarbon, 40: 1041-1083.

Stuut, J.-B.W. et al., 2005. Provenance of present-day eolian dust collected off NW Africa. Journal of Geophysical Research, 110.

Stuut, J.-B.W., Crosta, X., Van der Borg, K. and Schneider, R., 2004. Relationship between Antarctic sea ice and south-west African climate during the late Quaternary. Geology, 32: 909-912.

Sumner, G., Homar, V. and Ramis, C., 2001. Precipitation seasonality in eastern and southern coastal Spain. International Journal of Climatology, 21(2): 219-247.

Swezey, C., 2001. Eolian sediment responses to late Quaternary climate changes: temporal and spatial patterns in the Sahara. Palaeogeography, Palaeoclimatology, Palaeoecology, 167(1-2): 119-155.

Takahashi, K. and Okada, H. 2001. Paleoceanography for the last 195,000 years in the Solomon Sea (ODPSite 1109) by means of calcareous nannofossils. Marine Micropaleontology, 4: 45-59. 
Talbot, M.R., Filippi, M.L., Bo Jensen, N. and Tiercelin, J.-J., 2007. An abrupt change in the African monsoon at the end of the Younger Dryas. Geochem. Geophys. Geosyst., 8.

Ternois, Y., Sicre, M., Alexandrine and Paterne, M., 2000. Climatic changes along the northwestern African Continental Margin over the last 30 kyrs. Geophys. Res. Lett., 27(1): 133-136.

Tesoriero, A.J. and Pankow, J.F., 1996. Solid solution partitioning of $\mathrm{Sr} 2+, \mathrm{Ba} 2+$, and $\mathrm{Cd} 2+$ to calcite. Geochimica et Cosmochimica Acta, 60(6): 1053-1063.

Thierstein, H.R., Geitznauer, K.R., Molfino, B. and Shackleton, N.J. 1977. Global synchroneity of late Quaternary coccolith datum levels: validation by oxygen isotopes. Geology, 5 :400-404.

Tisserand, A. et al., 2009. African monsoon enhancement during the penultimate glacial period (MIS 6.5 170 ka) and its atmospheric impact. Paleoceanography, 24(2): PA2220.

Toscano, M.A. and Macintyre, I.G., 2003. Corrected western Atlantic sea-level curve for the last 11,000 years based on calibrated $14 \mathrm{C}$ dates from Acropora palmate framework and intertidal mangrove peat. Coral Reefs, 22: 257-270.

Tremolada, F., De Bernardi, B. and Erba, E., 2008. Size variations of the calcareous nannofossil taxon Discoaster multiradiatus (Incertae sedis) across the Paleocene-Eocene thermal maximum in ocean drilling program holes 690B and 1209B. Marine Micropaleontology, 67(3-4): 239-254.

Urey, H.C., 1947. The thermodynamic properties of isotopic substances. Journal of Chemical Society, 1947: 562-581.

van Huissteden, J., 2004. Methane emission from northern wetlands in Europe during Oxygen Isotope Stage 3. Quaternary Science Reviews, 23(18-19): 1989-2005.

Voelker, A.H.L., Lebreiro, S.M., Schönfeld, J., Cacho, I., Erlenkeuser, H. and Abrantes, F., 2006. Mediterranean outflow strengthening during northern hemisphere coolings: A salt source for the glacial Atlantic? Earth and Planetary Science Letters, 245(1-2): 39-55.

Weaver, P.P.E. and Pujol, C., 1988. History of the last deglaciation in the alboran sea (western Mediterranean) and adjacent north Atlantic as revealed by coccolith floras. Palaeogeography, Palaeoclimatology, Palaeoecology, 64(1-2): 35-42.

Weaver, P.P.E., Chapman, M.R., Eglinton, G., Zhao, M., Rutledge, D. and Read, G. 1999. Combined coccolith, foraminiferal and biomarker reconstruction of paleoceanographic conditions over the past $120 \mathrm{kyr}$ in the northern North Atlantic $\left(59^{\circ} \mathrm{N}, 2^{\circ} \mathrm{W}\right)$. Paleoceanography, 14 (3) : 336-349.

Weldeab, S., Lea, D.W., Schneider, R.R. and Andersen, N., 2007. 155,000 years of West African Monsoon and Ocean Thermal Evolution. Science, 316: 1303-1307.

Wells, P. and Okada, H. 1997. Response of nannoplankton to major changes in sea-surface temperature and movements of hydrological fronts over Site DSDP 594 (south Chatham Rise, southeast New Zealand), during the last 130 ky. Marine Micropaleontology, 32: 341-363.

Westbroek, P., Brown, C.W., Bleijswijk, J.v., Brownlee, C., Brummer, G.J., Conte, M., Egge, J., Fernández, E., Jordan, R., Knappertsbusch, M., Stefels, J., Veldhuis, M., van der Wal, P. and Young, J., 1993. A model system approach to biological climate forcing. The example of Emiliania huxleyi. Global and Planetary Change, 8(1-2): 27-46.

Westbroek, P., Young, J.R. and Linschooten, K., 1989. Coccolith production (biomineralization) in the marine alga Emiliania huxleyi. Journal of Eurkaryotic Microbiology, 36(4): 368-373.

Wilson, W.H., Tarran, G. and Zubkov, M.V., 2002. Virus dynamics in a coccolithophore-dominated bloom in the North Sea. Deep Sea Research Part II: Topical Studies in Oceanography, 49(15): 29512963.

Winter, A. , Reiss, Z. and Luz, B. 1979. Distribution of living coccolithophore assemblages in the Gulf of Elat (Aqaba). Marine Micropaleontology, 4, 197-223.

Winter, A. and Siesser, W.G., 1994. Coccolithophores. Cambridge University Press, Cambridge. 
Winter, A., Jordan, R.W. and Roth, P.H., 1994. Biogeography of living coccolithophores in ocean waters. In: A. Winter and W.G. Siesser (Editors), Coccolithophores. Cambridge University Press, Cambridge, pp. 161-178.

WOA, 1998.World Ocean Atlas 1998,Version 2,http://www.nodc.-noaa.gov/oc5/woa98.html.Tch.rep., National Oceanographic Data Center, Silver Spring,Maryland.

Xiang, R., Sun, Y., Li, T., Oppo, D.W., Chen, M. and Zheng, F., 2007. Paleoenvironmental change in the middle Okinawa Trough since the last deglaciation: Evidence from the sedimentation rate and planktonic foraminiferal record. Palaeogeography, Palaeoclimatology, Palaeoecology, 243(3-4): 378393.

Yokoyama, Y., Lambeck, K., Deckker, P.D., Johnston, P. and Fifield, L.K. 2000. Timing of Last Glacial Maximum from observed sea level minima. Nature, 406: 713-716.

Young, J. and Bown P. 1997b. Cenozoic calcareous nannoplankton classification. Journal of Nannoplankton Reseach, 19 (1): 36-47.

Young, J. and Bown, P. 1997a. Higher classification of calcareous nannofossils. Journal of Nannoplankton Reseach, 19 (1):15-20.

Young, J. and Henriksen, K., 2003. Biomineralization within vesicles: the calcite of coccoliths. In: P. Dove, Yoreo, J., Weiner, S. (Editors), Biomineralization. Reviews in Mineralogy and Geochemistry. 54, 189-215.

Young, J. and Ziveri, P., 2000. Calculation of coccolith volume and it use in calibration of carbonate flux estimates. Deep Sea Research Part II: Topical Studies in Oceanography, 47(9-11): 1679-1700.

Young, J., 1990. Size variation of Neogene Reticulofenestra coccoliths from Indian Ocean DSDP cores. Journal of Micropalaeontology, 9: 71-86.

Young, J., Davis, S.A., Bown, P.R. and Mann, S., 1999. Coccolith ultrastructure and biomineralisation. Journal of Structural Biology, 126: 195-215.

Young, J.R. 1994. Functions of coccoliths. In: Coccolithophores. Winter, A. and Siesser, W.G. (Editors). Cambridge University Press, Cambridge: 63-82.

Young, J.R. and Ziveri, P., 2000. Calculation of coccolith volume and it use in calibration of carbonate flux estimates. Deep Sea Research Part II: Topical Studies in Oceanography, 47(9-11): 1679-1700.

Young, J.R. et al., 2003. A guide to extant coccolithophore taxonomy. Journal of Nannoplankton Research, $125 \mathrm{pp}$.

Young, J.R., 1994. Functions of coccolihs. In: A. Winter and W.G. Siesser (Editors), Coccolithophores. Cambridge University Press, Cambridge, pp. 63-82.

Young, J.R., Geisen, M. and Probert, I., 2005. A review of selected aspects of coccolithophore biology with implications for paleobiodiversity estimation. Micropaleontology, 51(4): 267-288.

Zeebe, R. and Wolf-Gladrow, D., 2001. $\mathrm{CO}_{2}$ in seawater: equilibrium, kinetics isotope., 65. Elsevier, Amnsterdam.

Zeebe, R.E., Bijma, J., Hönisch, B., Sanyal, A., Spero, H.J. and Wolf-Gladrow, D.A., 2008. Vital effects and beyond: a modelling perspective on developing palaeoceanographical proxy relationships in foraminifera. Geological Society, London, Special Publications, 303: 45-58.

Zhao, M. et al., 2000. Marine and terrestrial biomarker records for the last 35,000 years at ODP site 658C off NW Africa. Organic Geochemistry, 31(9): 919-930.

Zhao, M., Beveridge, N.A.S., Shackleton, N.J., Sarnthein, M. and Eglinton, G., 1995. Molecular stratigraphy of cores off northwest Africa: Sea surface temperature history over the last $80 \mathrm{ka}$. Paleoceanography, 10.

Ziveri, P., Baumann, K.H., Boeckel, B., Bollmann, J. and Young, J.R., 2004. Biogeography of selected Holocene coccoliths in the Atlantic Ocean. In: H.R. Thierstein and J.R. Young (Editors), 
Coccolithophores: from molecular processes to a global impact. Springer, Berlin-Heidelberg, Germany, pp. 403-428.

Ziveri, P., Stoll, H., Probert, I., Klaas, C., Geisen, M., Ganssen, G. and Young, J., 2003. Stable isotope 'vital effects' in coccolith calcite. Earth and Planetary Science Letters, 210(1-2): 137-149.

Ziveri, P., Thunell, R.C. and Rio, D., 1995. Export production of coccolithophores in an upwelling region: Results from San Pedro Basin, Southern California Borderlands. Marine Micropaleontology, 24(3-4): 335-358. 




\section{Anexo I. Sistemática y consideraciones ecológicas}

La clasificación seguida en el presente trabajo para los taxones con representantes vivos se basa en la sistemática establecida por Jordan et al. (2004), como revisión al anterior trabajo de Jordan y Green (1994). Para el caso de los taxones extintos se sigue la propuesta de la INA (International Nannoplankton Association) según aparece en su págica web oficial: www.nhm.ac.uk/hosted_sites/ina/

Reino CROMISTA Cavalier-Smith ,1981

División (phylum) HAPTOPHYTA Hibberd emend Cavalier-Smith, 1986

Clase PRYMNESIOPHYCEAE Hibberd ,1976

Subclase PRYMNESIOPHYCIDAE Cavalier-Smith ,1986

\section{Heterococolitos}

Orden Coccolithales Schwarz, 1932; emend. Edvardsen

Familia Calcidiscaceae Young and Brown, 1997

Género Calcidiscus Kampter, 1950

Calcidiscus leptoporus (Murray and Blackman 1898) Loeblich y Tappan, 1978

Esta especie presenta la estrategia biológica de la $\mathrm{K}$, es decir, una tasa de reproducción baja, frente a un tamaño y longevidad mayores. C. leptoporus ocupa hábitats estables donde impera una alta competitividad interespecífica, por lo que su población no tolera cambios ambientales bruscos que la situarían en desventaja frente a otras especies oportunistas con mayor facilidad para adaptarse a las condiciones. Clásicamente se ha considerado una especie oligotrófica con preferencia por las aguas tropicales y subtropicales donde el rango de temperaturas oscila entre 20 y $30^{\circ} \mathrm{C}$ (Okada y Honjo, 1973) aunque se ha descrito una forma que vive en aguas de hasta $6{ }^{\circ} \mathrm{C}$ (McIntyre et al.,1970) y que recolocaría a C. leptoporus en el grupo de las euritermas. No tolera salinidades inferiores al $25 \%$ (Brand ,1994). En la corriente de las Agulhas, sobre el margen suroccidental de África, responde a los cambios de temperatura, presentando sus máximas abundancias en los periodos cálidos (Flores et al., 1999), aunque otros estudios de Giradeau (1992) no encuentran esta relación con la temperatura. En el Mediterráneo occidental se ha considerado una especie de aguas cálidas y/o oligotróficas (ColmeneroHidalgo, 2004) aunque otros autores señalan una relación entre la disponibilidad de nutrientes y las máximas abundancias de C. leptoporus (Pujos, 1992; Giraudeau ,1992 y Flores et al., 1997). 
Es una especie bien definida representada por tres sub-taxones, que dependiendo del autor se clasifican como morfotipos (Knappertsbusch et al., 1997), subespecies o especies. Se considera que la forma intermedia presenta una amplia distribución, y mayor preferencia por las aguas frías y pobres en nutrientes mientras que la forma grande aparece en ambientes de alta productividad (Renaud et al., 2002). Las preferencias ecológicas de la forma de menor tamaño no están aún bien establecidas ya que presenta una distribución parcheada y mal definida (Ziveri et al., 2004).

Género Oolithotus Reinhardt en Cohen y Reinhardt, 1968

Oolithotus fragilis (Lohman 1912) Martín y Müller, 1972

Este género es característico de zonas oligotróficas, con baja disponibilidad de nutrientes (Brand, 1994) donde suele ocupar la parte más profunda de la zona fótica superior (Young, 1994). Oolithotus fragilis aparece en la zona fótica media e inferior de la región ecuatorial y transicional del Pacífico, mientras que en el Atlántico Norte es común en aguas tropicales a transicionales (Okada y McIntyre, 1977).

Género Umbilicosphaera Lohmann, 1902

Umbilicosphaera sibogae (Weber-van Bosse, 1901) Gaarder, 1970 var. sibogae

Umbilicosphaera sibogae var. foliosa (Kmapter, 1963) Okada y McIntyre, 1977

Ocupan ambientes tropicales y subtropicales con preferencia por las aguas estratificadas y pobres en nutrientes (Geitznauer et al., 1977; Honjo, 1976; Okada y McIntyre, 1977; Giraudeau, 1992; Brand, 1994). Aparecen frecuentemente en los centros de los giros oligotróficos donde el rango de temperaturas oscila entre 18 y $24{ }^{\circ} \mathrm{C}$ (McIntyre y Bé, 1967; Okada y McIntyre, 1979). En el Pacífico, predominan en las aguas superficiales, disminuyendo su abundancia hacia zonas más profundas de la zona fótica (Honjo, 1976). Ciertos autores consideran la especie como característica de condiciones eutróficas (Young ,1994), a la vez que otros (Roth, 1994; Flores et al., 2003) indican una respuesta acorde con el incremento de nutrientes. En el sudoeste africano, esta especie típica de la corriente de Agulhas, presenta un comportamiento similar al de C. leptoporus y Syracosphaera spp., al aumentar su abundancia en los periodos interglaciales y alcanzar sus máximos durante las deglaciaciones (Flores et al., 1999). En los sedimentos holocenos del Mediterráneo occidental, se considera un taxón característico y representante de la asociación denominada de condiciones cálidas (Flores et al., 1997). De las dos variedades citadas, $U$. sibogae var. sibogae da lugar a cocosferas coloniales al unirse varias células (2-4), mientras que, U. sibogae var. foliosa, presenta una cocosfera compacta gracias a la correcta disposición de sus placolitos (Geisen et al., 2004). 
Familia Coccolithaceae Poche, 1913; emend. Young y Bown, 1997

Género Coccolithus Swarz, 1894

Coccolithus pelagicus (Wallich, 1877) Schiller, 1930 subsp. pelagicus

Esta especie es característica de regiones polares y subpolares donde puede llegar a ser el único habitante de la zona fótica (McItyre y Bé, 1967). Su mayor tamaño $(8-16 \mu \mathrm{m})$ y robustez, le confieren un alto potencial de preservación en el registro sedimentario (Cachão y Moita, 2000).

Clásicamente definido como indicador de aguas frías, aparece incluso en aguas con valores negativos de temperatura $\left(-1,7{ }^{\circ} \mathrm{C}\right)$ aunque el rango para su óptimo desarrollo se encuentre entre 2 y $12{ }^{\circ} \mathrm{C}$ (Okada y McIntyre, 1979). Además de su preferencia por aguas frías, se le considera indicador de aguas ricas en nutrientes, especialmente bajo condiciones de surgencia y frentes de corrientes de turbidez costeras o caracterizados por un incremento de aporte fluvial (Giraudeau, 1992; Cachão y Moita, 2000; Beaufort y Heussner, 2001; Álvarez et al., 2002).

Por ello, su distribución geográfica es más amplia y llega a alcanzar el Mediterráneo occidental y la costa surafricana, aunque con una menor abundancia (Giradeau, 1992; Roth, 1994; Flores et al.,1999).

Se han encontrado hasta tres morfotipos de $C$. pelagicus, que difieren en tamaño y nicho ecológico. C. pelagicus pelagicus se rodea de cocolitos de entre 7 y $11 \mu \mathrm{m}$ y es característico de las regiones subárticas. C. pelagicus braarudii produce cocolitos de entre 11 y $14 \mu \mathrm{m}$ y ocupa zonas de upwelling de la costa este atlántica. El tercer morfotipo, más desconocido, presenta tamaños de entre 15 y $17 \mu \mathrm{m}$ y está ligado al frente de las Azores, por lo que se le dado en llamar C. pelagicus azorinus (Parente et al., 2004; Narciso et al., 2006, Simón-Baile et al., para ser enviado).

Orden Isochrysidales Pascher, 1910 ; emend. Edvarsen y Eikrem, 2000

Familia Noelaerhabdaceae Jerkovic 1970; emend. Young y Bown, 1997

Género Emiliania Hay y Mohler en Hay et al. 1967

Emiliania huxleyi (Lohmann 1902) Hay y Mohler en Hay et al. 1967 var. huxleyi

Esta especie es el cocolitóforo más abundante de los océanos actuales y el que ha dominado las asociaciones de cocolitóforos a escala global desde hace 73.000 años. Su aparición ha sido datada en 268.000 años (Thierstein et al., 1977), evento con el que se ha establecido la biozona NN21 de nanofósiles calcáreos. E. huxleyi desciende probablemente de algún miembro del género Gephyrocapsa (McIntyre, 1967). 
Es una especie cosmopolita (Geitznauer et al., 1977; Brand, 1994; Roth, 1994; Winter et al., 1994), euriterma y eurihalina, ya que puede tolerar rangos de temperatura y salinidad muy amplios. Se han encontrado individuos en aguas con temperaturas entre 1 y $30{ }^{\circ} \mathrm{C}$ (Okada y McIntyre, 1977) y con salinidades de entre 10-20 \% y 40-45 \%o (Winter et al., 1979). Además, puede tolerar diferentes intensidades lumínicas, apareciendo a lo largo de toda la zona fótica, incluso bajo condiciones del $1 \%$ de irradiación (Winter et al., 1994).

Se desarrolla tanto en ambientes oligotróficos como eutróficos, y aunque sus mayores abundancias se den en aguas subpolares ricas en nutrientes, también alcanza altas concentraciones en los giros oceánicos subtropicales, en zonas de surgencia ecuatorial (Kinkel et al, 2000), upwelling costero, plataforma externa (Brand, 1994; Bollmann et al., 1998) y en mares marginales (Roth, 1994).

Su abundancia puede llegar a ser del $82 \%$ en el Atlántico norte y del $67 \%$ en el Pacífico (Geitznauer et al., 1977), es también la especie más abundante en el Mediterráneo donde domina las asociaciones durante las eclosiones invernales. Se considera un taxón claramente oportunista, estratega de la $\mathrm{R}$ (Brand, 1994) que aprovecha la disponibilidad de nutrientes para multiplicar su población, originando intensos blooms de densidades superiores a $10^{6}$ cocosferas por litro.

En el Pacífico se establecen tres variedades morfológicas relacionadas con distintas áreas geográficas, a saber, subártica, fría y cálida. Mientras que en el Atlántico, se distinguen dos morfotipos que difieren en tamaño y responden a cambios de temperatura de las aguas. (Geitznauer et al., 1977). Estudios biométricos sobre poblaciones fósiles del Atlántico Norte revelan la existencia de dos morfotipos de distinto tamaño (Pujos-Lamy, 1977; Weaver et al., 1999). Posteriormente, Colmenero-Hidalgo et al. (2002) y Flores et al., (2010) registran este morfotipo large en el Mediterráneo occidental y en el Atlántico y realizan estudios biométricos para precisar sus condiciones paleoecológicas. Se confirma así la existencia de un morfotipo de E. huxleyi $>4 \mu \mathrm{m}$ indicador de aguas frías y cuya mayor abundancia se asocia a las etapas glaciales.

\section{Género Gephyrocapsa Kamptner ,1943}

Este grupo aparece en todos los océanos actuales y se clasifica como uno de los géneros de mayor interés dada la abundancia de sus individuos y su amplia distribución geográfica tanto en el fitoplancton actual como en el registro fósil (Geitznauer et al., 1977; Okada y McIntyre, 1977; Bollmann et al., 1998).

La definición original establece como pertenecientes a este grupo, aquellos cocolitos que presentan un puente de calcita atravesando el área central. Con posterioridad, diferentes autores han establecido clasificaciones a partir de la medida del diámetro máximo y del ángulo que forma el puente con el eje mayor del cocolito (McIntyre et al., 1970; Pujos-Lamy, 1977; Geitznauer et al.,1977; Thierstein et al., 
1977). En estudios más recientes, Bollmann (1997), diferenció seis asociaciones morfológicas en sedimentos holocénicos relacionando estos estudios biométricos con rangos de temperatura (TSM) y de concentración de clorofila, y estableció así su distribución geográfica. La clasificación de las especies y/o grupos de este género se establece a partir de la propuesta por Flores et al. en 1999.

\section{"Small "gephyrocapsa}

Este grupo integra a las especies de Gephyrocapsa menores de $3 \mu \mathrm{m}$. Según la clasificación de Flores et al. (1999), consistiría en las siguientes especies:

-Gephyrocapsa aperta Kamptner, 1963

-Gephyrocapsa ericsonii McIntyre y Bé, 1967

La ecología de G. ericsonii no está aún bien descrita (Ziveri et al., 2004).

"Small " gephyrocapsa aparece normalmente junto a E. huxleyi. Ambos taxones son considerados indicadores de upwelling y alta productividad del medio marino (Wells y Okada, 1997; Roth, 1994; Brand, 1994), aunque estudios en la zona de la corriente de Agulhas (Flores et al,1999), relacionan sus máximos de abundancia con los periodos interglaciales y por tanto, con la temperatura.

Es un grupo dominante en el Mediterráneo occidental aunque su relación con las corrientes superficiales no está aún clara (Knappertsbusch, 1993).

\section{Gephyrocapsa oceanica Kamptner, 1943}

Nos encontramos ante una especie eutrófica que comparte muchos de los hábitats de E. huxleyi. Ambas dominan las asociaciones presentes en los giros centrales subtropicales, en regiones de surgencia ecuatorial, de surgencia costera y plataforma externa (Verbeek, 1990). Sin embargo, prefiere aguas más cálidas que E. huxleyi (Brand, 1994) y alcanza su desarrollo en el Pacífico bajo un rango de temperaturas de entre 19 y $31{ }^{\circ} \mathrm{C}$ (Okada y Honjo, 1973). Tolera un amplio rango de salinidades que oscila entre los $15 \%$ (Brand, 1994) y los 45-50\%. Su presencia dominante en muchos mares marginales indica su alta resistencia a cambios en las condiciones ambientales. Es una especie oportunista, cuya afinidad por las aguas fértiles, provoca un aumento de la población e incluso una eclosión de la misma (Roth, 1994). Knappertsbusch (1993) relaciona su presencia en el Mediterráneo con la entrada de aguas atlánticas superficiales y de baja salinidad (NASW) a través del estrecho de Gibraltar. 
Gephyrocapsa muellerae Bréhéret, 1978

Se considera una especie característica de aguas frías (Weaver y Pujol, 1988; Jordan et al., 1996; Flores et al., 1997; Bollmann, 1997). En la corriente de Agulhas, al SO de Africa, se ha observado una clara correlación entre el incremento de abundancia de la especie y los episodios glaciales (Flores et al., 1999).

Orden Syracosphaerales Hay, 1977; emend. Young et al., 2003

Familia Rhabdosphaeraceae Haeckel, 1894

Género Rhabdosphaera Haeckel, 1894

Rhabdosphaera clavigera Murray y Blackman, 1898

Esta especie presenta amplia distribución geográfica aunque prefiere ambientes tropicales y subtropicales donde ocupa la zona fótica superior y media $(0-80 \mathrm{~m})$ de las aguas estratificadas de los centros de los giros oceánicos (Okada y Honjo, 1973; Geitznauer et al., 1977; Okada y McIntyre, 1977, 1979; Jordan et al., 1996). Se considera un taxón especialista, estratega de la K y en general oligotrófico ya que no aumenta su abundancia en condiciones de upwelling y mayor disponibilidad de nutrientes (Brand, 1994). Presenta alta tolerancia a la salinidad y aparece bien representado en el registro fósil debido a su resistencia a la disolución (Roth, 1994).

Familia Syracosphaeraceae (Lohmann 1902) Lemmermann 1903

Género Syracosphaera Lohmann, 1902

Género cosmopolita que presenta una alta variabilidad de especies, de las que se han catalogado casi la treintena aunque sus preferencias ecológicas no estén aún bien definidas. No presenta una clara preferencia en su distribución vertical (Lancis, 1998; Flores et al., 1999) aunque suele ocupar las aguas de la zona fótica superior y media donde se dé un rango de temperaturas entre 5 y $30^{\circ} \mathrm{C}$ (Okada y McIntyre, 1977). Los investigadores no alcanzan un consenso en cuanto a su comportamiento paleoecológico. Flores et al. (1999), le adjudican el valor de indicador de aguas cálidas en el SO de África al observar una mayor abundancia en los episodios interglaciales. Por su parte, Pujos (1992) registra máximos en el Atlántico ecuatorial durante los periodos glaciales y no encuentra una relación clara entre los cambios de salinidad y de abundancia. Mientras que Weaver y Pujol (1988) registran máximos de abundancia en el mar de Alborán durante las T1a y T1b relacionados con una mayor entrada de terrígenos en la cuenca y el consiguiente descenso de la salinidad. Hipótesis que apoya 
Flores et al., (1997b) al sugerir que su abundancia en el Mediterráneo occidental, varía con la salinidad y el contenido de nutrientes más que con la temperatura. Syracosphaera pulcra es la especie más significativa y común de este género. Registra una amplia distribución geográfica, entre $\operatorname{los} 50^{\circ} \mathrm{N} \mathrm{y}$ $50^{\circ} \mathrm{S}$, y una abundancia menor al $8 \%$ respecto al total de la asociación para la región Atlántica. Los máximos se localizan en las áreas subtropicales oligotróficas (Ziveri et al., 2004).

Familia Calciosoleniaceae Kampter, 1927

Género Calciosolenia Gran, 1912; emend. Young et al., 2003

Calciosolenia murrayi Gran, 1912

Especie característica de aguas tropicales y subtropicales del Atlántico Norte y el Pacífico (Okada y McIntyre, 1977). Aparece en las asociaciones del Mediterráneo occidental (Flores et al., 1997). Sus individuos presentan la capacidad de desarrollarse favorablemente en aguas turbias superando las limitaciones de luminosidad y la competencia por la abundante concentración de diatomeas. Parece que prefiere la mayor concentración de nutrientes de las plataformas continentales a la del océano abierto.

Orden Zygodiscales Young y Bown, 1997

Familia Helicosphaeraceae Black, 1971; emend. Jafar y Martini ,1975

Género Helicosphaera Kamptner, 1954

Helicosphaera carteri Wallich, 1877

Esta es una especie cosmopolita que alcanza sus mayores abundancias en aguas tropicales y subtropicales (McIntyre, 1967; Geitznauer et al., 1977; Winter et al., 1979) donde la temperatura oscila entre 5 y $30^{\circ} \mathrm{C}$, aunque su óptimo desarrollo se encuentre a $21^{\circ} \mathrm{C}$ (McIntyre y Bé, 1967; Okada y McIntyre, 1979). Estudios de otros autores en el suroeste de África (Flores et al., 1999; 2003) definen máximos de esta especie en los periodos glaciales y observan su presencia en episodios de upwelling frente a las costas de Namibia donde su mayor abundancia parece deberse a condiciones de baja salinidad, alta fertilidad, turbidez y escasa transparencia del agua (Giraudeau, 1992). Por otra parte, Brand (1994) sostiene que el incremento de la población no se relaciona con la mayor presencia de nutrientes en las aguas, hipótesis apoyada por Ziveri et al. (1995) que registran en las costas de California un aumento del flujo de esta especie asociado a concentraciones bajas de nutrientes y establecen que este taxón es indicativo de turbidez en la zona eufótica. Abundancias bajas de $H$. carteri han sido también documentadas en aguas oligotróficas del Mediterráneo occidental 
(Knappertsbusch 1993). H. carteri presenta a su vez las siguientes tres variedades carteri, wallichii y hyalina (Jordan et al., 2004).

Helicosphaera pavimentum Okada y McIntyre, 1977

Aparece en bajas proporciones en muestras de la columna de agua del Mediterráneo occidental caracterizadas por salinidades mínimas (Knappertsbusch, 1993; Cros, 2002). También ha sido observada en sedimentos al este de Nueva Guinea (Takahashi y Okada, 2001) y en trampas de sedimentos frente a las costas canarias y somalíes (Abrantes et al., 2002).

Familia Pontosphaeraceae Lemmermann, 1908

Género Pontosphaera Lohmann, 1902

Género característico de aguas tropicales y subtropicales, aunque siempre con escasa representación. Abundancias relativamente altas pueden relacionarse con medios marinos someros (Roth y Thierstein, 1972; Müller, 1976), alcanzan su mayor variedad en la costa disminuyendo en diversidad y número de individuos hacia mar abierto (Perch-Nielsen, 1972). Frecuente en los estadios isotópicos cálidos 1 y 5 de sedimentos del Mediterráneo occidental (Flores et al., 1997b); ausente en el Pacífico y escasa en los sedimentos del Atlántico Norte (Okada y McIntyre, 1977). Las especies más comunes y significativas son Pontosphaera multipora y Pontosphaera japonica.

\section{Genera Incertae Sedis}

Familia Umbellosphaeraceae Young and Kleijne en Young et al., 2003

Género Umbellosphaera Paasche en Markali y Paasche, 1955

Este grupo lo integran formas delicadas que junto con Discosphaera tubifera conforman la asociación umbeliforme y ocupan aguas tropicales y subtropicales cuyo rango de temperatura oscila entre 20 y 30 ${ }^{\circ} \mathrm{C}$. Alcanza su óptimo desarrollo en aguas cálidas, salinas y pobres en nutrientes del centro del centro de los giros oceánicos del Pacífico y Atlántico (McIntyre, 1967; McIntyre y Bé, 1967; McIntyre et al., 1970; Okada y Honjo, 1973; Honjo, 1977; Geitznauer et al., 1977; Okada y McIntyre, 1977; Young, 1994). Son organismos especialistas que prefieren condiciones oligotróficas y no reaccionan al incremento de nutrientes (Young, 1994), presentando bajas tasas de reproducción y de producción de cocolitos. 


\section{Nanolitos}

Familia Braarudosphaeraceae Deflandre, 1947

Género Braarudosphaera Deflandre, 1947

Braarudosphaera bigelowii (Gran y Braarud, 1935) Deflandre, 1947

Esta especie prefiere los ambientes neríticos y manifiesta gran tolerancia a condiciones ambientales extremas (Roth, 1974), ya que se ha localizado tanto en los sedimentos del mar Negro (baja salinidad) como en el golfo Pérsico (alta salinidad). Sin embargo, los diferentes estudios parecen coincidir en su preferencia por ambientes de baja salinidad y alta turbidez debida a la entrada de terrígenos (PerchNielsen, 1985a, b; Roth, 1994). Se registra en condiciones de anoxia y aguas dulces en sedimentos del Oligoceno correspondientes al antiguo Paratethys, donde es fácil encontrar horizontes dominados casi o totalmente por este taxón (Peleo-Alampay et al., 1999; Kelly et al., 2003).

Familia Ceratolithaceae Norris, 1965

Género Ceratolithus Kampter, 1950

Ceratolithus cristatus Kmapter, 1950

Esta especie presenta cocolitos en forma de herradura formados por dos grandes cristales. Es común en la asociación actual del Caribe y del golfo de México y parece registrar un incremento en su abundancia en las cercanías de la dorsal atlántica, hacia $\operatorname{los} 42^{\circ} \mathrm{N}$ (Winter et al., 1994).

Familia Discoasteraceae Tann ,1927

Género Discoaster Tann, 1927

Son un grupo de nanolitos formados pro unidades de varios cristales que muestran simetría radial. Están extintos desde el Plioceno superior.

\section{Genera Incertae Sedis}

Género Florisphaera Okada y Honjo, 1973

Florisphaera profunda Okada y Honjo, 1973 var. profunda Okada y McIntyre, 1977

Es esta una especie peculiar por ser el habitante más común y significativo de la zona fótica inferior, que en los ambientes tropicales y subtropicales que ocupa $F$. profunda, está comprendida entre los 60 y 180 m en (Okada y Honjo, 1973). Aparece en aguas cálidas, no inferiores a $10^{\circ} \mathrm{C}$ y en latitudes 
medias y bajas que alcanzan desde los $40^{\circ} \mathrm{N}$ a los $40^{\circ} \mathrm{S}$ (Okada y Honjo, 1973; Okada y Wells, 1997). Presenta una clara preferencia por intensidades lumínicas bajas (Okada y Honjo, 1973; Ziveri et al., 1995) y rechaza termoclinas someras (Ziveri et al., 1995).Su desarrollo está estrechamente relacionado con la posición de la nutriclina y la termoclina y precisa de condiciones de estabilidad y escasa mezcla de aguas. Por ello que sus mayores abundancias aparecen cuando la zona fótica está altamente estratificada y la termoclina y nutriclina son más profundas, como en el verano mediterráneo (Beaufort et al., 1997; Flores et al., 1999). Si la nutriclina es más profunda, las asociaciones de la zona fótica superior ven limitado su acceso a los nutrientes y la productividad primaria total desciende, pero el hábitat más profundo de $F$. profunda le permite disponer de nutrientes, aumentar su abundancia relativa y dominar las asociaciones fósiles (Molfino y McIntyre, 1990). Si por el contrario, la nutriclina asciende, la mayor disponibilidad de nutrientes en superficie aumentará la productividad primaria y la abundancia relativa de F. Profunda descenderá (Beaufort et al., 2001). Con el propósito de interpretar las fluctuaciones de la nutriclina y por ende, de la termoclina, se propuso la Relación $\mathrm{N}$ ("small" Gephyrocapsa +E. huxleyi / "small" Gephyrocapsa + E. huxleyi + F. profunda) que compara la abundancia de los pequeños placolitos con la de F.profunda de modo que los valores más altos del índice suponen una posición más profunda de la nutriclina y la termoclina.

Además de la profundidad y la disponibilidad de nutrientes, también la transparencia o turbidez del agua condicionan la distribución de esta especie. En el Pacífico nororiental se ha registrado una relación directa entre la transparencia del agua y la abundancia relativa de $F$. profunda, mientras que la clorofila presenta una relación inversa (Ahagon et al., 1993). Florisphaera es escasa en sedimentos de plataforma (Okada y Wells, 1997) pero puede suponer el $70 \%$ de la asociación en áreas de talud y cuencas profundas (Ahagon et al., 1993). El tamaño de los cocolitos ha permitido definir varios morfotipos tanto de Florisphaera profunda var. profunda como de F. profunda var. elongata, aunque su significado ecológico aún no este claro (Quinn et al., 2005). 

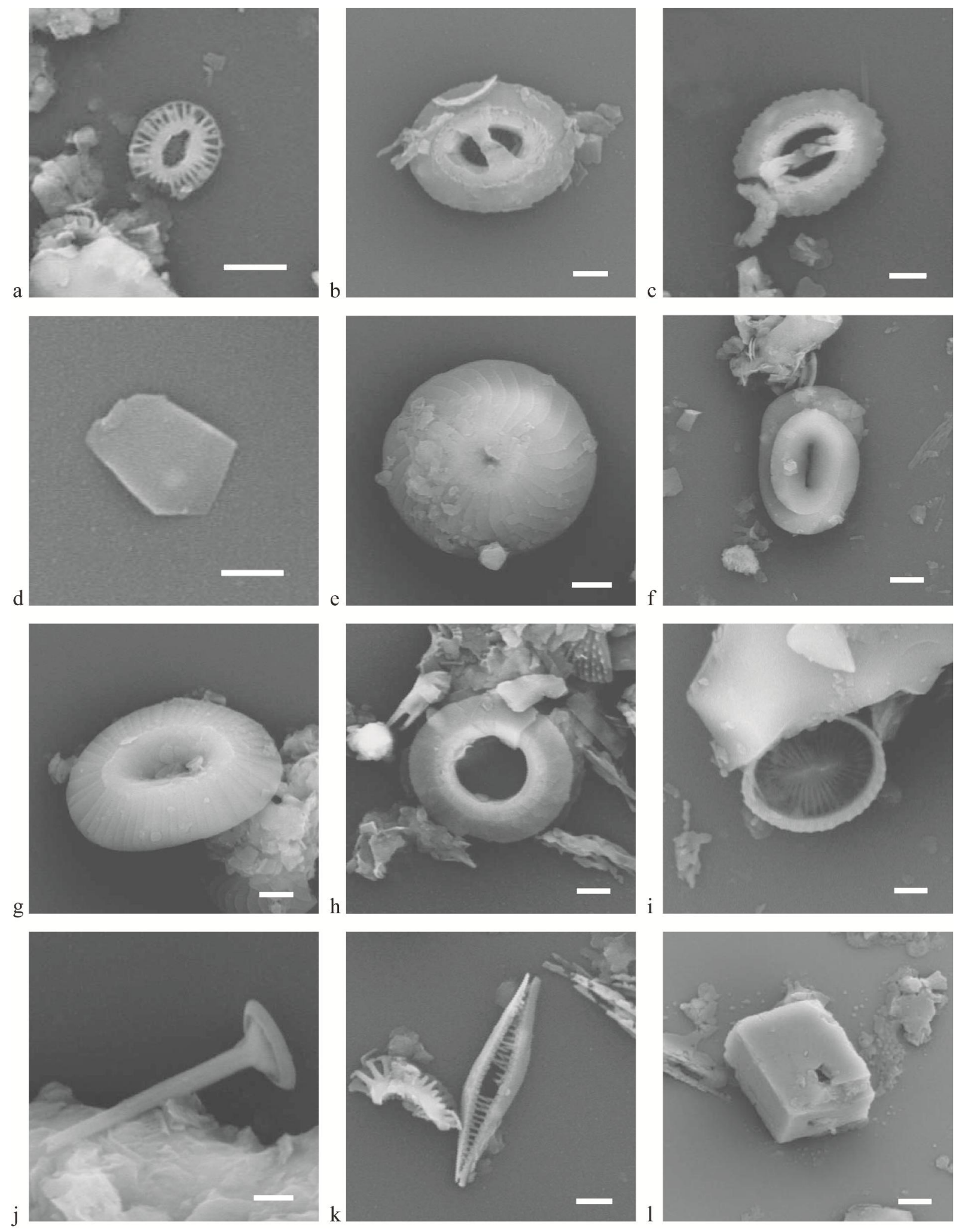

Lámina 1. Fotografías de microscopio electrónico de barrido (SEM) tomadas a 5000x, 7000x y 10000x:

a. Emiliania huxleyi. b. Gephyrocapsa oceanica. c. Gephyrocapsa muellerae. d. Florisphaera profunda.

e. Calcidiscus leptoporus. f. Helicosphaera carteri. g. Coccolithus pelagicus. h. Umbilicosphaera sibogae.

i. Syracosphaera spp. j. Rhabdosphaera clavigera. k. Calciosolenia murrayi. I. Cristal de dolomía

Barras de escala: b, c, d, h, i, j, k = $1 \mu \mathrm{m}$; a, e, f, g, l $=2 \mu \mathrm{m}$. 

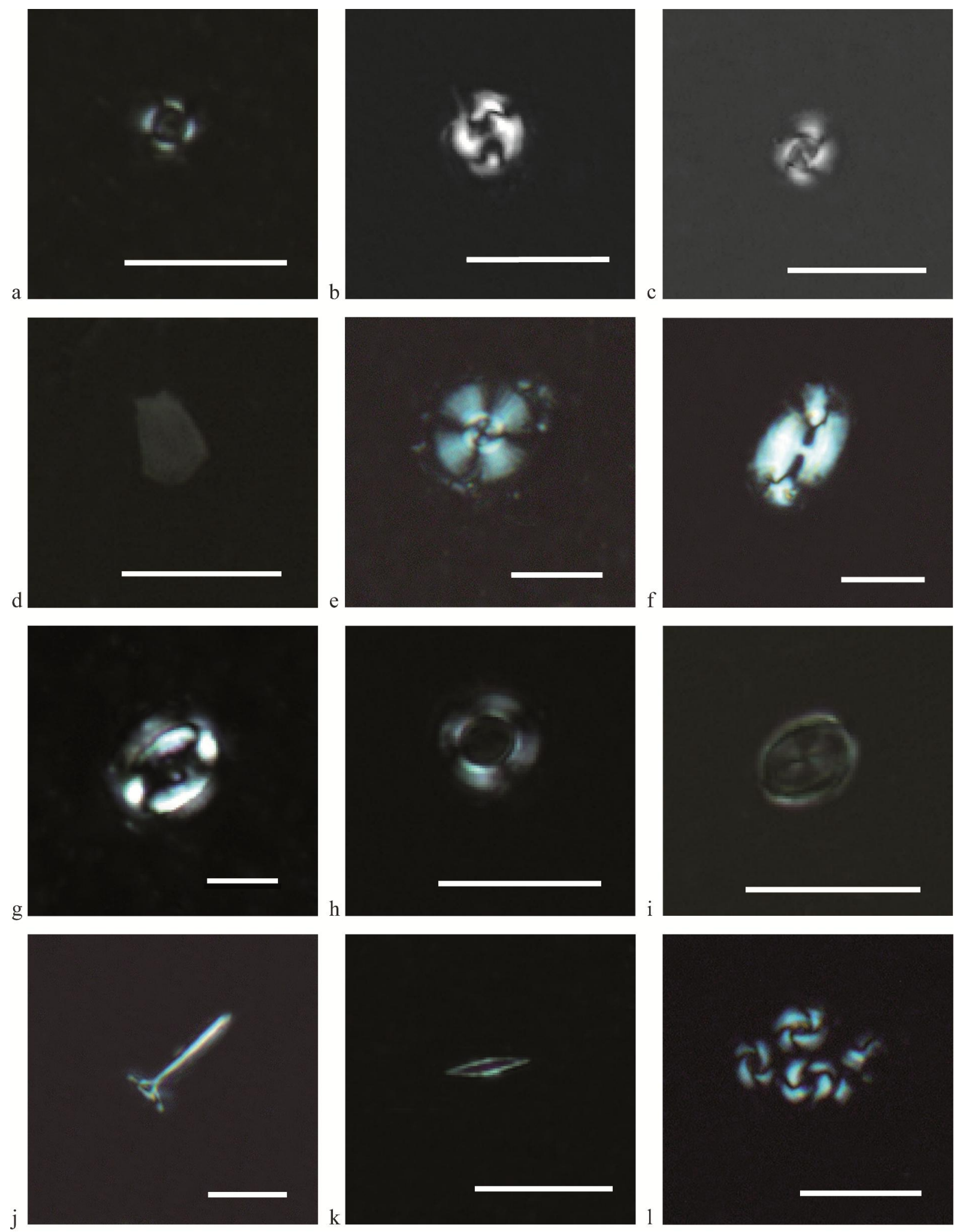

Lámina 2. Fotografías de microscopio óptico (LM), nícoles cruzados, tomadas a 1000x:

a. Emiliania huxleyi. b. Gephyrocapsa oceanica. c. Gephyrocapsa muellerae. d. Florisphaera profunda.

e. Calcidiscus leptoporus. f. Helicosphaera carteri. g. Coccolithus pelagicus. h. Umbilicosphaera sibogae. i. Syracosphaera spp. j. Rhabdosphaera clavigera. k. Calciosolenia murrayi. l. "Small" Gephyrocapsa

(Gephyrocapsa $<3 \mu \mathrm{m}$ ). Barras de escala: a, b, c, d, g, h, i, k=10 $10 \mathrm{~m}$; e, f, j, $1=6 \mu \mathrm{m}$. 

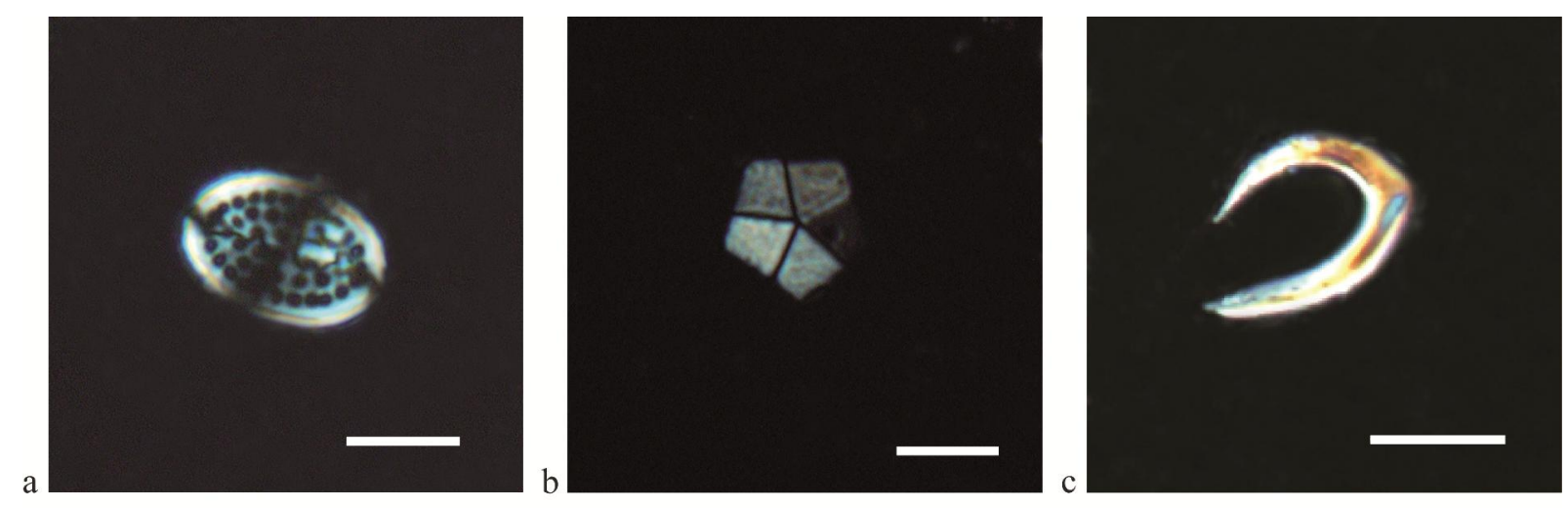

Lámina 3. Fotografías de microscopio óptico, nícoles cruzados, tomadas a 1000x:

a. Pontosphaera multipora. b. Braarudosphaera bigelowii. c. Ceratolithus cristatus.

Barras de escala: $\mathrm{a}, \mathrm{b}=6 \mu \mathrm{m} ; \mathrm{c}=10 \mu \mathrm{m}$. 
